\title{
ANALYSIS OF LOW GLOBAL WARMING POTENTIAL FLUORIDE WORKING FLUIDS IN VAPOUR COMPRESSION SYSTEMS. EXPERIMENTAL EVALUATION OF COMMERCIAL REFRIGERATION ALTERNATIVES.
}

Análisis de fluidos fluorados de bajo potencial de calentamiento atmosférico para sistemas de compresión de vapor. Evaluación experimental de alternativas para refrigeración comercial

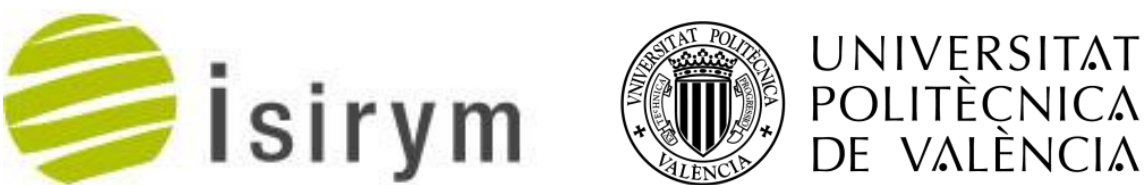

Instituto de Seguridad, Radiofísica y Medioambiente (ISIRYM)

Universidad Politécnica de Valencia

\section{TESIS DOCTORAL}

Programa de Doctorado en Ingeniería y Producción Industrial

Presenta:

Adrián Mota Babiloni
Directores:
Dr. Joaquín Navarro Esbrí
Dr. Gumersindo Verdú Martín

En Valencia, 1 de febrero de 2016 

Analysis of fluoride fluids with low global warming impact in vapour compression systems. Experimental evaluation of different alternatives for commercial refrigeration.

\section{Previous Ph.D. Thesis}

\section{Evaluation}

Following the proposal made by the Ph.D. Programme Academic Commission, the University (Doctoral School) will designate 3 experts in the subject of the Ph.D. thesis to evaluate the thesis draft prior to submission of the thesis. These experts may not work at the Universitat Politècnica de València or in any institution related to the main part of the Ph.D. Thesis.

The experts that have evaluated this Ph.D. Thesis are:

Dr. D. Carlos Amaris, Brunel University London

Dr. D. Sergio Chiva Vicent, Universitat Jaume I

Dr. D. Sylvain Quoilin, University of Liège 
Analysis of fluoride fluids with low global warming impact in vapour compression systems. Experimental evaluation of different alternatives for commercial refrigeration. 
Analysis of fluoride fluids with low global warming impact in vapour compression systems. Experimental evaluation of different alternatives for commercial refrigeration.

\section{Acknowledgements}

A mis directores de tesis. A Ximo por haberme formado en el mundo de la investigación y, más concretamente, en los sistemas de compresión de vapor. Pero sobre todo, gracias por haberme aguantado, quienes me conozcan bien sabrán que no es una tarea nada fácil. Y a Gúmer, por su colaboración, la cual ha sido vital para poder cursar mis estudios de doctorado.

A ISIRYM, por permitirme formar parte de su grupo y formarme como docente universitario, cumpliendo así uno de mis objetivos desde que empecé con mis estudios de ingeniería. Por otra parte, me gustaría agradecer al grupo de investigación ISTENER que me prestara sus instalaciones para realizar mis investigaciones; sus miembros (y colaboradores) han sido un gran apoyo en el desarrollo de esta tesis doctoral.

A los miembros del Laboratorio de Termodinámica de la Universidad de Lieja y del Departamento de Ingeniería Mecánica de la Universidad de Guanajuato, por haberme permitido colaborar con su equipo durante un breve pero fructífero periodo.

A Irene Elías Miranda, por la corrección lingüística del documento.

A mi familia, porque llegar hasta aquí habría sido imposible sin su apoyo. Aunque sea un poco distraído y no lo demuestre con palabras, ellos saben que son aquello más preciado que tengo. Ver en sus ojos el orgullo que sienten por mí ha sido la fuerza que me ha impulsado durante estos años (bueno, y lo mucho que me malcrían). La presentación de la tesis doctoral es un mérito de toda la familia Mota-Babiloni. 
Analysis of fluoride fluids with low global warming impact in vapour compression systems. Experimental evaluation of different alternatives for commercial refrigeration.

A mis amigos, a los de verdad, por saber cómo distraerme; da igual donde estén ahora mismo: España, (País Vasco), México, Bélgica, etc. Aunque, ciertamente, no sé si me han ayudado o perjudicado sacándome tanto de fiesta...

A ti, por saber siempre cómo sacarme una sonrisa.

Finalmente, este proyecto doctoral ha sido posible gracias a la financiación del Ministerio de Educación, Cultura y Deporte, a través de las Becas y Contratos de Formación de Profesorado Universitario del Programa Nacional de Formación de Recursos Humanos de Investigación del ejercicio 2012 (Referencia FPU12/02841). De la misma manera, las estancias de investigación realizadas durante el desarrollo de la tesis han sido realizadas gracias al apoyo proporcionado por el Banco Santander, S.A., a través de las Becas Iberoamérica. Jóvenes Profesores e Investigadores de la convocatoria 2014; y la Universidad Politécnica de Valencia junto con Unión Europea, a través del Programa Erasmus Prácticas (SMT - Student Mobility Training) de la convocatoria 2014-2015. 
Analysis of fluoride fluids with low global warming impact in vapour compression systems. Experimental evaluation of different alternatives for commercial refrigeration.

\section{Summary}

Climate change is one of the short term threats for humanity because of its effects on the environment and, consequently, on vegetal and animal life. If it is not stopped in next years, this effect will be irreversible. Climate change is produced by anthropogenic emissions of Greenhouse Gas to Earth's atmosphere. Vapour compression systems are one of the main contributors on this phenomenon. Among them, commercial refrigeration applications, through HFC usage, can be highlighted. Since 1990s, supermarkets of developed countries have been using refrigerants (mainly R134a, R404A and R507A) with great impact (high GWP values) on climate change due to leakages, especially from parallel compressor rack DX systems.

Recently, some regulations and directives have been approved to limit GWP values of HFC used in most extended refrigeration and air conditioning applications, directly affecting to commercial refrigeration. In this thesis, some low-GWP alternatives to replace the most commonly used HFC refrigerants in commercial refrigeration are evaluated, taking into account the limitations imposed by the mentioned regulations.

To carry out this evaluation, the current status of parallel compressor rack refrigeration systems and their fluids has been reviewed. Then, the different low-GWP options to replace R134a and R404A have been studied. HFOs and their mixtures with HFC have been highlighted as the most promising drop-in or retrofit alternatives. Thus, R1234yf, R1234ze(E) and R450A were proposed to replace R134a and R448A to substitute R404A.

The theoretical performance of the different low-GWP alternative fluids, as an overview of their potential use, has been studied at typical parallel compressor rack refrigeration operating conditions using the basic thermodynamic vapour compression 
Analysis of fluoride fluids with low global warming impact in vapour compression systems. Experimental evaluation of different alternatives for commercial refrigeration.

cycle. Given the good theoretical performance of these refrigerants, they have been tested in a vapour compression test bench.

From the experimental results it is depicted that R1234yf and R1234ze(E) are not acceptable as drop-in or light retrofit refrigerants from an energetic point of view. These fluids, when used in R134a systems, require system modifications (more severe in the case of R1234ze(E)) to achieve acceptable energy efficiency values. Moreover, due to the large refrigerant charge in PCRRS, both HFOs could present problems related to security.

Thus, while R450A presents a GWP value of 547, it appears as the best option to replace R134a due to the similar energy efficiency and properties. The R450A experimental mass flow rate and cooling capacity are slightly lower than R134a, but the final COP is approximately the same. The best $\mathrm{R} 450 \mathrm{~A}$ relative results are obtained at high CRs.

R448A shows very high performance when it is used in R404A systems with a minor TXV adjustment. Despite R448A lower cooling capacity than that R404A, this $\mathrm{HFC} / \mathrm{HFO}$ mixture can achieve great $\mathrm{CO}_{2}$ equivalent emission reductions and it is recommended as lower-GWP replacement for R404A. 
Analysis of fluoride fluids with low global warming impact in vapour compression systems. Experimental evaluation of different alternatives for commercial refrigeration.

\section{Resumen}

El cambio climático es una amenaza para la humanidad ya que puede afectar seriamente al medio ambiente y, en consecuencia, a la vida animal y vegetal. Si en los próximos años no se actúa para detenerlo, tal vez este efecto sea irreversible. Entre otros factores, el incremento de la temperatura global es producido por las emisiones antropogénicas de gases de efecto invernadero a la atmósfera.

La refrigeración comercial, basada en sistemas de compresión de vapor, contribuye de forma relevante a este fenómeno a través del uso de fluidos sintéticos como refrigerantes y del consumo de energía eléctrica procedente de combustibles fósiles. Desde la última década del siglo $\mathrm{XX}$, los supermercados de países desarrollados utilizan HFCs como fluidos de trabajo, principalmente R134a, R404A y R507A. Estos gases, de alto potencial de calentamiento atmosférico (PCA), contribuyen al cambio climático al fugarse accidentalmente de los sistemas de refrigeración, destacando las centrales de compresores en paralelo conectadas a sistemas de expansión directa.

El valor máximo de PCA de los HFCs utilizados en refrigeración y aire acondicionado va a ser controlado por normativas comunitarias, afectando a los fluidos usados en refrigeración comercial. Como consecuencia, esta tesis evalúa diferentes alternativas de bajo PCA para sustituir los refrigerantes HFC más utilizados en refrigeración comercial.

Para llevar a cabo dicho estudio, se revisa el estado actual de los sistemas de centrales de compresores en paralelo y sus fluidos. A continuación, se analizan las diferentes opciones de bajo PCA para sustituir al R134a y R404A. Al destacar los HFOs y sus mezclas con HFCs como alternativas para realizar un reemplazo con pocas modificaciones del sistema (propiedades similares); R1234yf, R1234ze(E) y R450A son propuestos para sustituir al R134a y R448A para R404A. 
Analysis of fluoride fluids with low global warming impact in vapour compression systems. Experimental evaluation of different alternatives for commercial refrigeration.

El rendimiento teórico de los diferentes fluidos alternativos de bajo PCA, para obtener una visión general del potencial de su uso, se estudia simulando las condiciones operativas típicas de las centrales de compresores en paralelo, usando el ciclo termodinámico de compresión de vapor básico. Dado el buen rendimiento mostrado por estos refrigerantes, son ensayados en un banco de pruebas de compresión de vapor.

De los resultados experimentales se observa que R1234yf y R1234ze(E) no son aceptables desde un punto de vista energético como sustitutivos directos. Dichos fluidos, cuando son utilizados en sistemas de R134a, requieren modificaciones del sistema (más severas en el caso del R1234ze(E)) para alcanzar valores aceptables de eficiencia energética. Por otra parte, debido a la gran carga necesaria en PCRRS, ambos HFOs podrían presentar problemas en cuanto a la seguridad.

Así, mientras que el R450A presenta un valor de PCA de 547, aparece como la mejor opción para sustituir al R134a debido a una eficiencia energética y propiedades similares. El caudal másico y la capacidad frigorífica del R450A son ligeramente inferiores en comparación con las del R134a, pero por otra parte, el COP resultante es aproximadamente el mismo. Los mejores resultados obtenidos para R450A son obtenidas a altas tasas de compresión.

Aunque puede ser obtenida una eficiencia energética más alta en sistemas de nuevo diseño, con sólo un ajuste menor de la válvula de expansión termostática, el R448A muestra valores muy altos de rendimiento en sistemas utilizados con R404A. A pesar de que la capacidad frigorífica del R448A es menor que la del R404A, esta mezcla de HFC y HFO puede dar lugar a grandes reducciones de emisiones de $\mathrm{CO} 2$ equivalentes, siendo así recomendado como reemplazo del R404A con menor PCA. 
Analysis of fluoride fluids with low global warming impact in vapour compression systems. Experimental evaluation of different alternatives for commercial refrigeration.

\section{Resum}

El canvi climàtic és una amenaça per a la humanitat ja que pot afectar seriosament el medi ambient $i$, en conseqüència, la vida animal i vegetal. Si en els propers anys no s'actua per aturar-lo, potser aquest efecte siga irreversible. Entre altres factors, l'increment de la temperatura global és produït per les emissions antropogèniques de gasos d'efecte hivernacle a l'atmosfera.

La refrigeració comercial, basada en sistemes de compressió de vapor, contribueix de manera rellevant a aquest fenomen per l'ús de fluids sintètics com refrigerants i pel consum d'energia elèctrica procedent de combustibles fòssils. Des de l'última dècada del segle XX, els supermercats dels països desenvolupats utilitzen HFCs com fluids de treball, principalment R134a, R404A i R507A. Aquests gasos, d'alt potencial d'escalfament atmosfèric (PCA en castellà), contribueixen al canvi climàtic quan s'escapen accidentalment dels sistemes de refrigeració. D'aquest tipus de sistemes destaquen com a grans emissors de diòxid de carboni les centrals de compressors en paral $\cdot$ lel connectades a sistemes d'expansió directa.

El valor màxim de PCA dels HFCs utilitzats en refrigeració i aire condicionat serà controlat per normatives comunitàries, cosa que afectarà els fluids utilitzats a sistemes de refrigeració comercial. Com a conseqüència, aquesta tesi avalua alternatives de baix PCA per substituir els refrigerants HFC més utilitzats en refrigeració comercial.

Per dur a terme aquest estudi, es revisa l'estat actual dels sistemes de centrals de compressors en paral-lel i els seus fluids. A continuació, s'analitzen les diferents opcions de baix PCA per substituir l'R134a i l'R404A. Els HFOs i les seves mescles amb HFCs com alternatives destaquen per permetre una substitució amb poques 
Analysis of fluoride fluids with low global warming impact in vapour compression systems. Experimental evaluation of different alternatives for commercial refrigeration.

modificacions del sistema (propietats similars); R1234yf, R1234ze(E) i R450A són proposats per substituir l'R134a i R448A per l'R404A.

Per obtenir una visió general del potencial de l'ús dels diferents fluids alternatius de baix PCA, s'estudia el seu rendiment teòric mitjançant una simulació de les condicions operatives típiques de les centrals de compressors en paral-lel. Per a aquesta simulació s'empra el cicle termodinàmic de compressió de vapor bàsic. Pel bon rendiment mostrat per aquests refrigerants, són assajats en un banc de proves de compressió de vapor.

Dels resultats experimentals s'observa que R1234yf i R1234ze(E) no són acceptables des d'un punt de vista energètic com a substitutius directes. Aquests fluids, quan són utilitzats en sistemes de R134a, requereixen modificacions del sistema (més severes en el cas de l'R1234ze(E)) per assolir valors acceptables d'eficiència energètica. D'altra banda, a causa de la gran càrrega necessària en PCRRS, tots dos HFOs podrien presentar problemes en temes de seguretat.

Així, mentre que el R450A presenta un valor de PCA de 547, apareix com la millor opció per substituir l'R134a a causa de una eficiència energètica i propietats similars. El cabal màssic i la capacitat frigorífica de l'R450A són lleugerament inferiors en comparació amb les de l'R134a, però d'altra banda, el COP resultant és molt proper. Els millors resultats de l'R450A són obtinguts a altes taxes de compressió.

Tot i que pot ser obtinguda una eficiència energètica més alta en sistemes de nou disseny, amb només un ajust menor de la vàlvula d'expansió termostàtica, l'R448A mostra valors molt alts de rendiment en sistemes utilitzats amb R404A. Encara que la capacitat frigorífica de l'R448A és menor que la de l'R404A, aquesta barreja de HFCs i HFO pot aconseguir grans reduccions d'emissions de $\mathrm{CO} 2$ equivalents, i es per tant es recomanada com a reemplaçament amb menor PCA de l'R404A.

$\mathrm{X}$ 
Analysis of fluoride fluids with low global warming impact in vapour compression systems. Experimental evaluation of different alternatives for commercial refrigeration.

\section{Index}

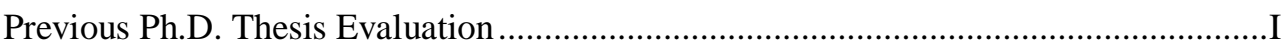

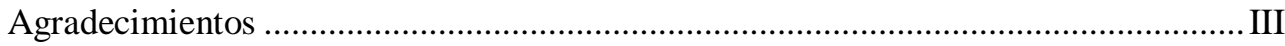

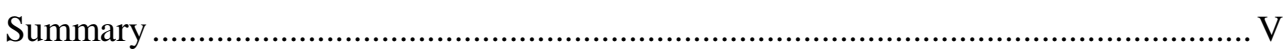

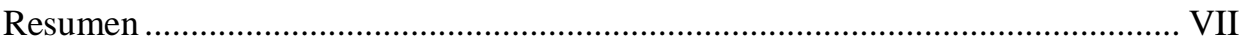

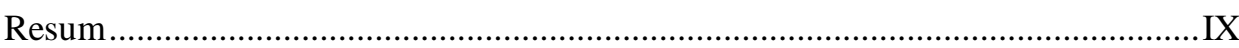

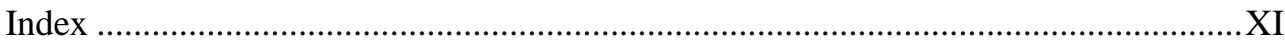

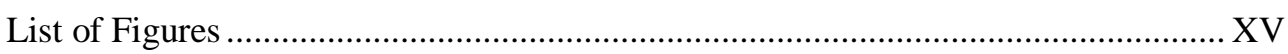

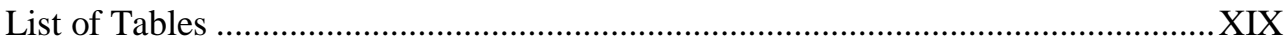

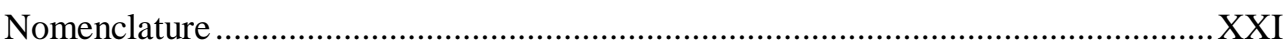

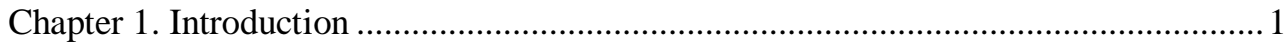

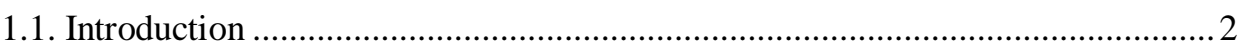

1.1.2. Environmental concern and refrigerant substitution ................................... 8

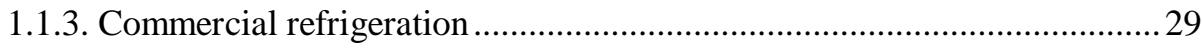

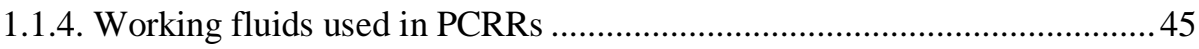

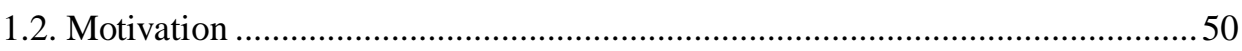

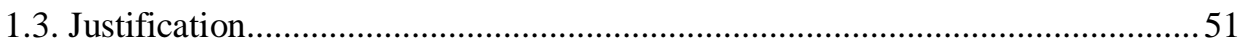

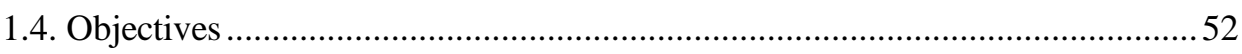

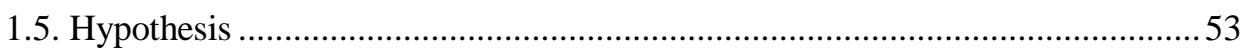

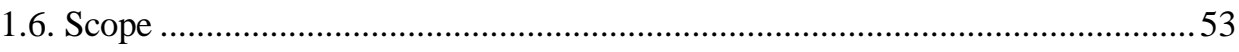

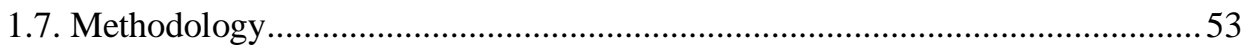


Analysis of fluoride fluids with low global warming impact in vapour compression systems. Experimental evaluation of different alternatives for commercial refrigeration.

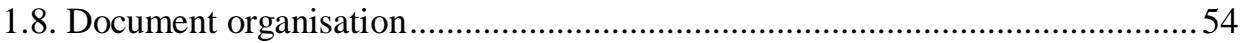

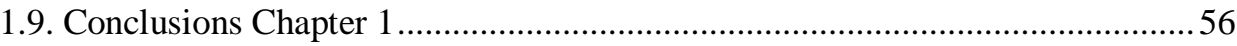

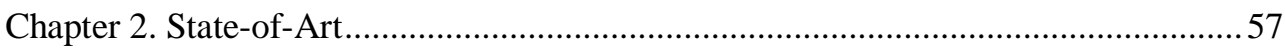

2.1. Overview of alternatives in commercial refrigeration systems .........................58

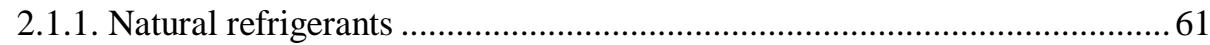

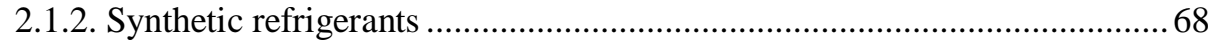

2.1.3. Alternatives to realise a substitution with minor system modifications.....71

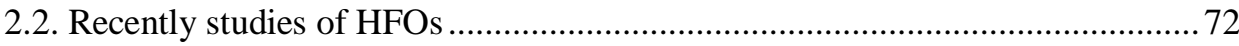

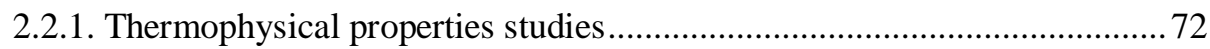

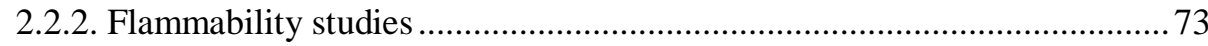

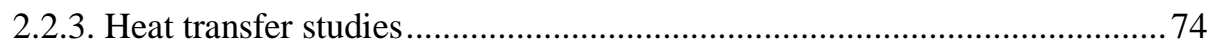

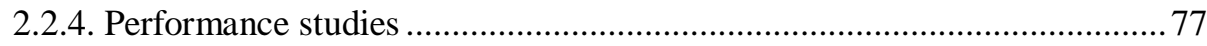

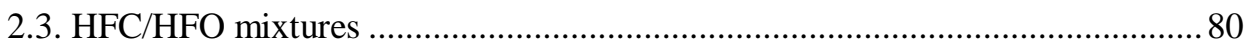

2.3.1. Thermodynamic properties studies for HFC/HFO mixtures .......................8 80

2.3.2. Flammability studies for HFC/HFO mixtures............................................... 82

2.3.3. Heat transfer studies for HFC/HFO mixtures ............................................... 82

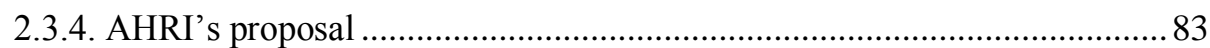

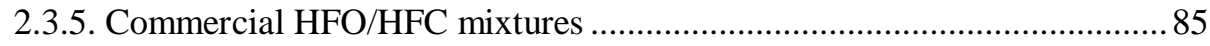

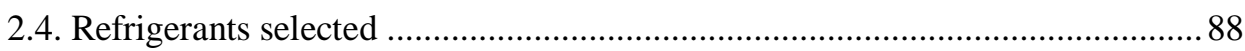

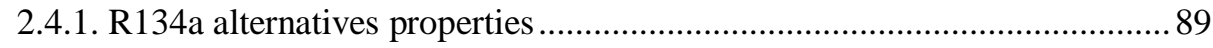

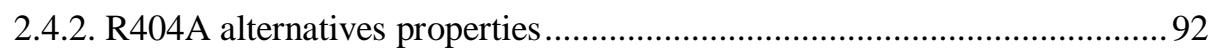

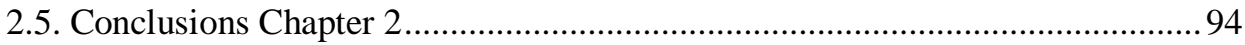


Analysis of fluoride fluids with low global warming impact in vapour compression systems. Experimental evaluation of different alternatives for commercial refrigeration.

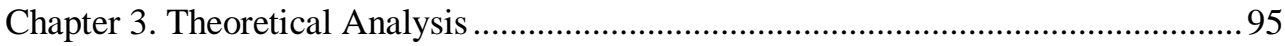

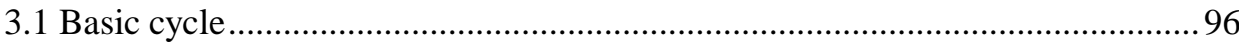

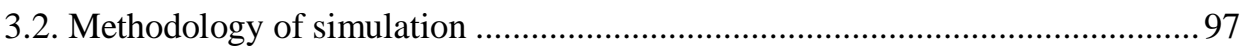

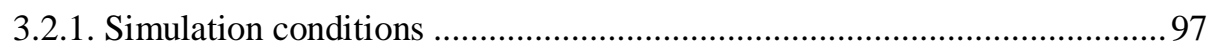

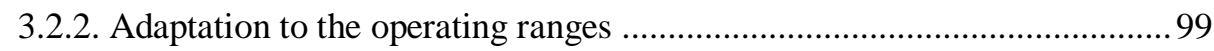

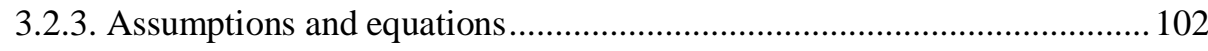

3.3. Theoretical results of comparison between R134a and alternatives ................. 104

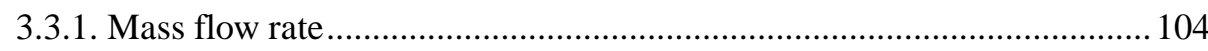

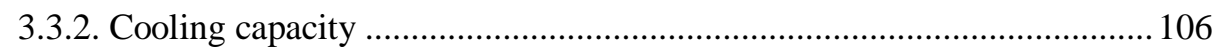

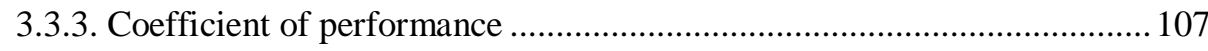

3.4. Theoretical results of comparison between R404A and alternatives ................ 109

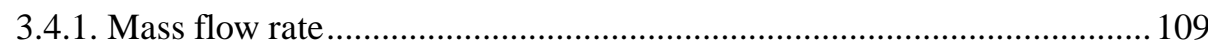

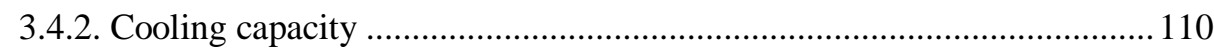

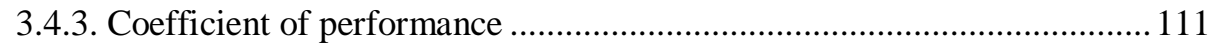

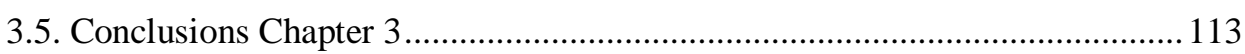

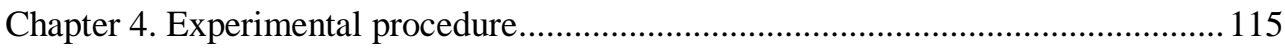

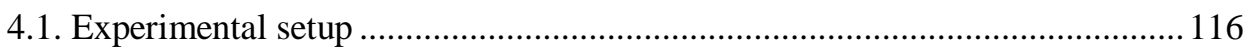

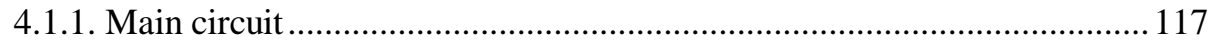

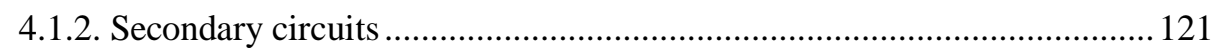

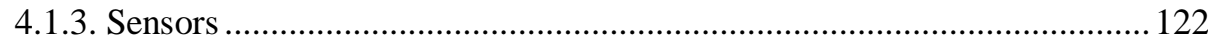

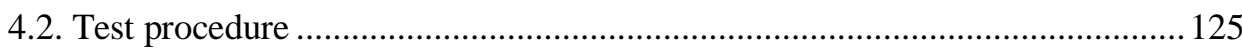

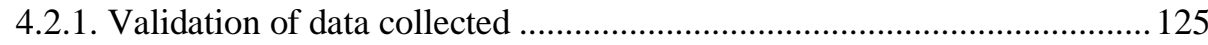


Analysis of fluoride fluids with low global warming impact in vapour compression systems. Experimental evaluation of different alternatives for commercial refrigeration.

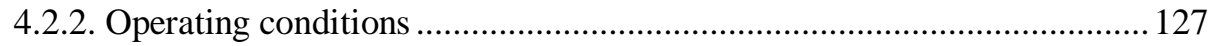

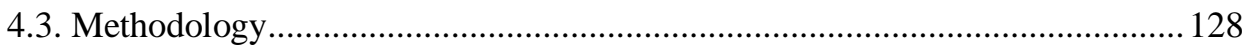

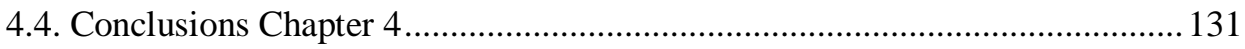

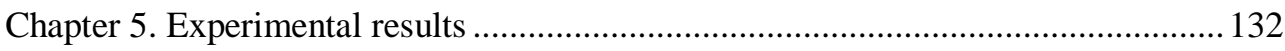

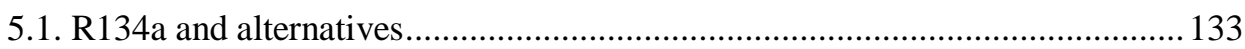

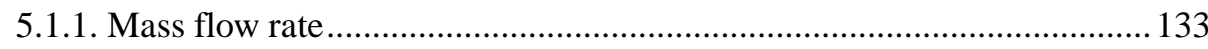

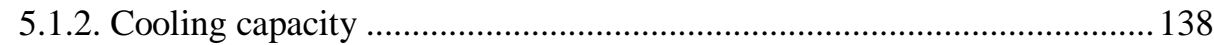

5.1.3. Coefficient of performance ……............................................................. 141

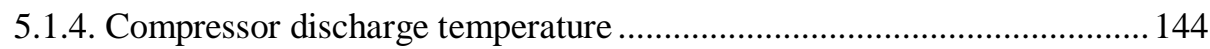

5.2. Experimental comparison between R404A and alternatives .......................... 148

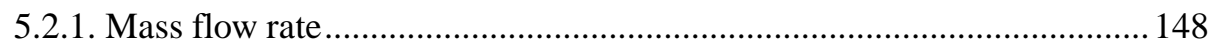

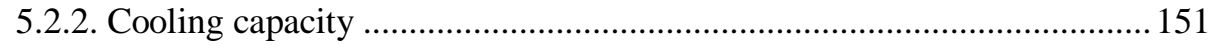

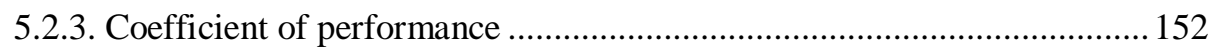

5.2.4. Compressor discharge temperature ………............................................ 154

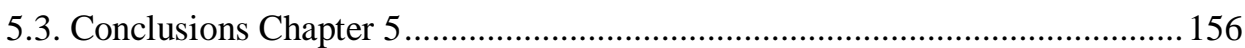

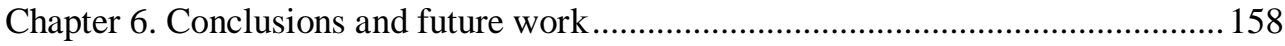

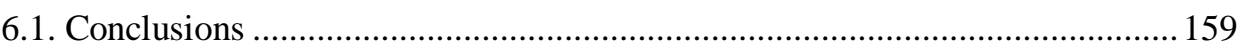

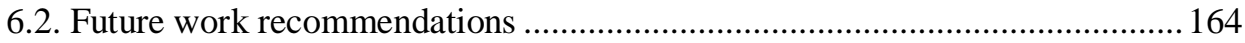

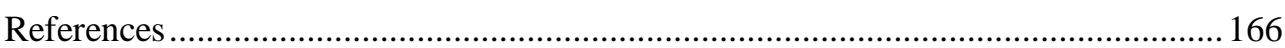

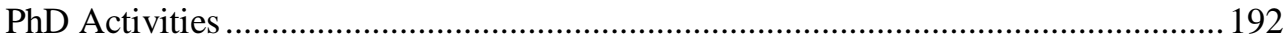


Analysis of fluoride fluids with low global warming impact in vapour compression systems. Experimental evaluation of different alternatives for commercial refrigeration.

\section{List of Figures}

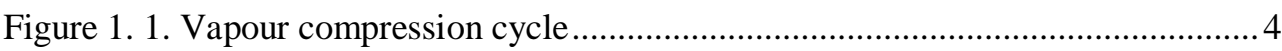

Figure 1. 2. The evolution of refrigerants by J.M. Calm [4] ...................................... 6

Figure 1. 3. Ozone depletion process .......................................................................

Figure 1. 4. Chlorine monoxide and ozone in the Southern Hemisphere in 1991 [10].10

Figure 1. 5. The relative increase in effective UV-doses related to ozone changes

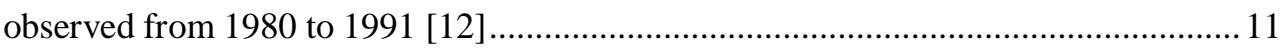

Figure 1. 6. Ozone Depletion substances: a) presence in stratosphere and b) source [14]

Figure 1. 7. Yearly consumption of refrigerants in USA ……........................................ 14

Figure 1. 8. Actual status of ozone layer and prediction until 2050 [19] ......................17

Figure 1. 9. Consumption of controlled ODS [20]........................................................ 18

Figure 1. 10. Global Temperature History Chart ............................................................ 19

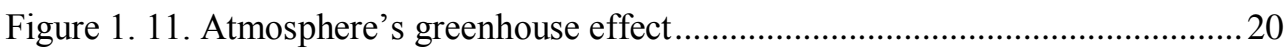

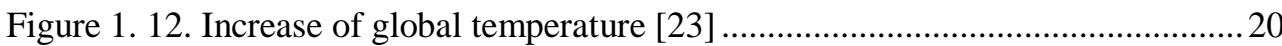

Figure 1. 13. Prediction of European Environmental Agency: European coastal cities affected by sea level rising and storm events ............................................................. 21

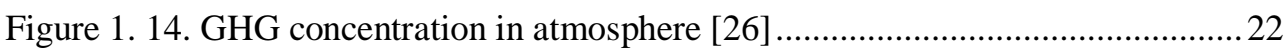

Figure 1. 15. Relevance in GHG emissions by region [27] .......................................22

Figure 1. 16. Status of the different parties in the Kyoto Protocol................................23

Figure 1. 17. Emissions of synthetic refrigerants predicted until 2050 [30] ................25

Figure 1. 18. \% of HFC emissions for different vapour compression applications in

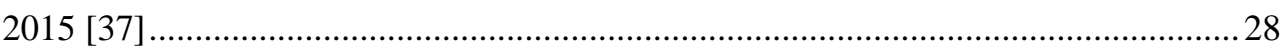

Figure 1. 19. Total number of supermarkets and hypermarkets ...................................29

Figure 1. 20. Energy consumption distribution in a typical: a) hypermarket [42] and b)

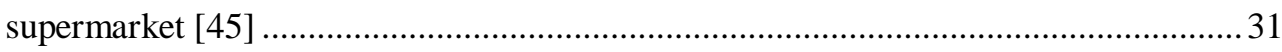

Figure 1. 21. Total Primary Energy Supply by resource 1993, 2011 and 2013 [46].....32 
Analysis of fluoride fluids with low global warming impact in vapour compression systems. Experimental evaluation of different alternatives for commercial refrigeration.

Figure 1.22. Condensing unit used to chill meat in a butcher 33

Figure 1. 23. Small hermetically sealed systems: a) Ice cream freezer and b) beverage

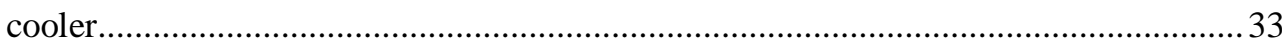

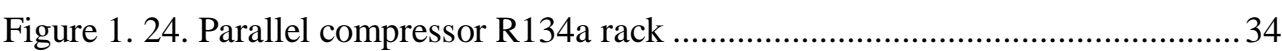

Figure 1.25. Thousands of number of items of small\&medium commercial equipment

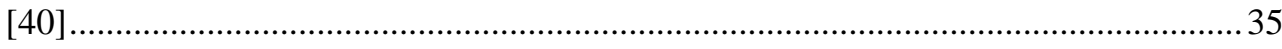

Figure 1. 26. Direct expansion systems: a) Centralised and b) distributed ....................38

Figure 1. 27. Cascade refrigeration system .................................................................. 40

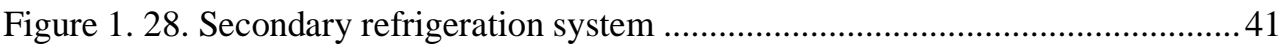

Figure 1. 29. R744 Transcritical refrigeration system: a) Scheme and b) Ph diagram .42

Figure 1. 30. System architecture and refrigerants replacement schedule proposed by

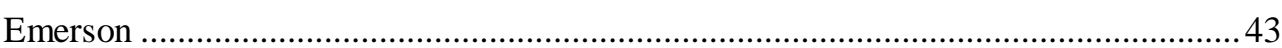

Figure 1. 31. Refrigerants in commercial refrigeration systems .................................46

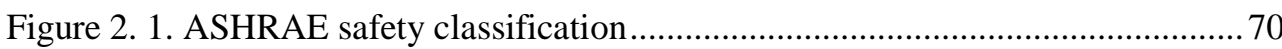

Figure 2. 2. HFC/HFO mixture alternatives to R404A and R134a; and their GWP and safety classification 84

Figure 3. 1. Diagram and P-h cycle of one stage cycle .............................................. 96

Figure 3. 2. Application of basic cycle in cascade and secondary systems ...................97

Figure 3. 3. Operating saturation temperatures and pressures....................................99

Figure 3. 4. Theoretical mass flow rate deviation between R134a and its alternatives 105

Figure 3. 5. Suction density for $\mathrm{R} 134 \mathrm{a}$ and alternatives ( $\mathrm{SH}=7 \mathrm{~K}$, no pressure drops) 105

Figure 3. 6. Theoretical cooling capacity and refrigerating effect reduction between R134a and: a) R1234yf, b) R1234ze(E) and c) R450A 107 
Analysis of fluoride fluids with low global warming impact in vapour compression systems. Experimental evaluation of different alternatives for commercial refrigeration.

Figure 3. 7. Theoretical COP deviation between R134a and: a) R1234yf (reduction), b) R1234ze(E) and c) R450A (reduction) .108

Figure 3. 8. Theoretical mass flow rate reduction between R404A and R448A ......... 110

Figure 3. 9. Suction density for R404A and R448A ( $\mathrm{SH}=7 \mathrm{~K}$, no pressure drops) ..... 110

Figure 3. 10. Theoretical cooling capacity and refrigerating effect deviation between

R404A and R448A. 111

Figure 3. 11. Theoretical COP deviation between R404A and R448A 111

Figure 4. 1. Experimental test bench 116

Figure 4. 2. Test bench scheme .117

Figure 4. 3. Main components of the experimental setup 118

Figure 4. 4. Shell-and-tube condenser inner structure and fluid path .120

Figure 4. 5. Shell-and-tube evaporator inner structure and fluid path. 121

Figure 4. 6. Secondary circuits 122

Figure 4. 7. Thermocouple and pressure transducer .123

Figure 4. 8. Flow meters 123

Figure 4. 9. Steady state test monitored 126

Figure 4. 10. Evaporator thermal balances a) R134a and alternatives and b) R404A and its alternative

Figure 5. 1. Volumetric efficiency versus compression ratio 134

Figure 5. 2. Experimental mass flow rate deviation between R134a and: a) R1234yf, b) R1234ze(E) (reduction) and c) R450A (reduction) 136

Figure 5. 3. Experimental cooling capacity reduction between R134a and: a) R1234yf, b) R1234ze(E) and c) R450A. 140

Figure 5. 4. Experimental COP and $P_{c}$ deviation (or reduction) between R134a and: a)

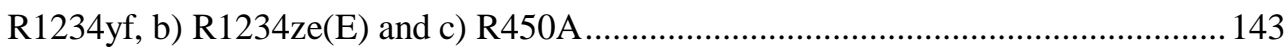

Figure 5. 5. Compressor global efficiency for R134a and its alternatives ................... 144 
Analysis of fluoride fluids with low global warming impact in vapour compression systems. Experimental evaluation of different alternatives for commercial refrigeration.

Figure 5. 6. Experimental discharge temperature difference between R134a and: a) R1234yf, b) R1234ze(E) and c) R450A. 147

Figure 5. 7. Volumetric efficiency versus compression ratio....................................... 149

Figure 5. 8. Mass flow rate relative reduction.......................................................... 151

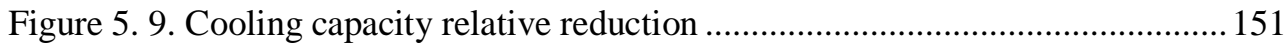

Figure 5. 10. Relative deviation: a) COP and b) Power consumption (Reduction) .... 153

Figure 5. 11. Compressor global efficiency for R404A and R448A .......................... 154

Figure 5. 12. Discharge temperature difference between R448A and R404A and

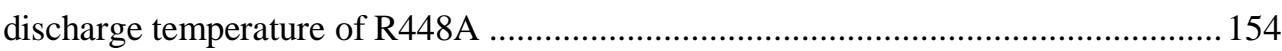


Analysis of fluoride fluids with low global warming impact in vapour compression systems. Experimental evaluation of different alternatives for commercial refrigeration.

\section{List of Tables}

Table 1. 1. CFCs and HCFCs most used until ODS phase-out in HVACR systems [15]

Table 1. 2. R12, R22 and R502 uses in HVACR systems ............................................ 17

Table 1. 3. HFCs most commonly used in HVACR systems........................................25

Table 1. 4. Placing on the market prohibitions by the EU Regulation No 517/2014 [32]

Table 1. 5. Total number of commercial refrigeration stores in Spain in 2012 ..............30

Table 1. 6. Amount of different commercial refrigeration systems [40].........................34

Table 1. 7. ISO 239553: Classification of commercial refrigeration systems ..................36

Table 1. 8. Range of temperatures in commercial refrigeration systems ........................38

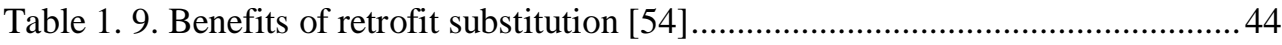

Table 1. 10. Refrigerants used in commercial refrigeration systems by region .............46

Table 1. 11. Situation of R134a and R404A after EU Regulation No 517/2014 approval

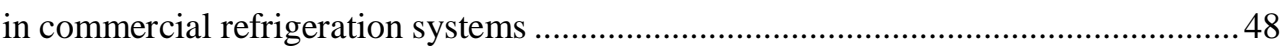

Table 2. 1. Considerations about natural refrigerants ..................................................59

Table 2. 2. Considerations about synthetic refrigerants ..................................................60

Table 2. 3. Future options for rack refrigeration services in Europe...............................60

Table 2. 4. Use of natural refrigerants in HVACR applications ..................................62 62

Table 2. 5. Flammability characteristics for $\mathrm{HC}$ refrigerants ...........................................63

Table 2. 6. HFC/HFO Mixtures composition by mass percentage................................. 84

Table 2. 7. Commercial HFC/HFO mixtures to replace R134a ......................................... 86

Table 2. 8. Commercial HFC/HFO mixtures to replace R134a ....................................... 87

Table 2. 9. Summary of desirable values of refrigerant properties for high COP [210]89

Table 2. 10. Characteristics of R134a and its alternatives .............................................90

Table 2. 11. Characteristics of R404A and the alternative R448A …..........................92 
Analysis of fluoride fluids with low global warming impact in vapour compression systems. Experimental evaluation of different alternatives for commercial refrigeration.

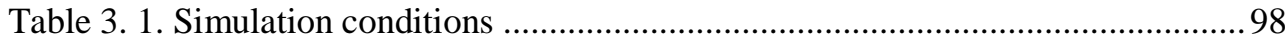

Table 3. 2. Compression ratios for R134a and its alternatives ..................................... 101

Table 3. 3. Compression ratios for R404A and its alternative ...................................... 101

Table 4. 1. Recommendation of compressors for various refrigerants and applications

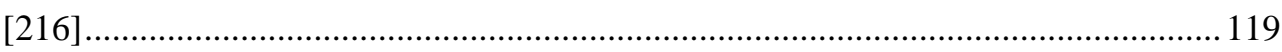

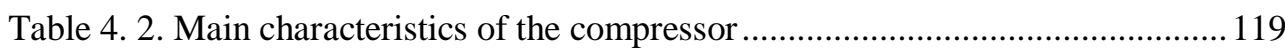

Table 4. 3. Main characteristics of the condenser ..................................................... 120

Table 4. 4. Main characteristics of the evaporator ……………………………......... 121

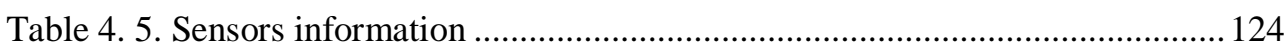

Table 5. 1. Regression between $\eta v o l$ and compression ratio and R2 resulting ........... 133

Table 5. 2. Isentropic process volumetric efficiency of 134a and its alternatives....... 135

Table 5. 3. Cooling capacity uncertainty for R134a and its alternatives...................... 140

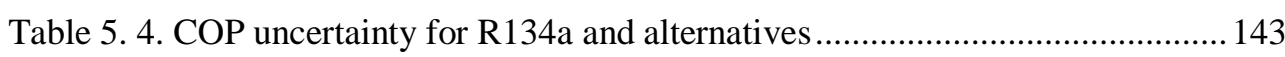

Table 5. 5. R134a experimental discharge temperature ............................................. 148

Table 5. 6. Regression between $\eta v o l$ and compression ratio and R2 resulting ............ 149

Table 5. 7. Adiabatic process volumetric efficiency of R404A and R448A ................ 150

Table 5. 8. Cooling capacity uncertainty for R404A and R448A ............................... 152

Table 5. 9. COP uncertainty for R404A and R448A.................................................. 153

Table 5. 10. R404A experimental discharge temperature .......................................... 155 
Analysis of fluoride fluids with low global warming impact in vapour compression systems. Experimental evaluation of different alternatives for commercial refrigeration.

\title{
Nomenclature
}

\author{
COP Coefficient of Performance \\ $c_{p} \quad$ Specific heat capacity $\left(\mathrm{kJ} \mathrm{kg}^{-1} \mathrm{~K}^{-1}\right)$ \\ E Clearance volume \\ $f \quad$ Function that describes the parameter which uncertainty is \\ calculated \\ $h \quad$ Specific enthalpy $\left(\mathrm{kJ} \mathrm{kg}^{-1}\right)$ \\ $\dot{m}_{\text {ref }} \quad$ Refrigerant mass flow rate $\left(\mathrm{kg} \mathrm{s}^{-1}\right)$ \\ $N \quad$ Compressor speed rotation (rev) \\ $P \quad$ Pressure $(\mathrm{kPa})$ \\ $\dot{P}_{c} \quad$ Power input to the motor $(\mathrm{kW})$ \\ $\dot{Q} \quad$ Heat transfer $(\mathrm{kW})$ \\ $\dot{q}_{o} \quad$ Refrigerating effect $\left(\mathrm{kJ} \mathrm{kg}^{-1}\right)$ \\ SH Superheating (K) \\ $T \quad$ Temperature (K) \\ $V_{G} \quad$ Compressor geometric volume $\left(\mathrm{m}^{3}\right)$ \\ $\dot{w}_{\text {comp }} \quad$ Isentropic compression work $\left(\mathrm{kJ} \mathrm{kg}^{-1}\right)$ \\ $x_{i} \quad$ independent variables of the function $f$
}

\section{Greek symbols}

Y

$\varepsilon_{\text {parameter }}$

$\varepsilon_{\text {instrument }, i}$

$\eta$

$\rho$
The ratio between the isobaric and the isochoric heat capacity

Error to the parameter studied

The uncertainty associated to the instrument that measures the variable $x_{i}$

Efficiency

Density $\left(\mathrm{kg} \mathrm{m}^{-3}\right)$ 
Analysis of fluoride fluids with low global warming impact in vapour compression systems. Experimental evaluation of different alternatives for commercial refrigeration.

\section{Subscripts}

$\begin{array}{ll}\text { disc } & \text { Compressor discharge } \\ \text { in } & \text { Inlet } \\ k & \text { Condenser, condensation } \\ o & \text { Evaporator, evaporation } \\ \text { out } & \text { Outlet } \\ \text { suc } & \text { Compressor suction } \\ \text { vol, volumetric } & \text { Volumetric }\end{array}$

\section{Abbreviations}

$\mathrm{AAD}$

AARD

AHRI

ASHRAE

CFC

CR

DX

EOS

GHG

GWP

$\mathrm{HC}$

HCFC

HFC

$\mathrm{HFO}$

HVACR

HTC
Absolute Average Deviation

Average Absolute Relative Deviation

Air-Conditioning, Heating, and Refrigeration Institute

American Society of Heating, Refrigerating, and Air-Conditioning Engineers

Chlorofluorocarbon

Compression Ratio

Direct Expansion

Equations of State

Greenhouse gas

Global Warming Potential

Hydrocarbon

Hydrochlorofluorocarbon

Hydrofluorocarbon

Hydrofluoroolefin

Heating, Ventilation, Air Conditioning and Refrigeration

Heat Transfer Coefficient 
Analysis of fluoride fluids with low global warming impact in vapour compression systems. Experimental evaluation of different alternatives for commercial refrigeration.

IHX

LCCP

LFL

LT

MAC

MT

NBP

ODP

ODS

TEWI

TXV

UNFCCC

UV

VCS

VLE
Internal Heat Exchanger

Life Cycle Climate Performance

Lower Flammability Limit

Low evaporating Temperature

Mobile (Automobile) Air Conditioning

Medium evaporation Temperature

Normal Boiling Point

Ozone Depletion Potential

Ozone Depleting Substance

Total Equivalent Warming Impact

Thermostatic Expansion Valve

United Nations Framework Convention on Climate Change

Ultraviolet lights (A, B or C)

Vapour compression system

Vapour Liquid Equilibrium 



\section{Chapter 1}

\section{Introduction}

The first chapter is devoted to expose general basis of the thesis. The evolution of refrigeration is presented and the evolution of working fluids of vapour compression systems and the main problems caused by their working fluids. Furthermore, the environmental issue is focused on parallel compressor racks of commercial refrigeration systems, one of the most important energy consumers of vapour compression system applications.

Therefore, the aim of this chapter is to acquaint the reader with the existing challenges in refrigeration systems and hereafter expose the main purposes of the Thesis project. The relevance of refrigeration systems in today's world, in terms of energetic consumption and $\mathrm{CO}_{2}$ equivalent emissions (contribution to greenhouse effect), is also noted.

Finally, the motivation, justification, objectives, hypothesis and the scope of the work are exposed. 
Analysis of fluoride fluids with low global warming impact in vapour compression systems. Experimental evaluation of different alternatives for commercial refrigeration.

\subsection{Introduction}

Refrigeration is a form of heat transfer and can be simply defined as the process of cold production, moving heat from one location to another. The purpose of the refrigeration is to keep the temperature of an item (or items) below that its surroundings. One of the main applications of refrigeration systems is to reduce the food temperature with respect to the ambient, cooling it or freezing it, to preserve food for longer. Nowadays, the most common way to produce cold is using vapour compression systems (VCS). However, before it was developed, other ways of food preservation were used.

Since the beginnings of the humanity, the control of the food temperature has always been essential to improve the human living conditions [1]. Earlier humans observed that dead animals were better preserved in a cave than outside. They understood that the cold places without airstreams delays the animals' decomposition. So meat started to be stored in caves or in holes caved in the ground with ice or snow. Moreover, these conservation places were isolated, preserving them from the sunlight.

From the industrial revolution until the end of the $19^{\text {th }}$ century, the most extended method of food conservation was the ice melting [2]. The ice industry grew quickly (in America the ice companies evolution was from 35 by 1879 to 2000 by 1909) because prices decreased using new methods of ice production, storage and transportation. The total amount of ice consumed in 1907 was quantified in about 15 million tons.

Some main concerns related to ice transportation and storage were solved. The ice melting losses decreased from $70 \%$ to less than $10 \%$ using the best isolating methods and materials, thus ensuring that majority of the ice arrived safely to the destination. Besides, finding clean sources of natural ice was more and more difficult and the ice 
Chapter 1. Introduction.

scraped caused health problems to humans due to pollution presence dragged by sewage dumping.

Throughout human history different methods of ice melting became very popular. For example in India, a method known as evaporative cooling was used: when a liquid is evaporated, its temperature goes down because exchanges energy with its surroundings. Otherwise in Europe, in the $17^{\text {th }}$ century, some chemicals (like sodium nitrate or potassium nitrate) were added to water to descend its temperature. This method was employed to cool drinks production (generally wine).

But, in fact, the ice melting and the other rudimentary methods were not sufficient to satisfy the industries' needs. Most of them require refrigerating their products to produce or ensure a minimum quality. Examples like this are brewing (control beer ferment conditions), meat packing (the meat could only be brought at winter) and dairy industries. This led to the development of mechanical refrigeration systems (based in vapour compression cycles), which absorbs heat from the space where are the products located, thus evaporating a refrigerant.

It should be noted that different methods for refrigeration have been developed and studied, for instance: sorption vapour cycles (absorption and adsorption), thermoelectric, magnetic, thermoacustic, thermoelectric, air cycle, Sterling cycle, etc.) even though vapour compression cycles are the most popular and extended refrigeration systems until these days. 
Analysis of fluoride fluids with low global warming impact in vapour compression systems. Experimental evaluation of different alternatives for commercial refrigeration.

\subsubsection{Vapour compression systems}

Vapour compression systems consist on four main elements: compressor, condenser (or gas cooler), expansion device and evaporator (Figure 1. 1). These systems extract heat from one medium through the evaporator and dissipates into another through the condenser, the working fluid inside the circuit is known as refrigerant and its pressure is generally increased by an electrically driven compressor [3].

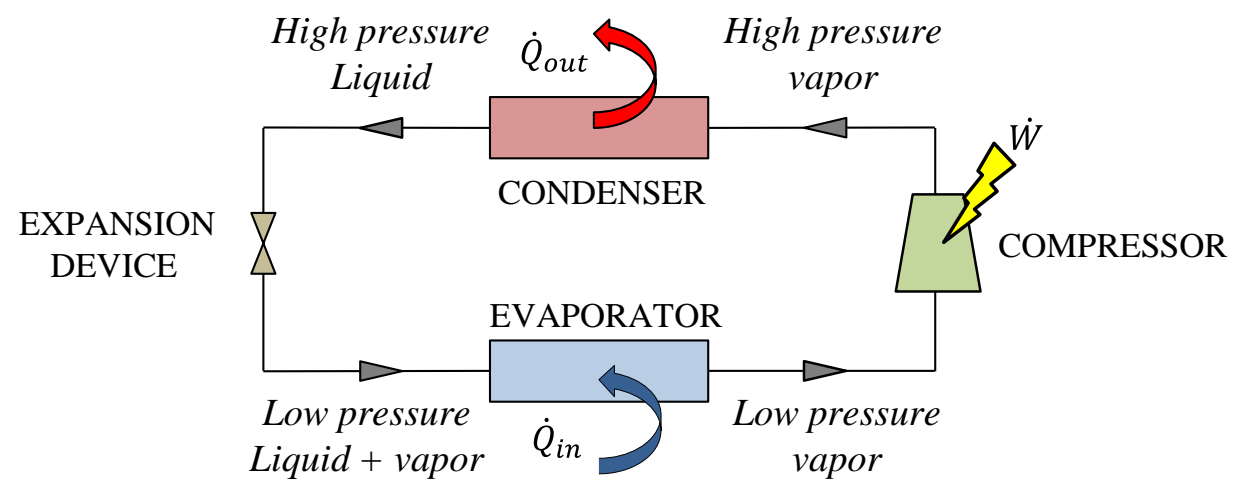

Figure 1. 1. Vapour compression cycle

To arrive to the current mechanical refrigeration systems, a long process in which VCSs were developed and improved started in the 1800s, overcoming the glitches gradually. Nowadays, mechanical refrigeration systems are essential and can be easily found in any sector: residential, commercial or industrial. The main goal in this process was to find systems in which safety, environmental compatibility and efficiency are the priorities. 
Chapter 1. Introduction.

The main developments in VCSs are listed below:

- 1834: Jacob Perkins manufactured a compression machine operating on diethyl ether.

- 1842: John Gorrie developed the first VCS (compression-condensationexpansion-evaporation), very similar to the one used nowadays.

- 1851: John Gorrie was granted the first U.S. patent for mechanical refrigeration. He went from cooling patients in a hospital to ice making.

- 1873: Carl von Linde designed the first practical and portable compressor refrigeration machine.

- 1876: Carl von Linde used ammonia rather than methyl ether in his earlier models.

- 1894: Linde later developed a new method for the liquefaction of large quantities of air.

The 1890s can be considered the decade when this technology was almost completely extended in industries and as stated before, the main benefited were the brewing, meat packing and dairy industries (industrial refrigeration). Refrigeration enabled the breweries to make a uniform product, through control of temperature. On the contrary, this technology was developed later for meat packing plants; it was the mid-1910s when majority of them had available mechanical refrigeration systems (using ammonia as working fluid), thus improving the meat quality. Then it was quickly extended to other applications, commercial (large supermarkets to smaller convenience stores) and domestic refrigeration (household refrigerators and freezers). 
Analysis of fluoride fluids with low global warming impact in vapour compression systems. Experimental evaluation of different alternatives for commercial refrigeration.

The evolution of refrigerants since the early stage until the present time is suggested by J.M. Calm [4] and shown in Figure 1. 2.

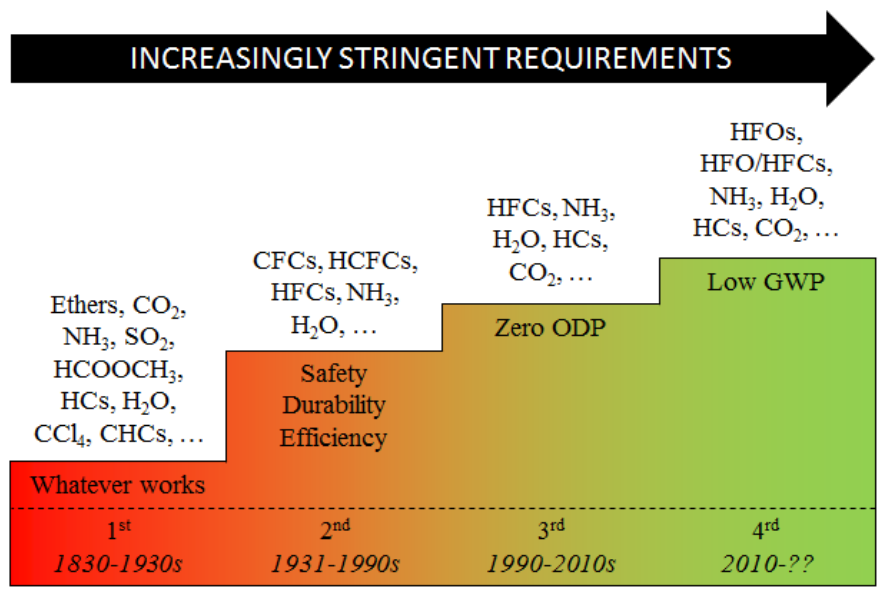

Figure 1. 2. The evolution of refrigerants by J.M. Calm [4]

\subsubsection{Earlier working fluids (refrigerants)}

At the beginning of 1990, the most relevant changes in refrigeration were motivated by issues related to refrigeration working fluids, also known as refrigerants.

During the first stage of refrigeration VCS (henceforth it will be referred simply as refrigeration systems), from approximately 1830 to 1930s, all the systems used substances developed for other appliances as common solvents, fuels or refrigerants named nowadays as "natural refrigerants": ammonia, carbon dioxide, hydrocarbons or water. In short, most common refrigerants were harmful substances; methyl chloride, ammonia, sulphur dioxide or carbon tetrafluoride [5].

If these substances are released in human presence, it can have dire consequences (for example, $0.3 \mu \mathrm{g} / \mathrm{m}^{3}$ of sulphur dioxide in air implies a potential risk for human health [6]). This accidental situation was very common on the first commercialised 
Chapter 1. Introduction.

refrigerators, which were equipped with methyl chloride (attacks central nervous system), due to the low reliability against refrigerant leakage. The impossibility of equipping refrigerators with safe refrigerants delayed their extension in houses and retail stores. Besides, ammonia quickly spread in industrial systems, large refrigeration systems for food and beverage processing and storage, and this situation remains until now.

So, chemical companies began seeking out stable, non-toxic and non-flammable chemicals to facilitate the diffusion of domestic and commercial refrigerators. A group of researchers (led by Thomas Midgley) analysed the periodic table of elements and concluded that only eight chemicals served to form the desired gases: carbon, nitrogen, oxygen, sulphur, hydrogen, fluorine, chlorine and bromine.

As a result, they developed in 1928 the chlorofluorocarbons (CFCs) [7]. CFCs were synthetic non-toxic and non-flammable fluids used as refrigerants, solvents, foam blowing agents and propellants in products like sprays. A massive production of the first CFC R12 started at 1931, and the following one was the R11 at 1932.

During the earlier- and mid-1900s, the Heating, Ventilation, Air Conditioning and Refrigeration (HVACR) appliances dominated. The gases used by these systems presented all desirable properties for an ideal refrigerant: they were safe, stable, and cheap; they have good thermodynamic properties and they performed efficiently. 
Analysis of fluoride fluids with low global warming impact in vapour compression systems. Experimental evaluation of different alternatives for commercial refrigeration.

The most relevant CFCs were R11, R12, and R502:

- R11 was used in equipment with centrifugal compressors for air conditioning of small buildings like factories, departmental stores, theatres, etc.

- R12 was highlighted for Mobile (automobiles) air conditioning (MAC) systems.

- R502 was extended in commercial refrigeration equipment of big universal shops, refrigeration facilities of food industry factories and transport refrigeration facilities.

This situation remained without problems until 1972, when James Lovelock demonstrated that the CFC accumulates in the atmosphere.

\subsubsection{Environmental concern and refrigerant substitution}

Two environmental concerns have motivated refrigerants substitution, ozone depletion and climate change.

\subsubsection{Ozone depletion}

In 1970, Paul J. Crutzen showed that $\mathrm{NO}$ and $\mathrm{NO}_{2}$ decompose catalytically the ozone, reducing the ozone content in the stratosphere [8]. Then Richard Stolarski and Ralph Cicerone proved that also free chlorine atoms in the atmosphere can reacts catalytically with ozone on similar ways as nitrogen oxides do.

\begin{tabular}{ccc}
$\mathrm{O}_{2}+\mathrm{UV}$ & $\rightarrow$ & $2 \mathrm{O}$ \\
$2 \mathrm{Cl}+2 \mathrm{O}_{3}$ & $\rightarrow$ & $2 \mathrm{ClO}+2 \mathrm{O}_{2}$ \\
$2 \mathrm{ClO}+2 \mathrm{O}$ & $\rightarrow$ & $2 \mathrm{Cl}+2 \mathrm{O}_{2}$ \\
\hline $2 \mathrm{O}_{3}$ & $\rightarrow$ & $3 \mathrm{O}_{2}$
\end{tabular}


Chapter 1. Introduction.

Using both investigations, Mario J. Molina and F. Sherwood Rowland, exposed the hypothesis of how ozone is formed and decomposed through chemical processes with chlorines from CFC fluids leakaged into the atmosphere [9]. They demonstrated that CFCs used during the last decades, which have anthropologic origin, were damaging the ozone layer. In 1974 Paul J. Crutzen corroborated the ozone depletion theory through measurements of CFCs and carbon tetrachloride in the stratosphere.

The ozone depletion process is as follows (Figure 1.3):

1. Ultra violet B (UVB) rays produced by the Sun arrive to Earth's stratosphere, where the ozone $\left(\mathrm{O}_{3}\right)$ and $\mathrm{CFCs}$ (this due to human action) are present. From CFC molecule and because of UV energy, the chlorine atom is released from CFC molecule.

2. Chlorine radical reacts with $\mathrm{O}_{3}$ and breaks bond in ozone molecule, a molecule of oxygen and chlorine monoxide result.

3. An atom of oxygen present in atmosphere destroy chlorine monoxide molecule.

4. The result is a molecule of oxygen and free chlorine radical.

5. The process is repeated depleting more ozone molecules.

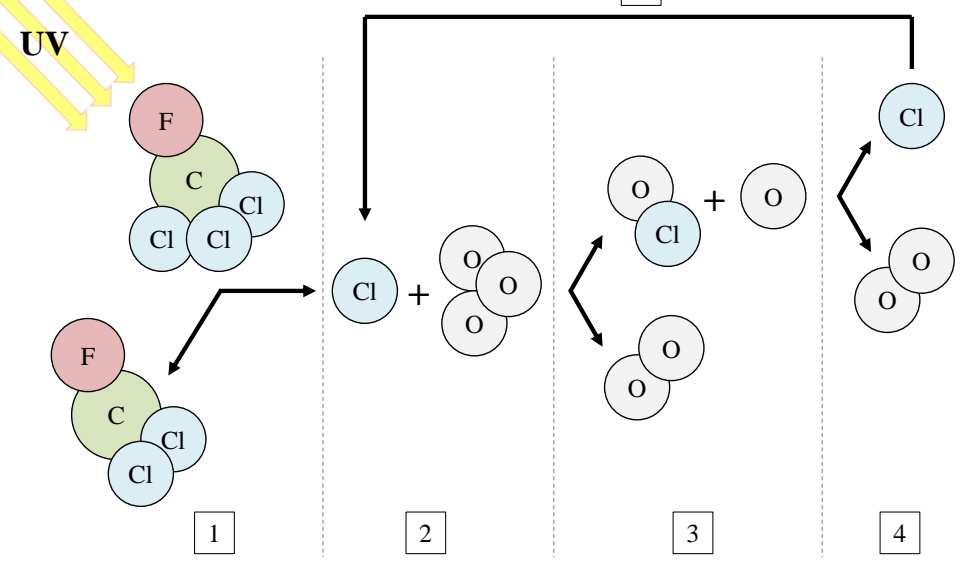

Figure 1. 3. Ozone depletion process 
Analysis of fluoride fluids with low global warming impact in vapour compression systems. Experimental evaluation of different alternatives for commercial refrigeration.

The amount of ozone accumulated in the stratosphere is known as the ozone layer, and protects the Earth's life from the harmful effects of the sun's radiation. The most important diminution was produced over Antarctica, Figure 1. 4.

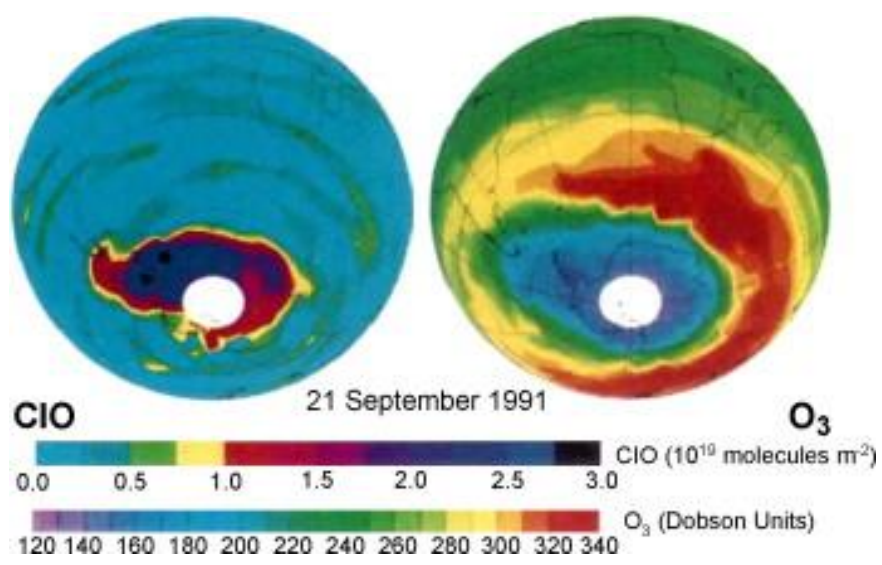

Figure 1. 4. Chlorine monoxide and ozone in the Southern Hemisphere in 1991 [10]

Among the different types of Ultra violet lights can be differenced UVA (between 320 and 400 nanometres), UVB (between 280 and 320 nanometres) and UVC (less than 280 nanometres) lights [11].

The ozone layer absorbs the totality of UVC (harmful to our ecosystems) and does not absorb UVA lights. But, depending on the thickness of the ozone layer, it can protect us to a greater or lesser extend from UVB lights. If UVB lights are not blocked by the ozone layer, they can cause problems in humans as: skin cancer, UV radiation is the primary cause; other skin problems as premature aging or Actinic keratosis; immune system suppression; and eye problems. The risk of skin cancer in Europe also increased due to the increase of UV lights at ground level [12], Figure 1. 5. 


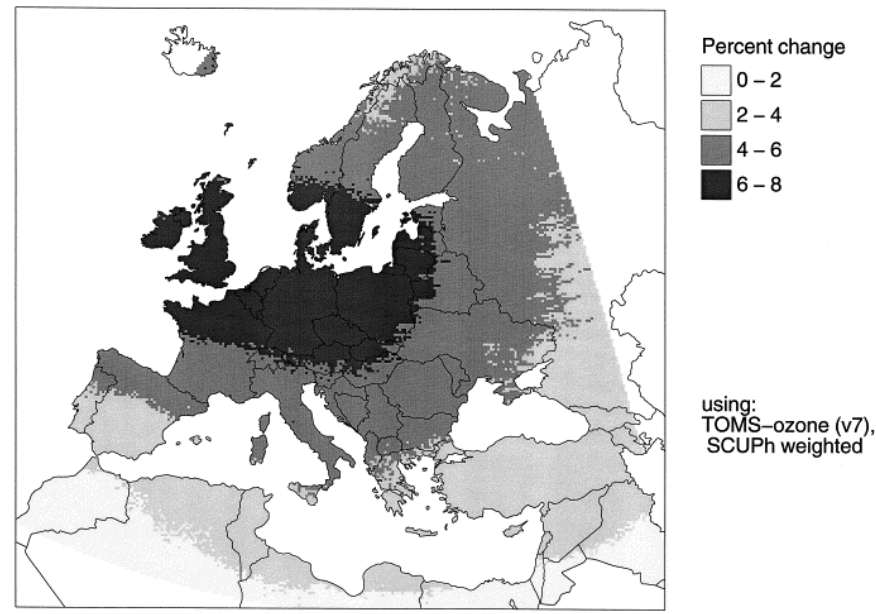

Figure 1. 5. The relative increase in effective UV-doses related to ozone changes observed from 1980 to 1991 [12]

Besides, Molina and Rowland also alerted about the critical situation of the ozone layer in the present and in the future if the humanity continues using CFCs at the same rate. Fortunately, this study was taken into account by many other scientists and governments all over the world. Despite CFC gases were considered ideal for the applications in which they were used, some measures were taken progressively to phase out or reduce the use of substances that damage the ozone layer.

The first most significant act was the Montreal Protocol on Substances that Deplete the Ozone Layer [13], in 1987. It establishes a mandatory timetable (reviewed regularly) to phase-out the ozone depleting substances, limiting the production and consumption to reduce to insignificant values their emission to the atmosphere. It allows a delay about 10-15 years for developing countries and established a financial mechanism to help developing countries to meet the objectives.

The Montreal Protocol has achieved universal ratification and it has been agreed by 197 countries. It entered into force on 1 January 1989 and it has been adjusted six times. It was the first and the most successful global environmental treaty of the present. 
Analysis of fluoride fluids with low global warming impact in vapour compression systems. Experimental evaluation of different alternatives for commercial refrigeration.

The Montreal Protocol controls nearly 100 different chemicals, known as Ozone Depleting Substances (ODSs): CFCs, halons, carbon tetrachloride, hydrochlorofluorocarbons (HCFCs), methyl chloroform, methyl bromide and other chemicals with very small markets as hydrobromofluorocarbons, bromochloromethane and other fully halogenated CFCs. The most relevant of them and their origin is shown in Figure 1. 6.

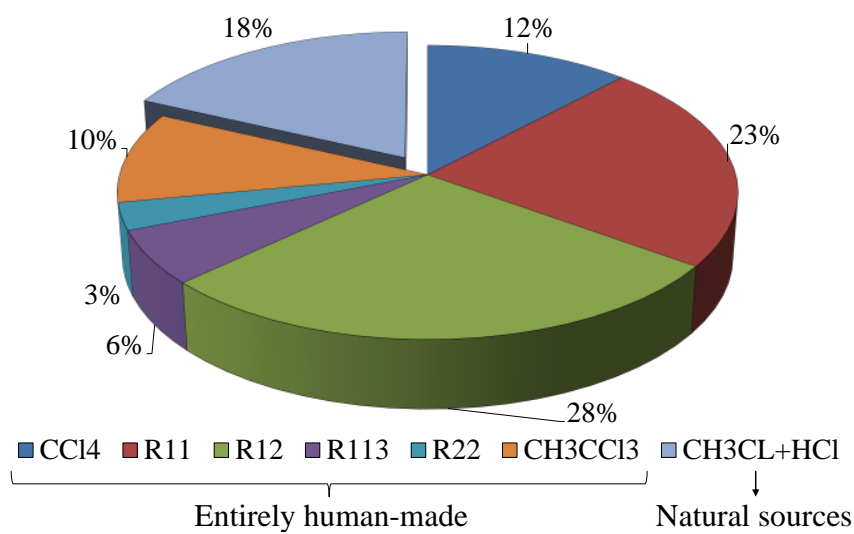

a)

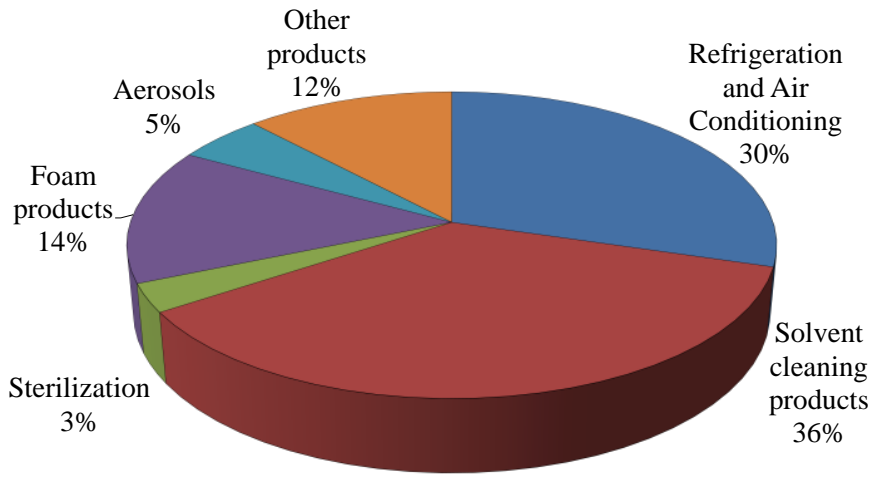

b)

Figure 1. 6. Ozone Depletion substances: a) presence in stratosphere and b) source [14] 
Chapter 1. Introduction.

Among these gases, HCFCs should be highlighted. These fluids have been developed as CFCs alternatives in HVACR because affects in a lower extend the ozone layer. R22 was the most common HCFC refrigerant and it was quickly extended in HVACR systems due to its excellent properties. It was used in multiple applications, covering residential air conditioning and diverse commercial refrigeration systems, Table 1. 1.

Table 1. 1. CFCs and HCFCs most used until ODS phase-out in HVACR systems [15]

\begin{tabular}{|c|c|c|c|}
\hline Appliance & Refrigerants & Appliance & Refrigerants \\
\hline Chillers & $\begin{array}{l}\text { R11, R12, R113, } \\
\text { R114, R13B1, } \\
\text { R22, R500 }\end{array}$ & Water coolers & $\mathrm{R} 12, \mathrm{R} 502$ \\
\hline $\begin{array}{l}\text { Industrial process } \\
\text { refrigeration systems }\end{array}$ & $\mathrm{R} 11, \mathrm{R} 12, \mathrm{R} 22$ & $\begin{array}{l}\text { Vending machines and } \\
\text { Commercial ice } \\
\text { machines }\end{array}$ & $\mathrm{R} 12, \mathrm{R} 502$ \\
\hline $\begin{array}{l}\text { Industrial process air } \\
\text { conditioning }\end{array}$ & $\mathrm{R} 12, \mathrm{R} 114$ & $\begin{array}{l}\text { Household refrigerators } \\
\text { and freezers }\end{array}$ & $\mathrm{R} 12, \mathrm{R} 502$ \\
\hline $\begin{array}{l}\text { Cold storage } \\
\text { warehouses }\end{array}$ & R12, R22, R502 & Mobile air conditioning & $\mathrm{R} 12$ and $\mathrm{R} 22$ \\
\hline Refrigerated transport & $\mathrm{R} 12, \mathrm{R} 502$ & $\begin{array}{l}\text { Residential and light } \\
\text { commercial air } \\
\text { conditioning and heat } \\
\text { pumps }\end{array}$ & R22 \\
\hline $\begin{array}{l}\text { Retail food } \\
\text { refrigeration }\end{array}$ & R12, R22, R502 & $\begin{array}{l}\text { Very low temperature } \\
\text { refrigeration systems }\end{array}$ & $\begin{array}{l}\text { R13, R13B1, } \\
\text { R503 }\end{array}$ \\
\hline
\end{tabular}

Figure 1.7 depicts the progressive replacement of the most used CFC, R12, by the most used HCFC, R22. CFCs and HCFCs are considered the second generation of refrigerants, thermodynamically ideal but low respectful towards environment. 
Analysis of fluoride fluids with low global warming impact in vapour compression systems. Experimental evaluation of different alternatives for commercial refrigeration.

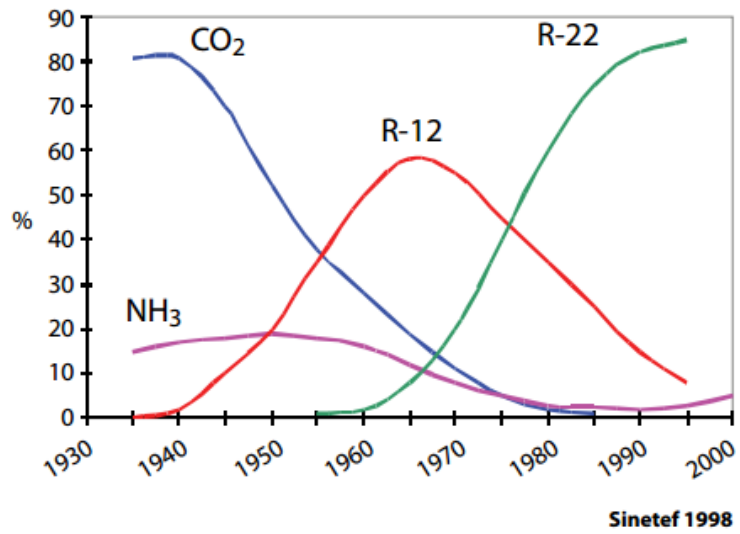

Figure 1. 7. Yearly consumption of refrigerants in USA

HCFCs present similar characteristics to CFCs and even though their impact on the ozone layer is lower, they also are ODSs (because they still contain chlorine atoms in their molecule) that have been included in regulations that control those substances.

The first ozone layer protective Regulation approved in Europe to adopt that established in the Montreal Protocol was the Council Regulation (EC) No 3093/94 [16] on substances that deplete the ozone layer.

This Regulation was replaced by the Regulation (EC) No 2037/2000 on substances that deplete the ozone layer [17] which established the total phase out of CFCs and CFCs, imposing additional measures. Regulation (EC) No 2037/2000 included the changes introduced in 1995, 1997 and 1999 in the Montreal Protocol. It established more stringent measures than those provided in Regulation (EC) No 3093/94 and takes into account the increasing availability of substitutes for ozone layer depleting. 
Chapter 1. Introduction.

The substances included by Regulation (EC) No 2037/2000 were chlorofluorocarbons, other fully halogenated chlorofluorocarbons, halons, carbon tetrachloride, 1,1,1trichloroethane, methyl bromide, hydrobromofluorocarbons and hydrochlorofluorocarbons, in any form: whether alone or in a mixture, and whether they are virgin, recovered, recycled or reclaimed.

The terms to phase out CFCs and HCFCs were as follows:

For CFCs:

- From 1 October 2000, all CFC (chlorofluorocarbon) banned for use in new equipment;

- From 1 January 2001, banned for use in the maintenance of existing equipment.

Besides R11, R12 and R502, other CFC refrigerants used in HVACR systems affected by ODS phase out are R13, R13B1, R113, R114, R115, R500, and R503.

\section{For HCFCs:}

- from Regulation approval, in equipment produced after 31 December 1995 for

○ non-confined direct-evaporation systems,

- domestic refrigerators and freezers,

- motor vehicle, tractor and off-road vehicle or trailer air conditioning systems operating on any energy source, except for military uses where the prohibition shall enter into force on 31 December 2008,

- road public-transport air-conditioning;

- from Regulation approval, in rail transport air-conditioning, in equipment produced after 31 December 1997;

- from 1 January 2000, in equipment produced after 31 December 1999 for

$\circ$ the public and distribution cold stores and warehouses,

○ for equipment of $150 \mathrm{kw}$ and over, shaft input; 
Analysis of fluoride fluids with low global warming impact in vapour compression systems. Experimental evaluation of different alternatives for commercial refrigeration.

- from 1 January 2001, in all other refrigeration and air-conditioning equipment produced after 31 December 2000, with the exception of fixed air-conditioning equipment, with a cooling capacity of less than $100 \mathrm{~kW}$;

- from 1 July 2002, the use of HCFCs shall be prohibited in equipment produced after 30 June 2002 and of reversible air conditioning/heat pump systems;

- from 1 January 2004, where the use of HCFCs shall be prohibited in all equipment produced after 31 December 2003;

- from 1 January 2010, the use of virgin HCFC shall be prohibited in the maintenance and servicing of refrigeration and air-conditioning equipment existing at that date;

- from 1 January 2015, all HCFC used as refrigerants shall be prohibited.

Besides R22, other typical HCFC refrigerants affected are R123, R141b, R401A, R401B, R402A, R402B, R409A, DI36 and DI44.

Although all of them are harmful for the atmospheric ozone, each ODS is characterised by a parameter that quantifies the relative amount of ozone layer depletion that it causes when it is released into the atmosphere. This parameter is known as Ozone Depletion Potential (ODP) and the takes as reference R11, with ODP=1.

The ODPs of the most used fluorine fluids during most part of the $20^{\text {th }}$ century in HVACR systems (Table 1. 2), is $0.82,0.28$ and 0.04 for CFC R12 and R502, and the HCFC R22, respectively. 
Chapter 1. Introduction.

Table 1. 2. R12, R22 and R502 uses in HVACR systems

\begin{tabular}{lccc}
\hline Application & R12 & R22 & R502 \\
\hline Commercial refrigeration & $\mathrm{x}$ & $\mathrm{x}$ & $\mathrm{X}$ \\
Domestic refrigeration & $\mathrm{x}$ & & \\
Transport refrigeration & $\mathrm{x}$ & $\mathrm{x}$ & \\
Mobile air conditioners & $\mathrm{x}$ & $\mathrm{x}$ \\
Unitary air conditioning & & $\mathrm{x}$ \\
\hline
\end{tabular}

Today, thanks to the Montreal Protocol implementation in 197 countries (or parties), the halogen concentrations in the stratosphere is being reduced and the ozone throughout most of the stratosphere is no longer decreasing (or it is slightly increasing) [18], Figure 1. 8. According to US Environmental Protection Agency, the ozone layer had not gotten thinner since 1998, but it is expected to return to normal levels until about 2075. To achieve the total recuperation of the ozone layer, a complete phase-out of ozone-depleting substances is required.
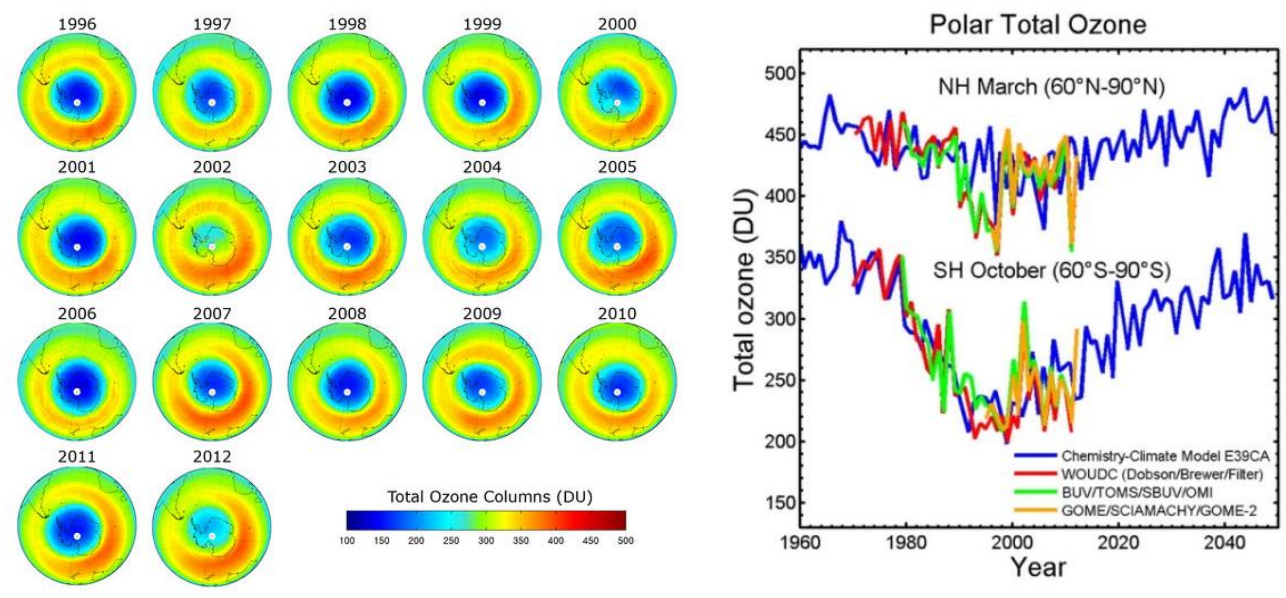

Figure 1. 8. Actual status of ozone layer and prediction until 2050 [19] 
Analysis of fluoride fluids with low global warming impact in vapour compression systems. Experimental evaluation of different alternatives for commercial refrigeration.

The total production and consumption of ODSs nowadays in European Union Member States together with Iceland, Liechtenstein, Norway, Switzerland and Turkey is near to zero [20], Figure 1. 9. Without the Montreal Protocol, the ozone loss at both poles would have become very much larger, at least a doubling in ozone depletion [21].

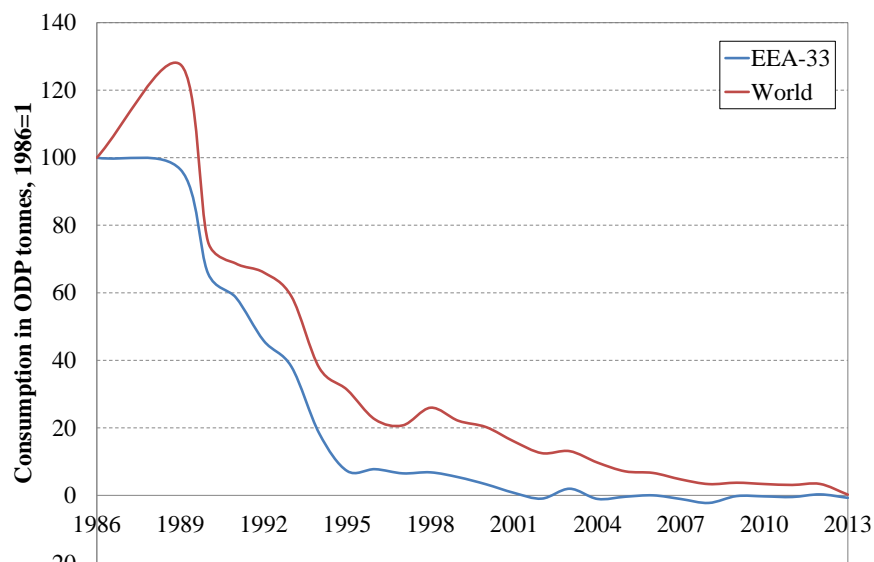

Figure 1. 9. Consumption of controlled ODS [20]

As HCFCs were not sufficient environmental friendly to replace CFCs in HVACR systems, hydrofluorocarbons (HFCs) were developed to prevent further damage. They do not possess chlorine atom in the molecule and consequently they do not affect the stratospheric ozone. Although less efficient than HCFCs, their performance remains at acceptable levels, are safe for humans, economic and present good thermophysical and thermodynamic properties.

HFCs were spread throughout HVACR systems to accomplish that signed in the Montreal Protocol. But once the ozone layer problem is being solved, another environmental concern is now threatening human, animal and vegetal life on Earth, the climate change. 


\subsubsection{Climate change}

The Earth's climate has changed naturally since its formation, as shown the data provided by European Project for Ice Coring in Antarctica (EPICA), Figure 1. 10 [22]. The problem arises when the variation in global temperature does not have natural origins, but anthropogenic (due to human action) phenomena.

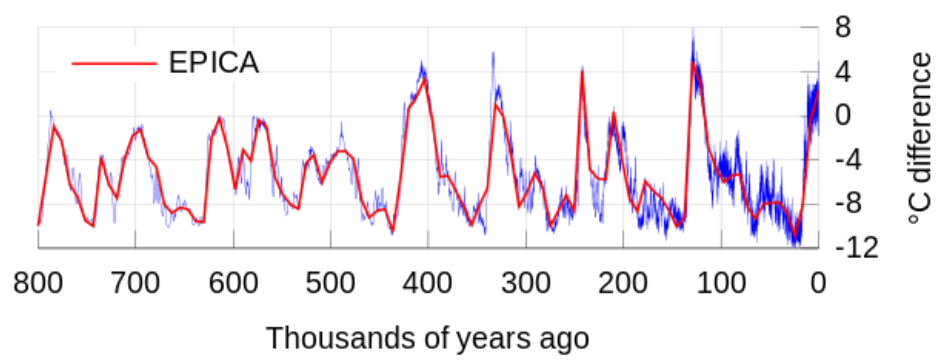

Figure 1. 10. Global Temperature History Chart

The greenhouse effect allows the Earth's life because increases the global temperature (that would be $255 \mathrm{~K}\left(-18^{\circ} \mathrm{C}\right)$ if it would not exist). This phenomenon is so called because it is similar to what happens in a greenhouse. The warm air is trapped by the plastic but in the case of the earth the layer of greenhouse gases (GHG). The effect can be summarised as follows, Figure 1. 11:

1. Most of solar short wave radiation (visible light) is absorbed by the Earth's surface and warms it.

2. Some solar radiation is reflected by the Earth and its atmosphere.

3. Some of the infrared radiation passes through the atmosphere. Some is absorbed and re-emitted in all directions by GHG molecules. The effect of this is to warm the Earth's surface and the lower atmosphere.

4. Infrared radiation (long wave) is emitted by the Earth's surface and it is trapped by GHGs. 
Analysis of fluoride fluids with low global warming impact in vapour compression systems. Experimental evaluation of different alternatives for commercial refrigeration.

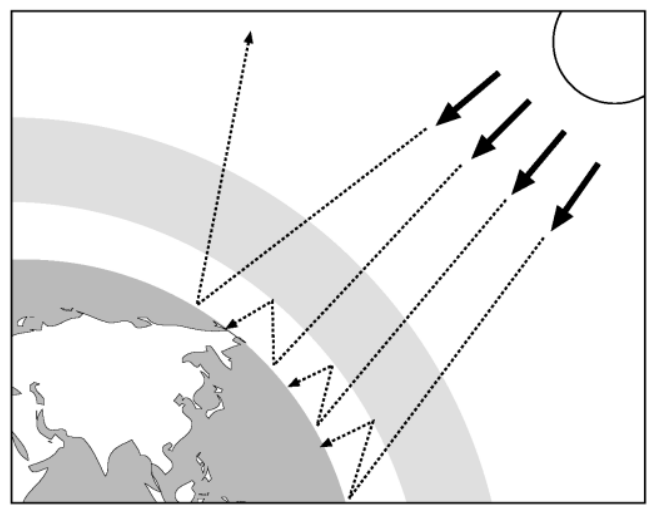

Figure 1. 11. Atmosphere's greenhouse effect

The greenhouse effect cannot be defined as harmful, since it is necessary for the existence of life on the planet. The influence of larger amount of GHG is that there is more re-emitted heat into the atmosphere (due to less heat escapes into outer space) than before the human activity. As consequence, the global temperature increases more than expected, Figure 1. 12.

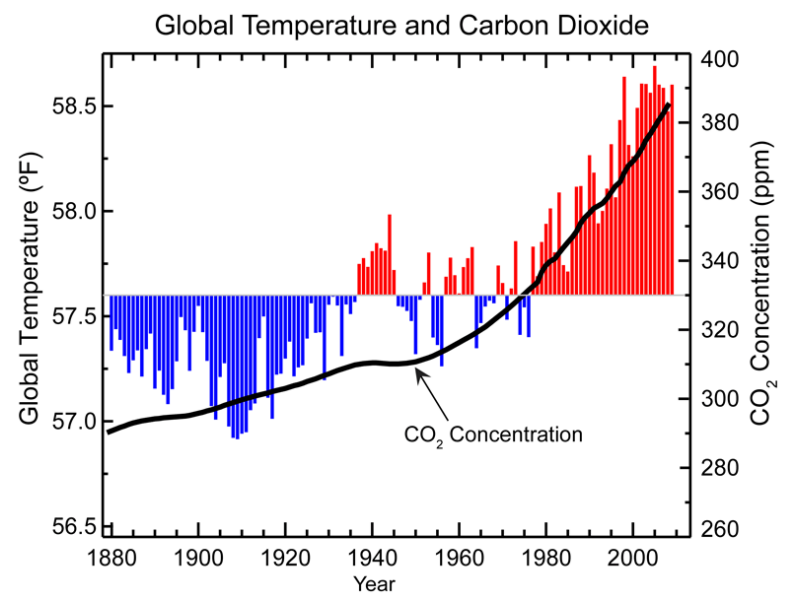

Figure 1. 12. Increase of global temperature [23] 
Chapter 1. Introduction.

The increase in temperature (according to NASA) has been $0.8 \mathrm{~K}$ between 1880 and 2013 and could have terrible consequences. More extreme weather incidents as drought and flooding, melting of ice poles, rising sea levels, vanishing islands and coastal areas, disappearance of certain animals and plants, etc.

According to different investigations, the sea level has raised between 1.0 to $2.2 \mathrm{~mm}$ per year in the $20^{\text {th }}$ century [24]. A study performed by Meehl et al. [25] predicts a another half degree and an additional $320 \%$ sea level rise by the end of the $21^{\text {st }}$ century, at the same GHG concentrations in the atmosphere. To illustrate the dramatic consequences of the human GHG emissions, Figure 1. 13 shows the most important European cities affected by sea level rising and storm events.

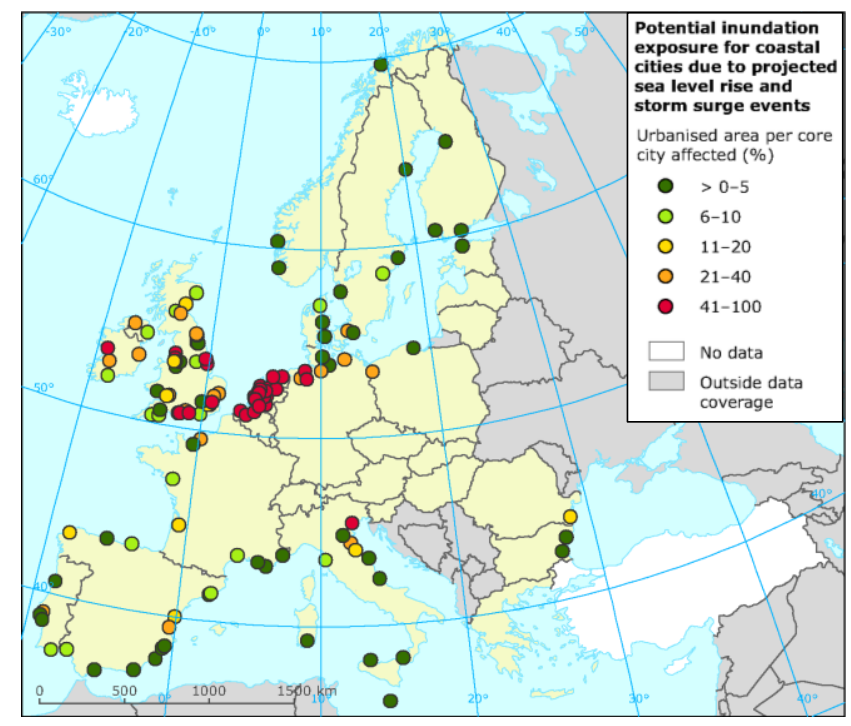

Figure 1. 13. Prediction of European Environmental Agency: European coastal cities affected by sea level rising and storm events

Hence, it is clear that the excess of GHG present in the atmosphere is due to the intervention of man. The most abundant GHG gases are water vapour, carbon dioxide, methane, nitrous oxide, ozone and CFCs (Figure 1. 14). 
Analysis of fluoride fluids with low global warming impact in vapour compression systems. Experimental evaluation of different alternatives for commercial refrigeration.

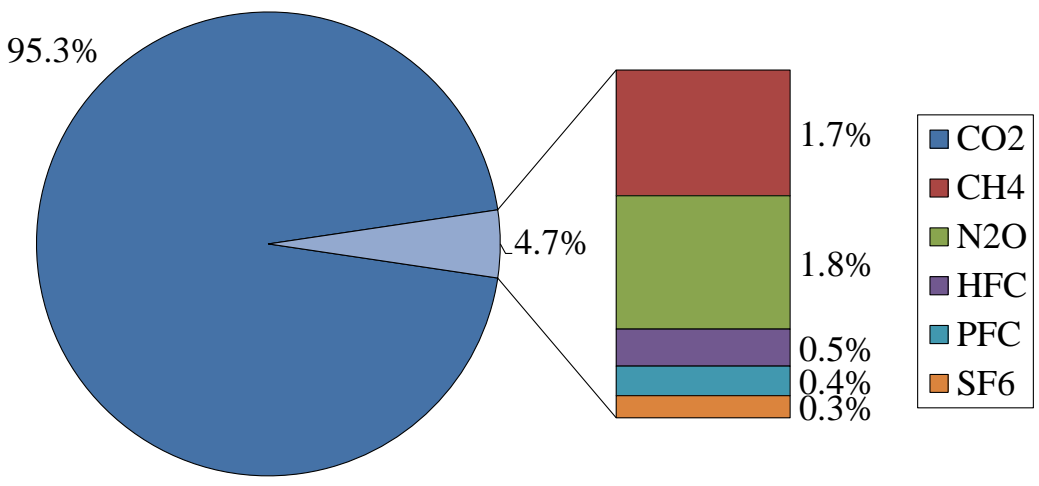

Figure 1. 14. GHG concentration in atmosphere [26]

Since the beginning of the industrial revolution, the human is issuing an unsustainable amount of GHGs (Figure 1. 15), mainly resulting from the burning of fossil fuels to produce electricity or thermal energy (increase $\mathrm{CO}_{2}$ emission) and land-use change (decrease $\mathrm{CO}_{2}$ transformation into $\mathrm{O}_{2}$ ). Those of methane and nitrous oxide emissions are primarily due to agriculture. $\mathrm{CFCs} / \mathrm{HCFCs} / \mathrm{HFCs}$ are used in VCSs as well as propellants.

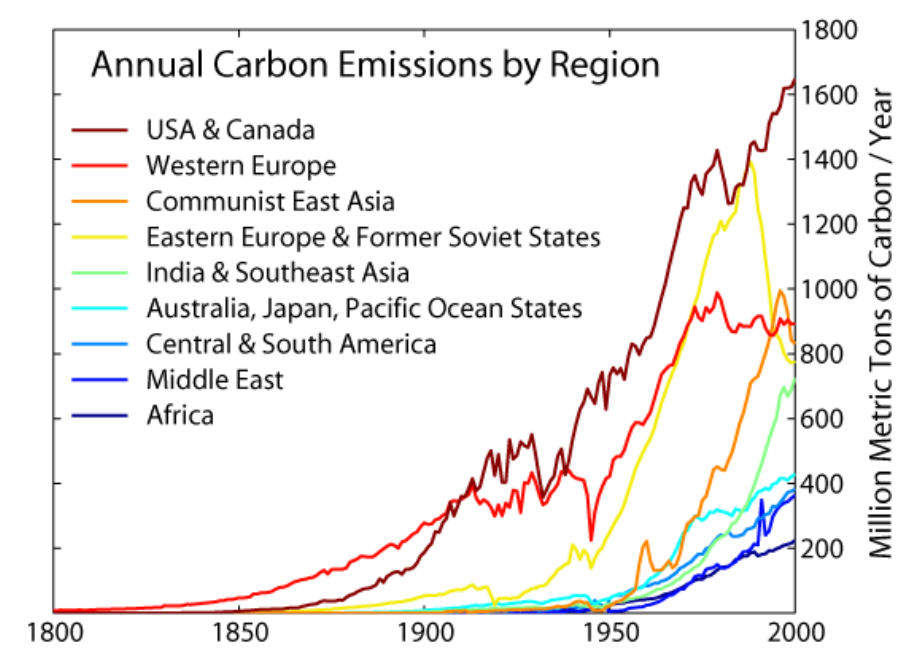

Figure 1. 15. Relevance in GHG emissions by region [27] 
Chapter 1. Introduction.

To avoid reaching an uncontrollable situation, an international response has been materialised through two treaties: United Nations Framework Convention on Climate Change (UNFCCC) and its Kyoto Protocol.

The aim of the UNFCCC is to stabilise atmospheric concentrations of GHGs at a level enough to harm the climate system at normal levels. Countries agreed on the Convention in 1992 and it entered into force in 1994.

The Kyoto Protocol [28] was approved in 1997 and entered into force in 2005. The Kyoto Protocol is an international agreement linked to the UNFCCC, which commits its Parties by setting internationally binding emission reduction targets for industrialised countries and created assistance mechanisms to meet these targets. These actions led into to reduce the emissions of GHGs.

When Kyoto Protocol entered into force, 55 Parties to the Convention ratified it (encompass 55\% of that group's carbon dioxide emissions in 1990). The industrialised countries (35 at the beginning) would reduce their collective emissions of GHGs by $5.2 \%$ compared with the year 1990. Then, in 2007, it has been ratified by 191 countries, Figure 1. 16.

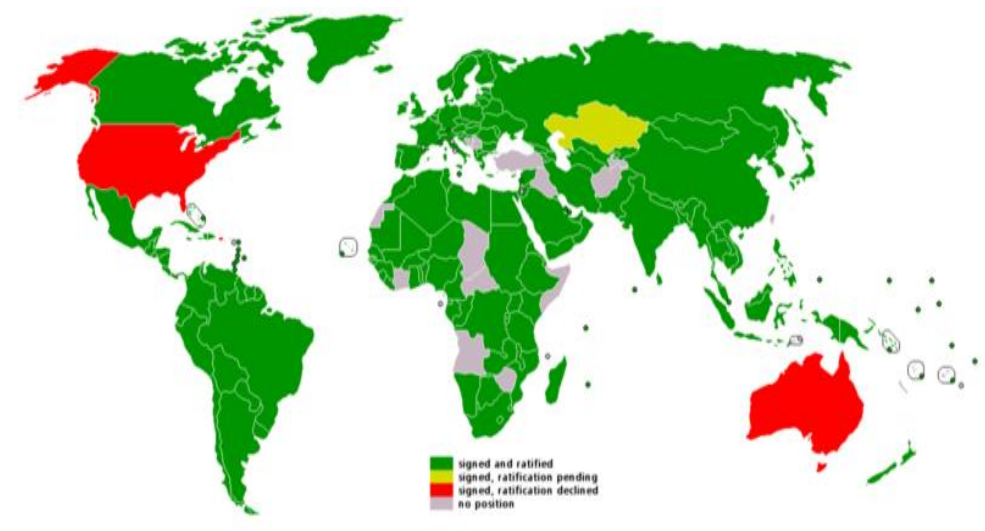

Figure 1. 16. Status of the different parties in the Kyoto Protocol 
Analysis of fluoride fluids with low global warming impact in vapour compression systems. Experimental evaluation of different alternatives for commercial refrigeration.

The GHGs listed by Kyoto Protocol are: Carbon dioxide, methane, nitrous oxide, HFCs (CFCs and HCFCs are also GHG gases but they are not included in this section because their phase-out is expected due to ozone layer protection regulations), perfluorocarbons and sulphur hexafluoride. This affects directly to refrigeration systems.

Thus, in the VCS there are present two main contributions to the greenhouse effect: the direct effect, produced by the direct emission of refrigerants (HFCs) in leakages; and the indirect effect, due to the burning of fossil fuels to produce electricity used in compressors, fans and other machinery required in these systems (emission of $\mathrm{CO}_{2}$ ).

As happens for ozone depletion, a parameter that measures the direct contribution of a substance to the greenhouse effect has been developed. This parameter is the Global Warming Potential (GWP) and take as reference the greenhouse effect produced by the same mass of carbon dioxide molecule $\left(\mathrm{CO}_{2} \mathrm{GWP}=1\right)$. The GWP values of the different substances are calculated by Intergovernmental Panel on Climate Change (IPCC) and the last revision (AR5) was made in 2013 [29].

The GWP value depends on the absorption of infrared radiation, spectral location of its absorbing wavelengths and atmospheric lifetime for each substance. To calculate it a time interval should be considered (20 and 100 years are the most common).

Around $80 \%$ of the global warming is due to HVACR $\mathrm{CO}_{2}$ emissions. The HFCs most commonly used in HVACR systems and their GWP is shown in Table 1. 3. They include the HFC, also known as third generation of refrigerants, ozone- respecting fluids developed to replace CFC and HCFC but that contributes to global warming. 
Chapter 1. Introduction.

Table 1. 3. HFCs most commonly used in HVACR systems

\begin{tabular}{|c|c|c|c|c|c|c|}
\hline Application & $\mathbf{R} 134 \mathbf{a}$ & R152a & $\begin{array}{l}\text { R404A } \\
\text { R507A }\end{array}$ & R407A & R407C & R410A \\
\hline $\mathrm{GWP}_{100-\mathrm{yr}}$ & 1300 & 138 & $\begin{array}{l}3943 \\
3985\end{array}$ & 1923 & 1624 & 1924 \\
\hline Commercial refrigeration & $\mathrm{x}$ & & $\mathrm{x}$ & $\mathrm{x}$ & $\mathrm{x}$ & \\
\hline Domestic Refrigeration & $\mathrm{x}$ & $\mathrm{x}$ & & & & \\
\hline Transport Refrigeration & $\mathrm{x}$ & & $\mathrm{x}$ & & $\mathrm{x}$ & $\mathrm{x}$ \\
\hline Mobile Air Conditioners & $\mathrm{x}$ & $\mathrm{x}$ & & & $\mathrm{x}$ & \\
\hline Unitary Air Conditioning & & & & & $\mathrm{x}$ & $\mathrm{x}$ \\
\hline
\end{tabular}

If Kyoto Protocol is not translated into national regulations, the HFC emissions are going to keep growing (Figure 1. 17) and the previsions of global temperature increase (and its consequences) will be true.

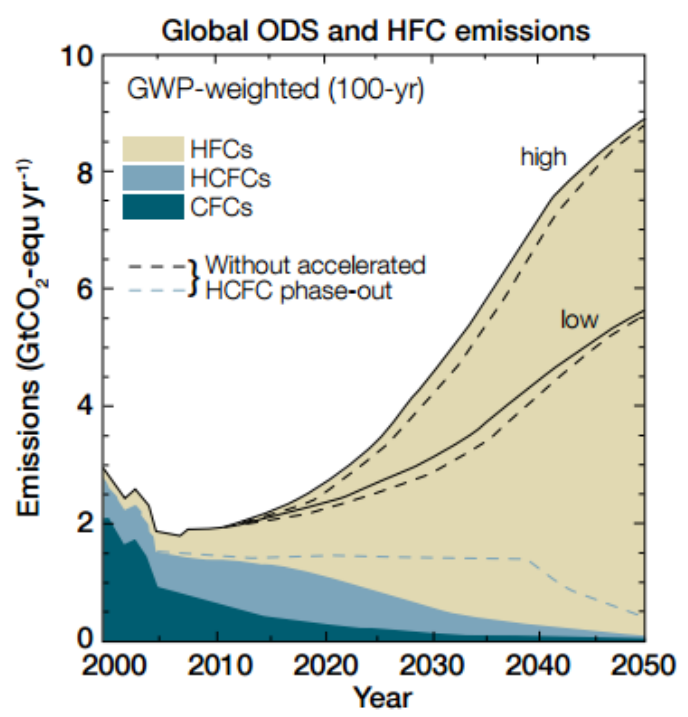

Figure 1. 17. Emissions of synthetic refrigerants predicted until 2050 [30] 
Analysis of fluoride fluids with low global warming impact in vapour compression systems. Experimental evaluation of different alternatives for commercial refrigeration.

As can be seen in Figure 1. 17, emissions of CFCs and HCFCs have a relevant contribution (that is reducing progressively) to equivalent $\mathrm{CO}_{2}$ emissions to the atmosphere before the Montreal Protocol and its implementation. Thus the phasing out of CFCs and HCFCs has reduced also refrigerants contribution to global warming (5 to 6 times larger than Kyoto Protocol first commitment period, 2008-2012 [20])

Europe has been one of the Kyoto Protocol parties that have approved regulations that prohibited or taxed refrigerants in to truly reduce $\mathrm{CO}_{2}$ emissions. In the case of HVACR systems, these regulations have been acting since years before and have produced a significant transformation of these applications.

In order to contain, prevent and thereby reduce emissions of GHG gases; the European Commission approved the European Directive 2006/40/EC [31] (commonly called Fgas regulation). This regulation affected refrigerants with GWP values above 150 used in MACs. The new systems was regulated from 2011 and the rest onward 2017, affecting directly to R134a, the most extended refrigerant in this application. This regulation also tried to improve the prevention of leaks from equipment containing GHG gases.

Then, the original F-gas Regulation was replaced by EU Regulation No 517/2014 [32]. The European Commission intention is to strengthen the limitations imposed by the previous Directive, controlling the total amount of the most important F-gases that can be sold in the EU from 2015 onwards and progressively phase out them until arrive at one-fifth of 2014 sales in 2030. The limitations imposed by EU Regulation No 517/2014 are reproduced and summarised in Table 1. 4. As can be seen, these prohibitions started at 2015 and will finish in 2022, covering most of the HVACR applications. 
Chapter 1. Introduction.

Table 1. 4. Placing on the market prohibitions by the EU Regulation No 517/2014 [32]

\begin{tabular}{ll}
\hline Products and equipment & Date $^{\mathrm{a}}$ \\
\hline Domestic refrigerators and freezers that contain HFCs with GWP $\geq 150$. & 2015 \\
Refrigerators and freezers for commercial use $\quad \mathrm{GWP} \geq 2500$. & 2020 \\
(hermetically sealed equipment) that contain HFCs with $\quad \mathrm{GWP} \geq 150$. & 2022 \\
Stationary refrigeration equipment, that contains, or whose functioning relies & 2020 \\
$\begin{array}{l}\text { upon, HFCs with GWP } \geq 2500 \text { except equipment intended for application } \\
\text { designed to cool products to temperatures below 223K. }\end{array}$ \\
$\begin{array}{ll}\text { Multipack centralised refrigeration systems for commercial use with a rated } & 2022 \\
\text { capacity } \geq 40 \mathrm{~kW} \text { that contain, or whose functioning relies upon, fluorinated }\end{array}$
\end{tabular}

GHGs with GWP $\geq 150$, except in the primary refrigerant circuit of cascade systems where fluorinated GHGs with a GWP $<1500$ may be used.

Movable room air-conditioning equipment (hermetically sealed equipment 2020 which is movable between rooms by the end user) that contain HFCs with $\mathrm{GWP} \geq 150$.

Single split air-conditioning systems containing less than $3 \mathrm{~kg}$ of fluorinated 2025 GHGs, that contain, or whose functioning relies upon, fluorinated GHGs with GWP $\geq 750$.

${ }^{\mathrm{a}} 1$ January.

Additionally to the EU Regulation, some European countries have approved their own regulations to accelerate the process of control direct GHG emissions [33]. Some countries have approved taxes on HFC acquisition [34]: for example, the R134a tax is $28.8 € \mathrm{~kg}^{-1}$ in Denmark, $55.3 € \mathrm{~kg}^{-1}$ in Norway, $35 € \mathrm{~kg}^{-1}$ in Sweden, $6.5 € \mathrm{~kg}^{-1}$ in Slovenia and $26 € \mathrm{~kg}^{-1}$ in Spain. France, Poland and Sweden have proposed HFC taxes and Austria, Belgium, Germany, Netherlands, Switzerland and United Kingdom promote the use of climate friendly technologies. On the contrary, Australia repealed in 2014 the carbon tax. 
Analysis of fluoride fluids with low global warming impact in vapour compression systems. Experimental evaluation of different alternatives for commercial refrigeration.

In Spain, particularly [35, 36], the tax rate exceeds (for some commonly used refrigerants) until 20 times their purchase price (R404A, on top of this this systems demands the highest charges). Therefore, that increases a lot the final cost and it makes the refrigerant consumers to consider other lower GWP options.

Among the different HVACR applications, commercial refrigeration is a major user of HFCs and presents the higher leakage rates so finding environment friendly alternatives is a major challenge for researchers, Figure 1. 18.

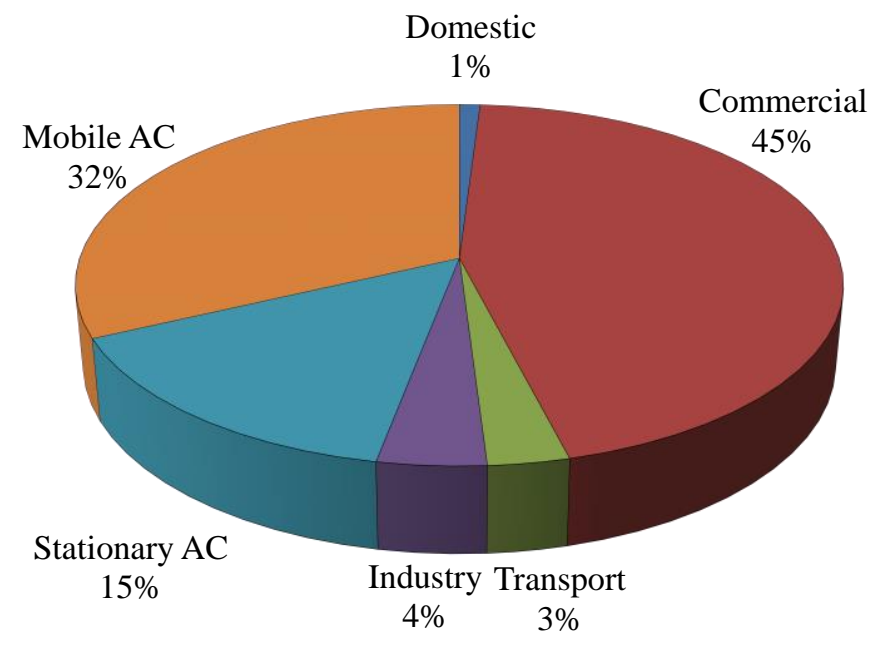

Figure 1. 18. \% of HFC emissions for different vapour compression applications in 2015 [37]

Such is the relevance of refrigerant leakage in commercial refrigeration systems that the U.S. department of Energy focused intensely on Commercial Refrigeration on a project intended to develop low-GWP refrigerant solutions for the HVACR market [38]. 
Chapter 1. Introduction.

\subsubsection{Commercial refrigeration}

Commercial Refrigeration comprises all the used equipment by retail outlets and food service industry for preparing, holding and displaying frozen and fresh food and beverages for customer purchase [39].

\subsubsection{Relevance of commercial refrigeration}

These refrigeration systems are extended in different type of stores all over the world, being focused in Europe, America and China, Figure 1. 19. Among that, it can be found:

- $\quad$ supermarkets and food sales

- grocery stores

- supermarkets

- convenience stores

- specialty food stores

- restaurants

- fast food establishments

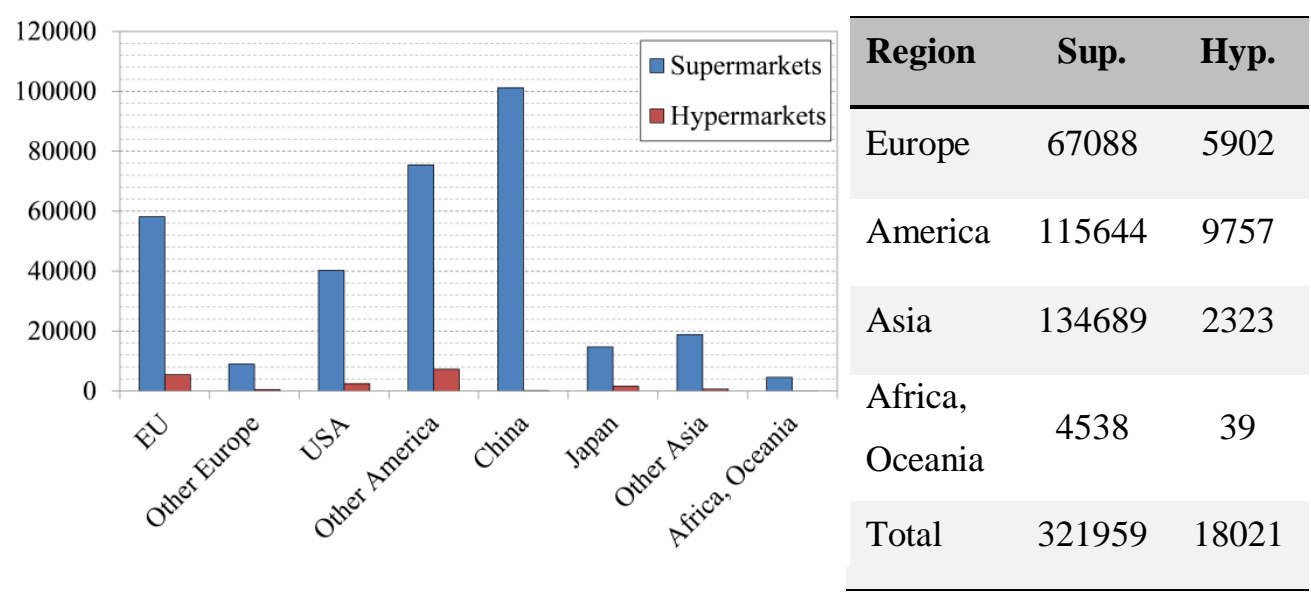

Figure 1. 19. Total number of supermarkets and hypermarkets 
Analysis of fluoride fluids with low global warming impact in vapour compression systems. Experimental evaluation of different alternatives for commercial refrigeration.

The relevance of commercial refrigeration stores in Spain (in 2012) is shown in Table 1. 5 [40]. The most relevant commercial refrigeration stores are comprised among the medium and large supermarkets (69.1\%). The total amount of surface is $12239666 \mathrm{~m}^{2}$.

Table 1. 5. Total number of commercial refrigeration stores in Spain in 2012

\begin{tabular}{lc}
\hline Commercial refrigeration store & Total number (\% amount / total) \\
\hline Hypermarket & $6258(14.8 \%)$ \\
Supermarkets $400-999 \mathrm{~m}^{2}$ & $3341(32.4 \%)$ \\
Supermarkets $\geq 1000 \mathrm{~m}^{2}$ & $478(36.7 \%)$ \\
Convenience stores & $10138(16.1 \%)$ \\
\hline
\end{tabular}

In developed countries, retail outlets and food service industry are responsible of around the $3 \%$ of total electrical energy consumption. Therefore, $1 \%$ of total GHG emissions [41]. Electricity costs are very relevant for the economic balance of the supermarket as they spend in electricity one third of their profit margins [42].

As average, half of the energy consumption in retail outlets is associated with the refrigeration system [43], being that the largest electricity consumer, followed by lighting, Figure 1. 20. The relevance of the refrigeration energy consumption varies between the different commercial refrigeration stores, for smaller stores the amount of energy used in refrigeration is higher than the energy used in large hypermarkets [41, 44]. Besides, this value can vary depending on climate. For example, only in the US, refrigeration consumption percentage is comprised between $44 \%$ and $62 \%$ [45]. 


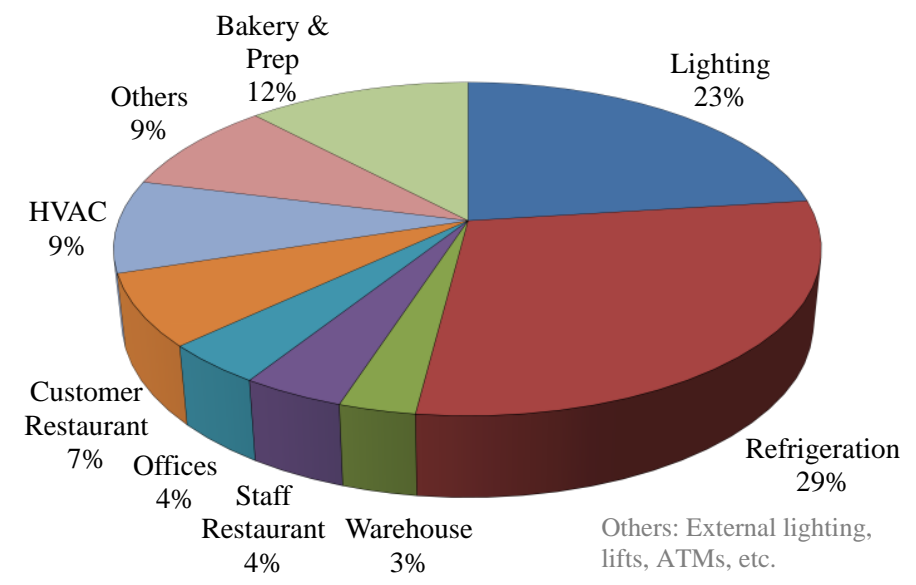

a)

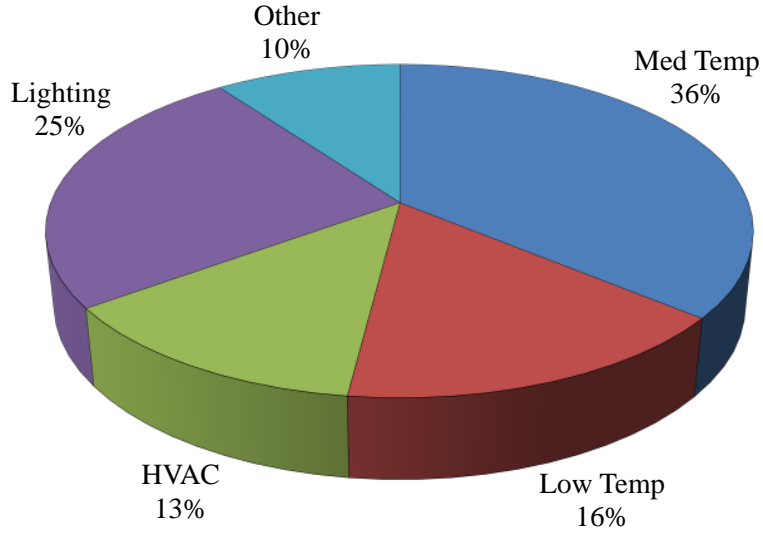

b)

Figure 1. 20. Energy consumption distribution in a typical: a) hypermarket [42] and b) supermarket [45]

Although it is decreasing, the main percentage of this electricity is provided from fossil-fuel power stations (Figure 1. 21), hence causing $\mathrm{CO}_{2}$ emissions to the atmosphere [46]. As GHGs, that produces an increment of global warming impact and attending the Kyoto Protocol objectives, these emissions should be reduced. 
Analysis of fluoride fluids with low global warming impact in vapour compression systems. Experimental evaluation of different alternatives for commercial refrigeration.

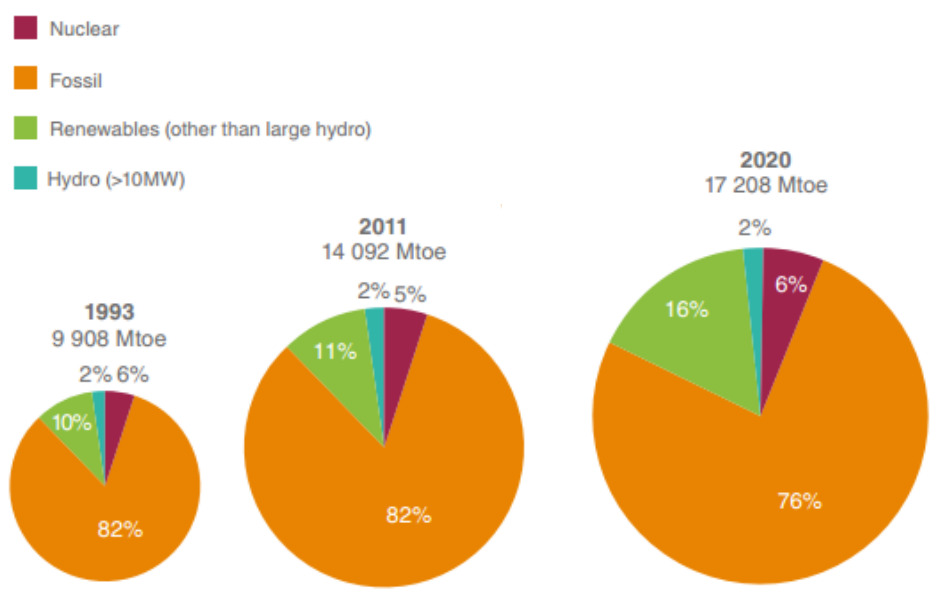

Figure 1. 21. Total Primary Energy Supply by resource 1993, 2011 and 2013 [46]

\subsubsection{Commercial refrigeration systems}

Commercial refrigeration systems are different among them to cover different needs of consumers. Their architecture, components and used refrigerant depends on numerous requirements and several classifications can be found. A general classification differences 3 main categories of equipment used in the commercial refrigeration sector: condensing units, hermetically sealed (stand-alone) systems and parallel compressors rack systems [47].

Condensing units are used in specialised small shops (bakeries, butchers), convenience stores and food service; and they are more popular in developed countries (Figure 1. 22). These are medium sized systems (one or two compressors) with one or two retail displays in the sales area cooled by a remote condensing unit comprising a compressor and a condenser, located at the back of the shop or outdoors. They typically contain between 2 and $10 \mathrm{~kg}$ of refrigerant. 


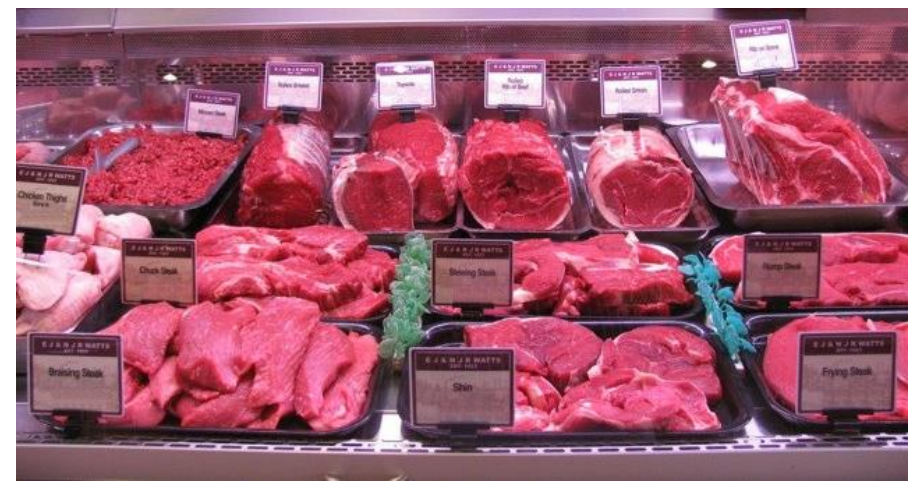

Figure 1. 22. Condensing unit used to chill meat in a butcher

Small hermetically sealed systems (Figure 1. 23) include ice cream freezers, bottle (wine, beer, refreshments) coolers, beverage vending machines and stand-alone retail displays. This equipment is usually installed in supermarkets, other small retail outlets and public buildings as train stations, schools, or hospitals. They dominate the commercial refrigeration in developing countries (because of the lower initial investment, flexibility and simplicity) even though they are also popular in developed countries. These systems work similar to domestic refrigerators and contain low charge of refrigerant (typically between 0.1 and $0.5 \mathrm{~kg}$ ). They are easy to install and have lower initial cost but are less efficient than other commercial refrigeration systems.
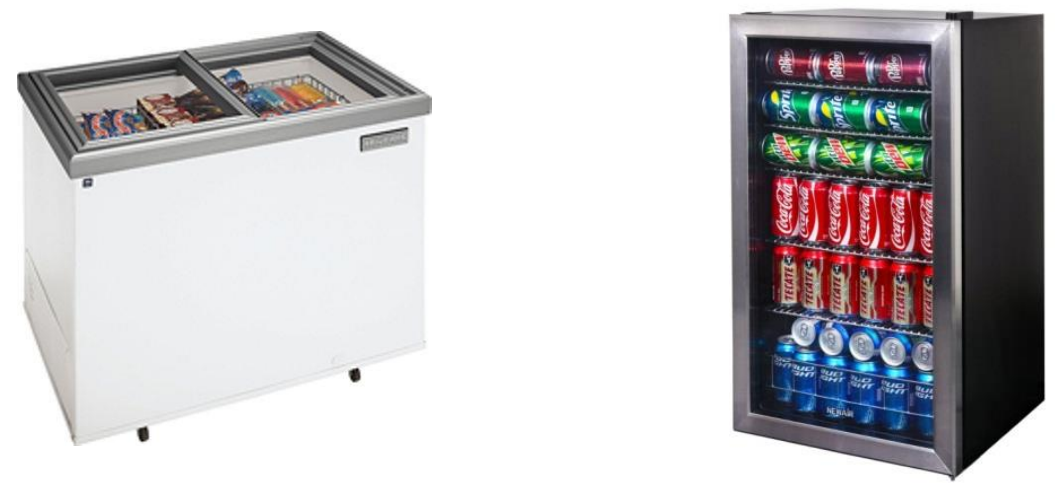

Figure 1. 23. Small hermetically sealed systems: a) Ice cream freezer and b) beverage cooler 
Analysis of fluoride fluids with low global warming impact in vapour compression systems. Experimental evaluation of different alternatives for commercial refrigeration.

Parallel compressor rack refrigeration systems (PCRSS) (Figure 1. 24), used in large supermarkets and other large stores as hypermarkets. Two or more (up to eight in some cases) compressors are connected to an external condenser and can provide cooling to loads with different evaporation conditions [48]. It demands a very great amount of refrigerant, up to $2300 \mathrm{~kg}$ of refrigerant in great hypermarkets [49].

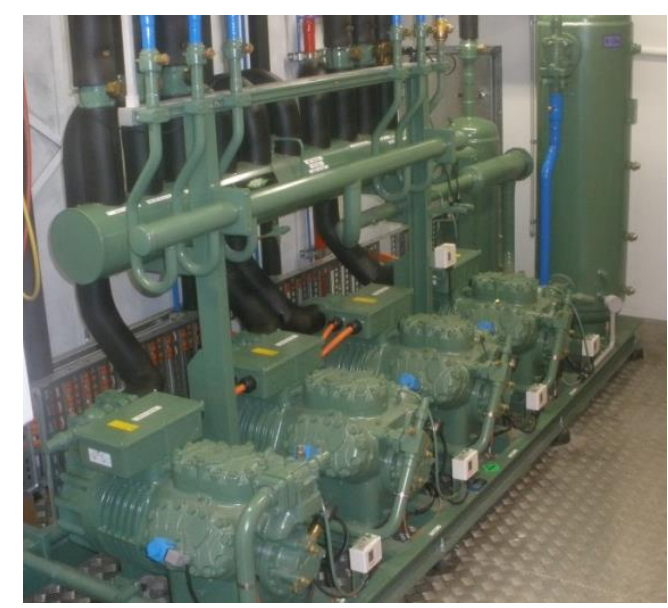

Figure 1. 24. Parallel compressor R134a rack

In Figure 1. 25 the amount of small and medium commercial refrigeration systems can be seen divided by regions (in Table 1.6 the total amount of systems can be seen). It highlights that globally exist around double of condensing units and hermetic groups in stand-alone equipment than vending machines.

Table 1. 6. Amount of different commercial refrigeration systems [40]

\begin{tabular}{lc}
\hline Type of commercial refrigeration system & Thousands of \\
\hline Condensing units & 32571 \\
Hermetic groups in stand-alone equipment & 31173 \\
Vending machines & 14707 \\
\hline
\end{tabular}




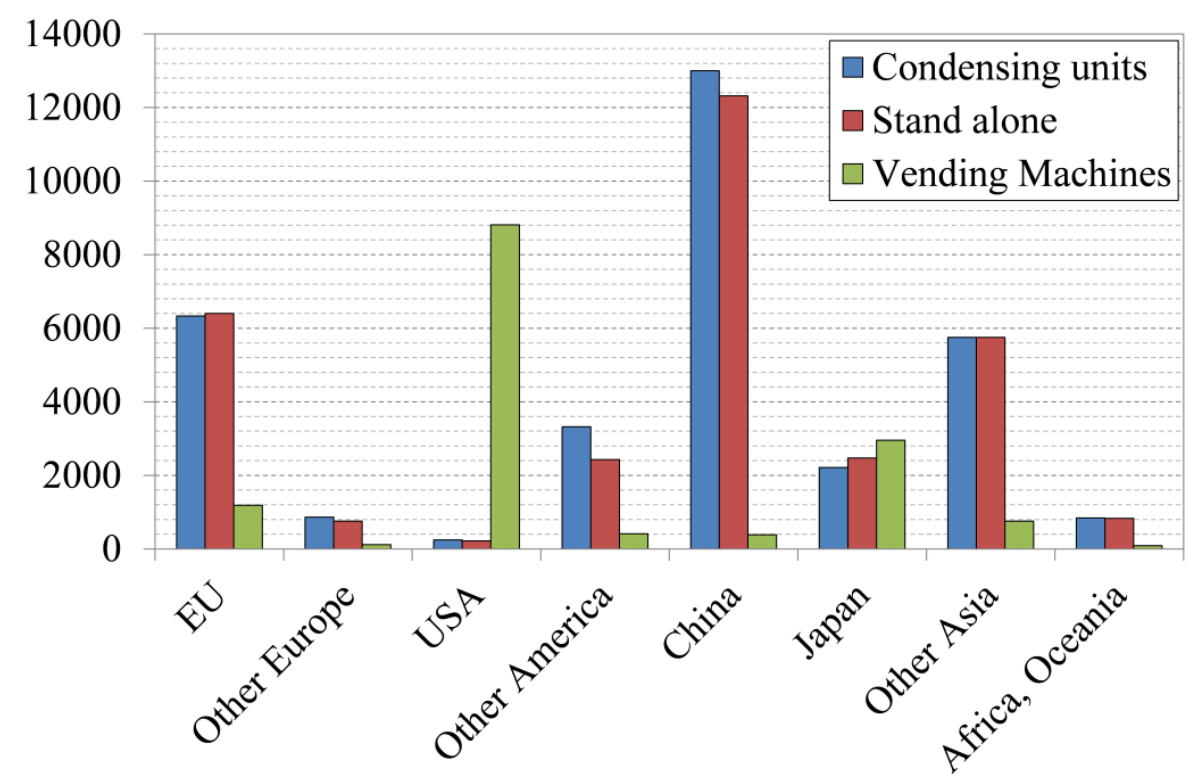

Figure 1. 25. Thousands of number of items of small\&medium commercial equipment [40]

There are a great amount of condensing units, stand alone and vending machines present worldwide, but if compared with other systems, their annual leakages are very lower because their leakage rate is quantified about $1-2 \%$ and the charge of refrigerant is at most $30 \mathrm{~kg}$. So, although the large supermarket systems number is estimated to be 80 times lower, their refrigerant leakage varies between $11 \%$ and $30 \%$ charge is up to $2500 \mathrm{~kg}$ and the direct GHG emissions to the atmosphere are more relevant [50].

\subsubsection{Cooling loads in commercial refrigeration}

Depending on the characteristics of the cabinet, they can be classified according to ISO 23953, Table 1.7. It establishes a vocabulary of terms and definitions relative to refrigerated display cabinets used for the sale and display of foodstuffs. They are first classified according to evaporation temperature level, then position and finally disposition in the supermarket lay-out and isolation of the cold service. 
Analysis of fluoride fluids with low global warming impact in vapour compression systems. Experimental evaluation of different alternatives for commercial refrigeration.

Table 1. 7. ISO 239553: Classification of commercial refrigeration systems

\begin{tabular}{|c|c|}
\hline Application Temperature positive & Temperature negative \\
\hline $\begin{array}{l}\text { To be used Chilled foodstuffs } \\
\text { for }\end{array}$ & $\begin{array}{l}\text { Frozen, quick frozen foodstuff } \\
\text { and ice cream }\end{array}$ \\
\hline
\end{tabular}

\begin{tabular}{|c|c|c|c|c|}
\hline \multirow{8}{*}{ Horizontal } & $\begin{array}{l}\text { Chilled, serve-over counter } \\
\text { open service access }\end{array}$ & $\mathrm{HC} 1$ & $\begin{array}{l}\text { Frozen, serve-over } \\
\text { counter open service } \\
\text { access }\end{array}$ & HF1 \\
\hline & $\begin{array}{l}\text { Chilled, serve-over counter with } \\
\text { integrated storage open service } \\
\text { access }\end{array}$ & $\mathrm{HC} 2$ & & \\
\hline & Chilled, open, wall site & $\mathrm{HC} 3$ & Frozen, open, wall site & HF3 \\
\hline & Chilled, open, island & $\mathrm{HC} 4$ & Frozen, open, island & HF4 \\
\hline & Chilled, glass lid, wall site & HC5 & $\begin{array}{l}\text { Frozen, glass lid, wall } \\
\text { site }\end{array}$ & HF5 \\
\hline & Chilled, glass lid, island & HC6 & Frozen, glass lid, island & HF6 \\
\hline & $\begin{array}{l}\text { Chilled, serve-over counter } \\
\text { closed service access }\end{array}$ & $\mathrm{HC7}$ & $\begin{array}{l}\text { Frozen, serve-over } \\
\text { counter closed service } \\
\text { access }\end{array}$ & HF7 \\
\hline & $\begin{array}{l}\text { Chilled, serve-over counter with } \\
\text { integrated storage closed } \\
\text { service access }\end{array}$ & $\mathrm{HC} 8$ & & \\
\hline \multirow{4}{*}{ Vertical } & Chilled, semi-vertical & $\mathrm{VC} 1$ & Frozen, semi-vertical & VF1 \\
\hline & Chilled, multi-deck & $\mathrm{VC} 2$ & Frozen, multi-deck & VF2 \\
\hline & Chilled, roll-in & VC3 & & \\
\hline & Chilled, glass door & VC4 & Frozen, glass door & VF4 \\
\hline
\end{tabular}


Continuation of Table 1.7.

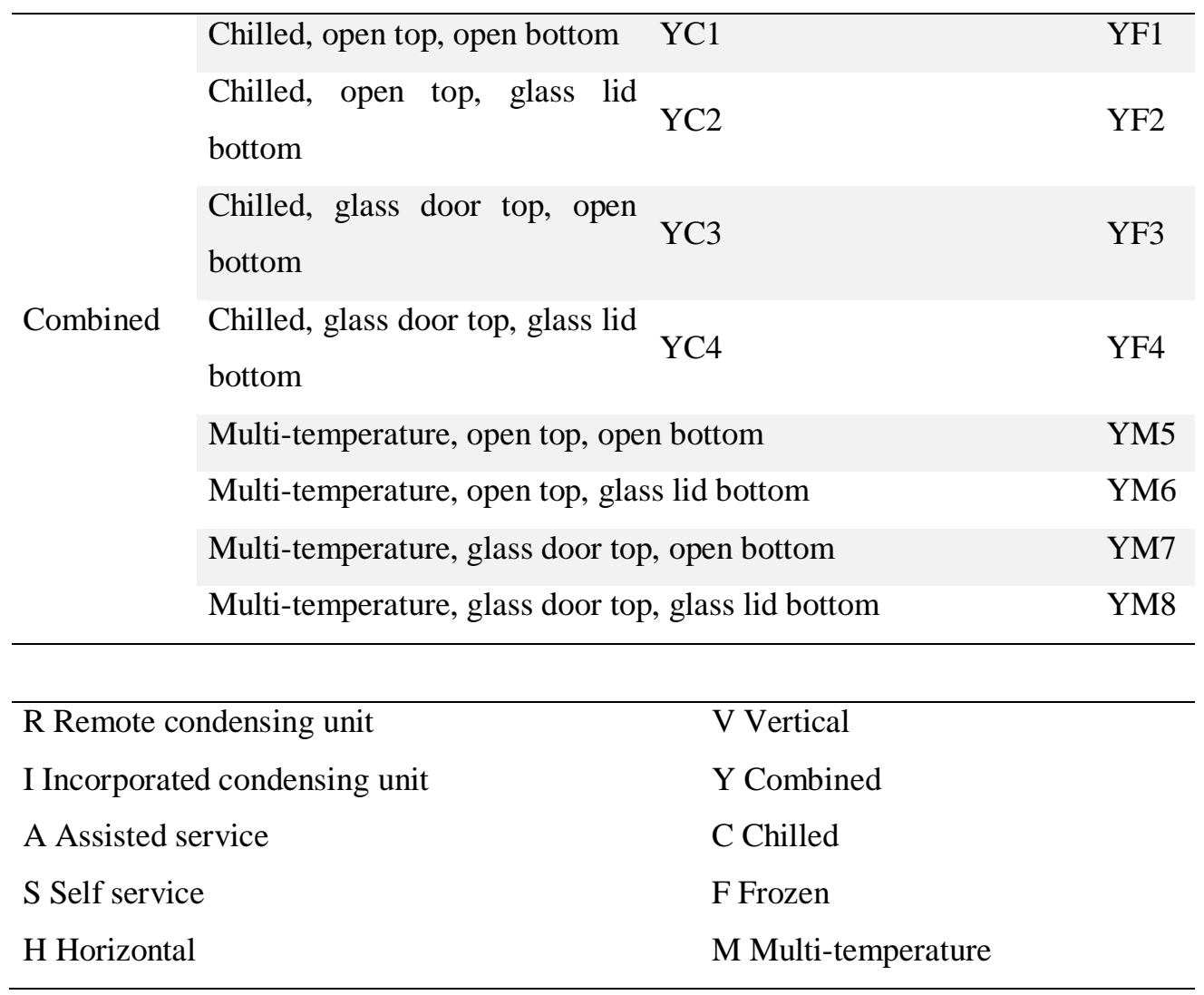

As Table 1.7 shows, commercial refrigeration comprises normally two temperature levels (Table 1. 8) associated to two general needs:

- Temperature positive (medium evaporation temperature, MT) for fresh food preservation.

- Temperature negative (low evaporating temperature, LT) for frozen products. 
Analysis of fluoride fluids with low global warming impact in vapour compression systems. Experimental evaluation of different alternatives for commercial refrigeration.

Table 1. 8. Range of temperatures in commercial refrigeration systems

\begin{tabular}{|c|c|c|c|}
\hline & Case Temp. & Evap Temp. & Temperature depends on: \\
\hline MT & $\begin{array}{l}274 \text { to } 259 \mathrm{~K} \\
\left(1 \text { to }-14^{\circ} \mathrm{C}\right)\end{array}$ & $\begin{array}{l}258 \text { to } 278 \mathrm{~K} \\
\left(-15 \text { to } 5^{\circ} \mathrm{C}\right)\end{array}$ & $\begin{array}{l}\text { - Product } \\
\text { - Display case (closed or open) } \\
\text { - System (direct or indirect). }\end{array}$ \\
\hline LT & $\begin{array}{c}261 \text { to } 255 \mathrm{~K} \\
\left(-12 \text { to }-18^{\circ} \mathrm{C}\right)\end{array}$ & $\begin{array}{c}233 \text { to } 243 \mathrm{~K} \\
\left(-30 \text { to }-40{ }^{\circ} \mathrm{C}\right)\end{array}$ & $\begin{array}{l}\text { - Product } \\
\text { - Country } \\
\text { - Ice cream: } 253 \text { to } 255 \mathrm{~K}\left(-18 \text { to }-20{ }^{\circ} \mathrm{C}\right)\end{array}$ \\
\hline
\end{tabular}

\subsubsection{PCRRSs architectures}

For PCRRSs, there are different architectures that appear from the different location and distribution of the components or that are derived from the basic vapour compression cycle [51].

Direct expansion (DX) systems

The most widespread are direct expansion (DX) systems; either centralised or distributed, where the primary refrigerant is circulated directly to the evaporators located at display cases, Figure 1. 26.

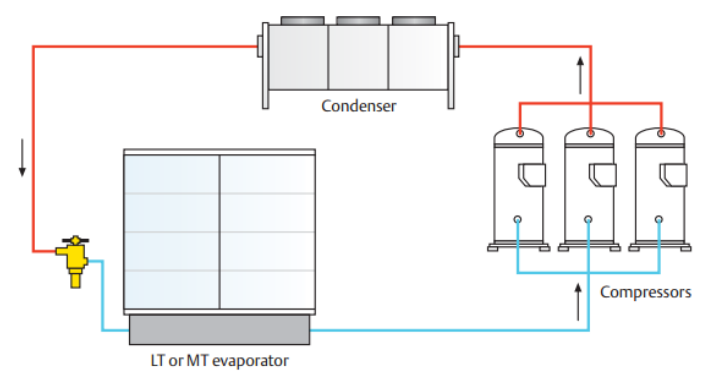

a)

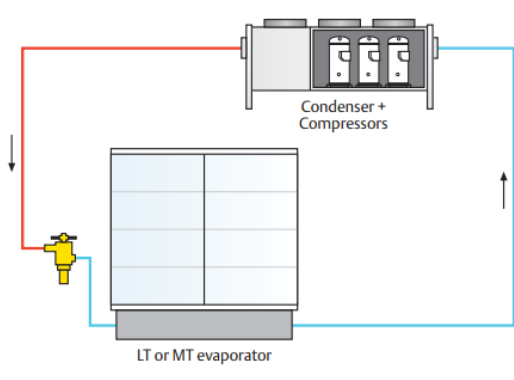

b)

Figure 1. 26. Direct expansion systems: a) Centralised and b) distributed 
Chapter 1. Introduction.

The most common architecture is centralised DX systems. Approximately $80 \%$ of the commercial refrigeration systems use this configuration that is composed by LT and MT evaporators that share separated compressors and condensers.

The number of compressors varies between three to eight which use is alternated and controlled to maintain efficiently the cooling capacity and temperature required. They are located in a separated room to reduce the acoustic effect over the supermarket (Figure 1. 24). The external condensers are air-cooled so the air flow controls the condensing temperature and pressure.

The advantages of these systems are low maintenance cost and noise, and that can be used to feed several evaporators. The great disadvantage is the large refrigerant leakages determined by two factors:

1. Significant refrigerant charge: because of the long connecting pipes (compressors room - external condensers - evaporators distributed by the entire supermarket),

2. Large leakage rate: for environmental calculations is usually considered $15 \%$.

Distributed DX systems are a variation of centralised DX systems. The most important difference is that the condenser and the compressors are located together at the exterior of the supermarket. The discharge lines are almost eliminated and the set can be mounted near the cabinets reducing the liquid and suction lines.

This system can be factory-assembled and both the refrigerant charge and the leakage rate are reduced. On the contrary, it only can be considered for certain supermarket buildings, where the structure can support the condenser-compressor set and the location is technically available. 
Analysis of fluoride fluids with low global warming impact in vapour compression systems. Experimental evaluation of different alternatives for commercial refrigeration.

Cascade refrigeration systems

The cascade systems are typically used with very low temperature applications as cryogenic. Cascade systems consist on two basic vapour compression cycles connected by a heat exchanger, Figure 1. 27. This component is used as evaporator for the high stage and as condenser for the low stage. So, the high GWP HFCs can be only used at the high stage for MT cabinets and the low stage covers the LT loads. The cascade system can solve several problems coming from the high pressure ratio or high discharge temperatures observed in low temperature refrigeration systems [52].

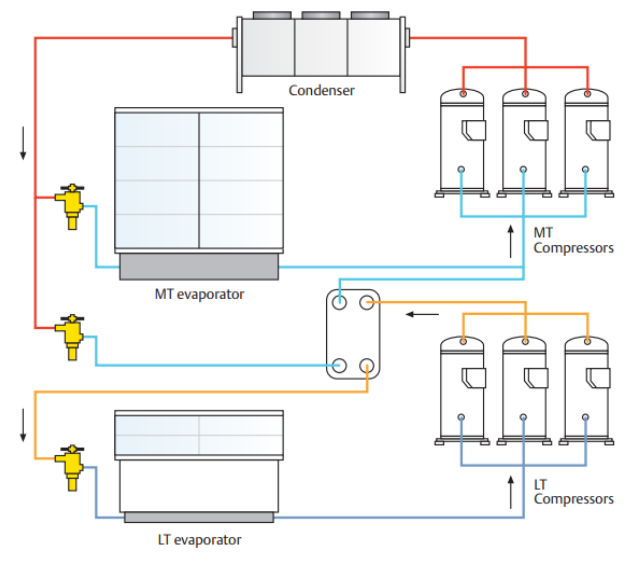

Figure 1. 27. Cascade refrigeration system

The ideal refrigerant to be used in the low stage of cascade systems is carbon dioxide (R744). Normally in DX systems, the use of R744 as refrigerant is avoided because at normal exterior conditions the condensing pressures are excessive. But with this system, the condensation pressures are reduced (from 3000 to $3500 \mathrm{kPa}$ ).

The advantage of R744 cascade system is that the HFC charge (GWP of 3943 or 1300) is reduced by the use of $\mathrm{R} 744(\mathrm{GWP}=1)$. The problem is that when compared with DX systems, the additional heat exchanger produces a slight loss in energy efficiency and 
Chapter 1. Introduction.

the initial costs are higher (cascade systems demands more components and that to be used with $\mathrm{CO}_{2}$ are more expensive than that of HFCs).

Secondary systems are also known as indirect refrigeration systems because the primary (or high stage) refrigerant uses another cycle to transfer heat to the cabinets through an extra heat exchanger, Figure 1. 28.

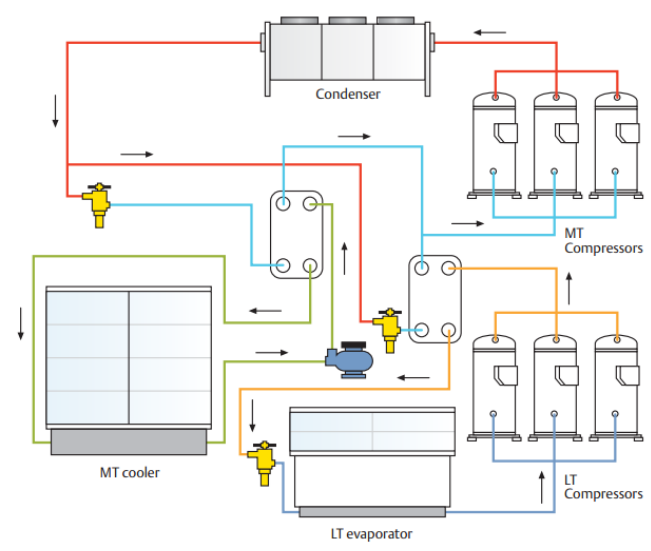

Figure 1. 28. Secondary refrigeration system

Secondary systems also introduce an extra heat exchanger in the refrigeration system, but instead of cascade systems, the heat is transferred to a secondary fluid that then exchanges this thermal power with the loads. Instead of a compressor, they use an additional pump. Secondary systems are being increasingly popular in Europe and USA (in conjunction with natural refrigerants and HFC respectively) [53]. Secondary fluids should have low cost and good heat transfer characteristics. Glycols or $\mathrm{CO}_{2}$ are the most popular secondary fluids.

The heat exchanger temperature difference leads to an increase in compressor energy consumption (the evaporation temperature should be lower than the DX system and therefore the compression ratio is greater and its efficiency lower). 
Analysis of fluoride fluids with low global warming impact in vapour compression systems. Experimental evaluation of different alternatives for commercial refrigeration.

Cascade and secondary refrigeration systems are also known as advanced refrigeration systems because allow GHGs refrigerant reduction between 42 and 78\% (and 3200 and $12000 €$ in refrigerant acquisition) compared to DX systems. These systems have lower initial costs and efficiency.

\section{R744 Transcritical system}

$\mathrm{CO}_{2}$ (R744) transcritical system is one of the most promising systems due to its lowGWP, Figure 1. 29. The operating principle of transcritical systems is similar to DX systems, but instead of condensing the gas discharged from the compressors; these systems cool R744 above the critical point (296K, $7500 \mathrm{kPa})$. R744 transcritical system also uses a pressure reduction valve and flash thank, where the liquid is distributed to the loads and the gas is directed to the suction of high stage compressors after an additional expansion.
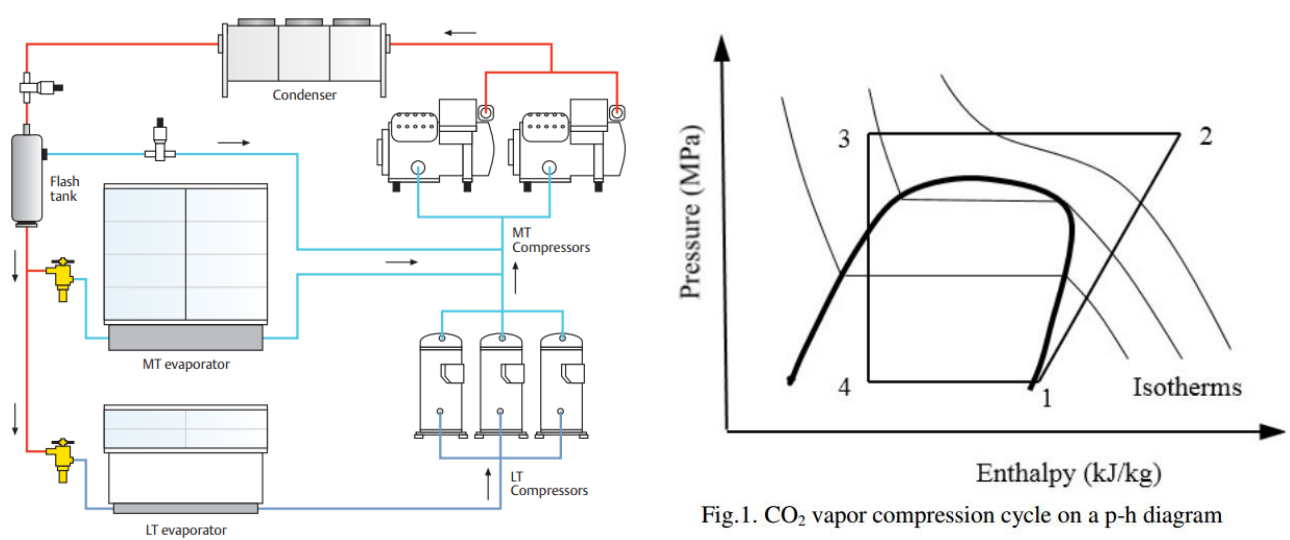

Fig.1. $\mathrm{CO}_{2}$ vapor compression cycle on a p-h diagram

Figure 1. 29. R744 Transcritical refrigeration system: a) Scheme and b) Ph diagram 
Chapter 1. Introduction.

\subsubsection{Architectures and refrigerants substitution}

Thus, in supermarket PCRRSs, DX systems allow minor cost investment and system adaptation to lower GWP alternatives, being the most feasible solutions at low- or midterm. But to achieve a significant $\mathrm{CO}_{2}$ direct emissions reduction; secondary, cascade or transcritical booster $\mathrm{CO}_{2}$ systems should be implemented in supermarkets.

However, significant $\mathrm{CO}_{2}$ equivalent emissions should be reduced considering the existing commercial refrigeration systems. Either the system or the working fluid is replaced (or modified). From an environmental point of view, R744 transcritical refrigeration systems are the best option to supply cold to retail cabinets. The problem is that these systems requires a new installation and meets with opposition from supermarket managers. So, retrofit HFC systems with low-GWP refrigerants can be a trade-off that can achieve significant $\mathrm{CO}_{2}$ equivalent emissions.

Emerson proposes secondary and $\mathrm{CO}_{2}$ transcritical systems to substitute centralised systems, Figure 1. 30. This evolution would be done together with the GHG refrigerants phase-out.
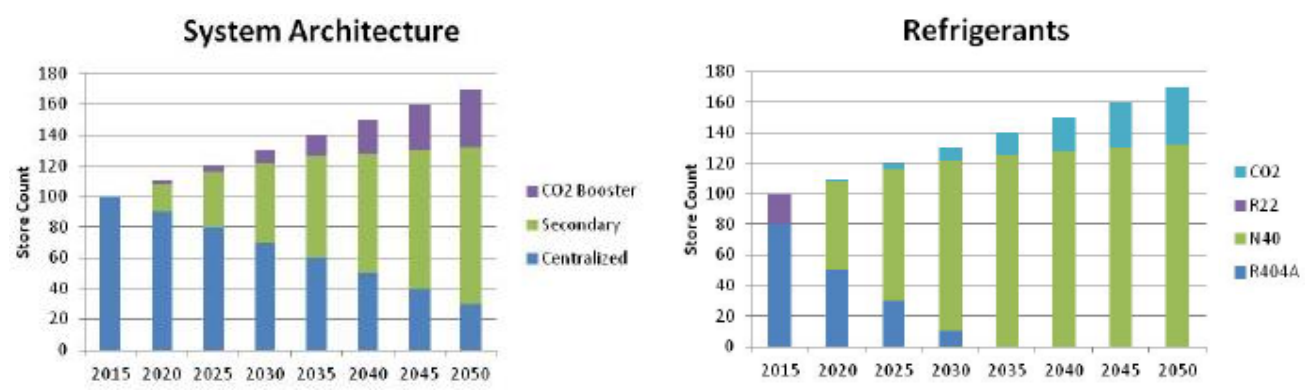

Figure 1. 30. System architecture and refrigerants replacement schedule proposed by Emerson 
Analysis of fluoride fluids with low global warming impact in vapour compression systems. Experimental evaluation of different alternatives for commercial refrigeration.

In this work, the most economical solutions to reduce $\mathrm{CO}_{2}$ eq. emissions, a refrigerant drop-in (or light retrofit) replacement, are considered. Retrofit substitutions in refrigeration systems consist on replacing the current refrigerants with other, carrying out system modifications in order to achieve higher performances. The severity of modifications should be studied depending on the energetic benefits and the economic costs (also trade-offs are needed). These modifications can go from a thermal expansion valve adjustment (only a few minutes are needed) from a compressor or heat exchanger substitution (expensive). Retrofit substitution offers the benefits presented in Table 1.9.

Table 1. 9. Benefits of retrofit substitution [54]

\begin{tabular}{ll}
\hline Energetic & Facilitates compliance with environmental regulations \\
& Potential to upgrade compressor technologies = increased \\
& efficiencies \\
\hline Equipment & Provides potential for improved compressor reliability and lifespan \\
& Avoid premature obsolescence of equipment \\
\hline Environmental & Enables accelerated transition away from ozone-depleting \\
& refrigerants \\
& Provides opportunity to promote environmental leadership \\
\hline Economical & Avoids costly equipment replacement / Improve life cycle cost of \\
& equipment \\
& Enables Continued use of existing equipment with minimal \\
& downtime for the refrigerant \\
\hline
\end{tabular}


Chapter 1. Introduction.

\subsubsection{Working fluids used in PCRRs}

Looking back briefly to that exposed before, the $\mathrm{CO}_{2}$ emission from electricity generation in power stations is not the only contribution made by VCS to the global warming. In HVACR systems, two GHG emissions can be differenced: indirect $\mathrm{CO}_{2}$ emissions (approximately $80 \%$ of the greenhouse contribution in R22 systems), produced for electricity generation; and GHG direct emissions (the remaining 20\%), due to refrigerants leakage from VCS [55].

\subsubsection{Refrigerant consumption}

The GHG direct emissions to the atmosphere from VCS are becoming more relevant. The quantity of refrigerant consumed increase yearly, in the year 1991 the worldwide refrigerant consumption was 484.2 tons/year [56] and the HFC demand in Europe is expected to increase annually around $2 \%$ per year, from 2008 to 2020 [57].

The largest refrigerant consumer was MAC with $31 \%$ (mainly R134a in developed countries, and R22 and R12 in developing), then unitary air-conditioning sectors with 28\% (R134a and R410A in developed countries, and R22 and R12 in developing), and commercial refrigeration systems, with 17\% (R134a, R404A, R507A in developed countries; and R22 and R502 in developing).

Figure 1. 31 represents the worldwide situation of refrigerant use in 2006 in commercial refrigeration systems [58]. Almost half of the commercial refrigeration systems still use ODSs as CFCs and HCFCs because they are in an earlier stage of ODS phase out (Article 5 countries). The percentage that uses HFCs represents Europe and other developed countries that have transitioned to zero ODP fluids. 
Analysis of fluoride fluids with low global warming impact in vapour compression systems. Experimental evaluation of different alternatives for commercial refrigeration.
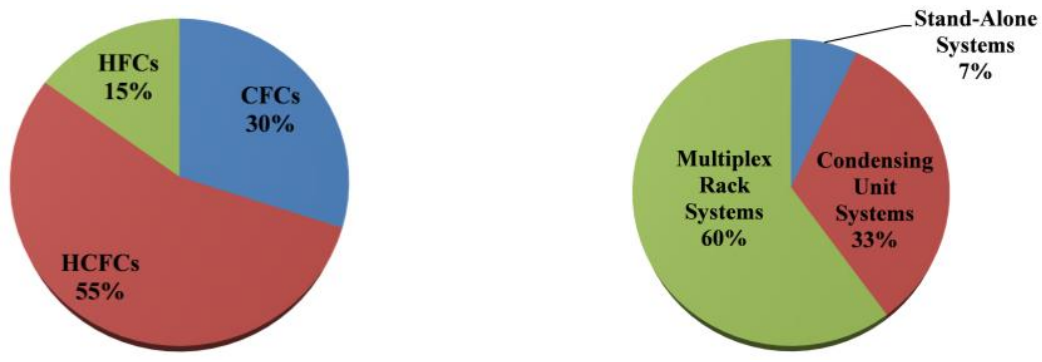

Figure 1. 31. Refrigerants in commercial refrigeration systems

Table 1. 10 details the actual situation of refrigerants in the world. The refrigerant emissions of CFCs, HCFCs, and HFCs were respectively of 44,000, 78,000, and 10,000 tonnes in 2003 [59].

Table 1. 10. Refrigerants used in commercial refrigeration systems by region

\begin{tabular}{|c|c|c|}
\hline \multirow[t]{2}{*}{ Europe } & R404A and R507A & $\begin{array}{l}\text { Larger capacity LT and MT condensing units. } \\
\text { LT centralised and stand-alone systems. }\end{array}$ \\
\hline & $\mathrm{R} 134 \mathrm{a}$ & MT Stand-alone systems. \\
\hline \multirow{3}{*}{ Japan } & R22 & $\begin{array}{l}\text { Dominates the market even though one-third of } \\
\text { new equipment employs HFCs. }\end{array}$ \\
\hline & $\mathrm{R} 404 \mathrm{~A}$ & LT commercial systems. \\
\hline & $\mathrm{R} 407 \mathrm{C}$ & MT commercial systems. \\
\hline \multirow{2}{*}{$\begin{array}{l}\text { USA and } \\
\text { Russia }\end{array}$} & R22 pure and blends & Existing MT systems. \\
\hline & $\begin{array}{c}\text { R404A } \\
\text { R507A R134a }\end{array}$ & $\begin{array}{l}\text { Becoming more widely used in stand-alone } \\
\text { systems. }\end{array}$ \\
\hline \multirow{2}{*}{$\begin{array}{l}\text { Developing } \\
\text { countries }\end{array}$} & $\mathrm{R} 22$ & $\begin{array}{l}\text { Stand-alone equipment is the main form used. } \\
\text { Condensing units used by larger food retailers. }\end{array}$ \\
\hline & R134a and R404A & Trends towards these refrigerants \\
\hline \multirow[t]{2}{*}{ China } & R22 & $\begin{array}{l}\text { Chinese regulatory groups prefer to switch } \\
\text { directly to HFCs instead of using HCFC blends }\end{array}$ \\
\hline & $\mathrm{R} 134 \mathrm{a}$ & Most used in commercial refrigeration \\
\hline
\end{tabular}


Chapter 1. Introduction.

1.1.4.2. Most used refrigerants in European commercial refrigeration systems: R134a and $R 404 A$

Focusing in the European commercial refrigeration systems, according to Regulation (EC) No 2037/2000, CFCs and HCFCs are not allowed in commercial refrigeration systems (among other). So, R22, the most used refrigerant in these applications during the second half of the $20^{\text {th }}$ century, was replaced by R134a, R404A and R507A [60]. These refrigerants are easily used in R22 systems with little modifications (retrofit) and have good performance characteristics.

Almost the same conclusions achieved for R404A can be applied to R507A and to simplify this work only considers R404A as LT and MT refrigerant commonly used in European commercial refrigeration systems [61]. Both refrigerants present almost the same composition and the thermodynamical behaviour can be considered approximately equal. The little differences are that R507A is azeotropic (R404A is near azeotropic); it presents slightly higher efficiency and lower discharge temperature. Due to their little differences, the election of the working fluid depends mainly on price market and availability of each refrigerant.

While R134a is used only in MT commercial applications, R404A is used in both MT and LT refrigeration commercial applications.

R134a is limited by its Normal Boiling Point (NBP), that is approximately $247 \mathrm{~K}$ and at temperatures below of that, the system pressure is lower than the atmospheric. In the case of only MT refrigeration requirements, R404A is the used refrigerant when the aim is to have low initial investment and R134a when higher energetic efficiencies are pursued, especially at high condensation temperatures. 
Analysis of fluoride fluids with low global warming impact in vapour compression systems. Experimental evaluation of different alternatives for commercial refrigeration.

Another difference between R404A and R134a are the operating range. For example, at $328 \mathrm{~K}, \mathrm{R} 134 \mathrm{a}$ condensation pressure is $1491 \mathrm{kPa}$ whereas R404A condensation pressure is $2585 \mathrm{kPa}$, so the system will allow higher condensation temperatures. Furthermore, the R134a systems present lower discharge temperatures than R404A systems.

R134a and R404A present GWP values of 1300 and 3943. For example, the GHG effect of release $1 \mathrm{~kg}$ of R134a is equivalent to a car circulating $4490 \mathrm{~km}$. R404A GWP is about three times greater than R134a and the same amount of R404A is equivalent to driving $15679 \mathrm{~km}$.

\subsubsection{Effects of EU Regulation No 517/2014}

Through the GWP limitation imposed in Europe by EU Regulation No 517/2014, both refrigerants are going to be phased from several applications in the next years. Table 1. 11 shows the commercial refrigeration applications in which these fluids are commonly used and the associated GWP limitations.

Table 1. 11. Situation of R134a and R404A after EU Regulation No 517/2014 approval in commercial refrigeration systems

\begin{tabular}{llcc}
\hline Applications for commercial use & \langle & GWP & $>$ \\
\hline - $\quad$ Refrigerators (hermetically sealed equipment) & & 150 & R134a \\
- $\quad$ Stationary refrigeration equipment (MT) & R134a & 2500 & R404A \\
- Multipack centralised refrigeration systems (MT) & & 150 & R134a \\
- $\quad$ Primary refrigerant circuit of cascade systems & R134a & 1500 & R404A \\
\hline
\end{tabular}


Chapter 1. Introduction.

R404A cannot be used in any of the commercial refrigeration applications considered by the Regulation due to its very high GWP. R134a can be used until 2022 in commercial hermetically sealed equipment (GWP<2500), but not from 2022 (GWP>150).

For stationary refrigeration equipment $(\mathrm{GWP}<2500)$ the limitation will not present a problem for R134a systems and it can be used in MT replacing R404A (or another nonflammable solution).

In parallel compressor rack (multipack) centralised refrigeration systems (GWP<150), R134a could be used as primary refrigerant circuit of cascade systems (GWP $<1500$ ), using $\mathrm{CO}_{2}$ (R744) in the low stage. Although R134a can be used in some applications, its replacement should be considered due to the high leakage rate of some systems and the acquisition tax, existing in some developed countries.

\subsubsection{4. $4^{\text {th }}$ generation of refrigerants}

GWP limitations and GWP taxes will imply important changes regarding to the actual situation. It is expected that the system/refrigerant combination that will be imposed in the market will depend on the system replacement costs and refrigerant adaptation, price of the refrigerant and flammability limitations. The refrigerants that are going to replace R134a and R404A have to show necessarily low-GWP values [62] (besides the characteristics required to the refrigerants previously used). These refrigerants form the $4^{\text {th }}$ generation of refrigerants.

There are different options to replace the refrigerants employed currently: hydrocarbons, efficient but with high flammability; natural refrigerants, highlighting ammonia (R717) and $\mathrm{CO}_{2}$ (R744) in transcritical systems or at the low stage in cascade 
Analysis of fluoride fluids with low global warming impact in vapour compression systems. Experimental evaluation of different alternatives for commercial refrigeration.

systems with a synthetic refrigerant at the high stage; and hydrofluoroolefin (HFO) as pure refrigerants or blends.

HFO and HFO/HFC mixtures are currently being developed and placed into market by chemical companies and their main advantage is that they can be used as drop-in or light retrofit replacements (as made HFC with HCFC and CFC).

Commercial refrigeration systems are widely extended worldwide and represent a great amount of energy consumption. They produce high $\mathrm{CO}_{2}$ equivalent emissions due to burning fossil fuels and refrigerants leakage. Once the CFC and HCFC are almost phased-out in these systems, their substitutes, HFCs, appear as a threat to the Earth's animal and vegetal life because on the increase in the greenhouse effect. This document presents a theoretical and experimental evaluation of different low-GWP alternatives of the HFCs most widely used in commercial refrigeration, R134a and R404A. The alternatives selected are HFO and HFC/HFO mixtures, which allow great GWP reductions without significant system modifications.

\subsection{Motivation}

Climate change is one of the most severe threats to modern humanity due to the serious effects on temperature and on the environment. If the humanity does not act immediately to reduce the GHG emissions to the atmosphere, the Earth's vegetal and animal life will be affected and the consequences would be irreversible. Stopping the climate change requires a global action in different areas and, unfortunately, almost always requires an economical effort.

This work is motivated by the contribution of commercial refrigeration systems on the greenhouse effect. Firstly due to the refrigerants leakages (direct emissions to 
Chapter 1. Introduction.

atmosphere), and secondly, to their big amount of energy consumption, which is influenced by the system energy efficiency.

Nowadays parallel compressor rack refrigeration systems (linked to DX) use a great amount of refrigerants with very high global warming contribution. This project evaluates different friendly environmental alternatives to these refrigerants. The introduction of alternative fluids without great systems modifications is a priority, causing on the entrepreneurs could be more willing to the replacement.

\subsection{Justification}

The electric energy consumed by HVAC, hot water and refrigeration utilities represents around $4 \%$ of the total energy use in developed countries as USA or France (in colder countries as Sweden the value is near to $3 \%$ ). $15 \%$ of the electricity consumed worldwide is used for refrigeration and the cold-chain accounts for approximately $1 \%$ of $\mathrm{CO}_{2}$ emission in the world. The retail store sector is highlighted as one of the largest energy consumers in the world (approximately double the energy compared by office buildings). Moreover energy analysis reveals that $50 \%$ of total supermarkets energy consumption is due to food freezing and conservation.

Specifically, a typical supermarket using R404A in a PCRRS with DX uses around 140 $\mathrm{MW} / \mathrm{h}$ for the LT cabinets and $270 \mathrm{MW} / \mathrm{h}$ for the MT. As $85 \%$ of the energy production comes from fossil fuels, conventional supermarket refrigeration systems are also responsible for $\mathrm{CO}_{2}$ emissions. $\mathrm{CO}_{2}$ emissions depend on the refrigeration systems performance due to the used refrigerant, system design and components selection.

On the other hand, since detrimental effect of HFC over the atmosphere was proved, there is major interest in phase them out. PCRR DX refrigeration systems used in retail 
Analysis of fluoride fluids with low global warming impact in vapour compression systems. Experimental evaluation of different alternatives for commercial refrigeration.

stores are pointed out because these are the systems with the highest leakages: by charge of refrigerant (1400-2300 kg of refrigerant) and leakage percentage (30\% annually).

The previsions for the rest of the century are ominous. Some studies predict that the 2030-2059 electricity consumption is thought to rise by up to 5.5\%. If HFCs are not phased out, the F-gases contribution to global warming will increase from approximately $1.3 \%$ (2004) to $7.9 \%$ (2050) over projected total anthropogenic $\mathrm{CO}_{2}$ emissions. Since the consumption and emission previsions are even more negative, reduction of $\mathrm{CO}_{2}$ equivalent emissions is a major concern for the humanity, using lower GWP fluids and increasing the system efficiency of HVACR systems.

\subsection{Objectives}

The main objective of this PhD Thesis is to evaluate different HFO and HFC/HFO mixtures as low-GWP alternatives to R134a and R404A, which are the most used working fluids in parallel compressor rack refrigeration systems. Goal that can be divided in the following specific objectives:

- State-of-art revision of the commercial refrigeration current status, including both, systems and refrigerants.

- Selection of low-GWP replacements that can be directly used (or with minor modifications) in parallel compressor rack refrigeration systems.

- Theoretical overview of the expected performance of alternative refrigerants at typical commercial refrigeration operating conditions.

- Experimental comparison between the reference fluids, R134a and R404A, and their low-GWP alternatives, regarding to energy performance, environmental regulations and security limitations. 


\subsection{Hypothesis}

HFO and HFC/HFO fluids can be good drop-in or light retrofit replacements for R134a and R404A in parallel compressor rack refrigeration systems. They can reduce GHG emissions to the atmosphere (both direct and indirect) without making significant system modifications and can be used immediately to stop climate change.

\subsection{Scope}

As exposed before, commercial refrigeration is widely extended around the world and is essential in supermarkets for food conversation and freezing, becoming very relevant in final energy consumption usage. Conclusions reached in this work could be applied to any parallel compressor rack refrigeration system to reduce energy consumption (economic reasons) and $\mathrm{CO}_{2}$ equivalent emissions (reduce the environmental concern), especially if the retail stores are located in countries which GWP values are controlled. The conclusions can cover different commercial refrigeration architectures, either direct expansion (centralised or distributed), cascade or secondary systems are comprised. Main results could be applied in other vapour compression applications where HFCs are also commonly used.

\subsection{Methodology}

In order to achieve the objectives proposed in this $\mathrm{PhD}$ thesis, the work methodology is based on experimental analysis of the performance and adaptation of different lowGWP fluids as R134a and R404A replacements. In this way, a literature review presents the different low-GWP alternative fluids to HFCs and justifies the consideration of some HFOs and HFC/HFO mixtures as HFCs drop-in replacements. 
Analysis of fluoride fluids with low global warming impact in vapour compression systems. Experimental evaluation of different alternatives for commercial refrigeration.

Previous to the experimental analysis, a theoretical thermodynamic evaluation of the fluids is carried out in order to check the potential of their use as alternatives to R134a and R404A. Then, the selected refrigerants are theoretically compared with the HFCs at typical commercial refrigeration operating conditions. Once the theoretical results confirm that R1234yf, R1234ze(E) and R450A could be good alternatives to R134a, and $\mathrm{R} 448 \mathrm{~A}$ to $\mathrm{R} 404 \mathrm{~A}$, reference and alternative fluids are tested in a vapour compression test bench at the same operating conditions carrying out only minor modifications. Firstly, the experimental installation and test procedure are presented and secondly, the experimental results are shown and discussed, focusing in energy efficiency comparison between alternatives and baselines. Finally, the conclusions and the possible future works derived from the $\mathrm{PhD}$ thesis are summarised.

\subsection{Document organisation}

Once established the basis of the work, the resulting structure of the document is:

- Chapter 1: Guides the reader to the current status of the vapour compression, commercial refrigeration and parallel compressor rack systems. Presents the environmental concerns caused by these applications and the working fluids used in those systems. Moreover, the bases of the $\mathrm{PhD}$ thesis are stablished.

- Chapter 2: The literature available of low-GWP alternatives to currently used HFCs is being reviewed, presents an analysis of the advantages and disadvantages of each option. Most of the chapter focuses on studies about HFOs and their mixtures.

- Chapter 3: Contains the basis of the theoretical analysis, covering from equations and conditions that were considered to the theoretical results, checking the potential of R1234ze(E), R1234yf and R450A as alternative for R134a, and R448A for R404A. Furthermore, an analysis of the operating pressures and other aspects related to the components design are addressed. 
Chapter 1. Introduction.

- Chapter 4: Includes relevant information about the vapour compression system used to carry out the experimental tests as well as details of the test procedure and the test conditions.

- Chapter 5: Shows the main results of the experimental energy performance comparison between the alternatives and the baselines and analyses the causes of the deviation with the theoretical (expected) results.

- Chapter 6: The main conclusions of the study is summarised in this chapter. Then, some future works that can continue with the conclusions extracted from this $\mathrm{PhD}$ thesis have been proposed. 
Analysis of fluoride fluids with low global warming impact in vapour compression systems. Experimental evaluation of different alternatives for commercial refrigeration.

\subsection{Conclusions Chapter 1}

The anthropogenic effect over the environment due to the refrigerants utilisation and electricity consumption in HVACR systems has been presented. Two environmental damages have been exposed, destruction of the ozone layer and global warming, as well as the human action have been quantified.

This chapter contains the evolution of refrigerants used in HVACR systems; since the VCSs were developed until the current situation, in which HFCs are going to be replaced by low-GWP refrigerants. It has been seen the influence of HFCs in climate change, highlighting commercial refrigeration working fluids as R134a and R404A.

Furthermore, this section has shown different commercial refrigeration systems and refrigerants and has focused on their great contribution on the climate change. Parallel compressor rack refrigeration systems appear to be one of the most relevant energy and refrigerant consumers and have been pointed out by environmental protection regulations.

Finally, other relevant aspects of the project have been established: its motivation, justification, main and secondary objectives, hypothesis and scope. 


\section{Chapter 2}

\section{State-of-Art}

The previous section presents the evolution of working fluids used in refrigeration systems. It has stated that the most widely used refrigerants in parallel rack compressor of commercial refrigeration systems are R134a and R404A. Besides, due to their very high GHG contribution, they are going to be phased-out in developed countries in the short term and substituted by lower GWP refrigerants.

This chapter presents the most recent investigations about low-GWP alternatives to $\mathrm{R} 134 \mathrm{a}$ and R404A, in order to place the starting point of this investigation and to look for the lack of knowledge in this area. Firstly, it is introduced the existing low-GWP alternatives to R134a and R404A in commercial systems. Then this section focuses on the state-of-art of pure HFOs (R1234yf, R1234ze(E)) and mixtures of them with HFC (R450A and R448A). These fluids can replace HFCs with minor system modifications obtaining a quick and low cost substitution that can reduce the direct GHG emissions on a great extent. 
Analysis of fluoride fluids with low global warming impact in vapour compression systems. Experimental evaluation of different alternatives for commercial refrigeration.

\subsection{Overview of alternatives in commercial refrigeration systems}

The difficulty in selecting suitable refrigerants for refrigeration systems has been increasing. First only functionality was demanded $\left(1^{\text {st }}\right.$ generation); then, only safe refrigerants could be used $\left(2^{\text {nd }}\right.$ generation). Then, the harmful effect of chloride molecules on the atmospheric ozone was demonstrated and only zero-ODP refrigerants were allowed ( $3^{\text {rd }}$ generation). Finally, the minimum climate change contribution is preferred and even controlled by several governments. Thus, nowadays, very lowGWP values are also solicited to refrigerants $\left(4^{\text {th }}\right.$ generation). To sum up, the following properties are identified as the most important requirements for refrigerants [63]:

- Desirable thermodynamic and thermophysical properties from the operating efficiency point of view.

- Non-toxic from human and animal safety point of view.

- Low-GWP and zero ODP from a sustainable environment point of view.

- Compatibility with the materials used in refrigeration systems (metals, polymers, lubricating oils, etc.) from design and operation points of view.

An energy efficiency as high as possible is a requirement that interest to all parts involved in VCSs: to clients, because good energy efficiency means low energy consumption and therefore, lower electricity costs; and to environmental authorities (humanity), because low energy consumption implies low carbon dioxide indirect emissions to atmosphere.

The energy efficiency (energy consumption) resulting when low-GWP refrigerants are used in VCSs must be controlled in order not to be counterproductive in equivalent $\mathrm{CO}_{2}$ emissions. In fact, it is predicted that the EU Regulation will imply a reduction of $85 \%$ in quantity of $\mathrm{CO}_{2}$ equivalent in HVACR systems but a $10 \%$ increase in energy consumption of systems [64]. 
Any refrigerant substitution that lowers overall efficiency is likely to have more adverse impact than benefit based on net global warming impacts (e.g., life-cycle GHG emissions or Total Equivalent Warming Impact, TEWI) [65]. So, besides looking for refrigerants that accomplish the GWP limitations, safe fluids that imply low energy consumption in VCSs should be used [4].

Unfortunately, there are no refrigerants in the horizon that completely meet these requirements. The possible options to replace R134a and R404A in commercial systems can be classified as "natural" and synthetic refrigerants.

The main considerations (advantages and disadvantages) about the refrigerants that can replace R134a and R404A are summarised in Table 2. 1 and Table 2. 2.

Table 2. 1. Considerations about natural refrigerants

\begin{tabular}{ll}
\hline Candidate & Considerations \\
\hline Hydrocarbons & $\bullet$ Efficient, flammable and non-toxic. \\
Very low-GWP & - Low charge systems. \\
Carbon Dioxide (R744) & - Not enough efficient, non-flammable and non-toxic. \\
GWP 1 & - At very high pressures and higher costs. \\
& - In transcritical systems or at the low stage of cascade \\
Ammonia (R717) & - systems. \\
Zero GWP & - In large industrial refrigeration systems. \\
\hline
\end{tabular}


Analysis of fluoride fluids with low global warming impact in vapour compression systems. Experimental evaluation of different alternatives for commercial refrigeration.

Table 2. 2. Considerations about synthetic refrigerants

\begin{tabular}{lll}
\hline Candidate & Considerations \\
\hline Lower GWP HFC & - & Similar efficiency, low flammable and non-toxic. \\
Medium/Low-GWP & - & GWP is only slightly reduced. \\
& - & Allows minor system modifications. \\
HFO & - & Less efficient, low flammable and non-toxic. \\
Very Low-GWP & - & Very low-GWP values. \\
& - & Significant system modifications to achieve original \\
& & system capacity. \\
HFO/HFC mixture & - Similar efficiency to HFC. \\
Medium/Low-GWP & - Can be used as drop-in or retrofit substitutes. \\
& - Either low-GWP and low-flammable or medium-GWP \\
& and non-flammable, depending on the composition. \\
\hline
\end{tabular}

Concretely in compressor rack refrigeration appliances, the most promising future options can be differenced in accordance to the GWP value and the flammability, as presented in Table 2. 3 .

Table 2. 3. Future options for rack refrigeration services in Europe

\begin{tabular}{llll}
\hline GWP & Flammability & Toxicity & Alternatives \\
\hline$>1500$ & Non & Non & HFC mixtures \\
$<1500$ & Non & Non & HFO/HFC mixtures, R134a \\
& High & Non & HCs \\
$<150$ & Low & Yes & R717 \\
& \multirow{2}{*}{ Non } & Non & HFO/HFC mixtures \\
& & Non & R744 \\
\hline
\end{tabular}


Chapter 2. State-of-Art.

Each group of alternatives has different characteristics, advantages and disadvantages.

Below the current status of investigations of each alternative is analysed.

\subsubsection{Natural refrigerants}

The natural refrigerants term refers to all naturally occurring, non-synthetic substances. They can be extracted directly from the environment (it occurs in nature's bio-chemical processes). It includes hydrocarbons (HC), carbon dioxide and ammonia (water and air are often considered in this group but their use is limited). Natural refrigerants present very low-GWP values because they are easily absorbed by nature.

They have always been an alternative since the beginning of the mechanical refrigeration (carbon dioxide was usually used) but their use was decreasing with the appearance of synthetic refrigerants (ammonia was maintained in industrial refrigeration). To be implemented in current refrigeration applications, much research work is still to be done [66]. They present different problems that have stopped their use:

- HCs, in moderate or high charge systems

- Ammonia, appliances with non-professional human presence

- Carbon dioxide: the energy consumption and the initial and maintenance cost should be reduced.

Non-governmental organisations as Greenpeace defend their use as very low-GWP alternatives to HCFCs and HFCs [67]. The International Institute of Refrigeration (IIR) also claims their use and convenes biennially the Gustav Lorentzen Conferences on natural refrigerants to expand the knowledge of these fluids [68]. 
Analysis of fluoride fluids with low global warming impact in vapour compression systems. Experimental evaluation of different alternatives for commercial refrigeration.

Natural refrigerants are considered by some researchers as the most suitable long term alternatives in HVACR applications [69]. Table 2. 4 shows that HCs, ammonia and $\mathrm{CO}_{2}$ can be used in commercial refrigeration systems and the final choice will be influenced by the different requirements of the refrigeration system.

Table 2. 4. Use of natural refrigerants in HVACR applications

\begin{tabular}{|c|c|c|}
\hline Sector & Compressor type & Refrigerant \\
\hline Domestic fridge/ freezers & Sealed hermetic unit & $\mathrm{HCs}$ \\
\hline \multirow{2}{*}{ MT commercial } & Sealed hermetic unit & $\mathrm{HCs}$ \\
\hline & Accessible semi-hermetic & $\mathrm{HCs}$ \\
\hline \multirow{2}{*}{ equipment } & Reciprocating open drive & $\mathrm{HCs}$ \\
\hline & Sealed hermetic unit & $\mathrm{HCs}$ \\
\hline \multirow[t]{2}{*}{ LT commercial equipment } & Accessible semi-hermetic & $\mathrm{HCs}$ \\
\hline & Reciprocating open drive & $\mathrm{HCs}, \mathrm{CO}_{2}$ \\
\hline Large commercial and & Reciprocating open drive & $\mathrm{HCs}$, ammonia, $\mathrm{CO}_{2}$ \\
\hline industrial & Screw & $\mathrm{HCs}, \mathrm{CO}_{2}$ \\
\hline \multirow[t]{3}{*}{ MAC or refrigeration } & Hermetic reciprocating open drive & $\mathrm{HCs}$ \\
\hline & Reciprocating open drive & HCs, ammonia \\
\hline & Centrifugal & $\mathrm{HCs}$ \\
\hline \multirow[t]{3}{*}{ Air conditioning } & Accessible semi-hermetic & $\mathrm{HCs}$ \\
\hline & Screw & HCs, ammonia \\
\hline & Hermetic & $\mathrm{HCs}$ \\
\hline
\end{tabular}

\subsubsection{Hydrocarbons (HCs)}

The most used HCs in refrigeration systems are ethane (R170), propane (R290) and isobutene (R600a). They have good thermodynamic properties and heat transfer performance, zero-ODP and GWP near unity. As they are significantly flammable (Table 2. 5), and to avoid risks, they are restricted to little (low charge) and 
hermetically sealed domestic and commercial refrigeration systems. For example, in different refrigeration applications as vending or ice-cream machines their amount of charge is limited to 150 gr. in each separate refrigerant circuit. The information is extracted from Table 3.1 of AS/NZS 1677.1.

Table 2. 5. Flammability characteristics for $\mathrm{HC}$ refrigerants

\begin{tabular}{|c|c|c|c|c|c|}
\hline \multicolumn{3}{|c|}{ Hydrocarbon refrigerant } & R170 & $\mathbf{R 2 9 0}$ & R600a \\
\hline \multicolumn{3}{|c|}{ ASHRAE 34 safety group } & A3 & A3 & A3 \\
\hline \multicolumn{3}{|c|}{ Practical limit $\left(\mathrm{kg} \mathrm{m}^{-3}\right)$} & 0.008 & 0.008 & 0.008 \\
\hline \multirow{4}{*}{ Flammability } & Lower limit LEL/LFL & $\mathrm{kg} \mathrm{m}^{-3}$ & 0.037 & 0.037 & 0.037 \\
\hline & & $\% \mathrm{v} / \mathrm{v}$ & 3.3 & 3.3 & 3.3 \\
\hline & Upper limit UEL/UFL & $\mathrm{kg} / \mathrm{m}^{-3}$ & 0.190 & 0.171 & 0.190 \\
\hline & & $\% \mathrm{v} / \mathrm{v}$ & 10.6 & 9.6 & 10.6 \\
\hline \multicolumn{3}{|c|}{ Auto ignition temperature (K) } & 788 & 723 & 803 \\
\hline
\end{tabular}

Most of the refrigeration experts agree that the safety issue should be overcome to expand the use of HCs as refrigerants [70]. On the one hand, the refrigerant charge could be reduced redesigning systems (shorter pipes) or using indirect systems and compact heat exchangers. On the other hand, sensors and alarms can be located to detect leakages (they are mandatory for ammonia refrigeration systems), and improve the ventilation of confined spaces. Furthermore, all these measures require careful design and skilled staff. Another option is that the governments, prioritising natural low-GWP refrigerants, could implement sensible and well balanced standards to allow HCs in other appliances [71].

HCs performance has been studied in small commercial refrigeration systems. Cleland et al. [72] tested the efficiency and safety of propane-ethane (R290-R170) mixture in on-farm milk cooling equipment. Coulbourne and Espersen [73] investigated the 
Analysis of fluoride fluids with low global warming impact in vapour compression systems. Experimental evaluation of different alternatives for commercial refrigeration.

flammability risk of R290A within horizontal type ice cream cabinets. They found the risks negligible compared to background, especially when the fan is on.

R290 shows good performance compared to R404A, R410A and R134a. Hwang et al. [74] examined R290, R404A and R410A at medium evaporation capacity matching capacities. On an equal first cost basis, Life Cycle Climate Performance (LCCP) of $\mathrm{R} 410 \mathrm{~A}$ is $4.2 \%$ lower and the LCCP of R404A is $1.8 \%$ higher than that of R290. In small charge walk-in refrigeration systems [75], R290 Coefficient of Performance (COP) and LCCP is under that of R404A based on different assumptions and load conditions. Mastrullo et al. [76] tested two light commercial vertical freezer prototypes. The conclusion was that a reduction up to $50 \%$ of the refrigerant side volume at the heat exchangers allows reducing the refrigerant charge of about $30 \%$ (with negligible effects on energy consumption). The replacement of R404A with R290 in a freezer reduces the energy consumption of the system by $34 \%$. He et al. [77] compared pure R290 and mixtures to R134a in a large capacity chest freezer. Experimental tests show that the R290 power consumption is $26.7 \%$ lower than that of R134a and that the optimal ratio of R290/R600a is $93.75 / 6.25 \%$ (mass percentage), being then the power consumption $27.5 \%$ lower than that of R134a.

\subsubsection{Carbon Dioxide}

Carbon dioxide (R744) is the only natural refrigerant known to be non-toxic, nonflammable, and not harmful to the environment. Since environmental regulations have pointed out the refrigerants with high GWP values while maintaining the safety standards, it has become one of the most promising refrigerants for refrigeration systems [78]. 
R744 has been limited historically by its low critical point (7.38 MPa at $304.25 \mathrm{~K})$ and high operating pressures. In order to overcome its low critical point, some authors claim that transcritical cycles are the solution that best fit in R744 refrigeration systems [79]. Moreover, its efficiency can be improved modifying the R744 basic cycle by considering the addition of thermostatic expansion valve (TXV), turbine or internal heat exchanger (IHX) [80].

Sharma et al. [81] compared a R404A multiplex DX system with seven R744 refrigeration systems. The transcritical booster system with bypass compressor performed equivalent to or better than the R404A system only in northern US portion (cold climate). Srinivasan [82] evaluated the optimum inter-stage pressure for twostage transcritical R744 refrigeration cycles, obtaining values above the typical pressure index (ratio between low and high stage pressures) of 0.5 .

Ge and Tassou [83] studied the parameters that affect the R744 booster system energy performance. The conclusion was that to increase the COP, the intermediate pressure and high temperature compressor efficiency ratio should be as low as possible. Ge and Tassou [84] also demonstrated that R744 booster system performance is benefited from a lower ambient temperature and a sizeable heat recovery. Heat recovery can satisfy $40 \%$ of the supermarket space heating demand.

Sawalha [85] studied a R744 transcritical system with heat recovery. It has lower energy consumption than conventional R404A with separate heat pump for heating needs and it is an efficient solution in cold climates. If an economiser is introduced in a one-stage transcritical R744 refrigeration machine, it can decrease the total cost of the final product. In hot climates it achieves an approximate cost reduction of 14\% [86]. 
Analysis of fluoride fluids with low global warming impact in vapour compression systems. Experimental evaluation of different alternatives for commercial refrigeration.

Hafner et al. [87] investigated an R744 supermarket system layout with ejectors and heat recovery for different climate conditions and they found improvements in system efficiency of up to $30 \%$. Minetto et al. [88] developed a new method for overfeeding multiple evaporators connected in parallel in a R744 refrigeration system: a two-phase ejector circulates liquid from the low pressure receiver back to the intermediate pressure receiver. The use of this method allows reducing the energy consumption by $13 \%$ when compared to classical thermostatic control (at test conditions).

In the low temperature stage of a cascade system, R744 can be used with separated circuits for LT and MT service. Da Silva et al. [89] compared R404A/R744 cascade system with R404A and R22 DX systems. They found many advantages using the cascade system proposed, as a reduction of the electric energy consumption, lower environmental impact or more compact installation, among others. Sanz-Kock [90] evaluated the R134a/R744 cascade system, concluding that the variation of intermediate pressure level produces a maximum COP variation of $6 \%$. Finally, another option is to use carbon dioxide as heat transfer fluid in secondary systems [91], taking advantage of its good environmental and security properties.

\subsubsection{Ammonia}

Ammonia (R717) is a very energy efficient [92] but dangerous refrigerant that can be considered for non-occupied and controlled spaces [93]. Although it is toxic their leakage can be detected easily by its pungent odour (besides is colourless). Its ignition energy $(14 \mathrm{~mJ})$ is 50 times higher than that of natural gas. Furthermore, R717 is highly soluble in water. 
It is typically used in industrial refrigeration where it can be properly controlled but in other refrigeration appliances its use is limited by very conservative safety regulations (requires a great amount of air renovations and only specialised technicians can stay within the same space that the system). It is becoming popular at the high stage of cascade systems where the ammonia charge can be greatly reduced and confined to a non-occupied space [94]. As HCs, the introduction of elements that reduce the fluid charge, as microchannel or compact heat exchangers is also interesting.

One of the most promising cascade refrigerant pairs in commercial refrigeration systems is R717/R744 (R717 at high stage and R744 at low stage) [95]. For the same conditions, when it is compared to R404A partial injection two-stage refrigeration system; this cascade system can compete at low evaporating temperatures (between $223 \mathrm{~K}$ and $243 \mathrm{~K}$ ) regarding energy, security and environmental parameters [96]. Cecchinato et al. [97] studied different lay-out and technological solutions using natural refrigerants. In their study the most efficient solution is a R717/R744 cascade that enables an annual energy saving higher than $15 \%$ with respect to the baseline solution (R404A). Fernández-Seara et al. [98] demonstrated that a R717/R744 cascade using plate freezers represents a viable alternative to current commercial refrigeration systems.

For the same reason that R717 is interesting in cascade systems, it is considered also in secondary systems, mainly using carbon dioxide as heat transfer fluid [91]. Inlow and Groll [99] developed a model for a secondary-loop refrigeration system for supermarkets using R717 in the primary-loop and carbon dioxide as a volatile secondary refrigerant. The results show that this system could become a cost effective alternative. 
Analysis of fluoride fluids with low global warming impact in vapour compression systems. Experimental evaluation of different alternatives for commercial refrigeration.

\subsubsection{Synthetic refrigerants}

As it has been introduced in the previous chapter, synthetic refrigerants have dominated the refrigeration sector since the VCSs became massive. They seemed to be almost perfect working fluids until it has been proved that CFCs and HCFCs are harmful for the ozone layer, and both plus HFCs are contributors to global warming.

Since the environmental protecting regulations are being approved, current synthetic refrigerants are being phased out or limited. As natural refrigerants present few but relevant limitations, HFC with lower GWP (than HFC used today) are presented as short-term and economic alternatives that can be easily adapted to existing systems.

\subsubsection{Low-GWP hydrofluorocarbons (HFCs)}

This group consist of HFCs based refrigerants that provide an intermediate solution allowing a minor disadvantage. The most relevant of them are R32, R152a and HFC mixtures.

Although R32 (GWP of 677 and low-flammable) is proposed to replace R410A in stationary air conditioning machines, it has also been compared to R134a presenting similar performance characteristics, and with R152a, showing a lower efficiency [100]. R152a presents a GWP value lower enough (138) to be used in any refrigeration system according to European limitations. Its use is hindered by safety regulations because it is low flammable, even though R152a is much less dangerous than HCs. It is typically suggested to replace R134a with in MACs because it offers better performance characteristics [101]. 
However R152a has also been extensively tested in refrigeration systems. R152a presented the best COP and lower power consumption in an exergetic analysis for display cases [102]. R407C (HFC mixture) and R152a show significantly higher average exergetic efficiency ratio (9\% and 14\%), lower TEWI (27\% and 25\%) and lower Integrated $\mathrm{CO}_{2}$ Factor (ICF) (34\% and 51\%) than R404A [103]. In addition, in the high stage of a cascade refrigeration system, R152a shows better performance results than any other HFC commonly used; R404A, R507A and R134a [104].

The most feasible short-term alternatives are the commercially available lower GWP HFC mixtures. R407A [105] and R407F [106] (GWP of 1923 and 1674, respectively) have been developed as R404A retrofit replacements due to its similar properties. They allow a GWP reduction of 50\%, presenting similar cooling capacity and energy efficiency savings up to $10 \%$. Bortolini et al. [107] obtained promising results for $\mathrm{R} 407 \mathrm{~F}$ in an experimental supermarket system. R410A is another HFC mixture (dominates the today's stationary air conditioning market) with GWP around 2000 that can be used as mid-term solution but it is not usable for LT systems because it causes compressor overheating.

To obtain a $17 \%$ reduction of $\mathrm{CO}_{2}$ equivalent emissions in the USA in 2033, the US Environmental Protection Agency (EPA) proposed in 2014 via its Significant New Alternatives Policy (SNAP) a phase-out of R404A and R507A in new supermarket refrigeration systems (among others) since 2016 [108]. The most acceptable substitutes identified were R407A and R407F because they are readily available and present good performance without significant modifications. In fact, more than $50 \%$ of USA supermarkets are already using them [109]. Although this is the more economic replacement solution, in a large compressor rack it can cost from 70000 to $130000 €$ and it is being rejected by the supermarket lobby [110]. 
Analysis of fluoride fluids with low global warming impact in vapour compression systems. Experimental evaluation of different alternatives for commercial refrigeration.

\subsubsection{Hydrofluoroolefines (HFOs)}

In the same way that HCFCs was developed to replace CFCs, and HFCs to replace HCFCs; at the beginning of the 2000s new type of compounds were developed to replace HFCs. These chemical compounds are known as hydrofluoroolefins (HFOs) and they are composed by hydrogen, fluorine and double bond carbon. At the present time, two HFO are highlighted as alternatives in HVACR systems: R1234yf [111] and R1234ze(E) [112]. R1234yf GWP is 1 and that of R1234ze(E) is 4 (under lower GWP HFCs) and present lower flammability than HCs or some lower GWP HFCs.

When HFOs were developed, a sub classification of low flammable refrigerants was introduced by American Society of Heating, Refrigerating, and Air-Conditioning Engineers (ASHRAE), to differentiate them from the rest of low flammable fluids, Figure 2. 1. ASHRAE Standard 15 contains the safety standards for refrigeration systems. Besides, ASHRAE Standard 34 regulates the designation and classification of refrigerants and its most recent version was approved in 2013 [113].

\begin{tabular}{|l|c|c|}
\cline { 2 - 3 } \multicolumn{1}{c|}{} & Lower Toxicity & Higher Toxicity \\
\hline Higher Flammability & A3 & B3 \\
\hline \multirow{2}{*}{ Lower Flammability } & A2 & B2 \\
\cline { 2 - 3 } & A2L & B2L \\
\hline No Flame propagation & A1 & B1 \\
\hline
\end{tabular}

Figure 2. 1. ASHRAE safety classification

So, A2L fluids are still low flammable fluids (Lower Flammability Limit (LFL) and heat of combustion $0.10 \mathrm{~kg} \mathrm{~m}^{-3}$ and $19000 \mathrm{~kJ} \mathrm{~kg}^{-1}$ ), but they present a maximum flammable burning velocity of $10 \mathrm{~cm} \mathrm{~s}^{-1}$ (at $333 \mathrm{~K}$ ). This value ensures that the flammable burning velocity is too slow to cause horizontal flame propagation or explosion. 
An example of A2L could be R32 or HFO (R152a is A2). A2L designation will be introduced in Europe in the next versions of the EN378 safety standards (would permit larger low flammable refrigerant amount).

All the information related to the security of these fluids can be consulted in the safety data sheets, which are continuously updated by the manufacturer. Section 5 . Firefighting Measures shows that, even though HFOs are classified as A2L refrigerants, in case of fire hazardous, R1234yf decomposition products may be produced such as hydrogen fluoride, carbonyl halides, carbon monoxide and carbon dioxide [114]. For R1234ze(E), hydrogen fluoride [115].

\subsubsection{Alternatives to realise a substitution with minor system modifications}

Both natural and synthetic refrigerants present good properties that can make them good candidates to replace HFCs in PCRRSs. However, due to the severity of the climate change and the little interest of the refrigeration sector to perform great investments to substitute the still working refrigeration systems, to propose working fluids that can substitute HFCs with minor system modifications (smaller investment cost and time) is a priority in this study.

Natural refrigerants demand an almost complete replacement of the system due to materials compatibility and fluids properties. Besides, the high flammability of hydrocarbons, the toxicity of ammonia and the high pressures of carbon dioxide are disadvantages in systems that typically use a great amount of refrigerant.

Therefore, the only refrigerant options to consider are low-GWP HFCs and HFOs. Among them, HFOs and mixtures between both groups of fluids allow system compatibility, great GWP reduction and low- or non-flammability at the same time. 
Analysis of fluoride fluids with low global warming impact in vapour compression systems. Experimental evaluation of different alternatives for commercial refrigeration.

A study of these fluids will be conducted in deep to determine which refrigerants will be compared, theoretically and then experimentally, with R134a and R404A.

\subsection{Recently studies of HFOs}

A great amount of research is being conducted to characterise accurately the behaviour and the properties of R1234yf and R1234ze(E) in order to realise a proper design of HVACR systems.

\subsubsection{Thermophysical properties studies}

Although R1234yf and R1234ze(E) have been recently developed, many studies have been conducted to characterise their properties and, therefore, thermal and energetic behaviour. Accurate thermophysical properties are necessary to design and construct efficient HVACR components (and systems). These studies can report individual properties measured in specific test rigs or they can analyse the accuracy of different Equations of State (EOSs) (or even modify them to improve their precision).

Qiu et al. [116] presented a density measurement system at pressures up to $100 \mathrm{MPa}$ and temperature from 283 to $363 \mathrm{~K}$, using a vibrating tube densimeter. The maximum expanded uncertainty with a confidence level of $0.95(\mathrm{k}=2)$ of R1234yf and $\mathrm{R} 1234 \mathrm{ze}(\mathrm{E})$ are $0.33 \%$ and $0.23 \%$, respectively. Meng et al. [117] reported viscosity measurements at temperatures between 243 and $373 \mathrm{~K}$ and saturated pressures up to 30 $\mathrm{MPa}$, using a vibrating-wire viscometer. The Absolute Average Deviation (AAD) of the experimental results from the correlations for R1234yf and R1234ze(E) are $0.44 \%$ and $0.59 \%$, respectively. Di Nicola et al. [118] measured triple point values for alternative refrigerants (including both HFOs) and obtained results closer to those present in open literature. 
An EOS is a thermodynamic equation that relates state variables (temperature, pressure, volume, internal energy or specific heat) and allows calculating fluid properties. Brown et al. [119] first estimated the R1234yf and R1234ze(E) thermodynamic properties with the Peng-Robinson EOS. Akasaka applied a new thermodynamic property model for R1234ze(E) [120]. Then, he presented a new EOS valid for temperatures from 240 $\mathrm{K}$ and $400 \mathrm{~K}$ and pressures up to $40 \mathrm{MPa}$ for R1234yf, and $240 \mathrm{~K}$ to $420 \mathrm{~K}$ and pressures up to $15 \mathrm{MPa}$ in the case of R1234ze(E) [121]. Average uncertainties for both fluids are $0.1 \%$ in liquid density, $0.05 \%$ in the vapour-phase speed of sound, and $0.1 \%$ in vapour pressure. Regarding the vapour density and liquid heat capacities, they were $0.3 \%$ and $2 \%$ for R1234yf and $0.2 \%$ and $3 \%$ for R1234ze(E).

Alavianmehr et al. [122] modified Tao-Mason EOS and the AAD of 34 R1234yf and R1234ze(E) points was 1.84 and 0.36, respectively. Lai et al. [123] used the molecular based BACKONE and PC-SAFT EOS to describe the thermodynamic properties of R1234ze(E). Relative differences are mostly within 1\%. For R1234yf, Lai et al. only used the BACKONE EOS and described the R1234yf properties also very accurately [124]; the uncertainties are $0.29 \%$ for liquid densities, $0.99 \%$ for vapour pressures and $\pm 5 \%$ for the liquid isobaric heat capacities.

\subsubsection{Flammability studies}

As happens for R1234yf in MAC systems (German automotive companies are opposing to apply F-gas regulation and defends $\mathrm{CO}_{2}$ as working fluid for this application), flammability difficult HFC substitution and therefore, the HFOs usage in HVACR systems. 
Analysis of fluoride fluids with low global warming impact in vapour compression systems. Experimental evaluation of different alternatives for commercial refrigeration.

As it was exposed before, both refrigerants are classified as low-flammable refrigerant (A2L) by ASHRAE 34 even though R1234ze(E) is slightly less flammable that R1234yf. R1234yf and R1234ze(E) LFL becomes quite low when the humidity of air increases to high values [125] and R1234ze(E) is non-flammable if the air humidity is equal to or less than $10 \%$ corrected for $296.15 \mathrm{~K}$ [126]. For heat pump systems, it is demonstrated that these refrigerants will not pose an ignition risk during normal operation [127]. In the case of release in the outdoor unit, risks involving R1234ze(E) are equal to that for R1234yf and four times lower than R32 (and well below the overall risk of house fires from any cause). A tests performed by Imamura et al. [128] confirms that if these refrigerants leak rapidly, the possibility of ignition is small.

\subsubsection{Heat transfer studies}

In the following, R1234yf and R1234ze(E) two-phase heat transfer and pressure drop studies are reviewed. As well as in the heat exchanger design and construction, where it is important to know the fluid behaviour; heat transfer studies and pressure drop also plays an important role in design and optimisation of VCSs (evaporator, condenser and intermediate heat exchanger).

The heat transfer performance of R1234yf was reviewed by Wang [129]. The most relevant conclusions of the study are the following (adding some more recent investigations):

- Smooth surface nucleate boiling: the Heat Transfer Coefficient (HTC) of $\mathrm{R} 1234 \mathrm{yf}$ is lower than that of R134a when heat flux is greater than $200 \mathrm{~kW}$ $\mathrm{m}^{-2}$.

- Microporous surface nucleate boiling: HTC for R134a is moderately higher than those of R1234yf. 
- Enhanced surface nucleate boiling (flat plain, Turbo-B, Turbo-C, and Thermoexcel-E): HTCs of HFO1234yf on all four surfaces are similar to those of HFC134a [130].

- External condensation: the HTC difference between R1234yf and R134a is negligible.

- In-tube convective boiling: HTC difference for R1234yf and R134a is quite small. The oil influence in HTC depends strongly on the heat flux and saturation temperatures [131].

- Minichannel convective boiling: HTC for R1234yf is much higher than that of R134a. Anwar et al. [132] claim that R1234yf HTC remains unaffected with varying mass flux and vapour quality.

- In-tube condensation: HTCs for R1234yf are lower to those of R134a and the difference increases with the rise of vapour quality.

- Minichannel condensation: R134a has higher HTC than R1234yf [133].

According to the flow boiling studies analysed, R1234ze(E) shows similar or lower HTC and higher pressure drop than R134a. In a $6.00 \mathrm{~mm}$ circular smooth tube, Grauso et al. [134] found that local HTC of R1234ze(E) and R134a during flow boiling were very similar, especially at medium and high saturation temperatures. However, R1234ze(E) HTC falls more at low vapour qualities. Conclusions reached in a microfin tube connected by U-bend are similar [135], where the HTC difference between R134a and R1234ze(E) appears only at low vapour qualities (below 0.3). Diani et al. [136] tested R1234ze(E) inside a $3.4 \mathrm{~mm}$ microfin tube, in this case R1234ze(E) flow boiling HTC was around 9\% lower than those obtained with R134a.

R1234ze(E) heat transfer studies in other geometries are also common in open literature. Results were similar to those obtained with horizontal circular tubes. In an off-the-shelf roll-bond and adjusting the compressor displacement to deliver the proper 
Analysis of fluoride fluids with low global warming impact in vapour compression systems. Experimental evaluation of different alternatives for commercial refrigeration.

refrigerant mass flow rate [137], the average HTC was approximately the same between R134a, R1234yf, R600a and R1234ze(E). Mancin et al. [138] obtained similar HTC in flow boiling heat transfer of R1234ze(E) and R134a inside an high porosity copper foam with 5 PPI and porosity of 0.93. Vakili-Farahani et al. [139] investigated experimentally the effects of heat flux, mass flux, vapour quality, and saturation temperature flow boiling heat transfer in a rectangular multiport aluminium extruded tube using R1234ze(E) and R245fa.

Van Rooyen and Thome [140] investigated pool boiling data for enhanced boiling tubes and developed a prediction method based on a boiling heat transfer mechanism in the near-wall region. The R1234ze(E) HTC was 11\% lower than R134a Wolverine Turbo-B5 and slightly lower in Wieland Gewa-B5 (R236fa HTC was lower than others).

Despite that observed in evaporating studies, in condensation The R1234ze(E) HTC is about 10\% lower than R134a and pressure drops are still higher. Del Col et al. [141] studied the R1234ze(E) behaviour in a $0.96 \mathrm{~mm}$ minichannel. The R1234ze(E) HTCs were lower than those of R32, similar to those of R134a (condenser heat transfer area needed for R1234ze(E) is $25 \%$ greater compared to that of R134a) and higher than those of R1234yf (Figure 2). In a brazed plate heat exchanger [142], R1234ze(E) HTC is lower than that of R134a (4\%-6\%). Park et al. [143] compared R1234ze(E) with refrigerants R134a and R236fa for a vertically aligned, aluminium multi-port tube. R134a had higher HTC values (about 15-25\%) than the two other refrigerants, being R1234ze(E) the lowest.

Agarwal and Hrnjak [144] developed a condenser model that considers five zones, eliminating discontinuities. The absolute mean deviation of R1234ze(E) was $15.7 \%$ (subcooled zone 26.6\%). Then they studied condensation in two-phase and 
superheated-condensation zone respectively through experimental data $(6.1 \mathrm{~mm}$ circular smooth copper tube) and correlations [145]. R134a presents approximately $10 \%$ a higher HTC compared to that of R1234ze(E).

\subsubsection{Performance studies}

Due to the approbation of the first European F-gas Regulation in 2006, MAC systems was affected and R1234yf was developed to substitute directly R134a [146]. The application of the Directive, which was delayed until 1 January 2013, has suffered the opposition of automobile manufacturers (Daimler). They raised concerns about the R1234yf safety (as mentioned before in 2.1.2.2) and decided to continue with the use of R134a [147]. Today, this conflict is still present, being the German government positioned together with German automobile manufacturers [148].

The application of R1234yf in R134a MAC systems has been widely studied in the past years, showing lower cooling capacity and COP for R1234yf. Lee and Jung [149] obtained that the COP and cooling capacity of R1234yf is up to 2.7 and $4.0 \%$ lower when compared to R134a. Zilio et al. [150] suggested some hardware modifications in order to reduce the difference between both refrigerants. Qi [151] studied the influence of superheating, subcooling, IHX and compressor efficiency on the R1234yf and R134a performance. Alternatively, this substitution has been proposed in refrigeration applications. For example, Jarall [152] and Navarro-Esbrí [153] reported that cooling capacity and COP for R1234yf are lower than using R134a.

Heat transfer performances of the condenser and compressor volumetric efficiency are the main responsible for the energy efficiency reduction of R1234yf in R134a systems. The use of IHX, ejector, expander, or adjustment of TXV is identified as possible solutions [154]. 
Analysis of fluoride fluids with low global warming impact in vapour compression systems. Experimental evaluation of different alternatives for commercial refrigeration.

For an air conditioning system, the maximum COP increment occurs at a condenser subcooling of $8.9 \mathrm{~K}$ for R1234yf (8.4\%) and R134a (5.9\%) [155]. All research performed agree that IHX usage allows greater benefits in R1234yf than in R134a systems. The IHX addition leads R1234yf to a slightly lower cooling capacity and COP than R134a basic cycle system and it is enough to accomplish cooling and efficiency system requirements either in MAC [156] or refrigeration systems [157].

Although R1234ze(E) presents lower flammability than R1234yf, its cooling capacity is considerably lower compared to R134a (around 30\%) and that makes unavailable the drop-in use of R1234ze(E) in R134a systems [158]. Besides, efficiency of R1234ze(E) matches that of R134a in some applications.

Therefore R1234ze(E) is promising as low-GWP alternative only in new systems or with relevant system modifications [159]. In new medium pressure air-cooled chillers, R1234ze(E) shows 12\% higher COP than R134a [160] and because of its lower pressure and higher efficiency, it achieves $7 \%$ lower LCCP. In oil-free centrifugal compressors [161], R1234ze(E) efficiency increases due to lower viscous losses and greater compressors. A condenser redesign is also suggested to avoid excessive pressure drops.

R1234yf and R1234ze(E) are studied in different applications to replace R134a allowing huge GWP reductions. All of them agree that R1234yf can substitute R134a with a little cooling capacity and efficiency penalisation and that R1234ze(E) needs equipment redesign but can be more efficient (overridden compressor to match the system cooling power [162]). Taking into account that these fluids are considered lowflammable, they are intended for low-charge appliances. 
In domestic refrigerators [163], while R1234yf can replace R134a, R1234ze(E) needs greater compressor running time and shorter time between defrost cycles. Same conclusions were achieved by the steady-state analysis of a domestic refrigeratorfreezer conducted by Leighton et al. [164]. In vending systems [165], R1234ze(E) efficiencies were lower than R134a (and R1234yf) due to greater pressure drop losses in the evaporator and compressor penalties (this effect can be diminished using a compressor properly sized for R1234ze(E)).

Besides, R1234yf and R1234ze(E) are compatible with most of materials and oil lubricants used with HFCs. Majurin et al. [166] studied the material compatibility of R1234yf, R1234ze(E) and its mixtures with R32; with nine different elastomers, three gaskets, five polymers, and ten motor materials and considering lubricant effect. Only a higher risk was found with a few materials that will require more investigation. R1234yf exhibited excellent frictional and wear performance on grey cast iron due to the formation of a fluorine-containing protective tribolayer on the topmost surface [165].

Wasim Akram [168] claimed that R1234yf exhibited better tribological performance with PAG oil than POE and both preserve their unique properties. Besides, Bobbo et al. [169] found partial immiscibility at temperatures higher than 293.15 K with PAG and above $303.15 \mathrm{~K}$ with DC-PAG in the high R1234yf mass fraction region. Sun et al. [170] proved that R1234ze(E) is highly soluble in two lubricants precursors of POE (PEC7 and PEC9) at temperatures from 283.15 to $353.15 \mathrm{~K}$.

It is proved that even though R1234yf and R1234ze(E) can be used in R134a systems, they present some limitations (specially low cooling capacity or energy efficiency in vapour compression systems). Disadvantages that can be partially solved mixing them with some HFCs (even though the final GWP is increased). 
Analysis of fluoride fluids with low global warming impact in vapour compression systems. Experimental evaluation of different alternatives for commercial refrigeration.

\subsection{HFC/HFO mixtures}

When mixing refrigerants some shortcomings (flammability, high GWP, low energy performance, etc.) of the former components (fluids used to compose the mixtures) are overcame because the final blend achieves intermediate properties that are enough for the system requirements [171]. The final composition of mixture refrigerants should be properly selected prior to commercialise them. Exhaustive investigations about HFC/HFO mixtures intended to replace R134a and R404A have been recently carried out to characterise them and study their properties and performance.

The most common HFCs selected as former refrigerants are R32, R125, R134a and R152a. The inclusion of HFOs, R1234yf and R1234ze(E), reduces the blend GWP. R1234ze(E) mixtures results cheaper and lower-flammable than those of R1234yf but HFCs proportion should be carefully studied to raise final cooling capacity [172].

\subsubsection{Thermodynamic properties studies for $\mathrm{HFC/HFO}$ mixtures}

Properties of binary mixtures of R1234yf with HFC were widely studied. Dang et al. studied the viscosity of R1234yf mixtures with R125 and R32. For vapour viscosity [173] they obtained an AAD of $0.189 \%$ for R32/R1234yf and $1.169 \%$ for R125/R1234yf with the Wilke mixture rule. Using REFPROP 9.1 the AAD is $0.555 \%$ for R32/R1234yf and 1.479\% for R125/R1234yf. For liquid viscosity [174] the AAD are 2.2 and 3.3\% for the R32/R1234yf and R125/R1234yf mixtures by RSH method, 2.8 and $1.3 \%$ for the R32/R1234yf and R125/R1234yf mixtures by Grunberg and Nissan method, while 3.5 and $2.4 \%$ for the R32/R1234yf and R125/R1234yf mixtures using REFPROP 9.1, respectively. Chen et al. [175] developed a model for experimental R134a/R1234yf gas phase PVTx data within an uncertainty of $\pm 0.20 \%$ in 
pressure and within $\pm 0.23 \%$ in density for the range of temperatures from 298.59 to $403.24 \mathrm{~K}$, and pressures up to $3171.2 \mathrm{kPa}$.

In the case of mixtures, VLE (Vapour-Liquid Equilibrium) data are used to estimate the performance and the optimal concentration. Between 283.15 and $323.15 \mathrm{~K}$ the overall $\mathrm{AAD}$ of pressures and vapour phase compositions are:

- $0.51 \%$ and 0.0039 with PR-vdW1f model and $0.27 \%$ and 0.0031 with PRWS-NRTL model, respectively, using R161/R1234yf [176].

- $0.36 \%$, and 0.0035 with PR EoS with vdW mixing rules, using R227ea/R1234yf [177].

- $0.22 \%$ and 0.0021 with PR EoS with vdW mixing rule, using R152a/R1234yf [178]. The temperature glide is less than $0.4 \mathrm{~K}$.

- $\quad 0.50 \%$ and 0.0040 with PR-vdW, and $0.20 \%$ and 0.0028 with PR-WS-NRTL, using R600a/R1234yf [179]. Azeotropic behaviour was found at a mole fraction near 0.88 for R1234yf.

- $0.46 \%$ and 0.0009 for PR EoS with vdW mixing rules, using R143a/R1234yf [180].

In the case of R1234ze(E) mixtures with other HFCs refrigerants, Dong et al. [181] measured VLE values for R134/R1234ze(E) (azeotropic behaviour) at temperatures from 258.15 to $288.15 \mathrm{~K}$. The pressures Average Absolute Relative Deviations (AARD) are comprised between $0.09 \%$ and $0.28 \%$. For the R152a/R1234ze(E) mixture (zeotropic behaviour) [182], it was correlated by the Peng-Robinson EOS and the maximum AARD of pressure is $0.17 \%$. The viscosity AARD between the free-volume theory and experimental data was between 2.9 and $6.5 \%$ for R32/R1234ze(E) mixtures [183], applying the most precise mixing rule (for pure R1234ze(E) was 0.8\%). Akasaka [184] also developed models to calculate VLE data for R1234ze(E)/R32 being the precision acceptable for most of HVACR systems. 
Analysis of fluoride fluids with low global warming impact in vapour compression systems. Experimental evaluation of different alternatives for commercial refrigeration.

Most of the studies presented for natural refrigerants mixed with R1234ze(E) are those performed considering $\mathrm{CO}_{2} / \mathrm{R} 1234 \mathrm{ze}(\mathrm{E})$. Di Nicola et al. [185] correlated CarnahanStarling-DeSantis EOS with experimental results at temperatures from 233 to $363 \mathrm{~K}$ and pressures from 104 to $1909 \mathrm{kPa}$. Two-phase pressure deviations were within up to $5-6 \%$ and in the superheated vapour region were within $\pm 1 \%$. Excluding the $\mathrm{CO}_{2}$ concentrations above 80\% [186], the Schröder equation does not describe the experimental result trend, showing high discrepancies. Kiani et al. [187] obtained that for $\mathrm{CO}_{2} / \mathrm{R} 1234 \mathrm{ze}(\mathrm{E})$, the Peng-Robinson EOS was the best performing ( $\mathrm{AAD}=1.98 \%$ ) and results with Tao-Mason EOS were considerably more deviated (AAD=7\%). Dong et al. [188] also correlated VLE data for R290/R1234ze(E) (azeotropic behaviour) by the Peng-Robinson EOS at temperatures from 258.15 to $283.15 \mathrm{~K}$. The maximum AARD of pressure is $0.35 \%$, while the maximum AAD of vapour phase mole fraction is 0.0033 .

\subsubsection{Flammability studies for $\mathrm{HFC} / \mathrm{HFO}$ mixtures}

Although R1234yf and R1234ze(E) are low-flammable, they can be used to reduce flammability potential of other fluids. For example, if they are mixed with ammonia they can decrease the combustion power of the pure refrigerant [189]. Kondo et al. also supplied a formula to calculate the flammability limits in dry air of ammonia mixtures. R1234ze(E) cannot suppress completely the flammability of R161 (GWP=13, R22 replacement in stationary air conditioning systems) in the range 268 to $328 \mathrm{~K}$ [190].

\subsubsection{Heat transfer studies for $\mathrm{HFC} / \mathrm{HFO}$ mixtures}

It is common to find heat transfer investigations of R32 with R1234yf and R1234ze(E) that can be used in upcoming HFC/HFO blends to replace R410A or even R404A. HTC of the refrigerant mixture R32/R1234yf at $20 \%$ of R32 is less than that of pure 
Chapter 2. State-of-Art.

R1234yf. The HTC of the mixture at 50\% is greater than that of pure R1234yf at large heat and mass fluxes [191].

Koyama et al. [192] carried out drop-in experiments with R410A, R1234ze(E) and R1234ze(E)/R32 mixture. They proved that the heating effect and performance of R1234ze(E) can be improved noticeably by adding R32. Considering that the drop-in pressure drops in both evaporator and condenser sides resulted similar, they suggested enlarging the tubes diameter before using alternatives in R410A systems.

In tests performed by Hossain et al. [193], it was found that the experimental R1234ze(E) HTCs are below those of R1234ze(E)/R32 (55/45 mass\%) mixture, $\mathrm{R} 410 \mathrm{~A}$ and R32. At 0.48 vapour quality and $300 \mathrm{~kg} \mathrm{~m}^{-2} \mathrm{~s}^{-1}$ mass velocity, R1234ze(E) HTC was $11 \%, 56 \%$ and $83 \%$ lower, respectively. Contrary to that, in horizontal microfin tube, Kondou et al. [194] concluded that the HTC of the R32/R1234ze(E) mixture is even lower than that of $\mathrm{R} 1234 \mathrm{ze}(\mathrm{E})$. HTC is minimised at $0.2 / 0.8$ by mass, where the mole fraction difference is maximised (and the temperature glide and the mass fraction distribution are maximised).

\subsubsection{AHRI's proposal}

The Air-Conditioning, Heating, and Refrigeration Institute (AHRI) began a collaborative investigation (with the support of various research groups) to study the behaviour of the new fluorinated refrigerants as alternatives to GHG refrigerants commonly used in HVACR systems (R134a, R404A, R410A and R22) [195]. These mixtures were developed by the most relevant chemical companies: Honeywell ${ }^{\mathrm{TM}}$, DuPont $^{\mathrm{TM}}$, Archema ${ }^{\mathrm{TM}}$ or Mexichem ${ }^{\mathrm{TM}}$. The HFC/HFO mixtures alternatives to R134a and R404A identified by the AHRI are presented in Table 2. 6. Besides, Figure 2. 2 shows the ASHRAE 34 expected classification and the GWP values. 
Analysis of fluoride fluids with low global warming impact in vapour compression systems. Experimental evaluation of different alternatives for commercial refrigeration.

Table 2. 6. HFC/HFO Mixtures composition by mass percentage

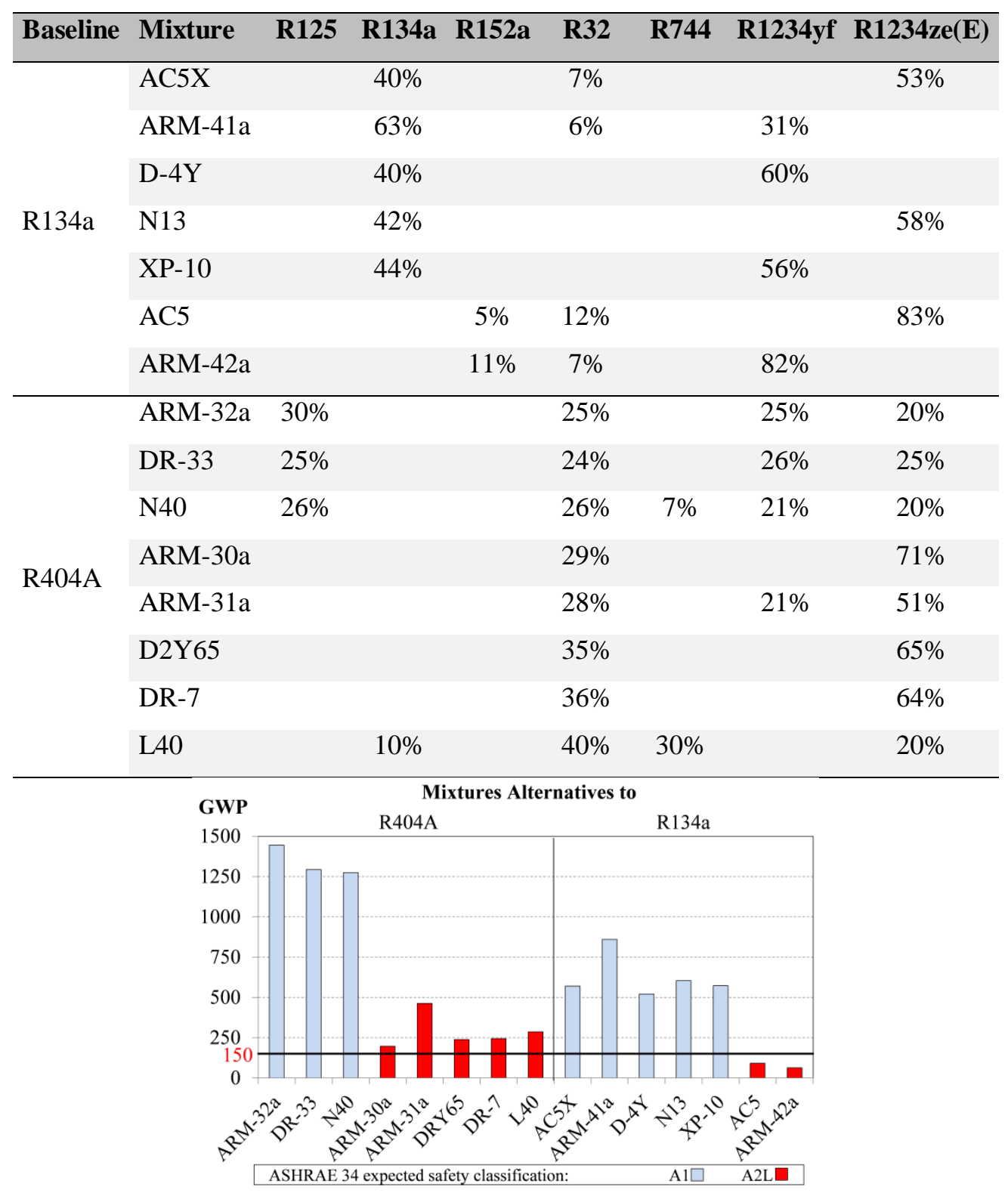

Figure 2. 2. HFC/HFO mixture alternatives to R404A and R134a, and their GWP and safety classification 
Some of these mixtures present great glide (around $7 \mathrm{~K}$ ) and that can be an additional problem if they are used as light retrofit alternatives (selective leakage is a relevant aspect). If new systems apply specific heat exchanger technologies, they could be benefited by the glide.

The complete list of AHRI investigations is exposed and continuously updated [196]. For refrigeration equipment, all mixtures are used as drop-in substitutes.

- In a R134a commercial bottle cooler/freezer [197], the average cooling capacity for XP-10 and N13 were 7.8\% and 5.2\% lower than R134a, and the average COP were 9.7\% (XP-10) and 5.7\% (N13) lower.

- In a R404A trailer refrigeration unit (under AHRI Standard 1110) [198], the cooling capacity at low and higher return air temperatures was $-21 \%$ and $10 \%$ for L40, -19\% and 5\% for ARM-30a and comparable or 11\% higher for DR-7, respectively.

- In an R404A ice machine [199] (under AHRI Standard 810 and ASHRAE Standard from 29 to 32), the best performing refrigerant was N40 (good capacity and energy efficiency).

\subsubsection{Commercial HFO/HFC mixtures}

Among the different mixtures proposed, only a few were registered, some of them with composition modifications to the initial mixture proposed.

\subsubsection{Commercial HFO/HFC mixtures to replace R134a}

Regarding R134a alternatives, R444A, R445A, R450A and R513A (previously known as Mexichem ${ }^{\mathrm{TM}}$ AC6, Mexichem ${ }^{\mathrm{TM}}$ AC5, Honeywell ${ }^{\mathrm{TM}}$ Solstice ${ }^{\circledR} \mathrm{N} 13$ and DuPont ${ }^{\mathrm{TM}}$ Opteon ${ }^{\circledR}$ XP10) are registered by the ASHRAE, Table 2. 7. 
Analysis of fluoride fluids with low global warming impact in vapour compression systems. Experimental evaluation of different alternatives for commercial refrigeration.

Table 2. 7. Commercial HFC/HFO mixtures to replace R134a

\begin{tabular}{llcl}
\hline Mixture & $\begin{array}{l}\text { Former refrigerants } \\
\text { Composition in mass } \%\end{array}$ & $\begin{array}{c}\text { GWP } \\
\text { ASHRAE }\end{array}$ & Application \\
\hline \multirow{2}{*}{ R444A } & R32/152a/1234ze(E) & 91 & R134a MAC \\
& $12 / 5 / 83$ & A2L & \\
\multirow{2}{*}{ R445A } & R744/134a/1234ze(E) & 120 & R134a MAC \\
& 6/9/85 & A2L & \\
\multirow{2}{*}{ R450A } & R134a/1234ze(E) & 548 & R134a medium pressure \\
& $42 / 58$ & A1 & HVACR \\
\multirow{2}{*}{ R513A } & R134a/1234yf & 572 & R134a medium pressure \\
& $44 / 56$ & A1 & HVACR \\
\hline
\end{tabular}

Discarding mixtures specifically developed for MAC applications, there are two options to replace R134a in MT circuits of refrigeration systems, R513A and R450A. Both refrigerants show similar energy efficiency values. DuPont ${ }^{\mathrm{TM}}$ tested R513A in a R134a MT circuit of hybrid cascade systems (using $\mathrm{CO}_{2}$ in the low temperature circuit) [200]. Also, R450A was tested resulting in a similar efficiency than R134a in a centrifugal chiller [201]. Mota-Babiloni et al. [202] obtained that R450A cooling capacity is slightly lower than R134a, similar values of COP were obtained. Schultz and Kujak [203] found poorer energetic results in a water-cooled screw chiller installation, between $12-15 \%$ reductions in capacity and $1-4 \%$ in energy efficiency.

In commercial refrigeration systems, Tewis Smart Solutions [204] obtained energy savings of $3.10 \%$ using R450A compared to R134a under winter conditions (condensation temperature of 313K). When tested in an existing supermarket [205], the energy consumption of the $\mathrm{R} 450 \mathrm{~A} / \mathrm{CO}_{2}$ cascade system was similar to that obtained with $\mathrm{R} 134 \mathrm{a} / \mathrm{CO}_{2}$ (global saving of 90 tons $\mathrm{CO}_{2}$ eq. per year). Discharge and oil temperature was also reduced using R450A. 


\subsubsection{Commercial HFO/HFC mixtures to replace R404A}

Regarding R404A alternatives, R448A, R449A and R452A (previously known as Honeywell Solstice ${ }^{\circledR}$ N40, DuPont ${ }^{\mathrm{TM}}$ Opteon ${ }^{\circledR}$ XP40 and DuPont ${ }^{\mathrm{TM}}$ Opteon ${ }^{\circledR}$ XP44) are registered by the ASHRAE, Table 2. 8.

Table 2. 8. Commercial HFC/HFO mixtures to replace R134a

\begin{tabular}{llcl}
\hline \multirow{2}{*}{ Mixture } & $\begin{array}{l}\text { Former refrigerants } \\
\text { Composition in mass \% }\end{array}$ & $\begin{array}{c}\text { GWP } \\
\text { ASHRAE }\end{array}$ & Application \\
\hline \multirow{2}{*}{ R448A } & R32/125/1234yf/134a/1234ze(E) & 1274 & R404A supermarket \\
& 26/26/20/21/7 & A1 & refrigeration \\
R449A & R32/125/134a/1234yf & 1277 & R404A supermarket \\
& $24.3 / 24.7 / 25.3 / 25.7$ & A1 & refrigeration \\
R452A & R32/125/1234yf & 1945 & R404A transport \\
& $11 / 59 / 30$ & A1 & refrigeration \\
\hline
\end{tabular}

Discarding R452A, developed to substitute R404A in transport refrigeration, R448A and R449A could replace R404A in supermarket refrigeration. DuPont ${ }^{\mathrm{TM}}$ ensures that R449A produces Energy efficiency savings of up to $10 \%$ with many systems [206]. Mota-Babiloni et al. [207] studied theoretically six R404A alternatives in four vapour compression configurations, obtaining high efficiency simulating with the R448A system. In a $2.2 \mathrm{~kW}$ semi-hermetic condensing unit with evaporator for walk-in freezer/cooler [208], R448A matches capacity of R404A with $6 \%$ higher efficiency. Rajendran [209] obtained lower energy consumption for R448A (3 to 8\%) in a centralised DX system (scroll compressors) with cases and food simulators. In another test facility that uses reciprocating compressors and two separate temperature/humidity controlled rooms [38], R448A average COP was $11.6 \%$ higher than that obtained with R404A. 
Analysis of fluoride fluids with low global warming impact in vapour compression systems. Experimental evaluation of different alternatives for commercial refrigeration.

Among the new mixtures registered by ASHRAE, in supermarket applications can be used R450A and R513A as R134a replacements, and R448A and R449A as R404A alternatives. All these refrigerants are classified as A1 (non-flammable, non-toxic) refrigerants and can be used in service and new design appliances. Compressors manufacturers have also approved these refrigerants to accelerate the HFC phase-out.

\subsection{Selected refrigerants}

This work evaluates the retrofit substitution of refrigerants R134a and R404A in a compressor rack systems for supermarket refrigeration. Among the alternatives presented, only synthetic refrigerants can be used as substitutes. Then, only HFOs and HFC/HFO mixtures are going to be tested because allow more reduction in GWP than lower GWP HFCs (these are even more flammable than HFOs) and HFC mixtures (greater GWP values than HFC/HFO mixtures).

On the one hand, R1234yf and R1234ze(E), the two HFO commercially available, are selected to be studied. Both are direct replacements for R134a since, according to the studies revised they present similar properties, operating range and materials and oil compatibility.

On the other hand, the mixtures available in the market to replace R134a and R404A are R450A and R513A, and R448A and R449A, respectively. Within them, only R450A and R448A are considered, since these fluids use R1234ze(E) in their composition, instead of R1234yf. This fact allows a lower cost and lower flammability (this is a very important fact because PCRRSs use a great amount of refrigerant). 
Prior to study the properties of the refrigerants selected in this work, the desired values of refrigerant properties to obtain a high COP in a refrigeration system are shown in Table 2.9 [210].

Table 2. 9. Summary of desirable values of refrigerant properties for high COP [210]

\begin{tabular}{|c|c|c|}
\hline Property & Desirable & General effect on refrigeration system \\
\hline $\begin{array}{l}\text { Latent heat } \\
\text { (Refrigerating effect) }\end{array}$ & High & $\begin{array}{l}\text { Smaller the required mass flow rate } \\
\text { Smaller size of the compressor. }\end{array}$ \\
\hline Critical temperature & $\begin{array}{l}\text { High } \\
\text { (trade-off) }\end{array}$ & $\begin{array}{l}\text { Higher COP. } \\
\text { (-) Lower volumetric refrigerating capacity. } \\
\text { (-) Larger compressor swept volume rate. }\end{array}$ \\
\hline $\begin{array}{l}\text { Liquid thermal } \\
\text { conductivity }\end{array}$ & High & Higher HTCs. \\
\hline Vapour density & High & $\begin{array}{l}\text { Lower pressure drop in HXs. } \\
\text { Higher capacity (for a given compressor). }\end{array}$ \\
\hline Vapour specific heat & $\begin{array}{l}\text { High } \\
\text { (trade-off) }\end{array}$ & $\begin{array}{l}\text { Lower compression work, discharge } \\
\text { temperature and higher thermal efficiency. } \\
\text { (-) Wet compression may be encountered. }\end{array}$ \\
\hline Liquid viscosity & Low & $\begin{array}{l}\text { Lower pressure drop in HXs. } \\
\text { Higher HTCs. }\end{array}$ \\
\hline Molecular weight & Low & $\begin{array}{l}\text { Larger enthalpy of evaporation. } \\
\text { Lower compressor's valves losses. }\end{array}$ \\
\hline
\end{tabular}

\subsubsection{R134a alternatives properties}

The refrigerants selected to replace R134a are R1234yf, R1234ze(E) and R450A, their main properties are shown in Table 2. 10. 
Analysis of fluoride fluids with low global warming impact in vapour compression systems. Experimental evaluation of different alternatives for commercial refrigeration.

Table 2. 10. Characteristics of R134a and its alternatives

\begin{tabular}{|c|c|c|c|c|}
\hline & R134a & R1234yf & R1234ze(E) & R450A \\
\hline $\begin{array}{l}\text { Molecular weight } \quad(\mathrm{kg} \\
\left.\mathrm{kmol}^{-1}\right)\end{array}$ & 102 & 114 & 114 & 108.6 \\
\hline $\mathrm{ODP} / \mathrm{GWP}_{100-\mathrm{yr}}$ & $0 / 1300$ & $0 / 1$ & $0 / 4$ & $0 / 548$ \\
\hline ASHRAE Safety Class. & A1 & $\mathrm{A} 2 \mathrm{~L}$ & $\mathrm{~A} 2 \mathrm{~L}$ & A1 \\
\hline Glide $_{0.1 \mathrm{MPa}}(\mathrm{K})$ & - & - & - & 0.78 \\
\hline Critical Pressure (kPa) & 4059.28 & $\begin{array}{l}3382.20 \\
(-17 \%)\end{array}$ & $\begin{array}{l}3634.90 \\
(-10 \%)\end{array}$ & $\begin{array}{c}4082.37 \\
(1 \%)\end{array}$ \\
\hline Critical Temperature (K) & 374.21 & $367.85(-2 \%)$ & $382.51(2 \%)$ & $378.80(1 \%)$ \\
\hline $\operatorname{NBP}(K)$ & 246.79 & $243.37(-1 \%)$ & $253.88(3 \%)$ & $248.70(1 \%)$ \\
\hline $\begin{array}{l}\text { Liquid density }^{\mathrm{a}} \\
\left(\mathrm{kg} \mathrm{m}^{-3}\right)\end{array}$ & 1295.27 & $\begin{array}{c}1176.76 \\
(-9 \%)\end{array}$ & $\begin{array}{c}1240.56 \\
(-4 \%)\end{array}$ & $\begin{array}{c}1253.19 \\
(-3 \%)\end{array}$ \\
\hline Vapour density ${ }^{\mathrm{a}}\left(\mathrm{kg} \mathrm{m}^{-3}\right)$ & 14.35 & $17.56(22 \%)$ & $11.65(-19 \%)$ & $13.92(-3 \%)$ \\
\hline $\begin{array}{l}\text { Liquid } \mathrm{c}_{\mathrm{p}}{ }^{\mathrm{a}} \\
\left(\mathrm{kJ} \mathrm{kg}^{-1} \mathrm{~K}^{-1}\right)\end{array}$ & 1.34 & $1.29(-4 \%)$ & $1.32(-2 \%)$ & $1.33(-1 \%)$ \\
\hline $\begin{array}{l}\text { Vapour } \mathrm{c}_{\mathrm{p}}^{\mathrm{a}} \\
\left(\mathrm{kJ} \mathrm{kg}^{-1} \mathrm{~K}^{-1}\right)\end{array}$ & 0.90 & $0.93(3 \%)$ & $0.88(-1 \%)$ & $0.89(0 \%)$ \\
\hline $\begin{array}{l}\text { Liquid therm. cond. }{ }^{\mathrm{a}} \text { (W } \\
\mathrm{m}^{-1} \mathrm{~K} \text { ) }\end{array}$ & 92.08 & $71.51(-22 \%)$ & $83.11(-10 \%)$ & $85.27(-7 \%)$ \\
\hline $\begin{array}{l}\text { Vapour therm. cond. }{ }^{\mathrm{a}} \text { (W } \\
\left.\mathrm{m}^{-1} \mathrm{~K}\right)\end{array}$ & 11.50 & $11.62(1 \%)$ & $11.57(1 \%)$ & $11.70(2 \%)$ \\
\hline Liquid viscosity ${ }^{\mathrm{a}}\left(\mathrm{Pa} \mathrm{s}^{-1}\right)$ & 267.04 & $\begin{array}{l}208.72 \\
(-22 \%)\end{array}$ & $\begin{array}{c}269.44 \\
(1 \%)\end{array}$ & $\begin{array}{l}258.12 \\
(-3 \%)\end{array}$ \\
\hline Vapour viscosity ${ }^{\mathrm{a}}\left(\mathrm{Pa} \mathrm{s}^{-1}\right)$ & 10.72 & $10.06(-6 \%)$ & $11.19(4 \%)$ & $11.15(4 \%)$ \\
\hline $\begin{array}{l}\text { Latent heat } \\
\left(\mathrm{kJ} \mathrm{kg}^{-1}\right)\end{array}$ & 198.72 & $\begin{array}{l}163.39 \\
(-18 \%)\end{array}$ & $\begin{array}{c}184.28 \\
(-7 \%)\end{array}$ & $\begin{array}{l}186.34 \\
(-6 \%)\end{array}$ \\
\hline
\end{tabular}

${ }^{\mathrm{a}}$ Temperature $=273 \mathrm{~K}$ 
According to the limitations established on the Montreal Protocol, all the refrigerants used in refrigeration installations must be zero-ODP. Using pure HFOs, R1234yf and R1234ze(E), the GWP is reduced near the unity, so both refrigerants can be used in any application according to EU Regulation. Furthermore, they do not pay GWP taxes in Spain (below 150). Although the GWP of R450A is below the half of that of R134a, it cannot be used in applications where the GWP limit is above 150 .

R1234yf and R1234ze(E) are low-flammable refrigerants and could emerge problems related to the maximum amount of fluid allowed in the VCSs. If safety regulations are not modified, considering low risk of flame with A2L refrigerants, they cannot be used in large quantities. Because R450A is classified as A1 by ASHRAE (as R134a), this is the only refrigerant considered that can be used without charge problems in any system.

$\mathrm{R} 450 \mathrm{~A}$ is a non-azeotrope mixture and has temperature glide. Concretely the glide is $0.78 \mathrm{~K}$ at $0.1 \mathrm{MPa}$. As happens to other refrigerants with little glides as R404A, it can be designed as near-azeotrope mixture because the glide effects are not so much severe.

Initially, it seems that there is no problem related to the use of alternatives in typical applications of R134a, because they can work at similar operating conditions. Critical temperatures of alternatives are very similar to R134a, being the critical pressures of R1234yf and R1234ze(E) 10\% and 17\% lower. NBPs of all fluids are close.

Analysing the thermophysical properties of this refrigerant, R1234yf shows lower liquid thermal conductivity, liquid viscosity and latent heat; and higher vapour density. This will affect the heat transfer coefficients in heat exchangers and mass flow rate. Also, both parameters will be little different using R1234ze(E). This refrigerant presents a much lower suction density and liquid thermal conductivity so it will perform lower mass flow rates. 
Analysis of fluoride fluids with low global warming impact in vapour compression systems. Experimental evaluation of different alternatives for commercial refrigeration.

\subsubsection{R404A alternatives properties}

In this project, the candidate proposed to replace R404A is R448A; the main properties of both refrigerants are shown in Table 2. 11 .

Table 2. 11. Characteristics of R404A and the alternative R448A

\begin{tabular}{|c|c|c|c|}
\hline & R404A & R448A & Rel. dev. \\
\hline Molecular Weight kg kmol ${ }^{-1}$ & 97.6 & 86.3 & $-12 \%$ \\
\hline $\mathrm{ODP} / \mathrm{GWP}_{100-\mathrm{yr}}$ & $0 / 3943$ & $0 / 1274$ & $/-68 \%$ \\
\hline ASHRAE Safety Class. & A1 & A1 & \\
\hline Glide $_{0.1 \mathrm{MPa}}(\mathrm{K})$ & 0.75 & 6.27 & \\
\hline Critical Temperature (K) & 3728.85 & 4674.93 & $25 \%$ \\
\hline Critical Pressure $(\mathrm{kPa})$ & 345.20 & 356.81 & $3 \%$ \\
\hline $\operatorname{NBP}(K)$ & 227.41 & 233.05 & $2 \%$ \\
\hline Liquid density ${ }^{\mathrm{a}}\left(\mathrm{kg} \mathrm{m}^{-3}\right)$ & 1150.59 & 1192.39 & $4 \%$ \\
\hline Vapour density ${ }^{\mathrm{a}}\left(\mathrm{kg} \mathrm{m}^{-3}\right)$ & 30.32 & 22.09 & $-27 \%$ \\
\hline Liquid $\mathrm{c}_{\mathrm{p}}^{\mathrm{a}}\left(\mathrm{kJ} \mathrm{kg}^{-1} \mathrm{~K}^{-1}\right)$ & 1.39 & 1.42 & $2 \%$ \\
\hline Vapour $\mathrm{c}_{\mathrm{p}}{ }^{\mathrm{a}}\left(\mathrm{kJ} \mathrm{kg}^{-1} \mathrm{~K}^{-1}\right)$ & 1.00 & 0.98 & $-2 \%$ \\
\hline Liquid therm. cond. ${ }^{\mathrm{a}}\left(\mathrm{W} \mathrm{m}^{-1} \mathrm{~K}\right)$ & $73.15 \cdot 10^{-3}$ & $92.41 \cdot 10^{-3}$ & $26 \%$ \\
\hline Vapour therm. cond. ${ }^{\mathrm{a}}\left(\mathrm{W} \mathrm{m}^{-1} \mathrm{~K}\right)$ & $12.82 \cdot 10^{-3}$ & $12.01 \cdot 10^{-3}$ & $-6 \%$ \\
\hline Liquid viscosity ${ }^{\mathrm{a}}\left(\mathrm{Pa} \mathrm{s}^{-1}\right)$ & $179.70 \cdot 10^{-6}$ & $188.35 \cdot 10^{-6}$ & $5 \%$ \\
\hline Vapour viscosity $^{\mathrm{a}}\left(\mathrm{Pa} \mathrm{s}^{-1}\right)$ & $11.00 \cdot 10^{-6}$ & $11.42 \cdot 10^{-6}$ & $4 \%$ \\
\hline Latent heat $\left(\mathrm{kJ} \mathrm{kg}^{-1}\right)$ & 165.95 & 200.58 & $21 \%$ \\
\hline
\end{tabular}

${ }^{\mathrm{a}}$ Temperature $=273 \mathrm{~K}$

R448A accomplishes the GWP limitation for stationary refrigerant equipment and also can be used in cascade multipack refrigeration systems. However, it will not be allowed in refrigerators and freezers or in DX multipack refrigeration systems. 
Chapter 2. State-of-Art.

Although R448A NBP is higher than that of R404A, it accomplishes freezing requirements (operating evaporator pressure above atmospheric at low case temperatures). R448A glide is considerably high and cannot be simplified to nearazeotropic mixture. For this reason redesigning of the R404A systems (or consider other technologies) to adapt non-azeotropic mixtures as R448A will lead to energy improvement. Furthermore, it cannot be used in systems with components where liquid can be collected e.g. suction line accumulators, flash tanks, receivers or pool boiling/flooded evaporators.

The replacement critical temperature and critical pressure are also higher, so the power required for compressing vapour goes down. The vapour density is lower for R448A and affects the suction volumetric flow rate. Vapour line pipes design should be revised due to great differences in vapour density and liquid. Great difference in liquid thermal conductivity could affect heat exchangers design. 
Analysis of fluoride fluids with low global warming impact in vapour compression systems. Experimental evaluation of different alternatives for commercial refrigeration.

\subsection{Conclusions Chapter 2}

In this chapter the present status of the low-GWP alternatives to HFC commonly used in commercial refrigeration systems have been exposed. Main characteristics and potential applications of natural refrigerants as HCs, carbon dioxide and ammonia have been discussed, concluding that even though they present good energy performance characteristics, they need a complete new design to take into account the security concerns as flammability (HCs and ammonia), toxicity (ammonia), high pressures (carbon dioxide) or material compatibility.

Other HFC with lower GWP can be used to replace R134a and R404A. Their environmental properties are overcame by other synthetic substances recently developed, HFOs, which offers greater GWP reductions while maintains similar properties and performance. Nowadays, R1234yf and R1234ze(E) are the most promising HFOs. Thermodynamic, flammability, heat transfer and energetic studies of both HFOs as well as their mixtures with HFCs have been reviewed.

A few years ago, a collaborative program to develop HFC/HFO mixtures to replace HFC was started. At this point, some of those fluids that are registered by ASHRAE and can work as R134a and R404A substitutes in different HVACR systems. Among them, R450A and R448A seem to be promising alternatives in the field of commercial refrigeration.

Attending to this chapter, the HFO refrigerants R1234yf and R1234ze(E) (GWP=1, low flammability) and the HFO/HFC mixture R450A (GWP 548, no-flammable) are considered as possible alternative to R134a. Regarding to R404A replacement, R448A can be used as a direct replacement for R404A, showing around one third of the GWP and higher energy performance 


\section{Chapter 3}

\section{Theoretical Analysis}

The previous chapter has reviewed the different low-GWP alternatives of R134a and $\mathrm{R} 404 \mathrm{~A}$, the most commonly refrigerants used in parallel compressor rack refrigeration systems of supermarkets. Moreover, it has been seen that the HFOs and its mixtures present good characteristics to replace R134a and R404A.

The aim of this section is to compare theoretically the baseline refrigerants (R134a and R404A) with the alternatives finally proposed in Chapter 2: R1234yf, R1234ze(E) and $\mathrm{R} 450 \mathrm{~A}$, and R448A. Those refrigerants are compared considering a one-stage basic cycle with working operating conditions that simulate the typical operating range of commercial refrigeration systems.

The theoretical analysis proposed in this chapter allows obtaining a first approach of the expected experimental results and to carry out a comprehensive performance assessment. Furthermore, this theoretical analysis will help to detect and discard wrong experimental tests. 
Analysis of fluoride fluids with low global warming impact in vapour compression systems. Experimental evaluation of different alternatives for commercial refrigeration.

\subsection{Basic cycle}

Nowadays, PCRRSs are commonly used in DX configurations, where (as it has been exposed previously) the refrigerant is compressed in a back room and flows through the externally located condenser/s, continuing up to the evaporators that cools the different food cabinets and flows back to the compressors where the cycle starts again. In a previous and simple analysis, this circuit can be considered as a basic refrigeration cycle (Figure 3.1) and its conclusions can be applied to the existing PCRRSs.
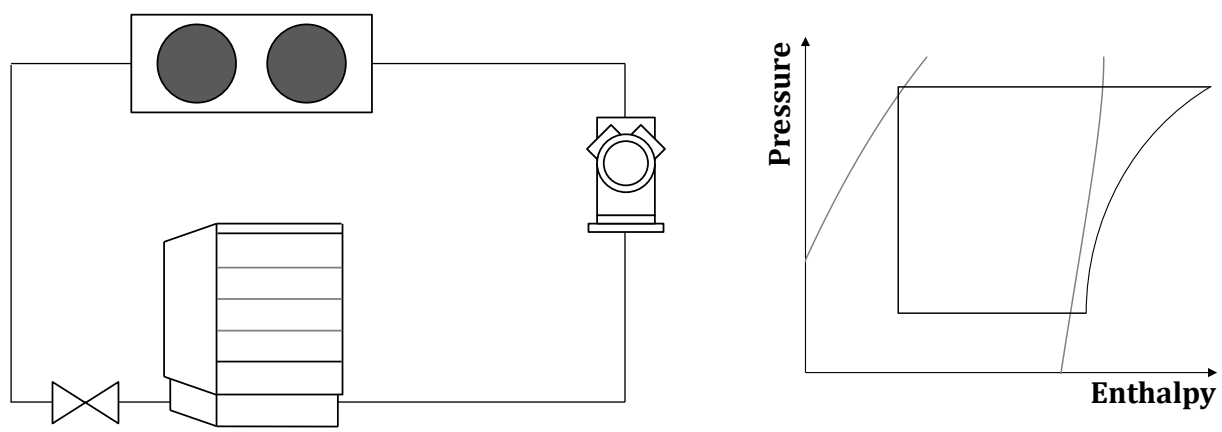

Figure 3. 1. Diagram and P-h cycle of one stage cycle

The purpose of the theoretical analysis is to obtain an initial overview of the refrigerants performance and check their possible use as drop-in or light retrofit alternatives. Furthermore, the theoretical analysis carried out is going to be also used to identify the differences between the alternatives and the reference of the fluids in terms of operating pressure and other relative aspects to components design.

As it was exposed in Chapter 1, other configurations that contain lower charge of GHG refrigerants are going to impose in PCRRSs. Moreover, they could permit the extension of low flammable refrigerants used in controlled spaces. These configurations are cascade systems (allows GWP up to 1500 in Europe) and secondary systems. Conclusions reached in basic cycle can also be applied to the high stage of both systems, Figure 3. 2. Comparing this Figure with the previous one, the similarity 
between the basic cycle and the high stage of both alternative configurations can be easily seen (the display case is substituted by an intermediate evaporator).
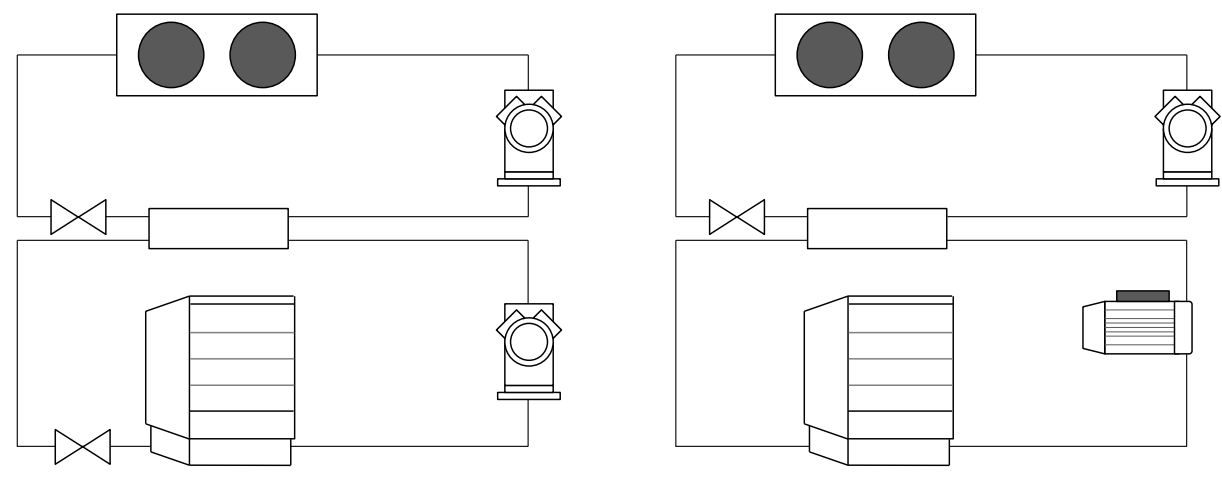

Figure 3. 2. Application of basic cycle in cascade and secondary systems

\subsection{Simulation methodology}

This section contains the simulated operating conditions, a brief analysis of the operating range of the HFCs and the alternatives, the made assumptions and the equations used in the theoretical analysis.

\subsubsection{Simulation conditions}

The operating conditions simulated to carry out the theoretical analysis consist of varying the evaporating and condensing temperatures. For future comparisons with experimental results, three levels of evaporation temperatures combined with three different levels of condensation temperatures are considered, according to the typical operating conditions of the baselines refrigerants, R134a and R404A, Table 3.1. 
Analysis of fluoride fluids with low global warming impact in vapour compression systems. Experimental evaluation of different alternatives for commercial refrigeration.

Table 3. 1. Simulation conditions

\begin{tabular}{lcc}
\hline Baseline & R134a & R404A \\
\hline Evaporation Temperature $\left(T_{o}\right)$ & $260 \mathrm{~K} / 270 \mathrm{~K} / 280 \mathrm{~K}$ & $240 \mathrm{~K} / 253 \mathrm{~K} / 265 \mathrm{~K}$ \\
Condensation Temperature $\left(T_{k}\right)$ & $305 \mathrm{~K} / 315 \mathrm{~K} / 325 \mathrm{~K}$ \\
\hline
\end{tabular}

Due to the low NBP of R134a (246.8 K), it can be used above atmospheric pressure $(101.325 \mathrm{kPa})$ at MT (food conservation applications). The evaporation temperatures selected for R134a are $260 \mathrm{~K} / 270 \mathrm{~K} / 280 \mathrm{~K}$. The R404A NBP is $227.4 \mathrm{~K}$ and works in both MT and LT conditions (food freezing and conservation applications, respectively) above atmospheric pressure. Therefore, for R404A and alternatives, the evaluated evaporation temperatures are $240 \mathrm{~K} / 253 \mathrm{~K} / 265 \mathrm{~K}$.

To simplify, the condensation temperatures were considered the same for both refrigerants: $305 \mathrm{~K} / 315 \mathrm{~K} / 325 \mathrm{~K}$ (from winter to summer or cold to warm countries ambient conditions).

To calculate the operating conditions for zeotropic mixtures the glide effect should be considered. The new evaporation and condensation temperatures were corrected according to refrigerant suppliers, Equation 3. 1 and Equation 3. 2 [211].

$$
\begin{aligned}
T_{o} & =\frac{1}{3} T_{\text {Bubble }}+\frac{2}{3} T_{\text {Dew }} \\
T_{k} & =\frac{1}{2} T_{\text {Bubble }}+\frac{1}{2} T_{\text {Dew }}
\end{aligned}
$$

Equation 3. 2 
Chapter 3. Theoretical Analysis.

\subsubsection{Adaptation to the operating ranges}

In drop-in or light retrofit substitutions, besides similar thermophysical and environmental properties between baselines and alternatives, the similitude between the operating working conditions is a relevant aspect to consider.

\subsubsection{Operating pressures and temperatures}

The operating saturation pressures that correspond to the saturation temperatures must be similar between baselines and alternatives to help in the substitution. For the conditions proposed in the simulation, the resulting operating range is shown in Figure 3. 3 .
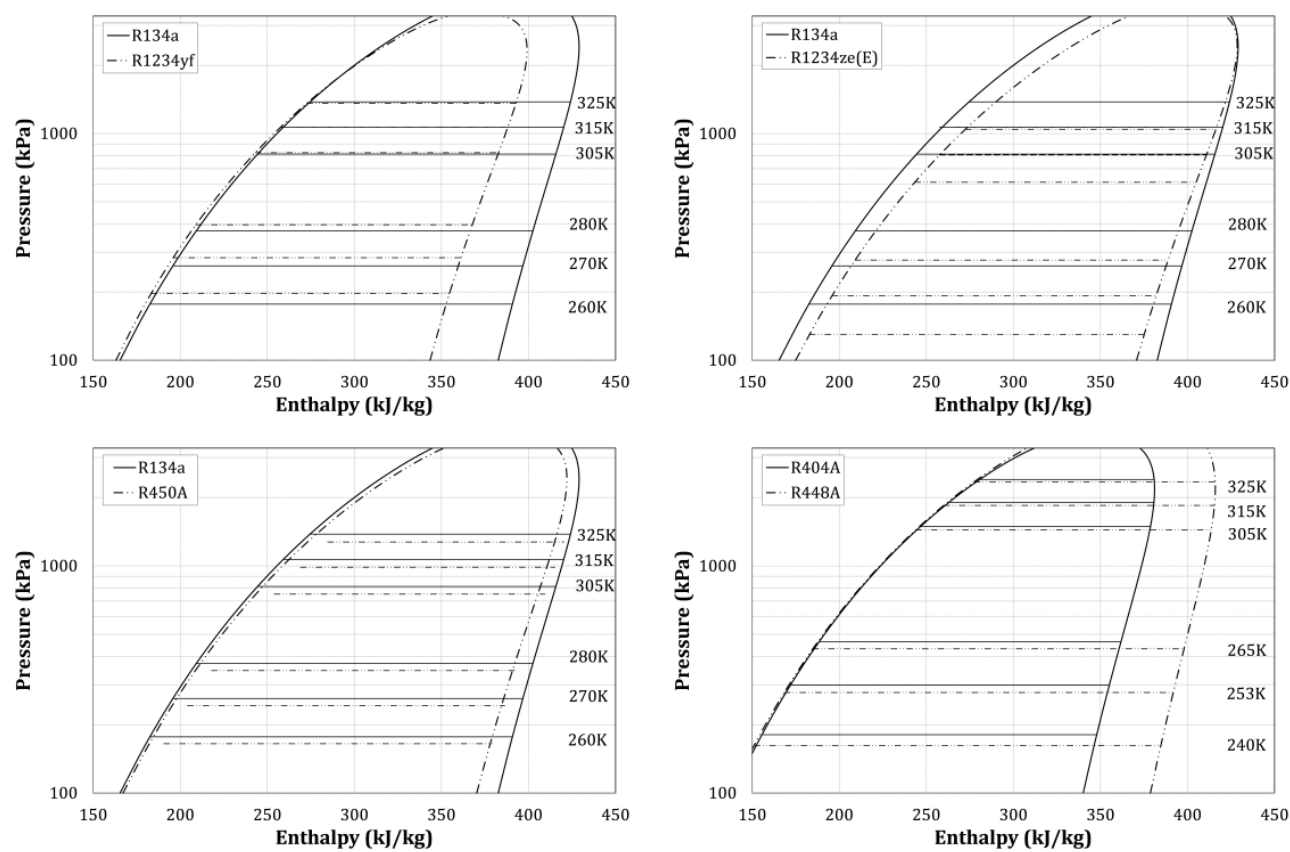

Figure 3. 3. Operating saturation temperatures and pressures 
Analysis of fluoride fluids with low global warming impact in vapour compression systems. Experimental evaluation of different alternatives for commercial refrigeration.

The R1234yf pressure range is very similar to that of R134a, especially considering their condensation pressures. R1234ze(E) pressures are much below that of R134a, being these approximated equal when using R450A. R448A operating pressures are also slightly lower than those obtained considering R404A, and the same conclusion can be achieved.

\subsubsection{Compression ratio}

The compression ratio (CR) is the ratio between the discharge and the suction pressure, Equation 3. 3. It has great relevance on compressors design (it is a critical parameter for screw compressors) and affects directly to the compressor efficiencies and the compression work: the higher the compression ratio, the lower the energetic performance.

$$
\text { Compression Ratio }=\frac{P_{\text {disc }}}{P_{\text {suc }}}
$$

Table 3. 2 and Table 3. 3 display the CRs of R134a and R404A and their alternatives considering the same operating conditions. It can be seen that the R1234ze(E) CRs are slightly greater than those of R134a. R450A has similar CR values to R134a and R1234yf CR is below than the baseline refrigerant. Besides, R448A CRs are notably higher than those of R404A. 
Chapter 3. Theoretical Analysis.

Table 3. 2. Compression ratios for $\mathbf{R} 134 \mathrm{a}$ and its alternatives

\begin{tabular}{llcccc}
\hline $\mathbf{T}_{\text {evap }}(\mathbf{K})$ & $\mathbf{T}_{\text {cond }}(\mathbf{K})$ & $\mathbf{R 1 3 4 a}$ & $\mathbf{R 1 2 3 4 y f}$ & $\mathbf{R 1 2 3 4 z e}(\mathbf{E})$ & $\mathbf{R 4 5 0 A}$ \\
\hline \multirow{2}{*}{260} & 305 & 4.59 & 4.18 & 4.70 & 4.58 \\
& 315 & 6.04 & 5.41 & 6.21 & 6.02 \\
& 325 & 7.81 & 6.90 & 8.06 & 7.77 \\
\hline \multirow{2}{*}{270} & 305 & 3.11 & 2.91 & 3.17 & 3.11 \\
& 315 & 4.09 & 3.76 & 4.19 & 4.09 \\
& 325 & 5.29 & 4.80 & 5.43 & 5.28 \\
280 & 305 & 2.18 & 2.08 & 2.20 & 2.18 \\
& 315 & 2.87 & 2.70 & 2.91 & 2.86 \\
& 325 & 3.70 & 3.44 & 3.78 & 3.70 \\
\hline
\end{tabular}

Table 3. 3. Compression ratios for $\mathbf{R} 404 \mathrm{~A}$ and its alternative

\begin{tabular}{llcc}
\hline $\mathbf{T}_{\text {evap }}(\mathbf{K})$ & $\mathbf{T}_{\text {cond }}(\mathbf{K})$ & $\mathbf{R 4 0 4 A}$ & $\mathbf{R 4 4 8 A}$ \\
\hline \multirow{2}{*}{240} & 305 & 8.29 & 9.34 \\
& 315 & 10.60 & 11.97 \\
& 325 & 13.36 & 15.19 \\
\hline \multirow{2}{*}{253} & 305 & 4.94 & 5.42 \\
& 315 & 6.31 & 6.95 \\
& 325 & 7.96 & 8.82 \\
\hline \multirow{2}{*}{265} & 305 & 3.22 & 3.46 \\
& 315 & 4.11 & 4.44 \\
& 325 & 5.19 & 5.64 \\
\hline
\end{tabular}

The effect of these deviations will be reflected in the rest of parameters, especially for R1234yf and R448A when compared with R134a and R404A, respectively. 
Analysis of fluoride fluids with low global warming impact in vapour compression systems. Experimental evaluation of different alternatives for commercial refrigeration.

\subsubsection{Assumptions and equations}

At the beginning of this chapter it has been mentioned that the theoretical comparison is conducted in order to obtain a first evaluation of the alternatives performance before testing them. Also, it helps to identify erroneous experimental tests (if the results do not follow a logical sequence) and to find the causes of performance results deviations due to irreversibilities.

When the theoretical calculations are performed before testing the refrigerants, some assumptions should be made to speed up the process and obtain general results that can be applied to almost any refrigerant application. The simplifications assumed in this work are the following ones:

- Pressure drops are neglected in heat exchangers and lines (well designed).

- Ideal compression (compressor efficiencies equal to 1).

- There is no heat transfer to the surroundings (components and pipes perfectly isolated).

- Isenthalpic process is considered at the expansion valve (this assumption is close to reality).

- The superheating and the subcooling degree for baselines are $7 \mathrm{~K}$ and $2 \mathrm{~K}$, respectively. For the zeotropic mixtures, a correction is applied at each condition [211], Equation 3. 4. This condition is applied also in experimental analysis, allowing minimum deviations.

$$
S H_{\text {alternative }}=S H_{\text {baseline }}-\frac{1}{3} \text { Glide }_{\text {baseline }}
$$

The thermodynamic states of the refrigerants are calculated using REFPROP 9.1 [212]. This program uses the most accurate and recent EOS and models currently available. It also includes most recent HFO and HFO mixtures properties in its fluid database. 
The reference EOS for R134a is presented by Tillner-Roth et Baehr [213], for R1234yf by Richter et al. [214] and for R1234ze(E) by Thol and Lemmon [215]. To obtain the mixing rule for each binary pair of the selected refrigerants, are obtained in REFPROP [212].

The energetic parameters considered in the comparison are the cooling capacity, $\dot{Q}_{o}$, (Equation 3. 5) and the Coefficient of Performance (Equation 3. 6), COP. The cooling capacity is the product of the mass flow rate and the refrigerating effect (evaporator enthalpy difference) and the COP is the ratio between the refrigerating effect and the isentropic compression work.

$$
\begin{gathered}
\dot{Q}_{o}=\dot{m}_{r e f}\left(h_{\text {out }}-h_{\text {in }}\right)_{o} \\
C O P=\dot{q}_{o} / \dot{w}_{\text {comp }}
\end{gathered}
$$

Equation 3. 6

Or can be also expressed in the form of Equation 3. 7.

$$
C O P=\dot{Q}_{o} / P_{C}
$$

Equation 3. 7

COP quantifies the energy efficiency in VCSs. In refrigeration systems, it is the ratio between the cooling produced and the electrical energy consumed. The compressor power consumption (also for the motor considering ideal operation), $P_{c}$, is obtained using Equation 3. 8.

$$
P_{c}=\dot{m}_{r e f}\left(h_{\text {out }}-h_{\text {in }}\right)_{c}
$$

Equation 3. 8 
Analysis of fluoride fluids with low global warming impact in vapour compression systems. Experimental evaluation of different alternatives for commercial refrigeration.

In order to obtain the theoretical mass flow rate, $\dot{m}_{r e f}$, a volumetric flow rate of $0.00653 \mathrm{~m}^{3} \mathrm{~s}^{-1}$ is considered at compressor suction (it is the swept volume of the compressor installed on the experimental setup), Equation 3. 9. In a theoretical situation, mass flow rate differences are only due to suction density values.

$$
\dot{m}_{\text {ref }}=\left(\dot{V}_{\text {ref }} \rho\right)_{\text {suc }}
$$

Equation 3. 9

The parameters analysed to perform the feasibility of HFC replacement are mass flow rate, cooling capacity and COP (the deviation in power consumption can be deduced from the last two parameters as shown previously). To help the comparison between the baselines and the alternatives, the results are shown as a relative deviation from baselines R134a and R404A (\% $\dot{Q}_{o}$ and \%COP), Equation 3. 10 to Equation 3. 12.

$$
\begin{aligned}
& \% \dot{m}_{\text {ref,alternative } / \text { baseline }}=\left(\frac{\dot{m}_{\text {alternative }}-\dot{m}_{\text {ref,baseline }}}{\dot{m}_{\text {ref,baseline }}}\right) \cdot 100 \quad \text { Equation 3.10 } \\
& \% \dot{Q}_{o, \text { alternative } / \text { baseline }}=\left(\frac{\dot{Q}_{o, \text { alternative }}-\dot{Q}_{o, \text { baseline }}}{\dot{Q}_{o, \text { baseline }}}\right) \cdot 100 \quad \text { Equation 3. 11 } \\
& \% C O P_{\text {alternative } / \text { baseline }}=\left(\frac{C O P_{\text {alternative }}-C O P_{\text {baseline }}}{C O P_{\text {baseline }}}\right) \cdot 100 \quad \text { Equation 3. 12 }
\end{aligned}
$$

\subsection{Theoretical results of comparison between $\mathrm{R} 134 \mathrm{a}$ and alternatives}

\subsubsection{Mass flow rate}

Figure 3. 4 presents the theoretical mass flow rate deviation between R134a and its alternatives at different evaporation temperatures. While R1234yf presents much higher values (between $20 \%$ and 26\%) than R134a, those values of R1234ze(E) are much lower (near-29\%). 
The theoretical mass flow rates achieved by R450A are very close to those of R134a (the greatest reduction is $2 \%$ ) even though its composition contains a $58 \%$ of R1234ze(E).

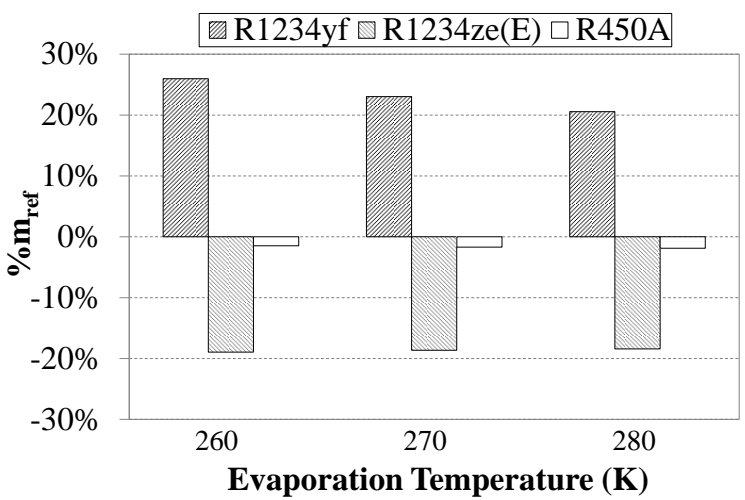

Figure 3. 4. Theoretical mass flow rate deviation between R134a and its alternatives

In the ideal case analysed here, the condensation temperature has no effect on mass flow rate. This parameter only depends on the suction density (evaporation pressure) and the theoretical deviations for both parameters are the same, Figure 3. 5. As introduced before, great density differences can also affect to the pressure losses (Table 2. 9) and henceforth, components design.

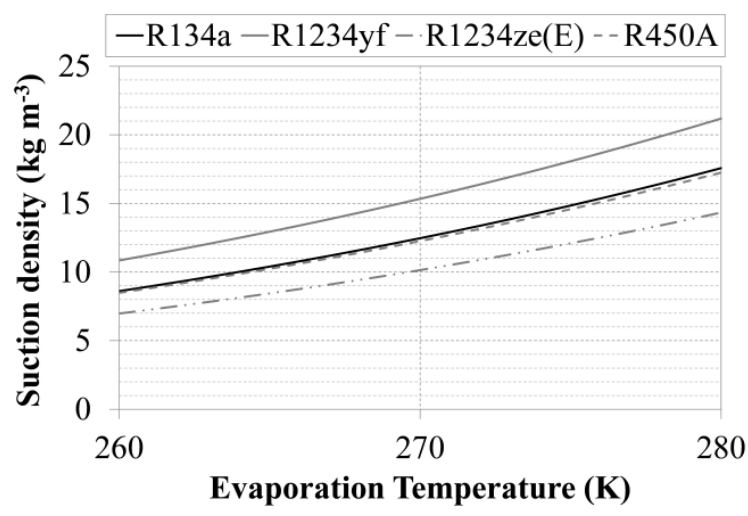

Figure 3. 5. Suction density for $\mathrm{R} 134 \mathrm{a}$ and alternatives ( $\mathrm{SH}=7 \mathrm{~K}$, no pressure drops) 
Analysis of fluoride fluids with low global warming impact in vapour compression systems. Experimental evaluation of different alternatives for commercial refrigeration.

\subsubsection{Cooling capacity}

The cooling capacity deviation of the different substitutes is shown in Figure 3. 6 . From that, all of them exhibit lower cooling capacity than R134a, which could cause difficulties in reaching (or maintain) the cabinet temperature. Since cooling capacity is the product of the mass flow rate (studied before) and the refrigerating effect, this effect is also shown in Figure 3. 6.

R1234yf cooling capacity deviation depends mostly on condensation temperatures. The cooling capacity reduction is quantified between $2 \%$ and $8 \%$. Despite the higher mass flow rates observed before, about $20-25 \%$, the reduced refrigerating effect (enthalpy difference between evaporator outlet and inlet), 20-27\% less than R134a, leads to the above mentioned cooling capacity reductions. The cooling capacity reduction performed by $\mathrm{R} 1234 \mathrm{ze}(\mathrm{E})$ reaches high values, between $25 \%$ and $28 \%$, due to the effect of mass flow rate reduction and, to a lesser degree, a small reduction in refrigerating effect. Finally, the cooling capacity of R450A is slightly lower than R134a, between $8 \%$ and $10 \%$. This reduction is mostly influenced by refrigerating effect reduction (easily visible in Figure 3. 3).
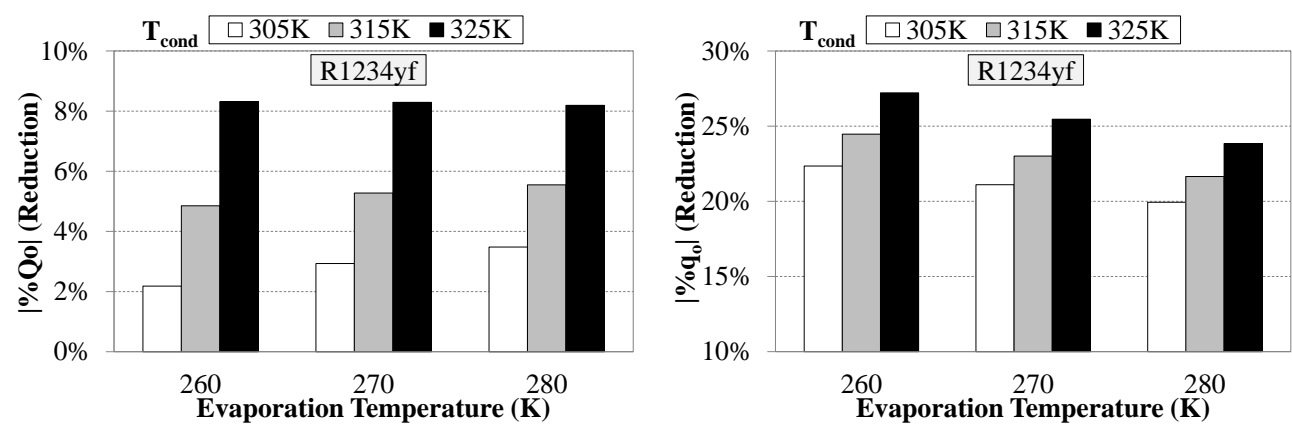

a) 

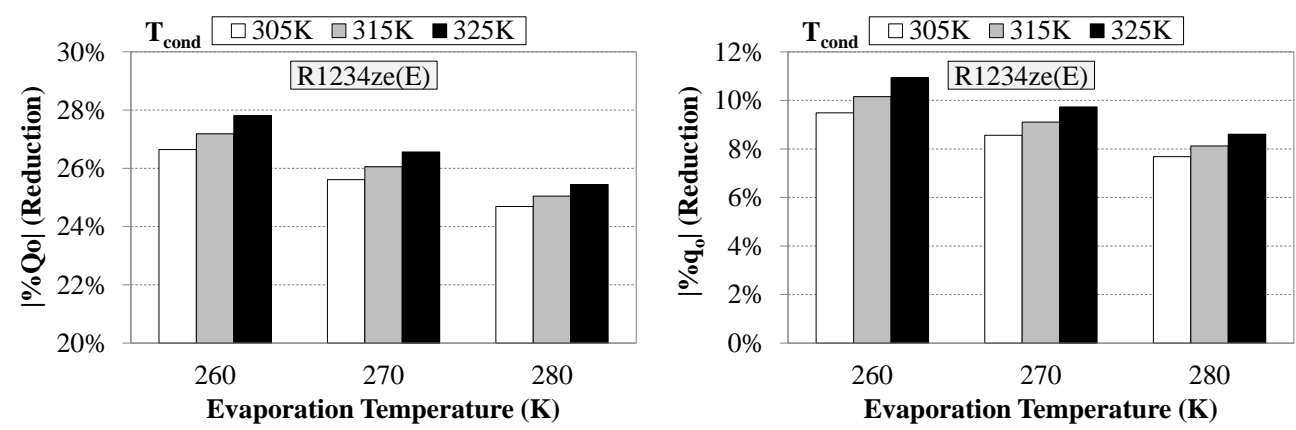

b)
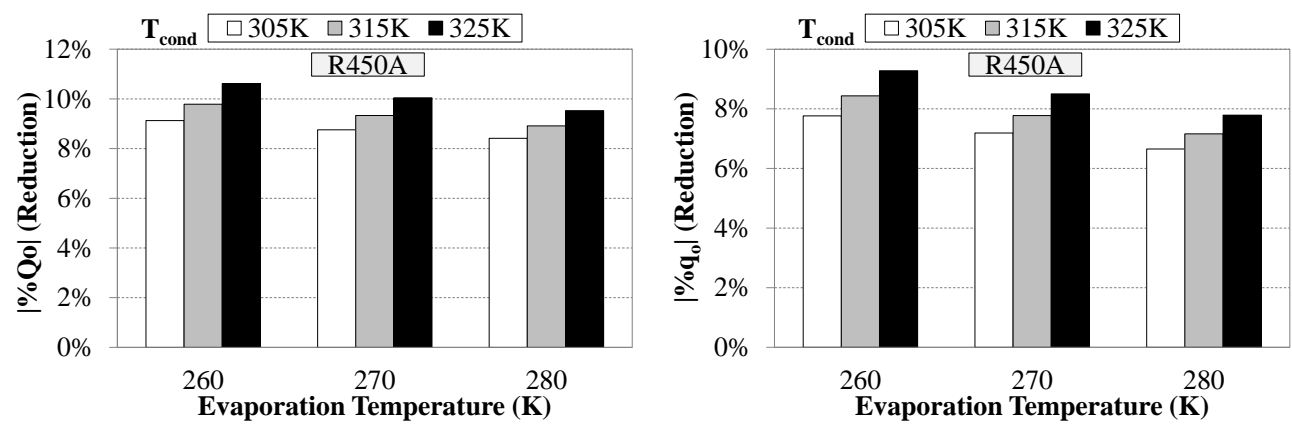

c)

Figure 3. 6. Theoretical cooling capacity and refrigerating effect reduction between R134a and: a) R1234yf, b) R1234ze(E) and c) $R 450 \mathrm{~A}$

\subsubsection{Coefficient of performance}

The last parameter analysed in this section is the COP, Figure 3. 7. The variation of refrigerating effect and mass flow rates has been studied before. So, in this section, the analysis of the isentropic compression work has been also included.

Although R1234yf and R450A cooling capacities are close to those of R134a, slightly lower, both alternatives perform under R134a in all conditions. The R1234yf COP reduction is comprised between 2 and $8 \%$ (same situation that cooling capacity) and for $\mathrm{R} 450 \mathrm{~A}$ the COP reduction is almost negligible, between 0.5 and 2\%. R1234ze(E) COP is close to that of R134a or even greater at high evaporation temperatures. 
Analysis of fluoride fluids with low global warming impact in vapour compression systems. Experimental evaluation of different alternatives for commercial refrigeration.
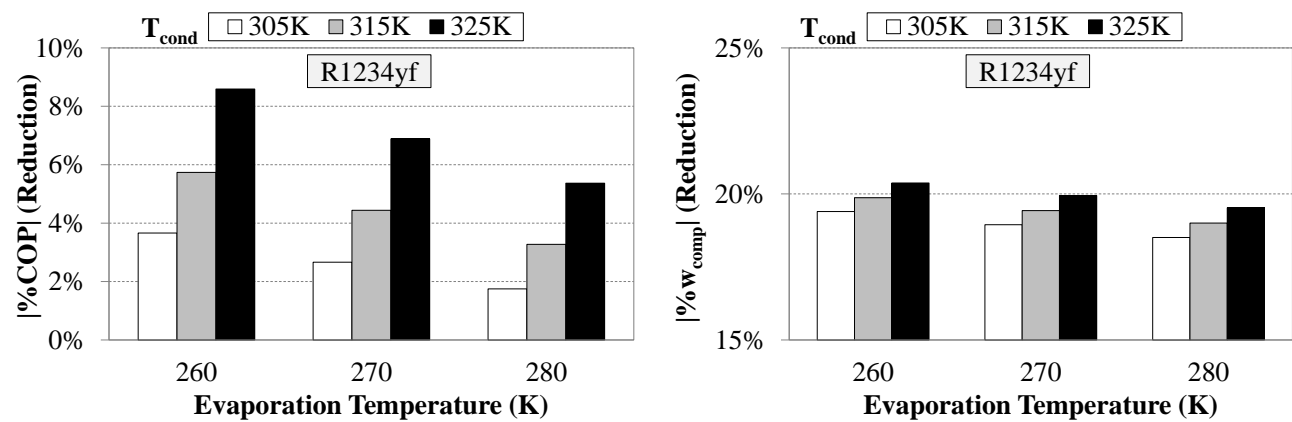

a)
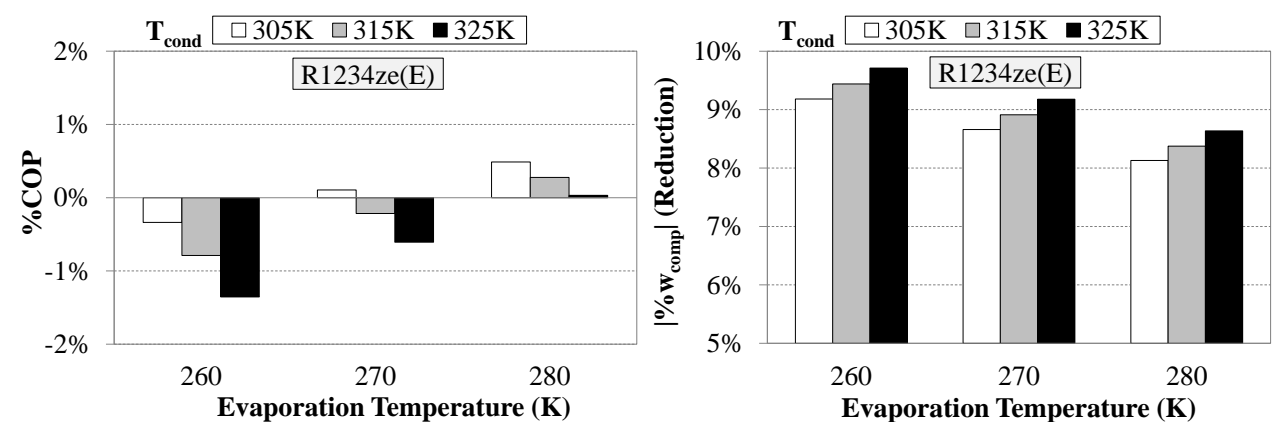

b)
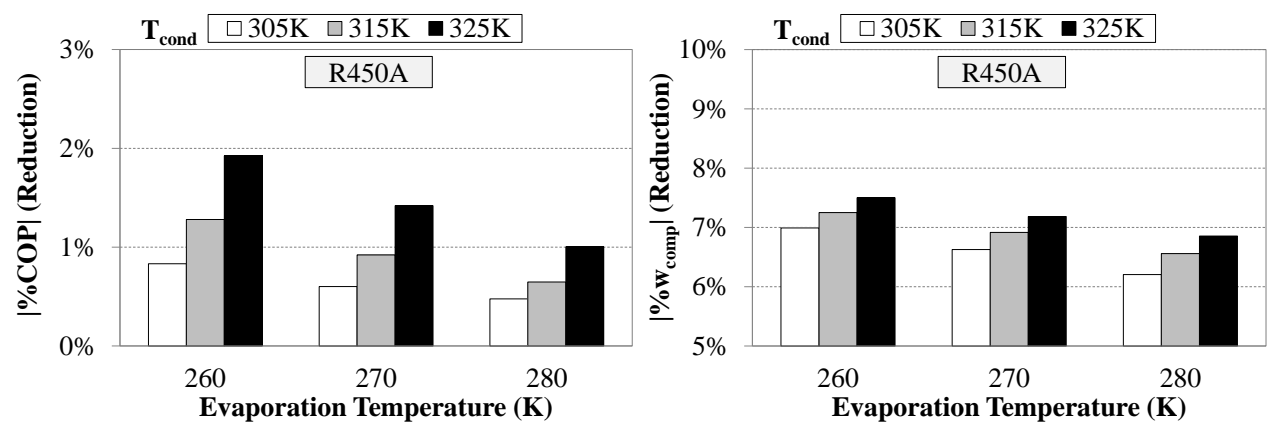

c)

Figure 3. 7. Theoretical COP deviation between R134a and: a) R1234yf (reduction), b) R1234ze(E) and c) R450A (reduction) 
Chapter 3. Theoretical Analysis.

The power consumption deviation results can be extracted considering either the COP divided by the cooling capacity (Equation 3. 7.) or as the product of isentropic compression work by the mass flow rate (Equation 3. 8.).

$\mathrm{R} 1234 \mathrm{yf}$ isentropic compression work is more than $15 \%$ lower than that of R134a, due to lower R1234yf inclination of the isentropic line so, regarding the mass flow rate values, the power consumption of R1234yf is modestly lower and diminishes even more with the increase of CR. The reduction for R1234ze(E) cooling capacity and compressor power consumption is very similar because its energy efficiency values match those of R134a (similar refrigerating effect and isentropic compression work decrease, even though the R1234yf inclination of the isentropic lines is lightly greater) than that of R134a. R450A power consumption is also lower than that of R134a, but not enough to consider R450A a more energy efficient fluid in refrigeration systems (slightly greater refrigerating effect than isentropic compression work decrease).

\subsection{Theoretical results of comparison between $R 404 \mathrm{~A}$ and alternatives}

In the same way that the previous section, where R134a and alternatives were considered, R404A and R448A are theoretically compared by terms of mass flow rate, cooling capacity and COP.

\subsubsection{Mass flow rate}

Mass flow rate of R448A is considerably lower than that of R404A, pushed down by the effect of the lower density of its former refrigerants, Figure 3. 8. These values are between 23 and $26 \%$ at 240 and $265 \mathrm{~K}$, respectively. 
Analysis of fluoride fluids with low global warming impact in vapour compression systems. Experimental evaluation of different alternatives for commercial refrigeration.

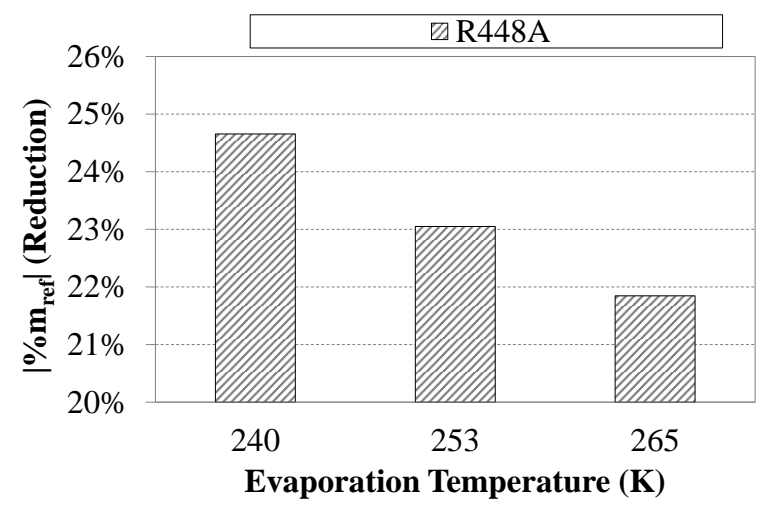

Figure 3. 8. Theoretical mass flow rate reduction between R404A and R448A

As it was exposed before, in the basis of the analysis, the much lower R448A theoretical mass flow rate indicated here is exclusively due to the diminution in suction density (Figure 3. 9), property that should be considered in the analysis of the VCS components.

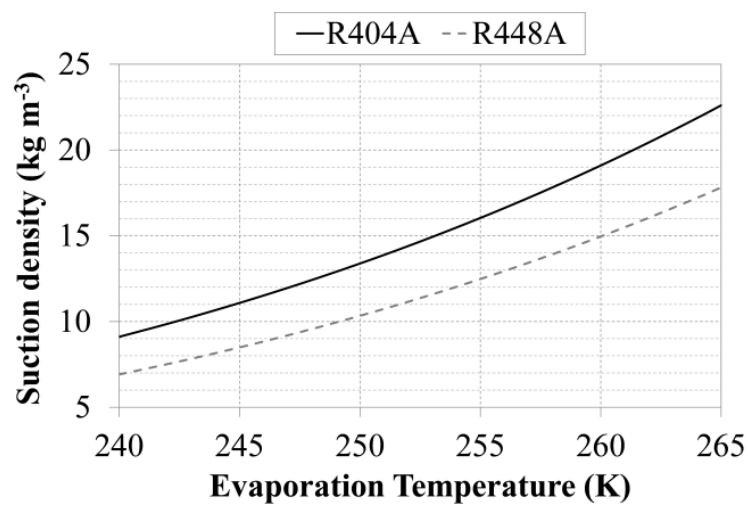

Figure 3. 9. Suction density for $\mathrm{R} 404 \mathrm{~A}$ and $\mathrm{R} 448 \mathrm{~A}$ ( $\mathrm{SH}=7 \mathrm{~K}$, no pressure drops)

\subsubsection{Cooling capacity}

Cooling capacity of R448A is always higher than that of R404A even though the mass flow rate was considerably lower, Figure 3. 10, as a consequence of the higher refrigerating effect shown by R448A at the operating range analysed, between $30 \%$ and 
$50 \%$. The R448A cooling capacity increment compared to R404A is unappreciable at low condensation temperatures and around $9-12 \%$ at high condensation temperatures.
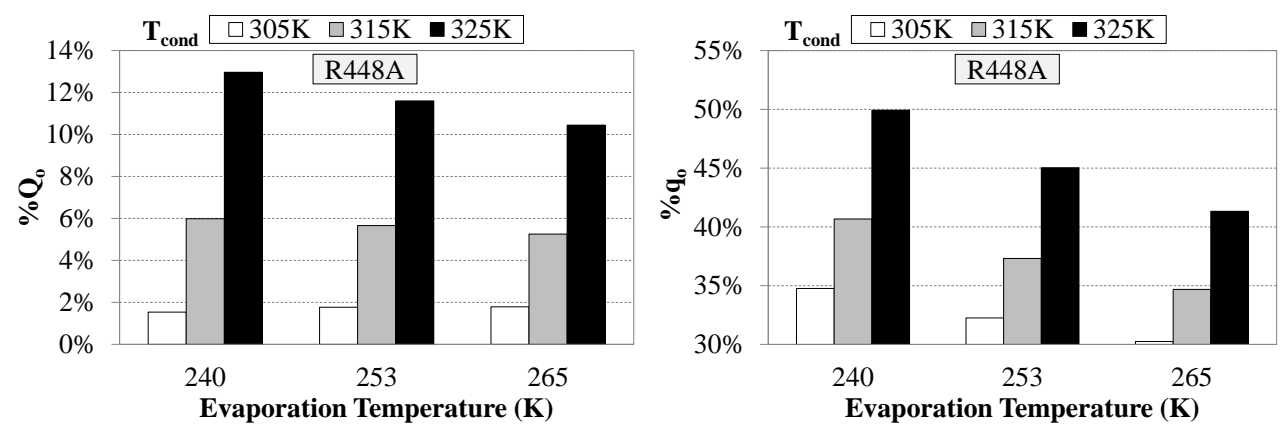

Figure 3. 10. Theoretical cooling capacity and refrigerating effect deviation between R404A and R448A

\subsubsection{Coefficient of performance}

Theoretically R448A is more efficient that R404A, following the trend observed in cooling capacity, Figure 3. 11. The deviation is even increased due to $4 \%$ lower R448A power consumption, motivated by lower mass flow rate, even though the isentropic compression work of R448A is significantly higher than that of R404A (greater CR and lower isentropic line inclination).
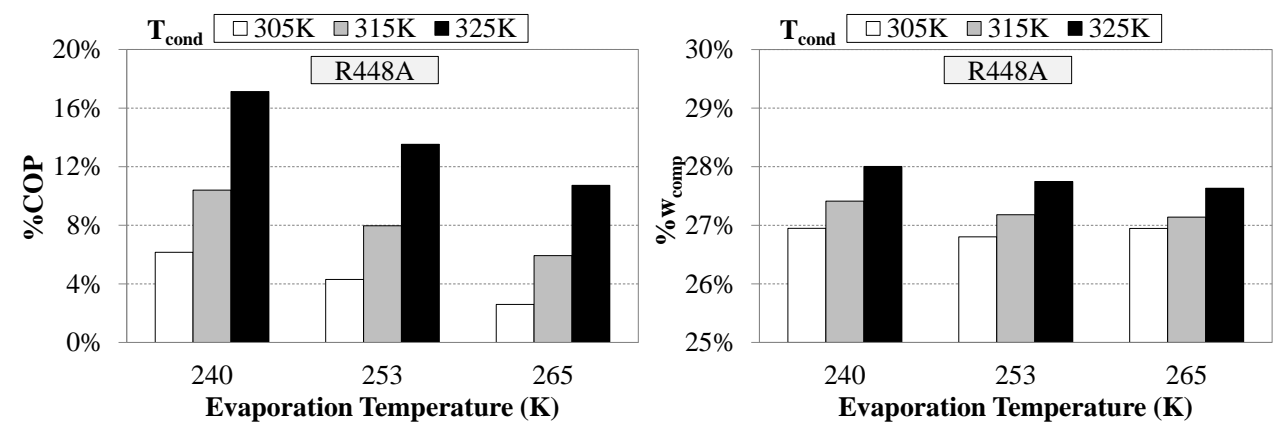

Figure 3. 11. Theoretical COP deviation between R404A and R448A 
Analysis of fluoride fluids with low global warming impact in vapour compression systems. Experimental evaluation of different alternatives for commercial refrigeration.

As it happens for cooling capacity, R448A COP is remarkable higher at high condensation temperatures (between 11 and 17\%) and remains between 3 and $6 \%$ at low condensation temperature.

Thus, the compressor power consumption of R448A is lower than that of R448A, especially at low evaporating temperature (freezing conditions). The decrease can be explained regarding to higher COP increase than cooling capacity decrease, or in terms of mass flow reduction and isentropic compression work influence. 


\subsection{Conclusions Chapter 3}

This chapter has theoretically justified the consideration of R1234yf, R1234ze(E) and R450A; and R448A as drop-in or light retrofit low-GWP alternatives to R134a and R404A. Being all of them proposed for experimental evaluation.

They have similar pressures at the same operating temperatures, so the components designed for R134a and R404A refrigeration installations can be used for the alternatives (according to the literature review performed before, the materials and the lubrication oil are also compatible with the new fluids). CR differences are small enough to use the existing compressor in the experimental tests with the substitutes.

Using the same swept volume, the mass flow rates theoretically observed for R134a alternative are quite different than those obtained for the reference fluid. R1234yf presents very higher mass flow rates, R1234ze(E) very lower and R450A similar to R134a. R1234yf and R450A could be used as drop-in or light retrofit replacements for R134a due to slightly lower cooling capacity (up to $10 \%$ below). However, R1234ze(E) cooling capacity diminution is so great that demands relevant system modifications (for example compressor substitution). Finally, the energy performance, quantified using the COP, indicates that R1234ze(E) and R450A can provide energy savings with the substitution of R134a, meanwhile R1234yf only approximates R134a COP at low CRs.

Moreover, R448A shows lower mass flow rate than R404A but very promising energetic results (higher cooling capacity and COP than R404A). 
Analysis of fluoride fluids with low global warming impact in vapour compression systems. Experimental evaluation of different alternatives for commercial refrigeration. 


\section{Chapter 4}

\section{Experimental}

\section{Procedure}

The theoretical performance of the alternatives to R134a (R1234yf, R1234ze(E) and $\mathrm{R} 450 \mathrm{~A}$ ) and R404A (R448A) have been analysed using a theoretical basic vapour compression cycle in the previous chapter. The theoretical study has proved that these working fluids can be promising HFCs substitutes (either drop-in or retrofit) with acceptable performance results.

This chapter describes the process of testing these refrigerants in a fully monitored vapour compression plant. It includes a detailed description of the test bench, a validation of the measurements, the test operating conditions and the methodology. The experimental work is carried out without any system modification (except a thermal expansion valve adjustment to maintain the superheating degree). 
Analysis of fluoride fluids with low global warming impact in vapour compression systems. Experimental evaluation of different alternatives for commercial refrigeration.

\subsection{Experimental setup}

The experimental tests are carried out in a VCS available by ISTENER research group at Thermal Machines and Heat Engines laboratory of the University Jaume I, Figure 4. 1.

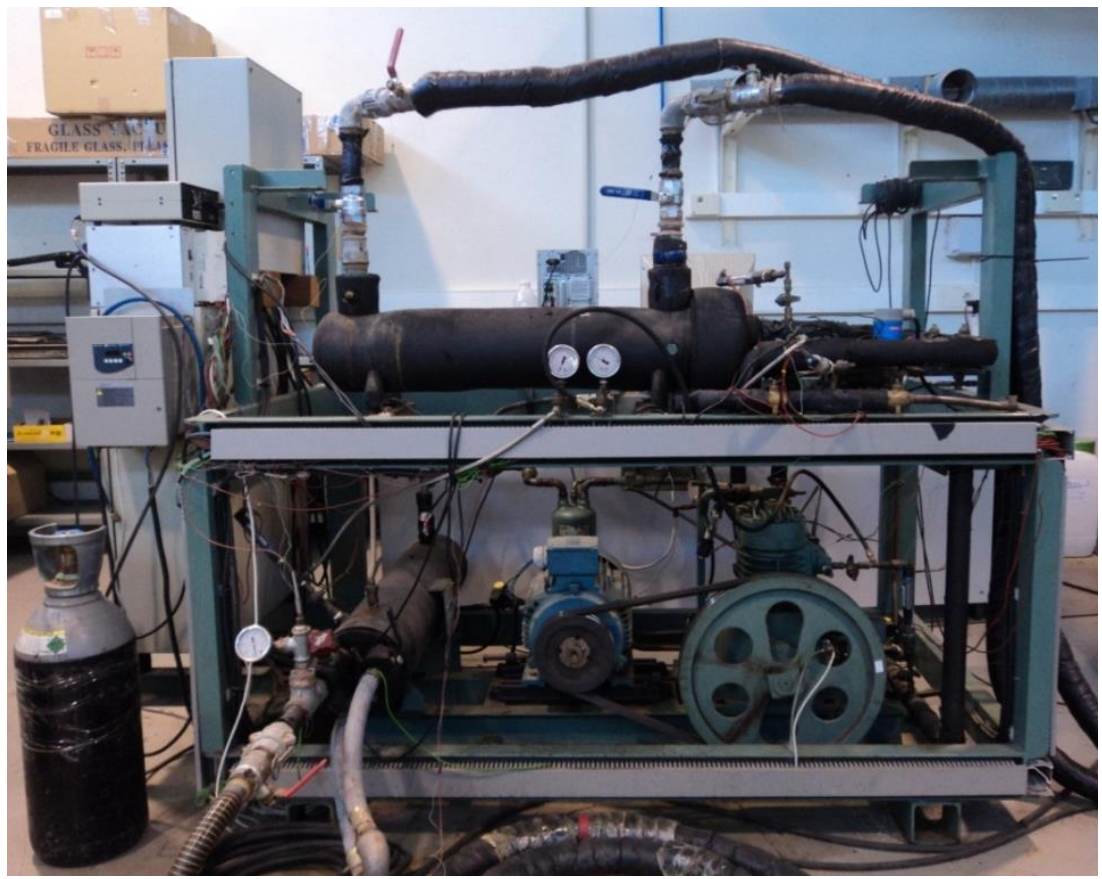

Figure 4. 1. Experimental test bench

The complete test bench consists of a main circuit, VCS, and two secondary circuits.

The main components of the experimental setup and the location of the elements are presented in Figure 4. 2. 


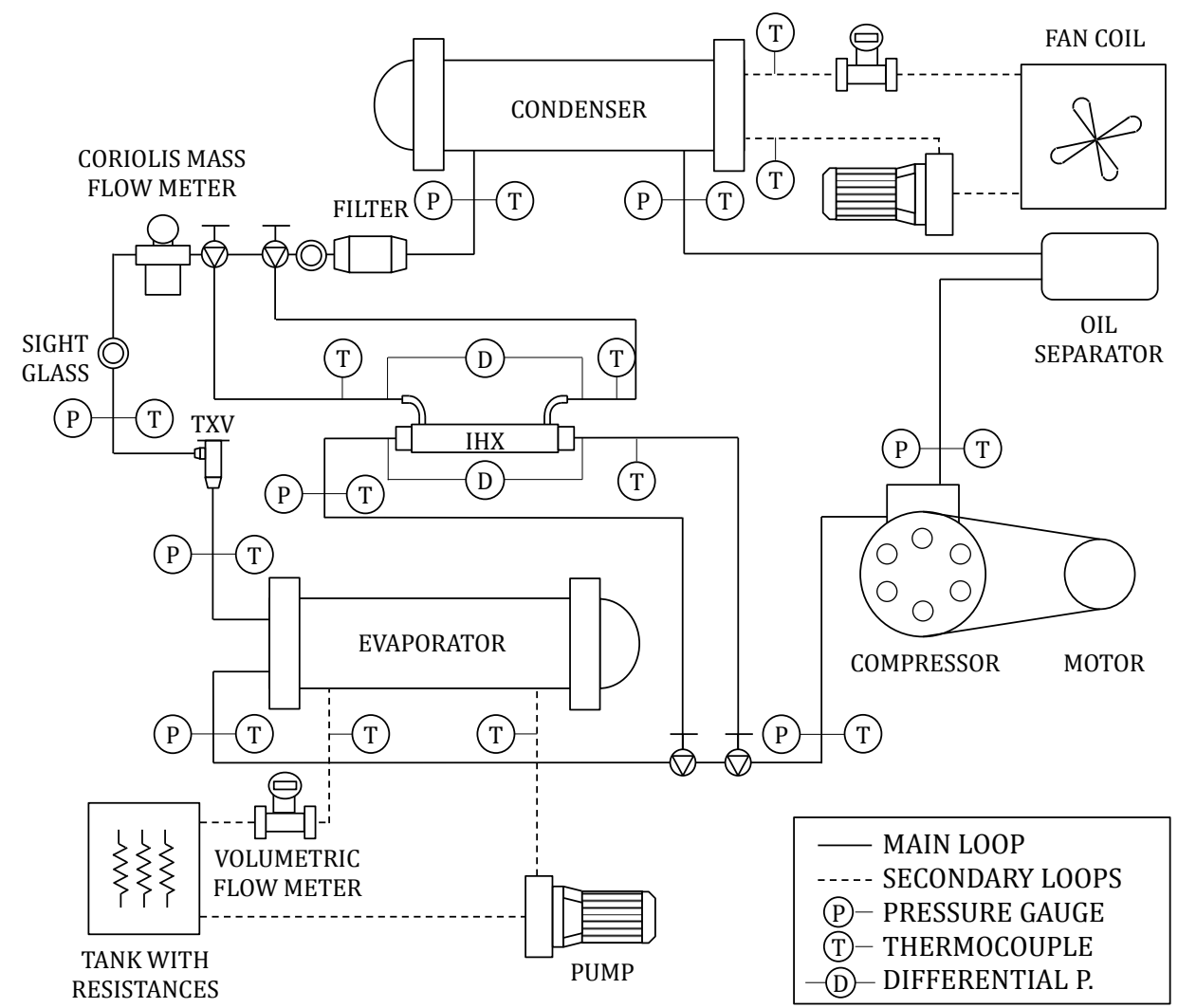

Figure 4. 2. Test bench scheme

\subsubsection{Main circuit}

The main circuit of the experimental setup consists of (Figure 4. 3):

- an open-type compressor Bitzer $\mathrm{V}$, driven by an $7.5 \mathrm{~kW}$ electric motor (equipped with a frequency inverter);

- R404A and R134a Danfoss TXVs;

- a shell-and-tube condenser (1-2) Cofrica RS-25, with an external thermal exchange area of $2.87 \mathrm{~m}^{2}$ where the refrigerant flows inside the shell and the secondary fluid across the tubes;

- an isolated counterflow tube-in-tube IHX; 
Analysis of fluoride fluids with low global warming impact in vapour compression systems. Experimental evaluation of different alternatives for commercial refrigeration.

- and an isolated shell-and-tube evaporator (1-2) ONDA TE/17 with an external thermal exchange area of $1.81 \mathrm{~m}^{2}$ where the refrigerant flows across the microfinned tubes and the secondary fluid along the shell.

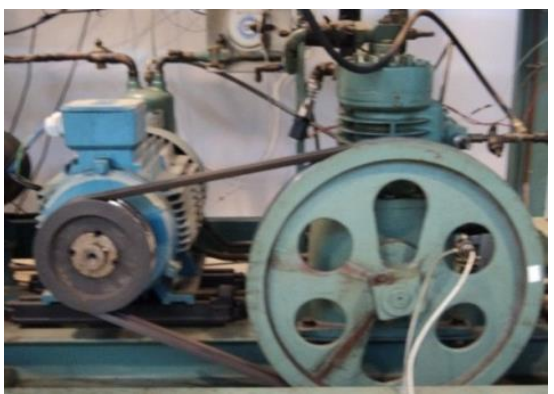

a) Open-type compressor

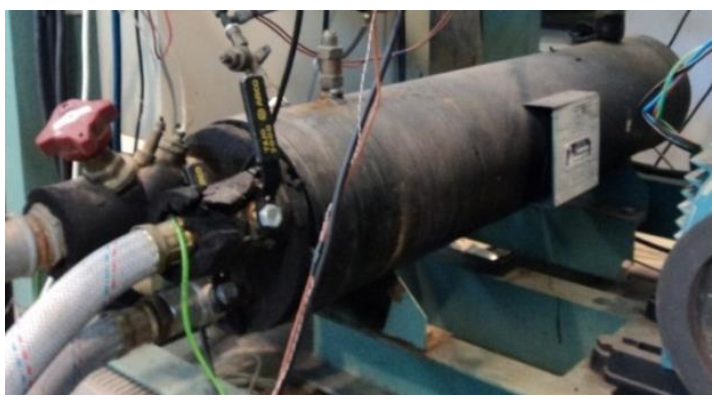

c) Shell-and-tube condenser (1-2)

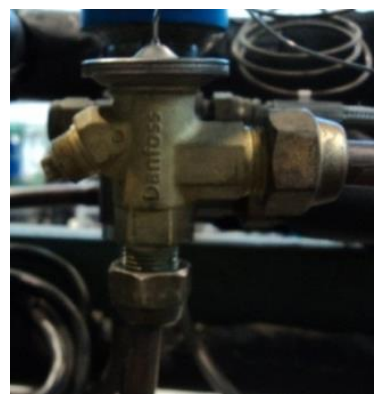

b) TXV

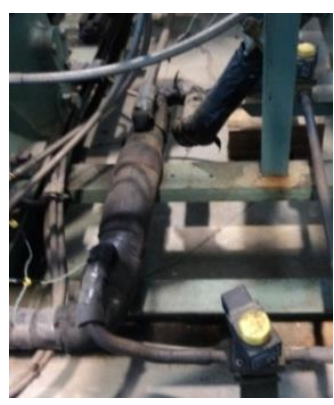

d) IHX

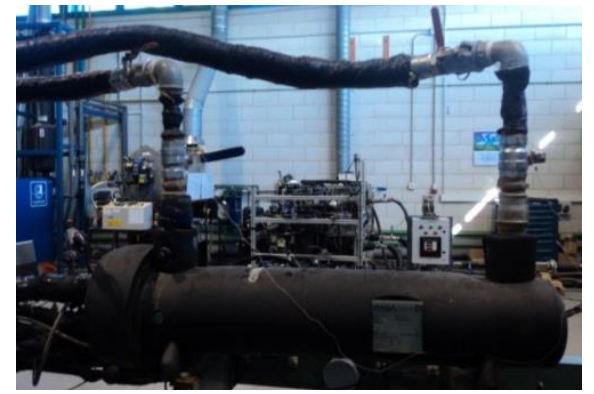

e) Isolated shell-and-tube evaporator (1-2)

Figure 4. 3. Main components of the experimental setup 
The compressor is an open-type reciprocating compressor, typically used with R134a and $\mathrm{R} 404 \mathrm{~A}$ for low and medium temperatures of refrigeration systems and in the range of low and medium compressor power input [216], Table 4. 1.

Table 4. 1. Recommendation of compressors for various refrigerants and applications [216]

\begin{tabular}{lcccccc}
\hline & \multicolumn{3}{c}{ LT } & \multicolumn{3}{c}{ MT } \\
Fluid & \multicolumn{3}{c}{ Compressor power input } & \multicolumn{2}{c}{ Compressor power input } \\
& $<\mathbf{1 k W}$ & $\mathbf{1 0 k W}$ & $>\mathbf{1 0 k W}$ & $<\mathbf{2 k W}$ & $\leq \mathbf{2 0 k W}$ & $>\mathbf{2 0 k W}$ \\
\hline R22, R134a & recip & Recip & screw & recip, vane & recip & screw \\
R404A, R507A & recip & Recip & screw & recip & recip & screw \\
\hline
\end{tabular}

The geometrical characteristics of the compressor are shown in Table 4. 2 .

Table 4. 2. Main characteristics of the compressor

\begin{tabular}{ll}
\hline Motor pulley $(\mathrm{m})$ & 0.180 \\
Cylinder number & 2 \\
Cylinder bore $(\mathrm{m})$ & 0.085 \\
Cylinder stroke $(\mathrm{m})$ & 0.060 \\
Oil type & POE \\
Oil charge $\left(\mathrm{m}^{3}\right)$ & 0.025 \\
\hline
\end{tabular}

The main characteristics of the shell-and-tube condenser are shown in Table 4. 3 and the schematic diagram is shown in Figure 4. 4. 
Analysis of fluoride fluids with low global warming impact in vapour compression systems. Experimental evaluation of different alternatives for commercial refrigeration.

Table 4. 3. Main characteristics of the condenser

\begin{tabular}{ll}
\hline Number of tube passes & 2 \\
Bundle tube count for pass & 20 \\
Number of baffles & 4 \\
Tube internal diameter $(\mathrm{m})$ & 0.013 \\
Tube external diameter $(\mathrm{m})$ & 0.016 \\
Pitch/tube diameter ratio & 1.22 \\
External thermal exchange area $\left(\mathrm{m}^{2}\right)$ & 2.87 \\
Shell internal diameter $(\mathrm{m})$ & 0.183 \\
Shell external diameter $(\mathrm{m})$ & 0.195 \\
\hline
\end{tabular}

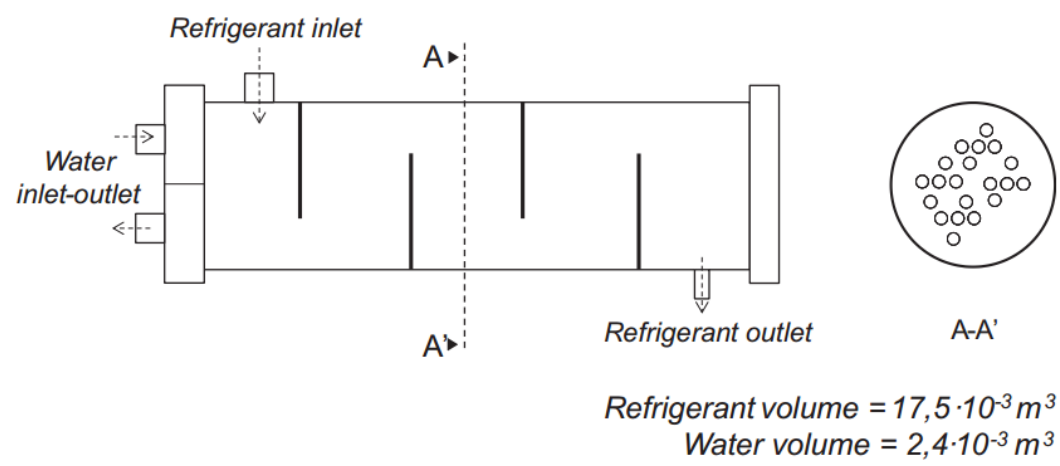

Figure 4. 4. Shell-and-tube condenser inner structure and fluid path

The main characteristics of the shell-and-tube evaporator are shown in Table 4.4 and a schematic diagram is shown in Figure 4. 5. 
Table 4. 4. Main characteristics of the evaporator

\begin{tabular}{ll}
\hline Total number of tubes & 76 \\
Number of tube passes & 2 \\
Number of shell passes & 1 \\
Inner tube diameter (m) & 0.00822 \\
Outside tube diameter (m) & 0.00952 \\
Number of micro-fins & 30 \\
Fin height (m) & $2 \cdot 10^{-4}$ \\
Helix angle $\left(^{\circ}\right)$ & 18 \\
Inner shell diameter (m) & 0.131 \\
Tube length (m) & 0.8182 \\
Transverse tube spacing (m) & 0.01142 \\
Clearance between tubes (m) & 0.0019 \\
Number of baffles & 5 \\
Tube material & Copper \\
\hline
\end{tabular}
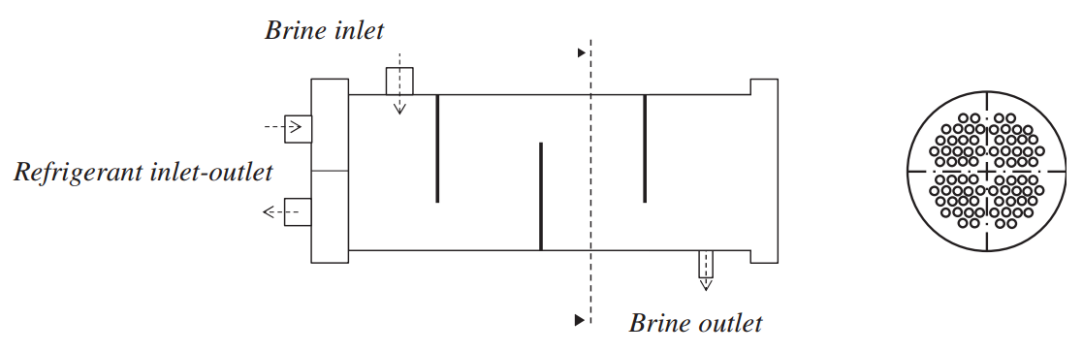

Figure 4. 5. Shell-and-tube evaporator inner structure and fluid path

\subsubsection{Secondary circuits}

The secondary circuits (discontinuous line in Figure 4. 2) allow simulating a wide range of evaporating and condensing conditions and they consist of the heat removal circuit and the heat load circuit (Figure 4. 6). 
Analysis of fluoride fluids with low global warming impact in vapour compression systems. Experimental evaluation of different alternatives for commercial refrigeration.

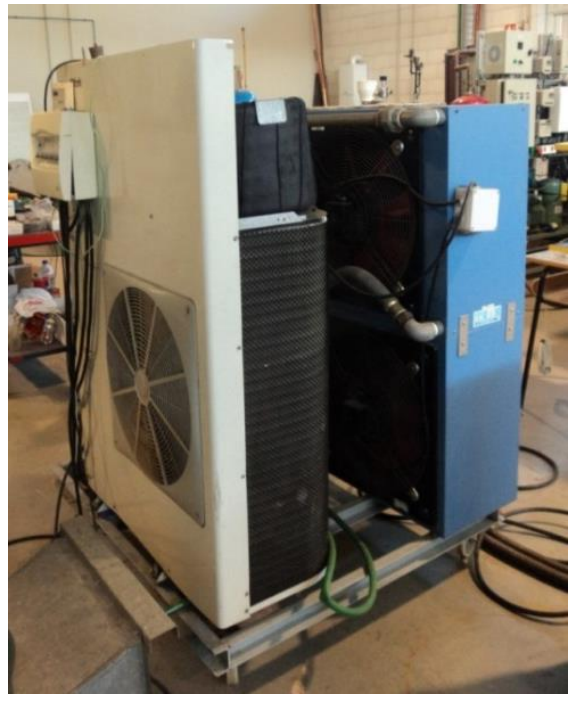

a) Heat removal circuit

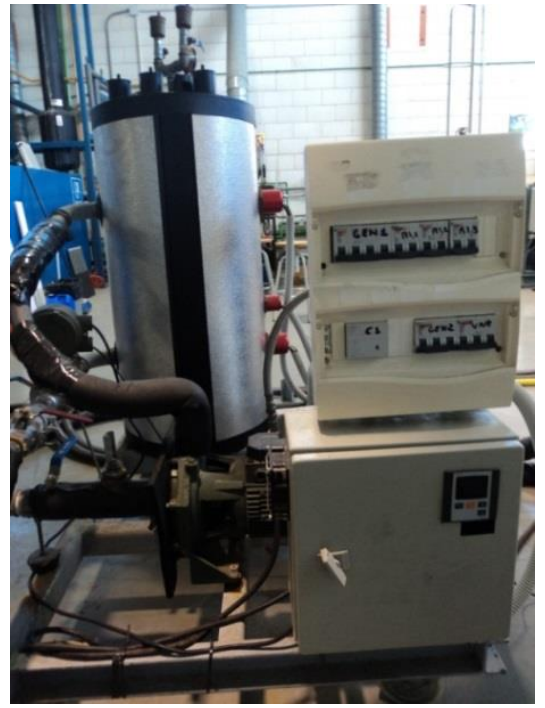

b) Heat load circuit

Figure 4. 6. Secondary circuits

The heat removal circuit, using water as secondary fluid, consists on a dry cooler with a variable-speed fan and a chiller.

The heat load circuit is formed by a set of electrical resistances $(15 \mathrm{~kW})$ immersed in an isolated tank (the temperature is settled by a PID controller) and a variable frequency pump, being the fluid employed a commercial water/glycol mixture (Luzar Orgánico 50\%, ASTM D 1177 freezing temperature of 236K).

\subsubsection{Sensors}

To collect the operating parameters information and allow performance calculations, the test rig is instrumented as follows (Figure 4.7 and Figure 4. 8):

- 8 pressure transducers are located at the inlet and outlet of each main component. 
- 15 thermocouples are positioned at the inlet and outlet of each main component, the secondary circuits and the last one measures ambient temperature.

- A Coriolis-effect flow meter can be found in the liquid line by-pass.

- Two volumetric flow meters are placed in the secondary circuits (allows calculating heat transfer balance in heat exchangers).

- Two differential pressure transducers in both flows of the IHX (liquid and gas).

- Electric motor power consumption is also measured using a Wattmeter.

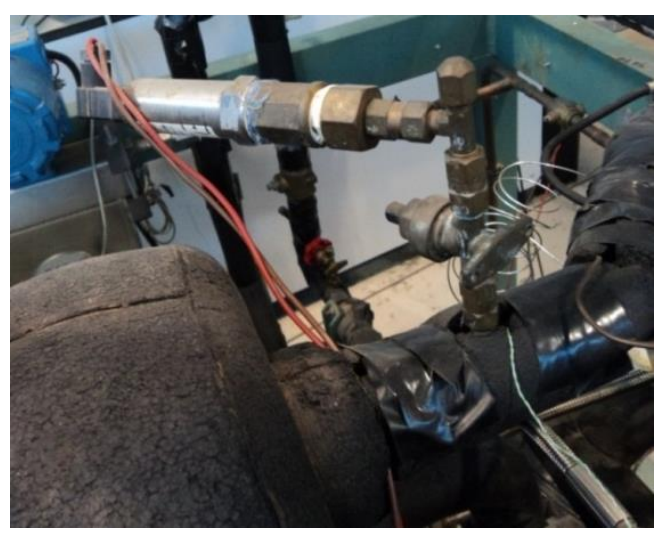

Figure 4. 7. Thermocouple and pressure transducer

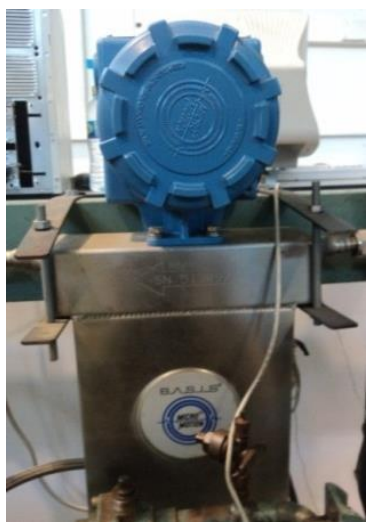

a) Coriolis-effect flow meter

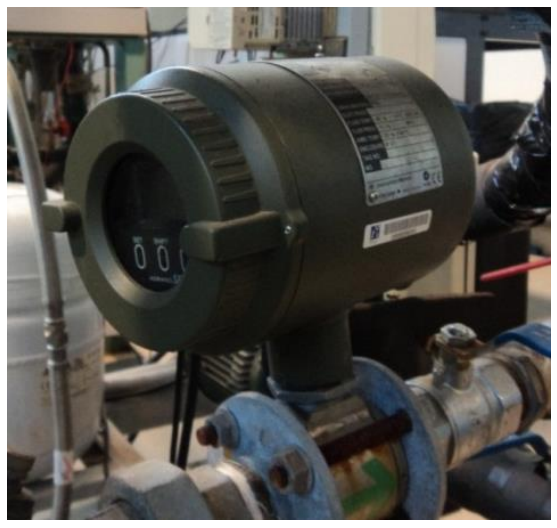

b) Volumetric flow meters

Figure 4. 8. Flow meters 
Analysis of fluoride fluids with low global warming impact in vapour compression systems. Experimental evaluation of different alternatives for commercial refrigeration.

Details about the sensors employed are given in Table 4. 5. All of them are calibrated in the laboratory installations.

Table 4. 5. Sensors information

\begin{tabular}{|c|c|c|}
\hline Measured parameters & Sensor & Uncertainty \\
\hline Temperatures $(\mathrm{K})$ & K-type thermocouples & $\pm 0.3 \mathrm{~K}$ \\
\hline Pressures $(\mathrm{kPa})$ & $\begin{array}{l}\text { Piezoelectric pressure } \\
\text { transducers }\end{array}$ & $\pm 7 \mathrm{kPa}$ \\
\hline Mass flow rate $\left(\mathrm{kg} \mathrm{s}^{-1}\right)$ & $\begin{array}{l}\text { Coriolis mass flow } \\
\text { meter }\end{array}$ & $\pm 0.22 \%$ (rate) \\
\hline Electric motor power consumption $(\mathrm{kW})$ & Digital wattmeter & $\pm 0.152 \%$ (rate) \\
\hline $\begin{array}{l}\text { Volumetric flow rate }\left(\mathrm{m}^{3} \mathrm{~s}^{-1}\right) \\
\text { Range: } 147.28 \cdot 10^{-6}-4908.61 \cdot 10^{-6}\end{array}$ & $\begin{array}{l}\text { Electromagnetic flow } \\
\text { meters }\end{array}$ & $\pm 0.33 \%$ (range) \\
\hline
\end{tabular}

All data measured are gathered with a National Instruments data acquisition system and it is monitored and stored through a Personal Computer. The chassis selected is the NI cDAQ-9188, in which is connected a 16-Channel Thermocouple Input Module, NI 9213, and two Analog Input Module (8 Channel and 16-Bit), NI 9203. The NI 9203 modules are used for the rest of measurements (pressures, mass flow rate, electric motor power consumption and volumetric flow rates).

Again, the thermodynamic states of the refrigerant are obtained from REFPROP 9.1 [212] database, using the measured pressures and temperatures.

The cooling capacity and COP uncertainties are calculated using the Root Sum Square (RSS) method [217] (Equation 4. 1) and they are presented in the experimental results chapter. 


$$
\varepsilon_{\text {parameter }}=\sqrt{\sum_{i=1}^{n}\left|\frac{\partial f(\text { parameter })}{\partial x_{i}}\right|^{2} \varepsilon_{\text {instrument }, i}^{2}} \quad \text { Equation 4. } 1
$$

Where,

- $\varepsilon_{\text {parameter }}$ is the related error to the parameter studied,

- $f$ is a function that describes the parameter,

- $x_{i}$ is the independent variables of the function $f$,

- $\varepsilon_{\text {instrument }, i}^{2}$ refers the uncertainty associated to the instrument that measures the variable $x_{i}$.

\subsection{Test procedure}

\subsubsection{Validation of collected data}

The process of selecting a steady state test consists on taking a time period of $20 \mathrm{~min}$, with a sample period of $0.5 \mathrm{~s}$, in which the condensing and evaporating pressure are within an interval of $\pm 2.5 \mathrm{kPa}$. Furthermore, in these tests all the temperatures are within $\pm 0.5 \mathrm{~K}$ and refrigerant mass flow rate is within $\pm 0.0005 \mathrm{~kg}_{-} \mathrm{s}^{-1}$. Once a steady state is achieved (with approximately 2400 direct measurements), the data used are obtained averaging over a time period of $5 \mathrm{~min}$ (600 measurements). Figure 4.9 shows the variation about the mean value in a random test for the condensing pressure, the evaporating pressure, the superheating degree and the refrigerant mass flow rate. 
Analysis of fluoride fluids with low global warming impact in vapour compression systems. Experimental evaluation of different alternatives for commercial refrigeration.

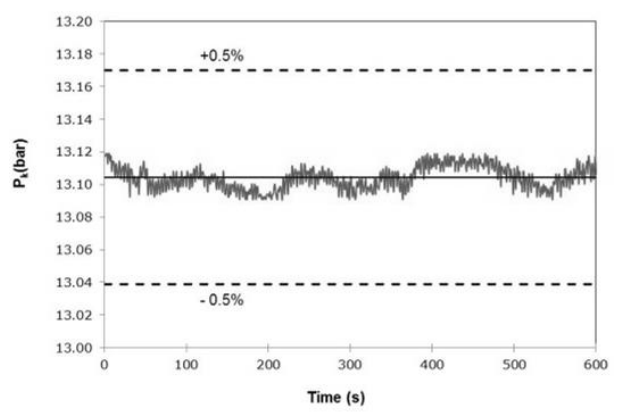

a) Condensation pressure

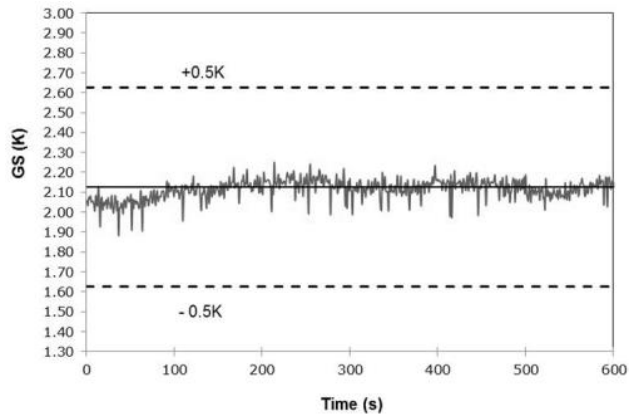

c) Subcooling degree

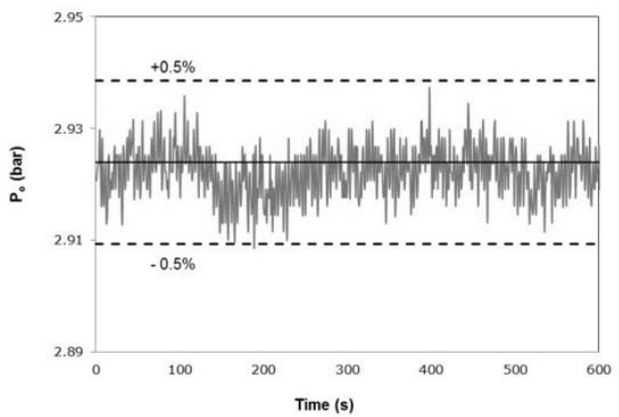

b) Evaporation pressure

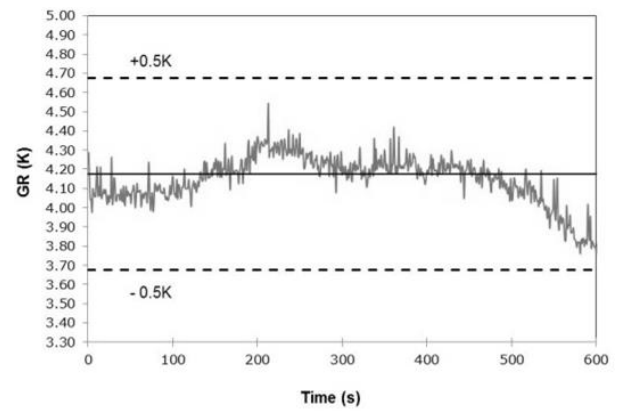

d) Superheating degree

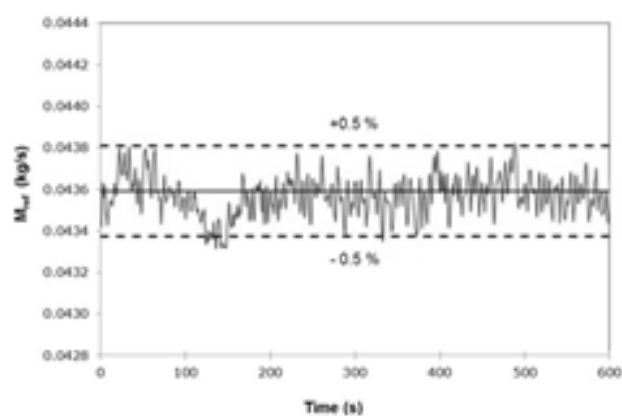

e) Refrigerant mass flow rate

Figure 4. 9. Steady state test monitored 


\subsubsection{Operating conditions}

The experimental tests are intended to present a complete range of R134a and R404A typical operating situations. To compare the experimental results with those obtained theoretically, the operating conditions are the same as those considered before. The experimental test conditions are as follows:

- R134a evaporation temperature: 260/270/280K. Corresponding to MT (food conservation).

- R404A evaporation temperature: 240/253/265. Corresponding to LT and MT (food freezing and conservation).

- Condensation temperature: 305/315/325K. Simulates different ambient conditions: either from cold to warm countries, or from winter to summer conditions.

- IHX off. The available IHX has not been activated since it is not typically used in PCRRSs.

- The superheating degree is fixed in $7 \mathrm{~K}( \pm 1 \mathrm{~K}$ variation) adjusting the $\mathrm{R} 134 \mathrm{a}$ and R404A TXV.

- The refrigerant charge was optimised, remaining the subcooling degree at a constant value of $2 \mathrm{~K}( \pm 1 \mathrm{~K}$ variation).

- The POE lubricant is BSE32 (recommended by the compressor manufacturer up to $328 \mathrm{~K})$. It is miscible under typical refrigeration conditions and was the same for all refrigerants tested.

The glide effects on heat exchangers are also considered to calculate the evaporation and condensation temperatures, and the superheating of the zeotrope mixtures. The equations used to obtain the corrections were exposed in Chapter 3. 
Analysis of fluoride fluids with low global warming impact in vapour compression systems. Experimental evaluation of different alternatives for commercial refrigeration.

\subsection{Methodology}

The analysed parameters in the experimental comparison are the mass flow rate, cooling capacity, $\mathrm{COP}$ and discharge temperature.

The mass flow rate is directly measured using the Coriolis-effect flow meter and it is affected by the volumetric efficiency, Equation 4. 2 and Equation 4. 3.

$$
\begin{gathered}
\eta_{\text {volumetric }}=\frac{\dot{m}_{\text {ref,real }}}{\dot{m}_{\text {ref,theoretical }}} \\
\dot{m}_{\text {ref,theoretical }}=\rho_{\text {suction }} V_{G} \frac{N}{60}
\end{gathered}
$$

Equation 4. 3

The volumetric efficiency is defined as the ratio between the experimental and the theoretical mass flow rate for the same conditions. The volumetric efficiency is mainly affected by the refrigerant properties, the compressor geometry and speed, the suction conditions and the condensing pressure. In this way, maintaining constant the compressor speed and the superheating degree, the volumetric efficiency depends on the refrigerant and the compression ratio.

The refrigerant side cooling capacity depends on the mass flow rate (previous section) and the refrigerating effect. The refrigerating effect is almost the same to the theoretically presented (could be slightly deviated by the sensors uncertainty or the $\pm 1 \mathrm{~K}$ deviation in superheating and subcooling degree). Thus, the experimental cooling capacity $\left(\dot{Q}_{o}\right)$ is calculated using Equation 4. 4.

$$
\dot{Q}_{o}=\dot{m}_{r e f}\left(h_{\text {out }}-h_{\text {in }}\right)_{o}
$$

Equation 4. 4 
In this case, for the evaporator enthalpy inlet, the enthalpy at the inlet of expansion valve is taken (the expansion valve is considered adiabatic). The enthalpy at the evaporator outlet is obtained using the pressure and temperature measurements. The evaporator enthalpy difference $\left(\left(h_{o u t}-h_{i n}\right)_{o}\right)$ is also known as refrigerating effect. Furthermore, the evaporator thermal balances are shown in Figure 4. 10.

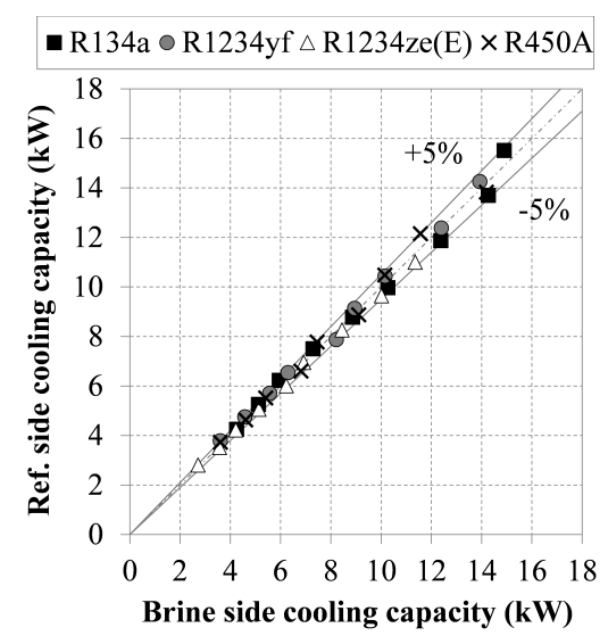

a)

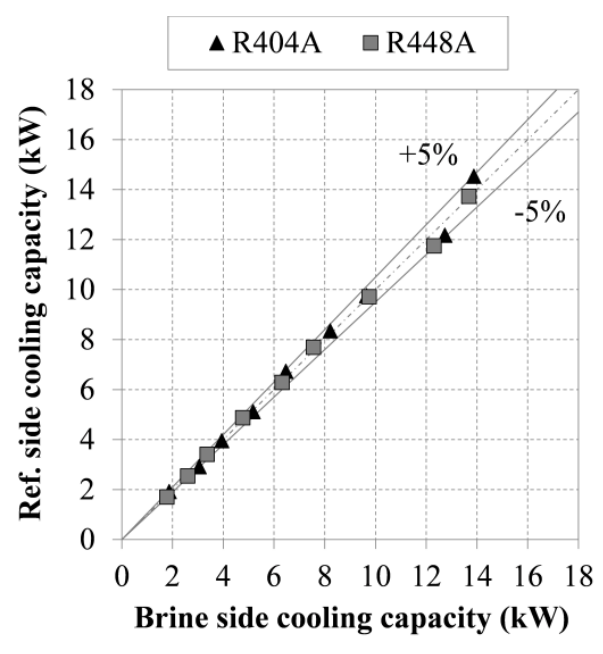

b)

Figure 4. 10. Evaporator thermal balances a) R134a and alternatives and b) R404A and its alternative

The energetic parameters used to evaluate the energetic performance of the refrigerants, COP is the ratio between the cooling capacity and the electric motor power consumption, Equation 4. 5. The electric motor power consumption $\left(P_{c}\right)$ is measured through a digital wattmeter.

$$
C O P=\dot{Q}_{o} / P_{c}
$$

Finally, the discharge temperature is measured using a K-type thermocouple. 
Analysis of fluoride fluids with low global warming impact in vapour compression systems. Experimental evaluation of different alternatives for commercial refrigeration.

Again, to facilitate the energetic comparison between the baselines (R134a and R404A) and the alternatives (R1234yf, R1234ze(E) and R450A for R134a; and R448A for $\mathrm{R} 404 \mathrm{~A})$, the results are shown as a relative deviation from baselines ( $\% \dot{Q}_{o}$ and $\% C O P$ ), Equation 3. 10 to Equation 3. 12. 


\subsection{Conclusions Chapter 4}

In this thesis, an experimental test bench is used to compare the performance of different promising alternatives to the most current used refrigerants in PCRRS systems. The use of this experimental setup allows performing a great amount of tests under a wide range of operating conditions, varying evaporation and condensation temperature, in order to cover the typical refrigeration operating range.

This chapter presents the experimental setup and exposes the methodology to obtain the tests and a validation of the experimental data. 
Analysis of fluoride fluids with low global warming impact in vapour compression systems. Experimental evaluation of different alternatives for commercial refrigeration.

\section{Chapter 5}

\section{Experimental results}

The experimental VCS facility used in this project and the experimental test methodology have been presented in the previous chapter. Therefore, once the theoretical analysis has been shown an initial estimation of the potential of the lowGWP refrigerants as alternatives to R134a and R404A, this chapter presents an experimental analysis of the energy performance of those alternative refrigerants in comparison to the reference fluids. In this way, the experimental results are analysed in terms of compressor volumetric efficiency, mass flow rate, cooling capacity, COP and compressor discharge temperature.

The organisation of the shown analysis is similar to the previous theoretical analysis, with the difference that the volumetric efficiency and the compressor discharge temperature analysis are included. The aim of the chapter is to conclude about the energy performance associated to the low-GWP fluids used as alternatives to R134a (R1234yf , R1234ze(E) and R450A) and R404A (R448A). 


\subsection{R134a and alternatives}

This section compares and discusses the experimental results obtained in the tests carried out with R134a, R1234yf, R1234ze(E) and R450A as working fluids.

\subsubsection{Mass flow rate}

The mass flow rate can be expressed as a function of the theoretical mass flow rate using the volumetric efficiency.

Figure 5. 1 shows the volumetric efficiency variation with the CR for each refrigerant. The figure presents the values of measured volumetric efficiency as a function of CR, as expressed in the literature and corroborated by the good agreement of a linear relationship between the volumetric efficiency and the CR is shown in Table 5. 1 .

Table 5. 1. Regression between $\eta_{v o l}$ and compression ratio and $\boldsymbol{R}^{2}$ resulting

\begin{tabular}{lcc} 
Working fluid & \multicolumn{1}{c}{$\boldsymbol{\eta}_{\text {vol }}$} & $\boldsymbol{R}^{2}$ \\
\hline R134a & $\mathrm{y}=-0.0390 \mathrm{x}+0.9556$ & 0.9549 \\
R1234yf & $\mathrm{y}=-0.0398 \mathrm{x}+0.9244$ & 0.9744 \\
R1234ze(E) & $\mathrm{y}=-0.0388 \mathrm{x}+0.9108$ & 0.9340 \\
R450A & $\mathrm{y}=-0.0378 \mathrm{x}+0.9393$ & 0.9267 \\
\hline
\end{tabular}


Analysis of fluoride fluids with low global warming impact in vapour compression systems. Experimental evaluation of different alternatives for commercial refrigeration.

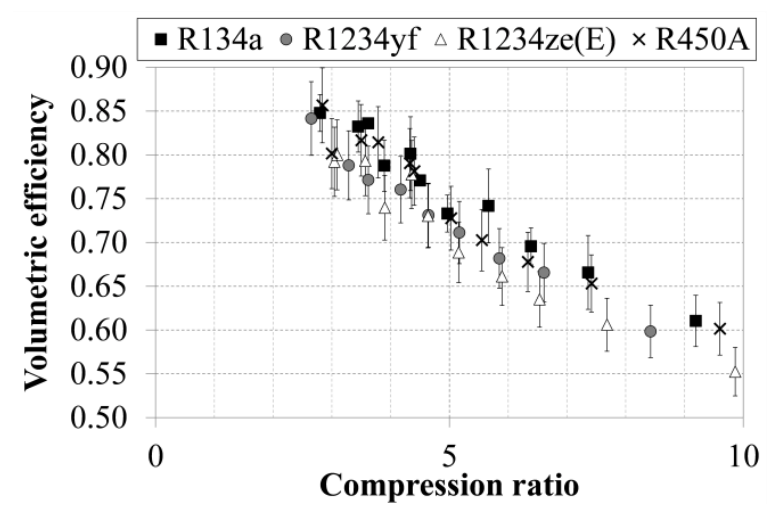

Figure 5. 1. Volumetric efficiency versus compression ratio

When CR is high (value of 8), the volumetric efficiency of R134a is around 3.8\% and 4.3\% higher than R1234yf and R1234ze(E). R450A are very close to that of R450A. The higher volumetric flow rate is associated with the alternative fluid R1234ze(E) (it presents the lowest suction density), and the pressure drops associated at the compressor can partially explain its lower values of volumetric efficiency. The values of volumetric efficiency presented by R450A, with volumetric flow rates similar to those of R134a, are close to R134a ones. In the case of R1234yf, the volumetric efficiency is between both alternatives. However, taking into account the uncertainties, no strong conclusions about volumetric efficiency of these can be extracted.

Theoretically, analysing the volumetric efficiency variations, this parameter can be expressed in the case of an isentropic compression as shown in Equation 5. 1. $E$ is the clearance volume and $\gamma$ is the heat capacity ratio, ratio between the isobaric $\left(c_{p}\right)$ and the isochoric heat capacity $\left(c_{V}\right)$.

$$
\eta_{\text {volumetric }}=1+E-E \cdot C R^{\frac{1}{\bar{\gamma}}}
$$

Equation 5.1 
Table 5. 2 shows the isentropic process volumetric efficiency obtained at the same condensation and evaporation temperatures, and at the same compression ratio (assuming $5 \%$ of clearance volume). The simulated conditions are also shown in table and the rest of assumptions are the same that the theoretical analysis.

Table 5. 2. Isentropic process volumetric efficiency of $134 a$ and its alternatives

\begin{tabular}{lcccccccc}
\hline \multirow{2}{*}{ Conditions } & \multicolumn{2}{c}{ R134a } & \multicolumn{2}{c}{ R1234yf } & \multicolumn{2}{c}{ R1234ze(E) } & \multicolumn{2}{c}{ R450A } \\
& $\mathrm{V}$ & $\eta_{\text {vol }}$ & $\mathrm{V}$ & $\eta_{\text {vol }}$ & $\mathrm{V}$ & $\eta_{\text {vol }}$ & $\mathrm{V}$ & $\eta_{\text {vol }}$ \\
\hline$T_{O}=270 \mathrm{~K}, T_{K}=315 \mathrm{~K}$ & 1.202 & 0.889 & 1.197 & 0.899 & 1.160 & 0.878 & 1.186 & 0.886 \\
$T_{O}=270 \mathrm{~K}, \mathrm{CR}=4$ & 1.201 & 0.891 & 1.205 & 0.892 & 1.158 & 0.884 & 1.185 & 0.889 \\
\hline
\end{tabular}

As it can be seen, there are not significant differences in volumetric efficiencies presented in Table 5. 2. Theoretically, slightly lower R1234ze(E) volumetric efficiency than that of R134a can be justified due to fluid properties.

In the theoretical analysis the great differences (positive and negative) in mass flow rate between the two pure HFOs and R134a have been exposed. Influenced by the suction density, R1234yf mass flow rate was theoretically higher than R134a, R1234ze(E) the opposite, and R450A slightly lower. The experimental tests present slight differences to these results, Figure 5. 2. 
Analysis of fluoride fluids with low global warming impact in vapour compression systems. Experimental evaluation of different alternatives for commercial refrigeration.

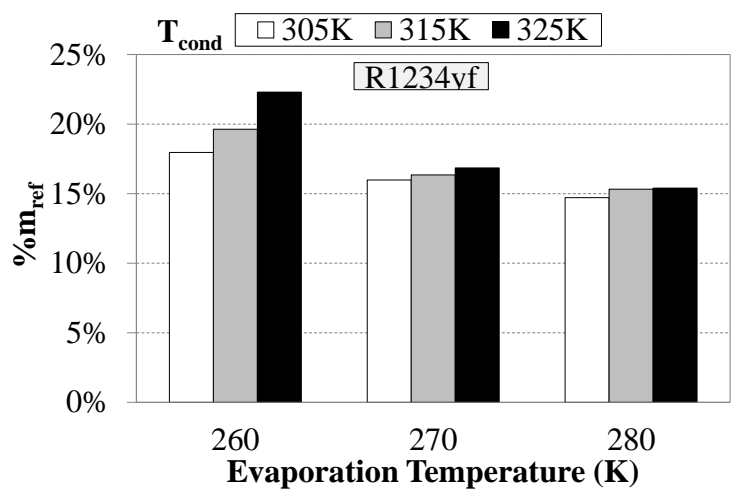

a)

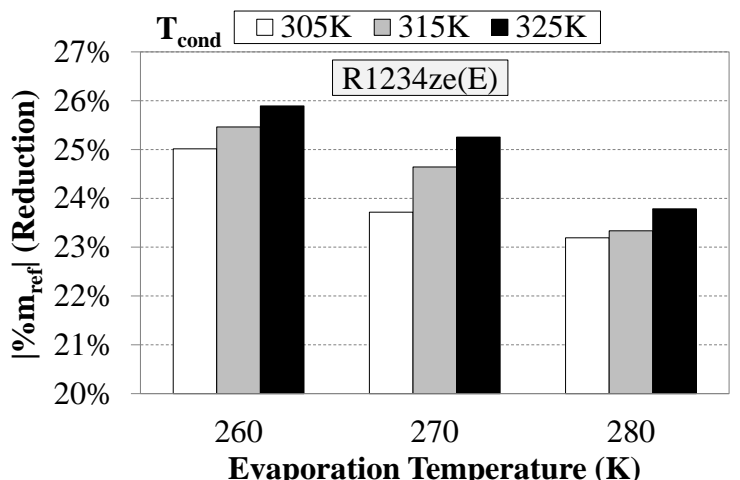

b)

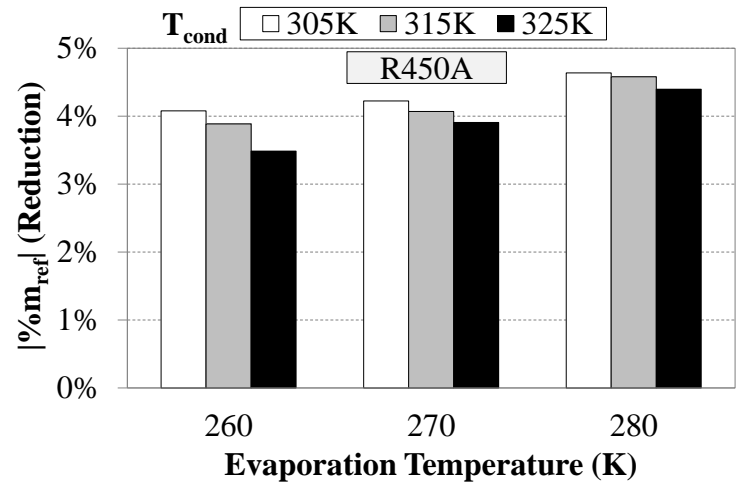

c)

Figure 5. 2. Experimental mass flow rate deviation between R134a and: a) R1234yf, b) $\mathbf{R} 1234 z e(E)$ (reduction) and c) $\mathbf{R 4 5 0 A}$ (reduction) 
The R1234yf mass flow rate increase is below that expected from the theoretical analysis. It is between $18 \%$ and $22 \%$ higher than that of R134a at $260 \mathrm{~K}$ and around $15.5 \%$ at $280 \mathrm{~K}$ (ideally it was $26 \%$ and $21 \%$ ). The influence of condensation temperature is mostly observed at lower evaporation temperatures (higher CR). The highest mass flow rate increase is observed at the highest CR conditions where the lowest volumetric efficiency difference takes place (0.5\%). This reduction in R1234yf mass flow rate gain (in comparison with the expected theoretically) is mainly due to major R1234yf pressure drops (which imply higher CR) and to the mentioned R1234yf loss in volumetric efficiency.

Unlike the theoretical study, the R1234ze(E) mass flow rate approximates to that of R134a. Indeed, this trend is the opposite of the observed when R1234yf and R134a were compared. The reason is that the volumetric efficiency difference between both fluids remains almost similar at the tested range. The major R1234ze(E) mass flow rate decrease is near $26 \%$ and the minor is $23 \%$ (theoretically were $26 \%$ and $21 \%$ ). In this case the suction line pressure drop is higher for R134a [218] and counteracts the R1234ze(E) volumetric efficiency reduction.

As it happens for the rest of R134a alternatives, the R450A mass flow rate deviation is lower than expected. So, the mass flow rate reduction is approximatelly $4 \%$, being lower at higher CRs (lower R450A mass flow rate reduction than expected theoretically). The trend followed is the same as that observed for R1234yf even though the volumetric efficiency reduction trend is the contrary. The R450A pressure drops are similar to those of R134a [218], so possibly the differences could be due to the sensor uncertainty. 
Analysis of fluoride fluids with low global warming impact in vapour compression systems. Experimental evaluation of different alternatives for commercial refrigeration.

\subsubsection{Cooling capacity}

Regarding to that depicted in the theoretical section (lower cooling capacity due to diminution in refrigerating effect for R1234yf and mass flow rate for R1234ze(E) and R450A) and experimental mass flow rate (values below theoretical), minor cooling capacity values are expected.

Figure 5. 3 shows the cooling capacity reduction obtained using R1234yf, R1234ze(E) and R450A as R134a drop-in replacement at different evaporation and condensation temperatures.

R1234yf is the refrigerant with lowest cooling capacity lessening, quantified by $8-12 \%$. Moreover, R1234yf cooling capacity reduction is between 4-6\% more than theoretical. The refrigerating effect is such that changes the trend observed in the mass flow rate comparison. Thus, the decrease grows with the condensation temperature increase and little difference is observed for evaporation temperature variation. These values in all the conditions tested are great enough to recommend at least minor system modifications when substituting R134a.

The most significant reduction in cooling capacity was observed when retrofitting R1234ze(E). Besides, R1234ze(E) was the fluid more affected by the mass flow rate reduction caused by the suction density and volumetric efficiency. Thus, the cooling capacity is reduced from $27 \%$ to $31-34 \%$ at $260 \mathrm{~K}$ and from $25 \%$ to $28-30 \%$ at $280 \mathrm{~K}$. The conclusions reached in the theoretical analysis can be applied also in this section, thereby confirming that R1234ze(E) needs large system modifications to be used in R134a systems if the same cooling capacity is pursued. 
An average reduction of $8 \%$ in refrigerating effect and $4 \%$ in mass flow rate leads the R450A cooling capacity between $10 \%$ and $11 \%$ below that of R134a. The deviation from theoretical values is smaller than the other fluids, justified by the lower volumetric efficiency difference and similar pressure drops to R134a. For R1234ze(E) and R450A (R1234ze(E) based alternatives), the cooling capacity reduction is higher at greater CRs (this trend agrees with theoretical results).

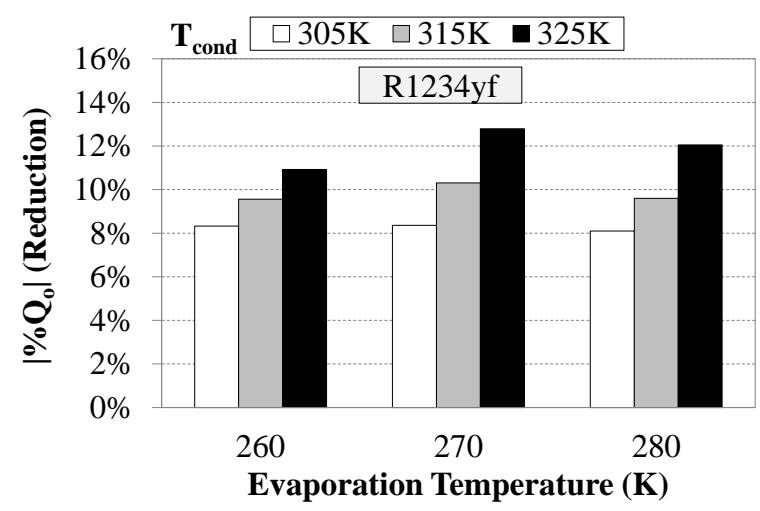

a)

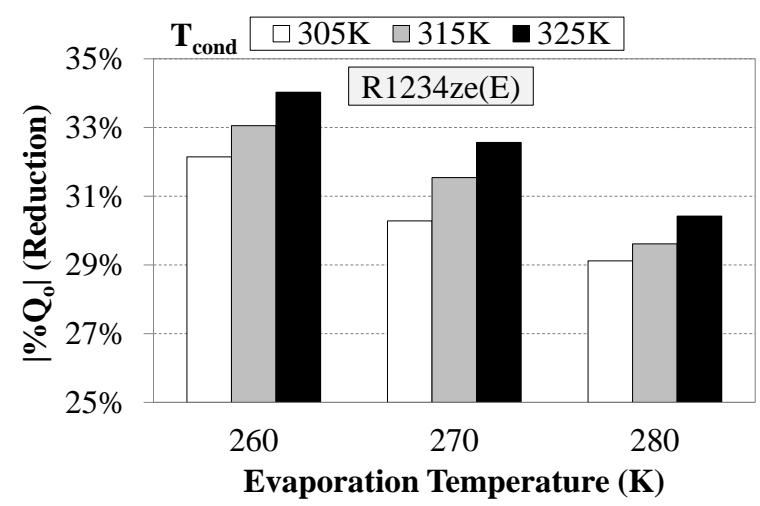

b) 
Analysis of fluoride fluids with low global warming impact in vapour compression systems. Experimental evaluation of different alternatives for commercial refrigeration.

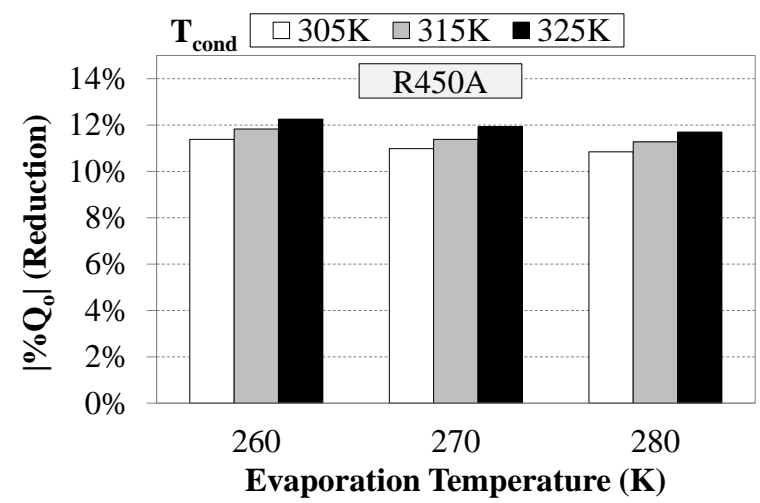

c)

Figure 5. 3. Experimental cooling capacity reduction between R134a and: a) R1234yf, b) R1234ze(E) and c) R450A

The reduction in cooling capacity for the alternatives is so great that the cooling capacity conclusions are not affected by the uncertainties. The average cooling capacity uncertainty (Equation 4. 1) of R134a, R1234ze(E) and R450A remains around 1.6\% and that of R1234yf is $1.9 \%$, Table 5. 3.

Table 5. 3. Cooling capacity uncertainty for R134a and its alternatives

\begin{tabular}{llcccc}
\hline $\mathbf{T}_{\text {evap }}(\mathbf{K})$ & $\mathbf{T}_{\text {cond }}(\mathbf{K})$ & $\mathbf{R 1 3 4 a}$ & $\mathbf{R 1 2 3 4 y f}$ & $\mathbf{R 1 2 3 4 z e}(\mathbf{E})$ & $\mathbf{R 4 5 0 A}$ \\
\hline \multirow{2}{*}{260} & 305 & $1.42 \%$ & $1.74 \%$ & $1.44 \%$ & $1.46 \%$ \\
& 315 & $1.54 \%$ & $1.84 \%$ & $1.57 \%$ & $1.60 \%$ \\
& 325 & $1.68 \%$ & $2.07 \%$ & $1.70 \%$ & $1.76 \%$ \\
270 & 305 & $1.39 \%$ & $1.66 \%$ & $1.41 \%$ & $1.42 \%$ \\
& 315 & $1.48 \%$ & $1.78 \%$ & $1.52 \%$ & $1.55 \%$ \\
& 325 & $1.64 \%$ & $2.01 \%$ & $1.65 \%$ & $1.72 \%$ \\
230 & 305 & $1.44 \%$ & $1.76 \%$ & $1.48 \%$ & $1.49 \%$ \\
& 315 & $1.57 \%$ & $1.93 \%$ & $1.62 \%$ & $1.67 \%$ \\
& 325 & $1.67 \%$ & $2.05 \%$ & $1.70 \%$ & $1.76 \%$ \\
\hline
\end{tabular}




\subsubsection{Coefficient of performance}

In this section, the experimental measurements of COP are shown in Figure 5. 4. Even if the motor electrical consumption deviation can be deduced from cooling capacity and COP, those figures are also added to this section to justify the COP variation.

The theoretical analysis presented good energy efficiency results for R1234ze(E) and R450A (greater than R134a in some conditions). However R1234yf energy efficiency is always theoretically below that of R134a. These values are influenced by a great amount of factors (irreversibilities), and given the experimental cooling capacity results lower COP values can be expected.

Pulled by the cooling capacity fall (the motor electrical consumption is similar), the R1234yf COP is lower than that obtained using R134a, between $-8 \%$ and $-12 \%$ at $260 \mathrm{~K}$ and $-6 \%$ and $-10 \%$ at $280 \mathrm{~K}$. The reduction from theoretical results is the same as that observed in cooling capacity (4\%), so the compressor efficiencies between R1234yf and R134a can also be considered similar. The maximum approach of the R1234yf COP to that of R134a occurs at the lowest CR.

The other pure HFO alternative, R1234ze(E), displayed better energy efficiency results than R1234yf but they are not high enough to overcome R134a COP. The rising R1234ze(E) COP deviation obtained in the theoretical section has been considerably reduced $(11 \%)$. As refrigerant unsuitable for drop-in substitution, the electric motor consumption was also notably lower than using R134a, around 28\%. The COP reduction reported was between $5 \%$ and $9 \%$ at $260 \mathrm{~K}$ but between $1 \%$ and $4 \%$ at $280 \mathrm{~K}$. 
Analysis of fluoride fluids with low global warming impact in vapour compression systems. Experimental evaluation of different alternatives for commercial refrigeration.

The COP deviation using R450A as drop-in replacement for R134a is reported in Figure 5. 4. As far as the comparison among the different refrigerants is concerned, it can be noted that the R450A COP obtained is similar to that obtained using R134a and taking into account the COP uncertainties cannot be extracted deeper conclusions. As it happened with the cooling capacity, power consumption was also reduced (between $10 \%$ and $12 \%$ ) so R450A COP matches that of R134a.
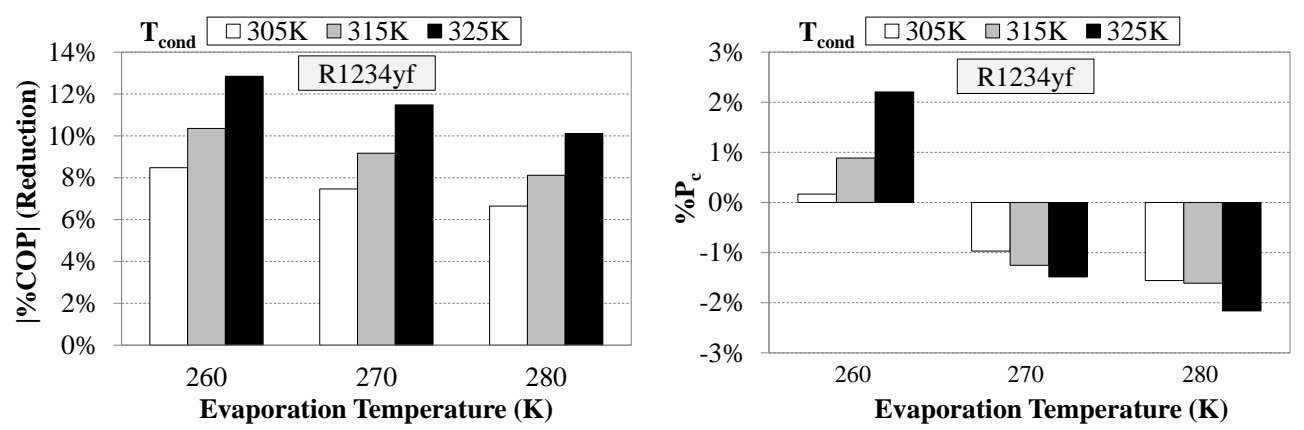

a)
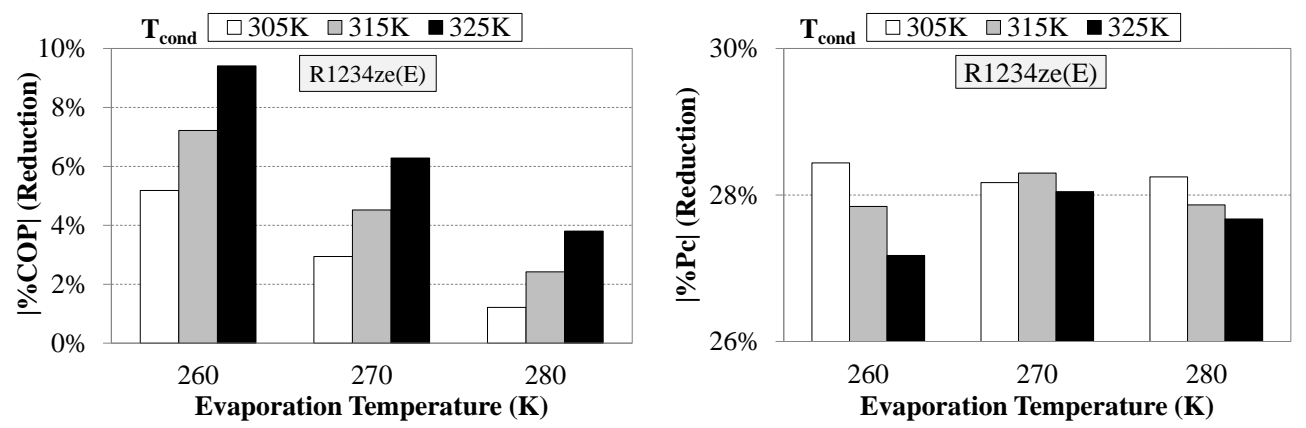

b) 

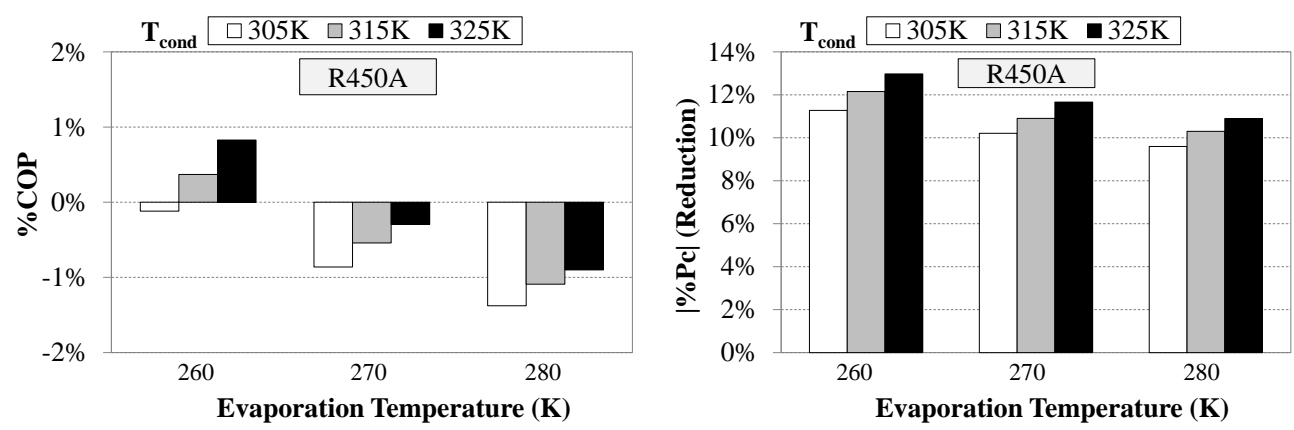

c)

Figure 5. 4. Experimental COP and $P_{c}$ deviation (or reduction) between R134a and: a) R1234yf, b) R1234ze(E) and c) R450A

The uncertainty for COP is lower than that of the cooling capacity due to the good precision of power consumption measurements (Equation 4. 1), Table 5. 4. The average values for R134a, R1234ze(E) and R450A are around $0.9 \%$ and for R1234yf around $1.1 \%$.

Table 5. 4. COP uncertainty for R134a and alternatives

\begin{tabular}{llcccc}
\hline $\mathbf{T}_{\text {evap }}(\mathbf{K})$ & $\mathbf{T}_{\text {cond }}(\mathbf{K})$ & $\mathbf{R 1 3 4 a}$ & $\mathbf{R 1 2 3 4 y f}$ & $\mathbf{R 1 2 3 4 z e}(\mathbf{E})$ & $\mathbf{R 4 5 0 A}$ \\
\hline \multirow{2}{*}{260} & 305 & $0.86 \%$ & $1.02 \%$ & $0.87 \%$ & $0.88 \%$ \\
& 315 & $0.92 \%$ & $1.07 \%$ & $0.93 \%$ & $0.95 \%$ \\
& 325 & $0.99 \%$ & $1.19 \%$ & $1.00 \%$ & $1.03 \%$ \\
\hline \multirow{2}{*}{270} & 305 & $0.84 \%$ & $0.98 \%$ & $0.86 \%$ & $0.86 \%$ \\
& 315 & $0.89 \%$ & $1.04 \%$ & $0.91 \%$ & $0.92 \%$ \\
& 325 & $0.97 \%$ & $1.16 \%$ & $0.98 \%$ & $1.01 \%$ \\
280 & 305 & $0.82 \%$ & $0.95 \%$ & $0.84 \%$ & $0.84 \%$ \\
& 315 & $0.87 \%$ & $1.00 \%$ & $0.86 \%$ & $0.89 \%$ \\
& 325 & $0.96 \%$ & $1.13 \%$ & $0.95 \%$ & $1.00 \%$ \\
\hline
\end{tabular}


Analysis of fluoride fluids with low global warming impact in vapour compression systems. Experimental evaluation of different alternatives for commercial refrigeration.

Regarding the high uncertainty obtained for the global compressor efficiency (between 2 and 4\%) and the proximity of the values (Figure 5. 5), this parameter cannot be used to extract conclusions about its influence on the COP.

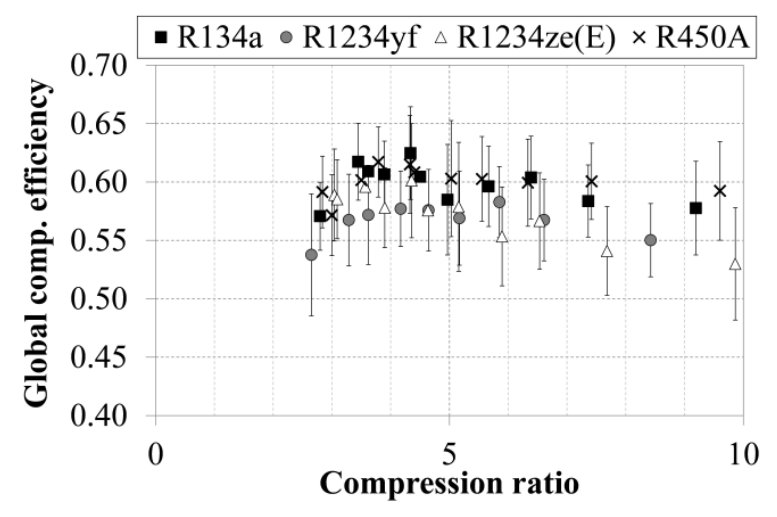

Figure 5. 5. Compressor global efficiency for R134a and its alternatives

\subsubsection{Compressor discharge temperature}

Finally, in drop-in or retrofit comparisons, the compressor discharge temperature is another important parameter to analyse. If the compressor discharge temperature reaches very high values, worn rings, acid formations and oil break down or carbonisation can occur, reducing the compressor lifespan.

The maximum compressor discharge temperature is given by the compressor manufacturer, being usually limited at $380 \mathrm{~K}$ (395K should be never reached) in the refrigeration applications. Lower compressor discharge temperatures ensure better lubrication and longer compressor life so the compressors VCS always operate more than $10 \mathrm{~K}$ below the limits. 
Maintaining the superheating degree and the compressor rotational speed, the compressor discharge temperature depends on the suction conditions, condensing pressure and refrigerant characteristics (isentropic lines, commented in theoretical chapter).

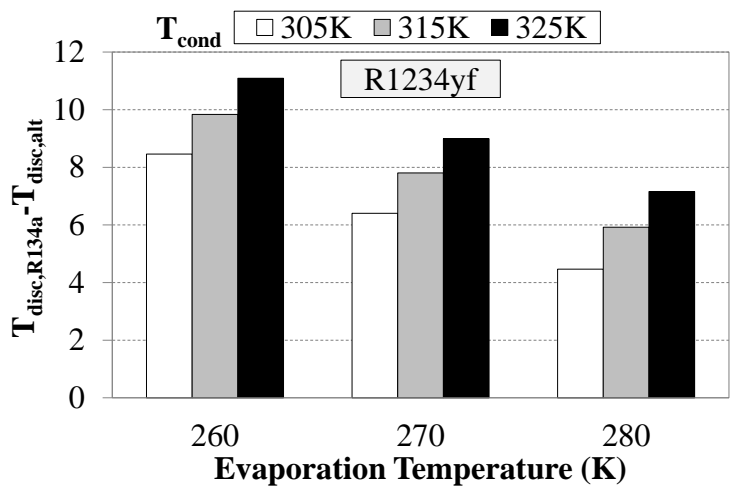

a)

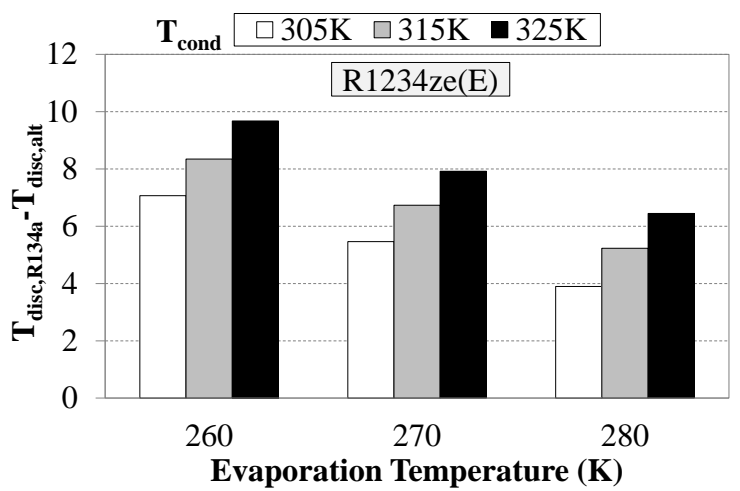

b) 
Analysis of fluoride fluids with low global warming impact in vapour compression systems. Experimental evaluation of different alternatives for commercial refrigeration.

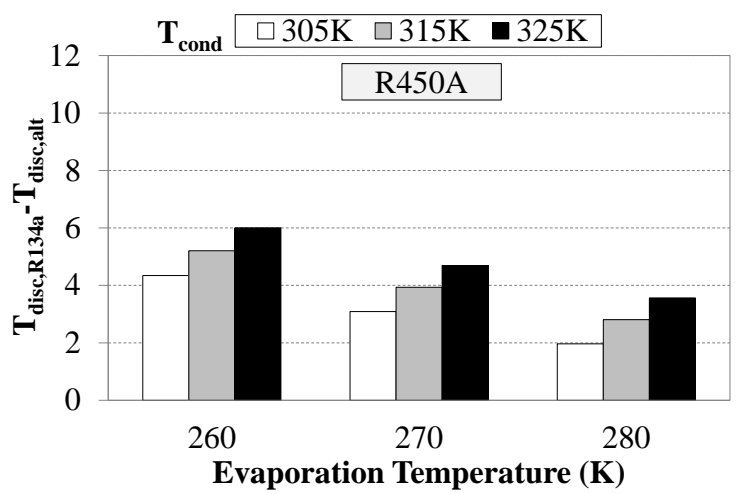

c)

Figure 5. 6 shows the difference in experimental discharge temperature between R134a and the alternatives. The highest discharge temperatures are obtained with R134a (greater isentropic compression work) so the alternatives will not present problems regarding this parameter.

More specifically, the use of R1234yf showed the lowest discharge temperature measured, being the difference between $8-11 \mathrm{~K}$ at low and $4-7 \mathrm{~K}$ at high evaporation temperatures (more horizontal slope and lower CR). Then, R1234ze(E) presents approximately values $1 \mathrm{~K}$ higher than those of R1234yf, resulting in differences between 7 and $10 \mathrm{~K}$ at $260 \mathrm{~K}$ and 4 and $6 \mathrm{~K}$ at $280 \mathrm{~K}$ (lower inclination but slightly higher CR). Finally, R450A exhibited intermediate values between R1234ze(E) and $\mathrm{R} 134 \mathrm{a}, 4-6 \mathrm{~K}$ at $260 \mathrm{~K}$ and 2 and $4 \mathrm{~K}$ at $280 \mathrm{~K}$ (values of isentropic line slope and CR close between both fluids). The discharge temperatures of alternatives approached to that R134a at higher CR. Uncertainty of discharge thermocouple $( \pm 0.3 \mathrm{~K})$ does not affect the conclusions, as the nearest discharge temperature to that of $\mathrm{R} 134 \mathrm{a}$ is $2 \mathrm{~K}$ below (R450A at 305K evaporation and $305 \mathrm{~K}$ condensation). 


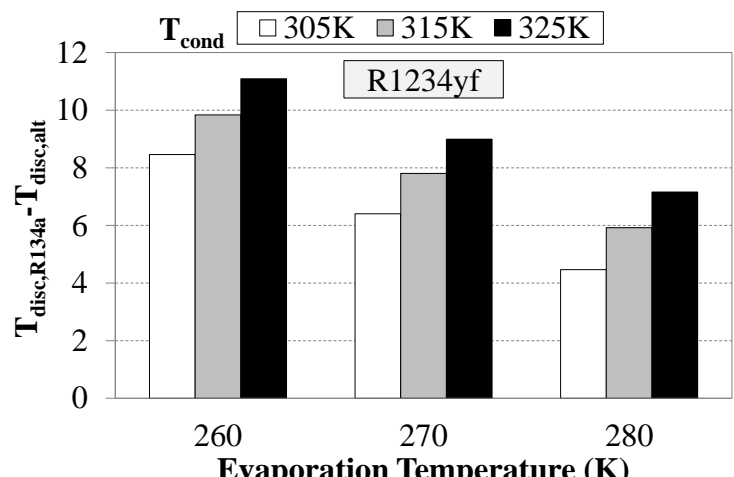

a)

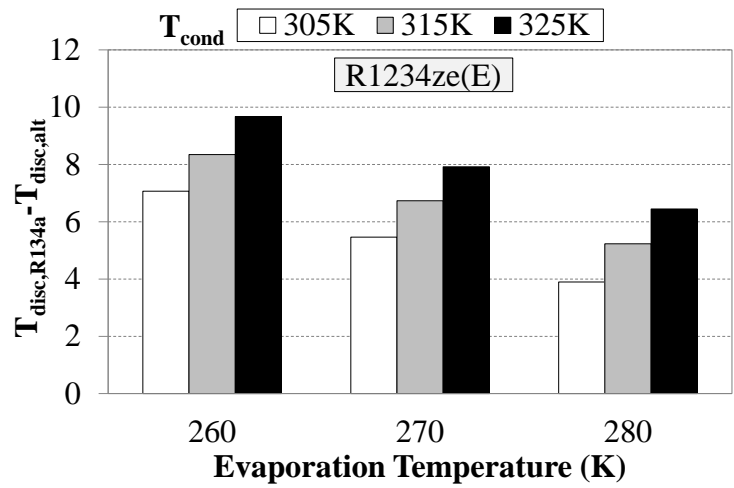

b)

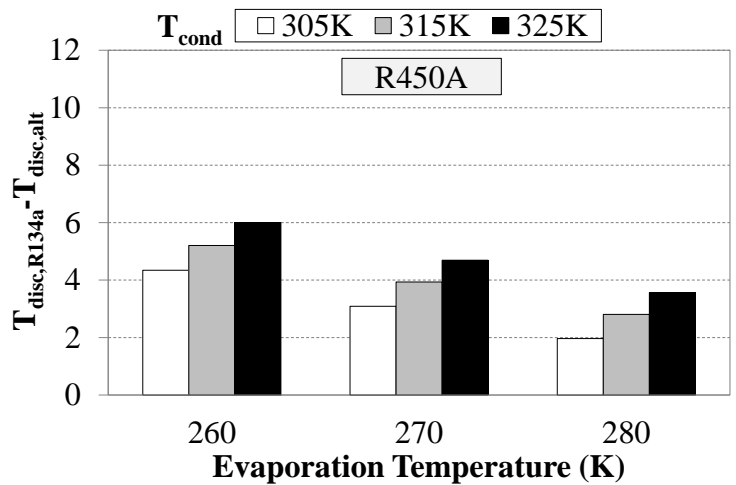

c)

Figure 5. 6. Experimental discharge temperature difference between R134a and: a) R1234yf, b) R1234ze(E) and c) R450A 
Analysis of fluoride fluids with low global warming impact in vapour compression systems. Experimental evaluation of different alternatives for commercial refrigeration.

The absolute values of the alternatives can be obtained adding the temperature difference observed in the previous figure to the R134a discharge temperature, shown in Table 5. 5.

Table 5. 5. R134a experimental discharge temperature

\begin{tabular}{llc}
\hline $\mathbf{T}_{\text {evap }}(\mathbf{K})$ & $\mathbf{T}_{\text {cond }}(\mathbf{K})$ & $\mathbf{R 1 3 4 a} \mathbf{T}_{\text {disc }}(\mathbf{K})$ \\
\hline \multirow{2}{*}{260} & 305 & 322.3 \\
& 315 & 333.3 \\
& 325 & 344.4 \\
\hline \multirow{2}{*}{270} & 305 & 319.5 \\
& 315 & 330.5 \\
& 325 & 341.4 \\
280 & 305 & 317.1 \\
& 315 & 328.3 \\
& 325 & 339.3 \\
\hline
\end{tabular}

\subsection{Experimental comparison between $R 404 A$ and alternatives}

As it has been made in the previous section for R134a, the comparison between the experimental results of R448A and R404A is presented and analysed below.

\subsubsection{Mass flow rate}

Figure 5. 7 depicts that R448A volumetric efficiency is lower than that of R404A. Again, the good agreement of a linear relationship between the volumetric efficiency and the CR is shown in Table 5. 6. 
Table 5. 6. Regression between $\eta_{v o l}$ and compression ratio and $\boldsymbol{R}^{2}$ resulting

\begin{tabular}{lcc}
\hline Working fluid & \multicolumn{1}{c}{$\boldsymbol{\eta}_{\text {vol }}$} & $\boldsymbol{R}^{\mathbf{2}}$ \\
\hline R404A & $\mathrm{y}=-0.0367 \mathrm{x}+0.9073$ & 0.9931 \\
$\mathrm{R} 448 \mathrm{~A}$ & $\mathrm{y}=-0.0385 \mathrm{x}+0.8688$ & 0.9722 \\
\hline
\end{tabular}

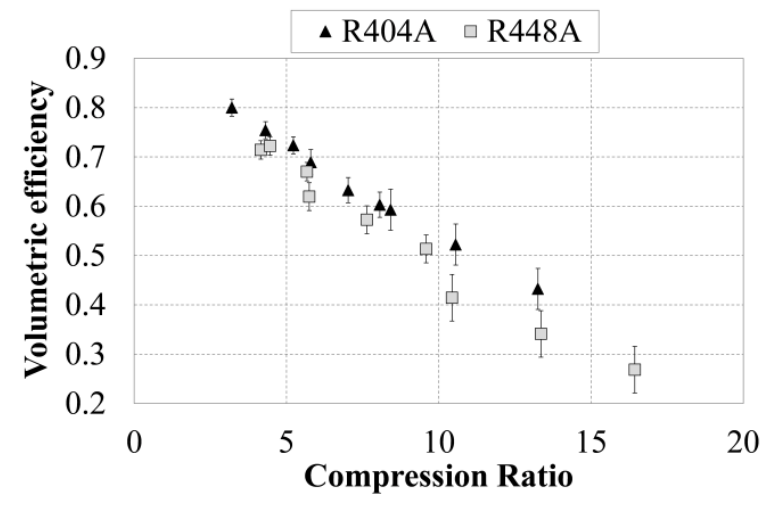

Figure 5. 7. Volumetric efficiency versus compression ratio

If the same CR is considered for both refrigerants, volumetric efficiency of R448A is between $5 \%$ and $7 \%$ below that resulting for R404A, being the difference higher at high CRs (food freezing and/or high ambient temperatures). Besides, there is also a great linear dependence between both parameters so these regressions can be used in design of R404A and R448A refrigeration systems.

In the same way as section 5.1., Table 5. 7 shows the adiabatic process volumetric efficiency obtained at the same condensation and evaporation temperatures, and at the same compression ratio ( $5 \%$ of clearance volume). 
Analysis of fluoride fluids with low global warming impact in vapour compression systems. Experimental evaluation of different alternatives for commercial refrigeration.

Table 5. 7. Adiabatic process volumetric efficiency of R404A and R448A

\begin{tabular}{lcccc}
\hline \multirow{2}{*}{ Conditions } & \multicolumn{2}{c}{ R404A } & \multicolumn{2}{c}{ R448A } \\
\hline $\boldsymbol{T}_{\boldsymbol{O}}=253 \mathrm{~K}, \boldsymbol{T}_{\boldsymbol{K}}=315 \mathrm{~K}$ & $\mathrm{~V}$ & $\eta_{\text {vol }}$ & $\mathrm{V}$ & $\eta_{\text {vol }}$ \\
$\boldsymbol{T}_{\boldsymbol{O}}=253 \mathrm{~K}, \mathrm{CR}=6.5$ & 1.285 & 0.84 & 1.201 & 0.799 \\
\hline
\end{tabular}

Table 5. 7 depicts that R448A volumetric efficiency is lowered by the greater compression ratio, when compared to R404A. However, when both CRs are the same, the R448A theoretical volumetric efficiency is still below that of R404A. The R448A experimental results are closer to that of R404A because of its lower pressure drops [219] (lower volumetric flow rate).

In Figure 5. 8 the mass flow rate relative reductions of R448A compared to that of $\mathrm{R} 404 \mathrm{~A}$ are presented. Considering the theoretical values obtained before (23\% to $26 \%$ of reduction), a greater alternative mass flow rate diminution highlights: from $36 \%$ to $41 \%$ at $240 \mathrm{~K}$ and from $29 \%$ to $30 \%$ at $265 \mathrm{~K}$. The results can be explained analysing different parameters that affect the mass flow rate:

- R448A presents lower volumetric efficiency than R404A.

- The reduction in volumetric efficiency is even greater regarding to R448A works with higher CRs than R404A.

- For the same total superheating degree and operating conditions, the R448A suction density is $23-26 \%$ smaller than that of R404A.

- Compressor geometric volume and compressor rotation speed are the same for both refrigerants.

- On the other hand, pressure losses of R448A are lower than those of R404A [219]. 


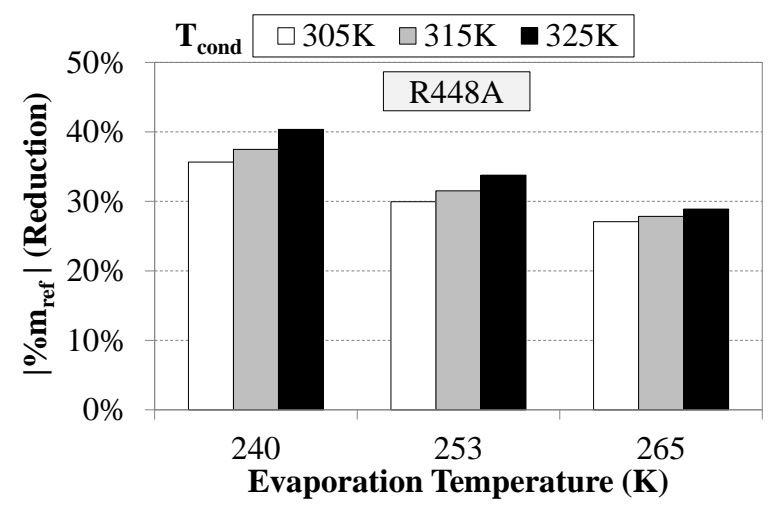

Figure 5. 8. Mass flow rate relative reduction

\subsubsection{Cooling capacity}

Figure 5. 9 contains the relative reduction between R448A cooling capacity and those performed by R404A. R448A is always below R404A in terms of mass flow rate. However, the opposite phenomenon happens for the refrigerating effect. R448A refrigerating effect is between $35 \%$ and $50 \%$ greater than that of $\mathrm{R} 404 \mathrm{~A}$ at low evaporation conditions and from $30 \%$ to $40 \%$ at higher evaporating temperatures. Both effects lead to a greater cooling capacity relative reduction than expected, between $12 \%$ to $15 \%$ at $240 \mathrm{~K}$ and $1 \%$ to $6 \%$ at $265 \mathrm{~K}$.

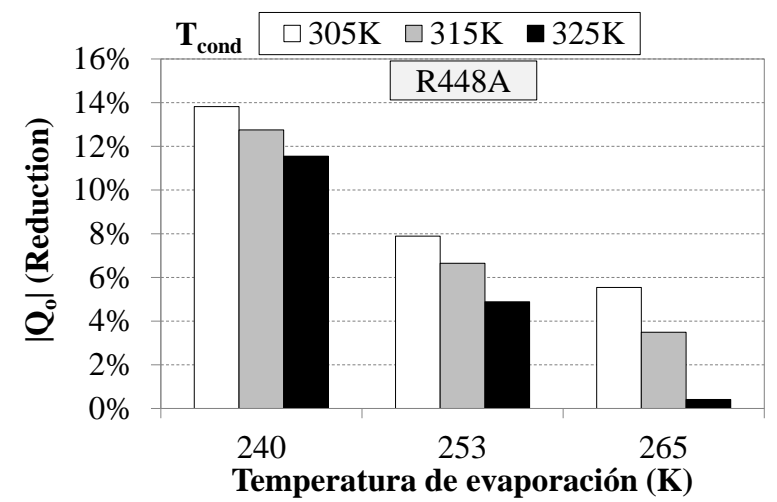

Figure 5. 9. Cooling capacity relative reduction 
Analysis of fluoride fluids with low global warming impact in vapour compression systems. Experimental evaluation of different alternatives for commercial refrigeration.

The average cooling capacity uncertainty (Table 5.8 ) is approximately $2 \%$ and $1.5 \%$ for R404A and R448A, respectively.R448A reaches close cooling capacity values at high condensation temperatures but the real approach of this value cannot be affirmed to that of R404A due to the uncertainties.

Table 5. 8. Cooling capacity uncertainty for R404A and R448A

\begin{tabular}{llll}
\hline $\mathbf{T}_{\text {evap }}$ & $\mathbf{T}_{\text {cond }}$ & $\mathbf{R 4 0 4 A}$ & $\mathbf{R 4 4 8 A}$ \\
\hline \multirow{3}{*}{240} & 305 & $1.83 \%$ & $1.48 \%$ \\
& 315 & $1.93 \%$ & $1.59 \%$ \\
& 325 & $1.97 \%$ & $1.69 \%$ \\
\hline \multirow{2}{*}{253} & 305 & $1.83 \%$ & $1.42 \%$ \\
& 315 & $1.96 \%$ & $1.56 \%$ \\
& 325 & $2.02 \%$ & $1.75 \%$ \\
\hline \multirow{2}{*}{265} & 305 & $1.82 \%$ & $1.40 \%$ \\
& 315 & $1.96 \%$ & $1.51 \%$ \\
& 325 & $2.21 \%$ & $1.71 \%$ \\
\hline
\end{tabular}

\subsubsection{Coefficient of performance}

Figure 5. 10.a) shows the relative COP difference between both refrigerants taking R404A as baseline. Despite having lower cooling capacity, energy consumption using $\mathrm{R} 448 \mathrm{~A}$ is to a great extent lesser than that of R404A (around $26 \%$ at freezing conditions and $13 \%$ at conservation conditions), Figure 5. 10.b). As a result, R448A COP is above that of R404A for all considered conditions. Specifically, the R448A COP increase ranges from $13 \%$ to $21 \%$ at $240 \mathrm{~K}$ and from $6 \%$ to $15 \%$ at $265 \mathrm{~K}$. 


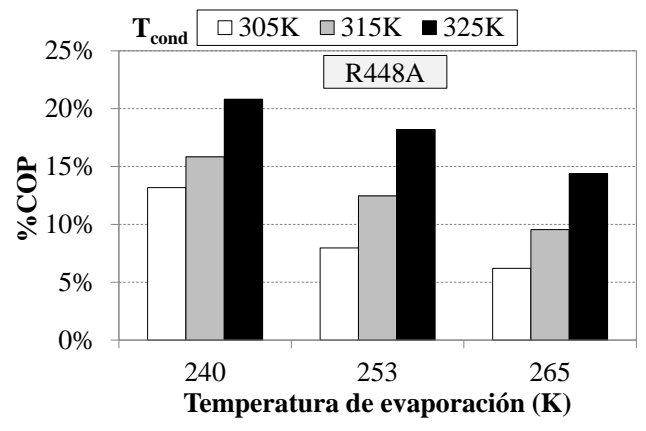

a)

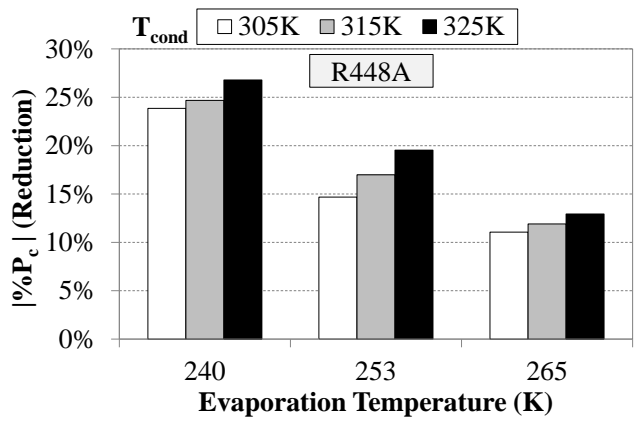

b)

Figure 5. 10. Relative deviation: a) COP and b) Power consumption (Reduction)

Table 5. 9 contains the COP uncertainty for R404A and R448A. The average values for $\mathrm{R} 404 \mathrm{~A}$ and $\mathrm{R} 448 \mathrm{~A}$ are $1.1 \%$ and $0.9 \%$. These values are small enough to conclude that the energetic performance of R448A in this system is higher than that of R404A.

Table 5. 9. COP uncertainty for $\mathrm{R} 404 \mathrm{~A}$ and $\mathrm{R} 448 \mathrm{~A}$

\begin{tabular}{llll}
\hline $\mathbf{T}_{\text {evap }}(\mathbf{K})$ & $\mathbf{T}_{\text {cond }}(\mathbf{K})$ & $\mathbf{R 4 0 4 A}$ & $\mathbf{R 4 4 8 A}$ \\
\hline \multirow{3}{*}{240} & 305 & $1.08 \%$ & $0.89 \%$ \\
& 315 & $1.14 \%$ & $0.94 \%$ \\
& 325 & $1.15 \%$ & $0.99 \%$ \\
\hline \multirow{2}{*}{253} & 305 & $1.07 \%$ & $0.86 \%$ \\
& 315 & $1.13 \%$ & $0.93 \%$ \\
265 & 325 & $1.16 \%$ & $0.89 \%$ \\
& 305 & $1.13 \%$ & $0.85 \%$ \\
& 315 & $1.08 \%$ & $0.90 \%$ \\
& 325 & $1.08 \%$ & $1.01 \%$ \\
\hline
\end{tabular}

Newly, the global compressor efficiency cannot be used to extract conclusions about its influence on the COP due to the proximity of the values and the uncertainty, Figure 5. 11. 
Analysis of fluoride fluids with low global warming impact in vapour compression systems. Experimental evaluation of different alternatives for commercial refrigeration.

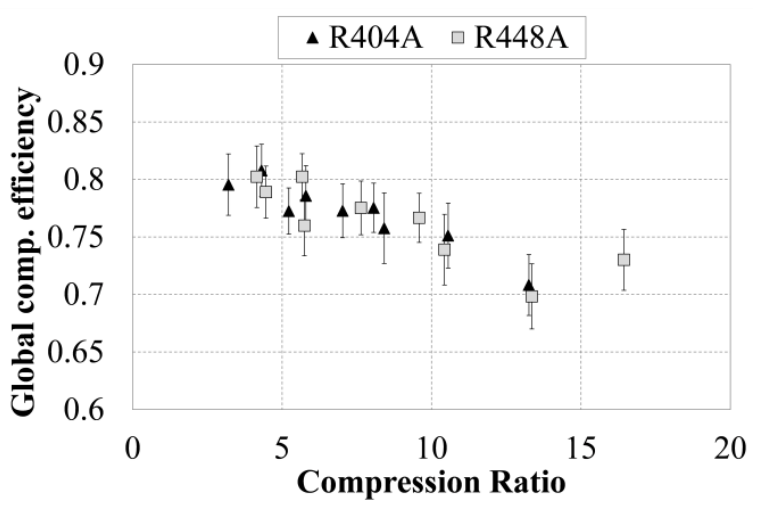

Figure 5. 11. Compressor global efficiency for R404A and R448A

\subsubsection{Compressor discharge temperature}

Figure 5. 12 shows that R448A discharge temperature is considerably higher than the resulting from using R404A. Firstly, R448A CRs are higher at the same operating conditions, and secondly, the isentropic work of the alternative is also higher (due to isentropic line inclination). The discharge temperature difference increases with the CR augmentation, as expected theoretically. These values are comprised between 12.5 and $14.7 \mathrm{~K}$ at low evaporation conditions and between 9.4 and $11.2 \mathrm{~K}$ at high evaporation temperatures.

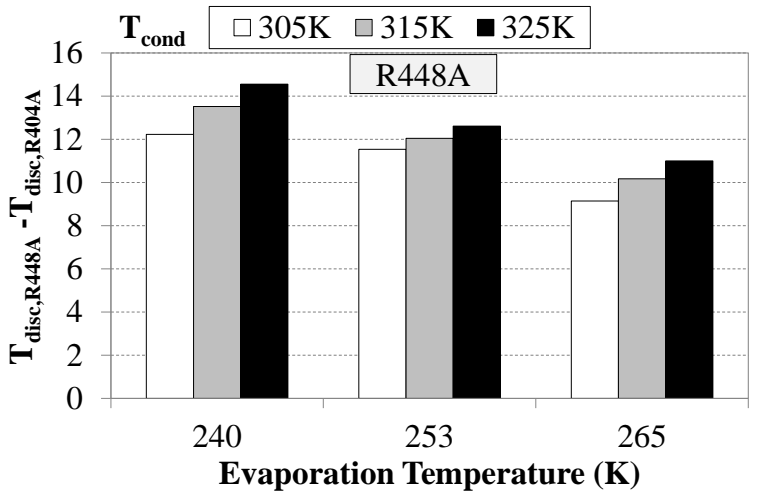

Figure 5. 12. Discharge temperature difference between $R 448 A$ and $R 404 A$ and discharge temperature of $\mathbf{R} 448 \mathrm{~A}$ 
Although a R448A discharge temperature is higher than that of R404A in refrigeration systems, that fact will not provoke problems due to excessive discharge temperature ( $\mathrm{R} 448 \mathrm{~A}$ maximum value is $10 \mathrm{~K}$ below the normal operation limit, Table 5. 10). The worst condition considered to happen at the maximum CR studied: evaporation and condensation temperature of $240 \mathrm{~K}$ and $265 \mathrm{~K}$, respectively. If $\mathrm{R} 448 \mathrm{~A}$ is going to be used at lower evaporation temperatures than those considered in this project, an study of the discharge temperature is recommended.

Table 5. 10. R404A experimental discharge temperature

\begin{tabular}{llc}
\hline $\mathbf{T}_{\text {evap }}(\mathbf{K})$ & $\mathbf{T}_{\text {cond }}(\mathbf{K})$ & $\mathbf{T}_{\text {disc, } \mathbf{R 4 4 8 A}}(\mathbf{K})$ \\
\hline \multirow{2}{*}{240} & 305 & 345.0 \\
& 315 & 357.6 \\
& 325 & 370.0 \\
\hline \multirow{2}{*}{253} & 305 & 338.5 \\
& 315 & 350.3 \\
& 325 & 362.4 \\
\hline \multirow{2}{*}{265} & 305 & 332.3 \\
& 315 & 344.7 \\
& 325 & 357.1 \\
\hline
\end{tabular}


Analysis of fluoride fluids with low global warming impact in vapour compression systems. Experimental evaluation of different alternatives for commercial refrigeration.

\subsection{Conclusions Chapter 5}

This chapter has exposed the drop-in performance comparison between R134a and three low-GWP refrigerants, R1234yf, R1234ze(E) and R450A; and between R404A and its lower-GWP mixture alternative, R448A. Mass flow rate, cooling capacity, COP and discharge temperature were the parameters analysed at the same temperatures considered in the theoretical analysis: evaporation temperatures of 260/270/280K for R134a and alternatives and 240/253/265K for R404A and alternatives; and condensing temperature of $305 / 315 / 325 \mathrm{~K}$ for all the tested fluids.

The R134a alternatives present lower volumetric efficiencies, but those reductions are not significant. In the case of R404A alternative, R448A presents significant reductions of volumetric efficiency for high compression ratios. The mass flow rate results are extremely different: those of R1234yf are above R134a values, but those of R1234ze(E) are much below the flow rates with R134a. Besides, R450A values are slightly lower than those of R134a. Taking into account the refrigerating effect mentioned in the theoretical analysis, the average cooling capacity reductions using R1234yf, $\mathrm{R} 1234 \mathrm{ze}(\mathrm{E})$ and $\mathrm{R} 450 \mathrm{~A}$ are around $10 \%, 30 \%$ and $6 \%$, respectively, compared to R134a. It is therefore advisable minor system modifications for R1234yf and R450A (but not strictly necessary) in R134a systems but severe system modifications if $\mathrm{R} 1234 \mathrm{ze}(\mathrm{E})$ is going to be used as R134a retrofit replacement.

The COP reduction for HFOs is also lower, being that of $\mathrm{R} 1234 \mathrm{yf}$ the worst case. COP of $\mathrm{R} 450 \mathrm{~A}$ is around that of R134a. That implies similar power consumption for R1234yf, much lower for R1234ze(E) and slightly lower for R450A (in the same extend that cooling capacity reduction). In the case of HFOs, the lower energy efficiency can cause higher indirect global warming increase than direct global 
warming reduction when compared to $\mathrm{R} 134 \mathrm{a}$. The discharge temperature is not a problem for the alternatives as well as R134a.

Moving on conclusions from comparison between R448A and R404A, R448A presents lower mass flow rate, cooling capacity and power consumption than R404A. As a result, R448A COP is higher and becomes an interesting alternative in refrigeration systems (greater compression power reduction than refrigerating effect). Regarding to discharge temperature, R448A reach higher values than R404A but not enough to be inadequate. Better results were obtained with R448A if compared to those of R404a at MT conditions and higher temperatures. 
Analysis of fluoride fluids with low global warming impact in vapour compression systems. Experimental evaluation of different alternatives for commercial refrigeration.

\section{Chapter 6}

\section{Conclusions and}

future work

The experimental results of this work have been presented in the previous chapter, showing the adaptability and performance of the different alternatives on HFC refrigeration systems. Since the aim of this work has been achieved, this chapter summarises the main conclusions of the study.

This chapter contains some future work recommendations to continue with the investigation, extending thus the impact and the scope of the study. 


\subsection{Conclusions}

Vapour compression system is the dominant technology in air conditioning and refrigeration systems. Due to its working fluids, two main environmental problems have appeared: atmospheric ozone depletion and global warming (climate change). Since the ozone depleting substances have almost disappeared in developed countries, the global warming is the main concern that the most used refrigerants present today, the HFCs.

In this work, commercial refrigeration systems have been identified as one of the most relevant VCSs applications in terms of annual energy consumption and refrigerant leakages. Commercial refrigeration applications comprise the cold production systems in supermarkets, hypermarkets or retail stores and are used throughout the world. The different commercial refrigeration appliances have been reviewed, concluding that PCRRSs used together with DX systems produce the highest carbon dioxide equivalent emissions because of the high refrigerant charges (long pipe lines, components size), great leakage rates and energy consumption (these systems feed a lot of loads).

The state-of-art review depicts that R134a and R404A are the most commonly used refrigerants in DX systems of developed countries. They present great GWP values (1300 and 3943, respectively) so their replacement using alternative (low-GWP) refrigerants is a priority in order to stop the climate change.

Moreover, the current status of the different options to substitute the currently used HFCs in PCRRS has been studied. Natural refrigerants are discarded if the purpose is to perform a retrofit or drop-in substitution. Thus, two HFOs, R1234yf and R1234ze(E), and two R1234ze(E) based mixtures, are identified as possible R134a and R404A dropin or light retrofit alternatives in PCRRS systems. 
Analysis of fluoride fluids with low global warming impact in vapour compression systems. Experimental evaluation of different alternatives for commercial refrigeration.

R1234yf and R1234ze(E) are two HFOs with very low-GWP values (1 and 4, respectively) and low-flammability (ASHRAE security classification: A2L). R450A is a non-flammable refrigerant and can be used as safe working fluid in systems where fluids with GWP $<1500$ are allowed according to present and possible future regulations. Besides, R448A has a GWP of 1274 and is a non-flammable option to replace R404A in DX supermarket refrigeration systems. R448A offers greater GWP reduction than other synthetic non-flammable options (R407A or R407F for example).

This thesis evaluates the potential of drop-in or retrofit substitution of R134a and R404A in large commercial refrigeration systems considering HFO and HFO/HFC mixtures as replacements. The refrigerants finally compared with R134a were R1234yf, R1234ze(E) and R450A; and with R404A, R448A was evaluated.

The alternatives considered in this study can be used in R134a and R404A systems, because these refrigerants work at very similar operating conditions (temperature, pressure), present similar thermophysical properties, and oil, material and components compatibility.

Firstly, theoretical thermodynamic evaluation of the fluids has been carried out, simulating a basic cycle refrigeration system. Three different evaporation temperatures for R134a and its alternatives, 260/270/280K, and another three for R404A and its substitutes, 240/253/265K, have been considered. The target condensation temperatures were $305 / 315 / 325 \mathrm{~K}$. The evaluation assumptions and the equations have been also presented.

Regarding to R134a alternatives, the results suggest that R1234yf presents lower cooling capacity and COP and R1234ze(E) similar COP but much lower cooling capacity (should be considered in retrofit systems). R450A is a good mid-term solution 
which considerably surpasses the R1234ze(E) cooling capacity results. Besides, R448A is very promising in terms of energy efficiency as R404A substitute even though R448A CR is slightly higher.

Secondly, a complete set of steady-state tests are carried out at the same conditions that the theoretical approach. The experimental setup consist on a VCS equipped with an open-type reciprocating compressor, shell-and-tube condenser, shell-and-microfin tube evaporator and two by-passed TXVs (designed for R134a and R404A). The alternatives have been tested simulating a light retrofit, so the only modification was a TXV adjustment.

Volumetric efficiencies of R1234yf and R1234ze(E) are lower than R134a, but, regarding to the uncertainty of this parameter, cannot be considered significant. The average cooling capacity reductions using R1234yf, R1234ze(E) and R450A are around 10\%, 30\% and 6\% comparing with R134a. The difference between R1234yf and R134a is mostly affected by the variation in condensation temperature. For $\mathrm{R} 1234 \mathrm{ze}(\mathrm{E})$ and R450A, the reduction is higher at greater CRs. The suction density values presented in the thermodynamic overview have great influence on this parameter.

The COP differences are strongly affected by the isentropic compression work (the global compressor efficiency differences are below uncertainties). The COP obtained using R1234yf is between $6 \%$ and $12 \%$ lower than that obtained with R134a. In the case of R1234ze(E) these values are between $1 \%$ and 9\%, although COP improvements can be found in optimised chillers. The compressor power consumption is much lower using R450A than R134a, so the R450A COP rises until being comparable to that $\mathrm{R} 134 \mathrm{a}$ at low evaporation conditions. 
Analysis of fluoride fluids with low global warming impact in vapour compression systems. Experimental evaluation of different alternatives for commercial refrigeration.

The discharge temperature of all of the alternatives is lower than that of R134a, so this parameter is not going to be critical in system design. Maximum discharge temperatures of R1234yf and R1234ze(E) are very far from that of R134a, and those of R450A are only $2 \mathrm{~K}$.

Although R1234yf and R1234ze(E) produce a great $\mathrm{CO}_{2}$ eq. direct emission reduction, experimental results confirm that their energy efficiency values are to some extent below those of R134a and these substitutions could be detrimental in terms of total $\mathrm{CO}_{2}$ eq. emissions. R450A offers better performance than other HFC mixtures and HFOs (slightly lower cooling capacity and similar COP) and results a very interesting alternative to R134a. Although R450A does not accomplish some European GWP limitations, it reduces direct emissions and its performance is almost the same that $\mathrm{R} 134 \mathrm{a}$ so it can be a very interesting R134a, R12 or R22 alternative in refrigeration systems.

The use of R448A can be interesting from an environmental point of view because it reduces the direct and indirect $\mathrm{CO}_{2}$ equivalent emissions compared to R404A.

In terms of cooling capacity, R448A can be considered a good replacement for MT applications (food conservation) and higher condensation temperatures (warmer countries) being possibly not enough for freezing applications. Regarding condensation temperature influence, it is observed that the cooling capacity difference decreases due to the greater refrigerating effect increase for R448A. However, the lower R448A cooling capacity implies higher running time in supermarket systems, so it is recommended to use this refrigerant in redesigned systems. 
R448A presents slightly lower volumetric efficiency that together with the suction density variation implies much lower mass flow rates. The use of R448A instead of $\mathrm{R} 404 \mathrm{~A}$ produces a higher reduction in power consumption than the diminution of cooling capacity, so the R448A energy efficiency is higher. Higher condensation temperatures impair less to R448A energy efficiency than that of R404A. Although $\mathrm{R} 448 \mathrm{~A}$ discharge temperature is higher, it is below limits.

For any alternative considered, a system redesign and optimisation is always advisable in order to achieve higher cooling effect, energy efficiency and hence, lower power consumption. That would be reflected in a decrease in the final environmental impact derived from indirect emissions.

When considering real supermarket installations, the suction lines are much longer than those used in this test bench; if they are not well isolated or well-sized, higher suction temperatures (higher total superheating degree) or greater pressure drops (lower suction pressure) can cause a discharge temperature increase, being higher than those values presented in this work (even though it is far than the limit this effect should be considered). Although in this work only compressor-motor consumption is considered to calculate the system efficiency, in supermarket systems, fans energy consumption are also to be taken into account. 
Analysis of fluoride fluids with low global warming impact in vapour compression systems. Experimental evaluation of different alternatives for commercial refrigeration.

\subsection{Future work recommendations}

Although the low-GWP alternatives have been tested in a wide range of operating conditions, further work can be done before to extend their use in supermarket refrigeration systems and minimise $\mathrm{CO}_{2}$ equivalent emissions:

To test low-GWP alternatives in existing supermarket systems

The experimental results, while being very close to those expected in existing supermarket systems, are not exactly the same (larger pressure drop and heat transfer to the ambient, refrigerant leakages, etc.). This study should be considered as a previous (and essential) step to the lower GWP refrigerant implementation in real systems. As the experimental results shown are encouraging, supermarket owners would be well disposed to test these refrigerants in their existing systems.

To consider system modifications for existing systems

The positive results with R450A and R448A have been obtained performing minimum changes (TXV adjustment). They could be even improved considering more relevant system modifications as component substitution performing a proper design and selection.

- Some of the most relevant compressors manufacturers have launched to market models designed for new low-GWP refrigerants.

- Heat exchanger design is even more relevant for refrigerants with high temperature glide, as R448A. It is well known that through specific heat exchanger technology that considers glide effects; higher energy savings can be obtained. 
To develop methods of leakages reduction

Most of the efforts of environmental protection organisations and communitarians as well as national government are focused on promote lower GWP refrigerants $\left(4^{\text {th }}\right.$ generation of refrigerants). DX PCRRS present the greatest leakage rate (between 15 and 30\%) and refrigerant charge (until $1200 \mathrm{~kg}$ ). Those limitations will have a minor effect if leakage reduction is not prioritised.

- This phenomenon could be reduced installing another configurations (cascade or secondary), smaller components, more frequent leakage revisions, etc.

- Moreover, high leakages affects directly to the system energy efficiency. It would imply higher energy consumption and economic losses together with the well-known greenhouse effect increase.

To revise safety and environmental standards and normative

Before it was stated that pure HFO are very promising refrigerants that present a great disadvantage, their flammability. Thus, security standards oppose the use of these fluids in large charge refrigeration systems (as DX systems) to minimise risks of human exposition (the same happens to $\mathrm{HCs}$ ).

If the concentration requirements are revised, superior $\mathrm{CO}_{2}$ direct emissions reduction could be reached, using this low-GWP and low flammable fluids. These actions could be complemented by stablishing more strict leakage detection and room ventilation requirements, or promote cascade and secondary systems where only a safe fluid is used in the low stage or secondary circuit. 
Analysis of fluoride fluids with low global warming impact in vapour compression systems. Experimental evaluation of different alternatives for commercial refrigeration.

\section{References}

[1] Dincer, I., Kanoglu, M., 2010. Refrigeration Systems and Applications, second ed. John Wiley \& Sons, Inc.

[2] International Institute of Refrigeration. A Brief History of Refrigeration. Retrieved online at: http://www.iifiir.org/userfiles/file/webfiles/indepth_files/History_refrigeration_Duminil_EN.pdf (23.10.15)

[3] Briley, G.C., 2004. A History of Refrigeration. ASHRAE J. 46, 31-34.

[4] Calm, J.M., 2008. The next generation of refrigerants e historical review, considerations, and outlook. Int. J. Refrig. 31, 1123-1133.

[5] ASHRAE, 2012. ASHRAE Position Document on Refrigerants and their Responsible Use.

[6] US Department of Health and Human Services and U.S. Department of Labor, 1979. Occupational Health Guideline for Sulfur Dioxide. Retrieved online at: http://www.cdc.gov/niosh/docs/81-123/pdfs/0575.pdf (23.10.15.).

[7] Giunta, C.J., 2006. Thomas Midgley, Jr., and the invention of Chlorofluorocarbon Refrigerants: It ain't necessarily so. Bull. Hist. Chem., 31(2), 66-74. 
[8] Rowland, F. S., 2007. Stratospheric Ozone Depletion by Chlorofluorocarbons (Nobel Lecture). Retrieved online at: http://www.eoearth.org/view/article/156270/ (23.10. 15.).

[9] Molina M.J., Rowland F.S., 1974. Stratospheric sink for chlorofluoromethanes: chlorine atom-catalysed destruction of ozone. Nature 249, 810-812.

[10] World Meteorological Organization, 2002. Scientific Assessment of Ozone Depletion: 2002, Global Ozone Research and Monitoring Project, Report No. 47.

[11] Moan, J., 2001. 7 Visible Light and UV Radiation. Radiation, 69.

[12] Slaper, H., Velders, G.J.M, Matthijsen, J., 1998. Ozone depletion and skin cancer incidence: a source risk approach. J. Hazard. Mater. 61(1-3), 77-84.

[13] UNEP, 1987. Montreal Protocol on Substances that Deplete the Ozone Layer. Final Act. United Nations, New York.

[14] Waters, J.W., Froidevaux, L., Read, W.G., Manney, G.L., Elson, L.S., Flower, D.A., 1993. Stratospheric $\mathrm{ClO}$ and ozone from the microwave limb sounder on the upper atmosphere research satellite. Nature 362, 597-602.

[15] World Meteorological Organization, 1994. Scientific Assessment of Ozone Depletion: 1994, Global Ozone Research and Monitoring Project, Report No. 37.

[16] The Council of the European Union, 1994. Council Regulation (EC) No 3093/94 of 15 December 1994 on substances that deplete the ozone layer. Off. J. Eur. Communities 333, 1-20.

[17] European Parliament and of the Council, 2000. Regulation (EC) No 2037/2000 of the European Parliament and of the Council of 29 June 2000 on substances that deplete the ozone layer. Off. J. Eur. Communities 244, 1-24.

[18] World Meteorological Organization, 2007. Scientific assessment of ozone depletion: 2006, Global Ozone Research and Monitoring Project, Report No. 50. 
Analysis of fluoride fluids with low global warming impact in vapour compression systems. Experimental evaluation of different alternatives for commercial refrigeration.

[19] Bodeker, G., May 2-4, 2011. The Current and Future States of the Ozone Layer. 8th Ozone Research Managers Meeting, Geneva, Switzerland.

[20] European Environmental Agency (EEA), 2015. Production and consumption of ozone-depleting substances. Retrieved online at: http://www.eea.europa.eu/data-and-maps/indicators/production-andconsumption-of-ozone-2/assessment (23.10.15.).

[21] Chipperfield, M.P., Dhomse, S.S., Feng, W., McKenzie, R.L., Velders G.J.M., Pyle, J.A., 2015. Quantifying the ozone and ultraviolet benefits already achieved by the Montreal Protocol. Nat. Commun. 6:7233.

[22] Augustin, L., Barbante, C., Barnes. P.R.; et al., 2004. Eight glacial cycles from an Antarctic ice core. Nature 429, 623-628.

[23] National Centers for Environmental Information. Global Climate Change Indicators. Retrieved online at: https://www.ncdc.noaa.gov/indicators/ (23.10.15.).

[24] Lemley, B., 2002. The Next Ice Age. Discover. Retrieved online at: http://www.discovermagazine.com/2002/sep/cover (23.10.15.).

[25] Meehl, G.A., Washington, W.M., Collins, W.D., Arblaster, J.M, Hu, A., Buja, L.E., Strand, W.G., Teng, H., 2005. How Much More Global Warming and Sea Level Rise? Science 307, 1769-1772.

[26] Ministry of Economy, Trade and Industry (METI), 2008. History of Fluorocarbons. Retrieved online at: http://www.meti.go.jp/policy/chemical_management/ozone/files/pamplet/pane 1/08e_basic.pdf (23.10.15.).

[27] Lee Hannah, 2015. Chapter 2 - The Climate System and Climate Change, In Climate Change Biology (Second Edition). Academic Press, Boston, Pages $13-53$.

[28] United Nations, 1998. Kyoto Protocol to the United Nations Framework Convention on Climate Change. 
[29] IPCC, September 23-26, 2013. Anthropogenic and Natural Radiative Forcing, Supplementary Material. Climate Change 2013: The Physical Science Basis IPCC Working Group I Contribution to AR5. 12th Session of Working Group I (WGI-12), Stockholm, Sweden.

[30] Carbajal, P.T., Kanter, D., 2009. HFCs: A growing threat to the climate. The worst greenhouse gases you've never heard of.... Updated edition, December 2009.

[31] European Parliament and of the Council, 2006. Directive 2006/40/EC of the European Parliament and of the Council of 17 may 2006 relating to emissions from air conditioning systems in motor vehicles and amending council directive 70/156/EC. Off. J. Eur. Union 161, 1-11.

[32] European Parliament and of the Council, 2014. Regulation (EU) No 517/2014 of the European Parliament and the Council of 16 april 2014 on fluorinated greenhouse gases and repealing regulation (EC) No 842/2006. Off. J. Eur. Union 150, 195-230.

[33] Thompson, M., 2014. Climate Change Regulation and the Next Generation of Refrigerants. Retrieved online at: http://www.trane.com/commercial/uploads/pdf/cso/138/Refrigerants.pdf (23.10.15.).

[34] Maratou, A., 3-5 February 2015. EU policy update - F-gas regulation, HFC taxes \& fiscal incentives for natural refrigerants. ATMOsphere Asia 2014 Technology \& Innovation, Tokyo, Japan.

[35] Jefatura del estado, 2013. Ley 16/2013, de 29 de octubre. Boletín Oficial del Estado 260, 87528-87568.

[36] Ministerio de Hacienda y Administraciones Públicas, 2013. Real Decreto 1042/2013, de 27 de diciembre, Boletín Oficial del Estado 312, 106498106510. 
Analysis of fluoride fluids with low global warming impact in vapour compression systems. Experimental evaluation of different alternatives for commercial refrigeration.

[37] US EPA and ADEME, 2004. Determination of comparative HCFC and HFC emission profiles to the Foam and Refrigeration sectors until 2015; Part 1 Refrigerant emissions profiles. Retrieved online at: http://www3.epa.gov/ozone/snap/emissions/downloads/FoamEmissionProfiles _Part1.pdf (23.10.15.).

[38] Abdelaziz, O., 2014. Working Fluids: Low Global Warming Potential Refrigerants. 2014 Building Technologies Office Peer Review. Retrieved online at: http://energy.gov/sites/prod/files/2014/10/f18/emt13_abdelaziz_042414.pdf (23.10.15.).

[39] Intergovernmental Panel on Climate Change/Technology and Economic Assessment Panel, 2005. IPCC/TEAP Special Report: Safeguarding the Ozone Layer and the Global Climate System, Chapter 4: Refrigeration. Cambridge University Press, UK.

[40] Rochina, R., June 11, 2014. Diseño e instalación de sistemas de refrigeración comercial de elevada eficiencia y reducidos costes de implantación. Jornada sobre ahorro energético en supermercados, Madrid, Spain.

[41] Tassou, S.A., Ge, Y., Hadawey, A., Marriott D., 2011. Energy consumption and conservation in food retailing. Appl. Therm. Eng. 31, 147-156.

[42] U.S. Environmental Protection Agency, 2003. Putting energy into profits guidebook: ENERGY STAR ${ }^{\circledR}$ Guide for Small Business. Retrieved online at: http://www.energystar.gov/ia/business/small_business/sb_guidebook/smallbiz guide.pdf (23.10.15.).

[43] Billiard, F., 2000. Commercial refrigeration: a fast-expanding sector. Int. J. Refrig. 23(5), 333-335.

[44] Departamento Técnico Refrigeración Grupo Cofrico, 2010. Ahorro Energético en Refrigeración Comercial. Retrieved online at: 
http://www.cofrico.com/newswp/blog/ahorro-energetico-en-refrigeracioncomercial/ (23.10.15.).

[45] E Source Companies LLC, 2002. Managing Energy Costs in Grocery Stores Managing Energy Costs in Grocery Stores. National Grid USA Service Company, Inc. Retrieved online at: http://www.nationalgridus.com/non_html/shared_energyeff_groceries.pdf (23.10.15.).

[46] World Energy Council. World Energy Resources. World Energy Council, London, UK, 2013.

[47] Pedersen, H., 2012. Low GWP Alternatives to HFCs in Refrigeration. The Danish Environmental Protection Agency, Environmental Projekt no 1425.

[48] Whitman, B., Johnson, B., Tomczyk, J., Silberstein, E. 2012. Refrigeration and air conditioning technology, seventh ed. Cengage Learning.

[49] Ming, Z., 2006. Energy Analysis of Various Supermarket Refrigeration Systems. 11th International Refrigeration and Air Conditioning Conference at Purdue West Lafayette, USA, Paper 856.

[50] Koronaki, I.P., Cowan, D., Maidment, G., Beerman, K., Schreurs, M., Kaar, K., Chaer, I., Gontarz, G., Christodoulaki, R.I., Cazauran, X., 2012. Refrigerant emissions and leakage prevention across Europe - Results from the RealSkillsEurope project. Energy 45(1), 71-80.

[51] Emerson Climate Technologies, 2010. Refrigerant Choices for Commercial Refrigeration. Retrieved online at: http://www.emersonclimate.com/europe/documents/resources/tge124_refriger ant_report_en_1009.pdf (23.10.15.).

[52] Rosa, W., September 19-22, 2010. Advanced Refrigeration Systems. Maintaining $\mathrm{CO}_{2}$ Secondary \& Cascade Systems. Energy \& Store Development Conference, Hilton, Minneapolis, USA. 
Analysis of fluoride fluids with low global warming impact in vapour compression systems. Experimental evaluation of different alternatives for commercial refrigeration.

[53] Bansal, P.K., Jain S., 2007. Cascade systems: past, present, and future ASHRAE Trans., 113(1), 245-252.

[54] Saunders, M., Tebbe, R., February 18, 2015. Refrigerants Management \& Retrofits. Food Retail Forum Presentations, Anaheim, California, USA.

[55] James, S.J., James, C., 2010. The food cold-chain and climate change. Food Res. Int. 43, 1944-1956.

[56] Horst, K., September, 2000. Refrigerant Use in Europe, ASHRAE J., 16-24.

[57] Velders G.J.M., Fahey D.W., Daniel J.S., McFarland M., Andersen S.O., 2009. The large contribution of projected HFC emissions to future climate forcing. Proc. Natl. Acad. Sci. USA 106(27), 10949-10954.

[58] United Nations Environment Programme (UNEP), 2007. UNEP 2006 Report of the Refrigeration, Air Conditioning and Heat Pumps Technical Options Committee. 2006 Assessment. UNEP Nairobi, Ozone Secretariat, Kenya.

[59] U.S. Environmental Protection Agency, October, 2010. Transitioning to LowGWP Alternatives in Commercial Refrigeration. Retrieved online at: http://www3.epa.gov/ozone/downloads/EPA_HFC_ComRef.pdf (23.10.15.).

[60] Yang, Z., Wu, X., 2013. Retrofits and options for the alternatives to HCFC-22. Energy 59, 1-21.

[61] Arora, A., Kaushik, S.C., 2008. Theoretical analysis of a vapour compression refrigeration system with R502, R404A and R507A. Int. J. Refrig. 31(6), 9981005 .

[62] Goetzler, W., Burgos, J., Sutherland, T., 2010. Ultra-Low GWP Refrigerants. ASHRAE J. 52(10), 34-43.

[63] Venkatarathnam, G., Srinivasa Murthy, S., 2012. Refrigerants for Vapour Compression Refrigeration Systems. Resonance 17(2), 139-162.

[64] Hughes, M., November 11, 2014. In the Shadow of F-Gas: The HFC Phasedown - Impact and Solutions. ACRIB F Gas Implementation Conference, London, UK. 
[65] Calm, J.M., 2002. Emissions and environmental impacts from air-conditioning and refrigeration systems. Int. J. Refrig. 25, 293-305.

[66] Riffat, S.B., Afonso, C.F., Oliveira, A.C., Reay, D.A., 1997. Natural refrigerants for refrigeration and air-conditioning systems. Appl. Therm. Eng. 17(1), 33-42.

[67] Maté, J., Papathanasopoulos, C., Latif, S., 2012. Cool technologies: working without HFCs. Examples of HFC-Free Cooling Technologies in Various Industrials Sectors 2012 EDITION. Retrieved online at: http://www.greenpeace.org/international/Global/international/publications/cli mate/2012/Fgases/Cool-Technologies-2012.pdf(23.10.15.).

[68] Coulomb D., 2005. A Word from the Director: Natural refrigerants: a renaissance. Int. J. Refrig. 28(5), 633-634.

[69] Bolaji, B.O., Huan, Z., 2013. Ozone depletion and global warming: Case for the use of natural refrigerant - a review. Renew. Sust. Energ. Rev. 18, 49-54.

[70] Palm, B., 2008. Hydrocarbons as refrigerants in small heat pump and refrigeration systems - A review. Int. J. Refrig. 31, 552-563.

[71] Granryd, E., 2001. Hydrocarbons as refrigerants — an overview. Int. J. Refrig. 24(1), 15-24.

[72] Cleland, D.J., Keedwell, R.W., Adams, S.R., 2009. Use of hydrocarbons as drop-in replacements for HCFC-22 in on-farm milk cooling equipment. Int. J. Refrig. 32, 1403-1411.

[73] Colbourne, D., Espersen, L., 2013. Quantitative risk assessment of R290 in ice cream cabinets. Int. J. Refrig. 36, 1208-1219.

[74] Hwang, Y., Jin, D.H., Radermacher, R., 2007. Comparison of R-290 and two HFC blends for walk-in refrigeration systems. Int. J. Refrig. 30, 633-641.

[75] Hwang, Y., Jin, D.H., Radermacher, R., 2004. Comparison of hydrocarbon R290 and two HFC blends R-404A and R-410A for medium temperature 
Analysis of fluoride fluids with low global warming impact in vapour compression systems. Experimental evaluation of different alternatives for commercial refrigeration.

refrigeration applications. ARI: Global Refrigerant Environmental Evaluation Network (GREEN) Program. Final Interim Report 2004.

[76] Mastrullo, R., Mauro, A.W., Menna, L., Vanoli G.P, 2014. Replacement of R404A with propane in a light commercial vertical freezer: A parametric study of performances for different system architectures. Energy Conv. Manag. 82, $54-60$.

[77] He, M.G., Song, X.Z., Liu, H., Zhang Y., 2014. Application of natural refrigerant propane and propane/isobutane in large capacity chest freezer. Appl. Therm. Eng. 70, 732-736.

[78] Bansal, P., 2012. A review - Status of $\mathrm{CO}_{2}$ as a low temperature refrigerant: Fundamentals and R\&D opportunities. Appl. Therm. Eng. 41, 18-29.

[79] Ma, Y., Liu, Z., Tian, H., 2013. A review of transcritical carbon dioxide heat pump and refrigeration cycles. Energy 55, 156-172.

[80] Pérez-García, V., Belman-Flores, J.M., Navarro-Esbrí, J., Rubio-Maya, C., 2013. Comparative study of transcritical vapor compression configurations using $\mathrm{CO}_{2}$ as refrigeration mode base on simulation. Appl. Therm. Eng. 51(12), 1038-1046.

[81] Sharma, V., Fricke, B., Bansal, P., 2014. Comparative analysis of various $\mathrm{CO}_{2}$ configurations in supermarket refrigeration systems. Int. J. Refrig. 46, 86-99.

[82] Srinivasan, K., 2011. Identification of optimum inter-stage pressure for twostage transcritical carbon dioxide refrigeration cycles. J. Supercrit. Fluids 58, 26-30.

[83] Ge, Y.T., Tassou, S.A., 2011. Thermodynamic analysis of transcritical $\mathrm{CO}_{2}$ booster refrigeration systems in supermarket. Energy Conv. Manag. 52, 1868 1875 .

[84] Ge, Y.T., Tassou, S.A., 2011. Performance evaluation and optimal design of supermarket refrigeration systems with supermarket model "SuperSim". Part II: Model applications. Int. J. Refrig. 34, 540-549. 
[85] Sawalha S., 2013. Investigation of heat recovery in $\mathrm{CO}_{2}$ trans-critical solution for supermarket refrigeration. Int. J. Refrig. 36, 145-156.

[86] Fazelpour, F., Morosuk T., 2014. Exergoeconomic analysis of carbon dioxide transcritical refrigeration machines. Int. J. Refrig. 38, 128-139.

[87] Hafner, A., Försterling, S., Banasiak K., 2014. Multi-ejector concept for R-744 supermarket refrigeration. Int. J. Refrig. 43, 1-13.

[88] Minetto, S., Brignoli, R., Zilio, C., Marinetti, S., 2014. Experimental analysis of a new method for overfeeding multiple evaporators in refrigeration systems. Int. J. Refrig. 38, 1-9.

[89] Da Silva, A., Bandarra Filho, E.P., Pontes Antunes, A.H., 2012. Comparison of a R744 cascade refrigeration system with R404A and R22 conventional systems for supermarkets. Appl. Therm. Eng. 41, 30-35.

[90] Sanz-Kock, C., Llopis, R., Sánchez, D., Cabello. R., Torrella. E., 2014. Experimental evaluation of a $\mathrm{R} 134 \mathrm{a} / \mathrm{CO}_{2}$ cascade refrigeration plant. Appl. Therm. Eng. 73(1), 41-50.

[91] Wang, K., Eisele, M., Hwang, Y., Radermacher, R. 2010. Review of secondary loop refrigeration systems. Int. J. Refrig. 33(2), 212-234.

[92] Ust, Y., Karakurt, A.S., 2014. Analysis of a Cascade Refrigeration System (CRS) by Using Different Refrigerant Couples Based on the Exergetic Performance Coefficient (EPC) Criterion. Arab. J. Sc. Eng. 39, 8147-8156.

[93] Ciconkov, R., Ayub Z.H., 2009. New Technologies in Ammonia Refrigerating and Air-Conditioning Systems. Heat Transfer Eng. 30, 324-329.

[94] Pearson, A., 2008. Refrigeration with ammonia. Int. J. Refrig. 31(4), 545-551.

[95] Getu, H.M., Bansal P.K., 2008. Thermodynamic analysis of an R744-R717 cascade refrigeration system. Int. J. Refrig. 31, 45-54.

[96] Messineo A., 2012. R744-R717 Cascade Refrigeration System: Performance Evaluation compared with a HFC Two-Stage System. Energy Procedia 14, 5665. 
Analysis of fluoride fluids with low global warming impact in vapour compression systems. Experimental evaluation of different alternatives for commercial refrigeration.

[97] Cecchinato, L., Corradi, M., Minetto, S., 2012. Energy performance of supermarket refrigeration and air conditioning integrated systems working with natural refrigerants. Appl. Therm. Eng. 48, 378-391.

[98] Fernández-Seara, J., Dopazo, J.A., Uhía, F.J., Diz, R., 2012. Experimental Analysis of the Freezing Process in a Horizontal Plate Freezer With CO2 as Refrigerant in a Cascade Refrigeration System. Heat Transfer Eng. 33, 11701176.

[99] Inlow, S.W. Groll. E.A., 1996. Analysis of Secondary-Loop Refrigeration Systems Using Carbon Dioxide as a Volatile Secondary Refrigerant. HVAC\&R Res. 2, 107-120.

[100] Bolaji, B.O., 2010. Experimental study of R152a and R32 to replace R134a in a domestic refrigerator. Energy 35(9), 3793-3798.

[101] Bryson, M., Dixon, C., St Hill, S., 2011. Testing of HFO-1234yf and R152a as mobile air conditioning refrigerant replacements. Ecolibrium May, 30-38.

[102] Söğüt, M.Z., 2015. Investigation of Environmental Effects Based on Exergetic Irreversibility for Display Cases' Units in Commercial Cooling. Int. J. Green Energy 12, 15-22.

[103] Söğüt, M.Z., Yalcın, E., Karakoc, H., 2012. Refrigeration inventory based on $\mathrm{CO} 2$ emissions and exergetic performance for supermarket applications. Energy Build. 51, 84-92.

[104] Kilicarslan, A., Hosoz, M., 2010. Energy and irreversibility analysis of a cascade refrigeration system for various refrigerant couples. Energy Conv. Manag. 51, 2947-2954.

[105] Linde Gases Division. R407A. Lower Global Warming Potential replacement for R404A. Retrieved online at: http://www.lindegas.com/internet.global.lindegas.global/en/images/BAMPG_Refrigerants_407 A_fin17_92206.pdf (23-10-15.). 
[106] Linde Gases Division. R407F - Genetron ${ }^{\circledR}$ Performax ${ }^{\text {TM }}$ LT. Lower Global Warming Potential replacement for R404A. Retrieved online at: http://www.lindegas.com/internet.global.lindegas.global/en/images/BAMPG_Refrigerants_407 F_fin17_92205.pdf (23-10-15.).

[107] Bortolini, M., Gamberi. M., Gamberini, R., Graziani, A., Lolli, F., Regattieri, A., 2015. Retrofitting of R404a commercial refrigeration systems using R410a and R407f refrigerants. Int. J. Refrig. 55, 142-152.

[108] Environmental Protection Agency, 2014. Proposed Rule - Protection of Stratospheric Ozone: Change of Listing Status for Certain Substitutes under the Significant New Alternatives Policy Program.

[109] Rajendran, R., 2015. Navigating a new frontier in foodservice refrigerants. E360 Outlook 1(2), 14-15.

[110] Stephanie K. Barnes, 2014. Response to: Protection of Stratospheric Ozone: Change of Listing Status for Certain Substitutes Under the Significant New Alternatives Policy Program; Proposed Rule. Food Marketing Institute.

[111] Honeywell International Inc, 2012. Honeywell Solstice ${ }^{\mathrm{TM}}$ yf Refrigerants. Technical Bulletin. Retrieved online at: http://www.honeywellrefrigerants.com/europe/wp-content/uploads/2013/03/honeywell-solstice-yftechnical-bulletin.pdf (23-10-15.).

[112] Honeywell International Inc, 2014. Solstice® ze Refrigerant (HFO-1234ze). The Environmental Alternative to Traditional Refrigerants. Retrieved online at: http://www.honeywell-refrigerants.com/europe/wpcontent/uploads/2014/10/Solstice-ze-brochure-Fourth-Generation-LR140925.pdf (23-10-15.).

[113] American Society of Heating, Refrigerating and Air-Conditioning Engineers, 2013. ANSI/ASHRAE Standard 34, Designation and Safety Classification of Refrigerants. 
Analysis of fluoride fluids with low global warming impact in vapour compression systems. Experimental evaluation of different alternatives for commercial refrigeration.

[114] Honeywell International Inc., 2015. Solstice ${ }^{\circledR}$ yf Refrigerant (R-1234yf). Safety data sheet.

[115] Honeywell International Inc., 2015. Solstice ${ }^{\circledR}$ 1234ze. Safety data sheet.

[116] Qiu, G., Meng, X., Wu, J., 2013. Density measurements for 2,3,3,3tetrafluoroprop-1-ene (R1234yf) and trans-1,3,3,3-tetrafluoropropene (R1234ze(E)). J. Chem. Thermodyn. 60, 150-158.

[117] Meng, X., Qiu, G., Wu, J., Abdulagatov, I.M., 2013. Viscosity measurements for 2,3,3,3-tetrafluoroprop-1-ene (R1234yf) and trans-1,3,3,3tetrafluoropropene (R1234ze(E)). J. Chem. Thermodyn. 63, 24-30.

[118] Di Nicola, G., Brandoni, C., Di Nicola, C., Giuliani, G., 2012. Triple point measurements for alternative refrigerants. J. Therm. Anal. Calorim. 108, 627631.

[119] Brown, J.S., Zilio, C., Cavallini, A., 2010. Thermodynamic properties of eight fluorinated olefins. Int. J. Refrig. 33, 235-241.

[120] Akasaka, R., 2010. An application of the extended corresponding states model to thermodynamic property calculations for trans-1,3,3,3-tetrafluoropropene (HFO-1234ze(E)). Int. J. Refrig. 33, 907-914.

[121] Akasaka, R., 2011. New Fundamental Equations of State with a Common Functional Form for 2,3,3,3-Tetrafluoropropene (R-1234yf) and trans-1,3,3,3Tetrafluoropropene (R-1234ze(E)). Int. J. Thermophys. 32, 1125-1147.

[122] Alavianmehr, M.M., Pahlavan, F., Moghadasi, J., Hosseini, S.M., 2014. Modeling thermodynamic properties of refrigerants from new version of TaoMason equation of state. Int. J. Refrig. 45, 100-106.

[123] Lai, N.A., 2014. Equations of state for HFO-1234ze(E) and their application in the study on refrigeration cycle. Int. J. Refrig. 43, 194-202.

[124] Lai, N.A., Vrabec, J., Raabe, G., Fischer, J., Wendland, M., 2011. Description of HFO-1234yf with BACKONE equation of state. Fluid Phase Equilib. 305(2), 204-211. 
[125] Kondo, S., Takizawa, K., Tokuhashi, K., 2014. Effect of high humidity on flammability property of a few non-flammable refrigerants. J. Fluorine Chem. $161,29-33$.

[126] Kondo, S., Takizawa, K., Tokuhashi, K., 2012. Effects of temperature and humidity on the flammability limits of several $2 \mathrm{~L}$ refrigerants. J. Fluorine Chem. 144, 130-136.

[127] Lewandowski, T.A., 2012. Risk Assessment of Residential Heat Pump Systems Using 2L Flammable Refrigerants. AHRI Project 8004 Final Report.

[128] Imamura, T., Kamiya, K., Sugawa, O., 2015. Ignition hazard evaluation on A2L refrigerants in situations of service and maintenance. Journal of Loss Prevention in the Process Industries 36, 553-561.

[129] Wang, C.C., 2013. An overview for the heat transfer performance of HFO1234yf. Renew. Sust. Energy Rev. 19, 444-453.

[130] Lee, Y., Kang, D.G., Kim, J.H., Jung, D., 2014. Nucleate boiling heat transfer coefficients of HFO1234yf on various enhanced surfaces. Int. J. Refrig. 38, 198-205.

[131] Han, X., Li, P., Yuan, X., Wang, Q., Chen, G., 2013. The boiling heat transfer characteristics of the mixture HFO-1234yf/oil inside a micro-fin tube. Int. J. Heat Mass Tran. 67, 1122-1130.

[132] Anwar, Z., Palm, B., Khodabandeh, R., 2015. Flow boiling heat transfer, pressure drop and dryout characteristics of R1234yf: Experimental results and predictions. Exp. Therm. Fluid Sci. 66, 137-149.

[133] Illán-Gómez, F., López-Belchí, A., García-Cascales, J.R., Vera-García, F., 2015. Experimental two-phase heat transfer coefficient and frictional pressure drop inside mini-channels during condensation with R1234yf and R134a. Int. J. Refrig. 51, 12-23.

[134] Grauso, S., Mastrullo, R., Mauro, A.W., Thome, J.R., Vanoli, G.P., 2013. Flow pattern map, heat transfer and pressure drops during evaporation of R- 
Analysis of fluoride fluids with low global warming impact in vapour compression systems. Experimental evaluation of different alternatives for commercial refrigeration.

1234ze(E) and R134a in a horizontal, circular smooth tube: Experiments and assessment of predictive methods. Int. J. Refrig. 36, 478-491.

[135] Kedzierski, M.A., Park, K.J., 2014. Horizontal Convective Boiling of R134a, R1234yf/R134a, and R1234ze(E) within a Micro-Fin Tube with Extensive Measurement and Analysis Details. NIST Technical Note 1807, doi: 10.6028/NIST.TN.1807.

[136] Diani, A., Mancin, S., Rossetto, L., 2014. R1234ze(E) flow boiling inside a 3.4 mm ID microfin tube. Int. J. Refrig. 47, 105-119.

[137] Righetti, G. Zilio, C. Longo, G.A., 2015. Comparative performance analysis of the low GWP refrigerants HFO1234yf, HFO1234ze(E) and HC600a inside a roll-bond evaporator. Int. J. Refrig. 54, 1-9.

[138] Mancin, S., Diani, A., Doretti, L., Rossetto, L., 2014. R134a and R1234ze(E) liquid and flow boiling heat transfer in a high porosity copper foam. Int. J. Heat Mass Transf. 74, 77-87.

[139] Vakili-Farahani, F., Agostini, B., Thome, J.R., 2013. Experimental study on flow boiling heat transfer of multiport tubes with R245fa and R1234ze(E). Int. J. Refrig. 36, 335-352.

[140] Van Rooyen, E., Thome, J.R., 2013. Pool boiling data and prediction method for enhanced boiling tubes with R-134a, R-236fa and R-1234ze(E). Int. J. Refrig. 36, 447-455.

[141] Del Col, D., Bortolato, M., Azzolin, M., Bortolin, S. 2015. Condensation heat transfer and two-phase frictional pressure drop in a single minichannel with R1234ze(E) and other refrigerants. Int. J. Refrig. 50, 87-103.

[142] Longo, G.A., Zilio, C., Righetti, G., Brown, J.S., 2014. Condensation of the low GWP refrigerant HFO1234ze(E) inside a brazed plate heat exchanger. Int. J. Refrig. 38, 250-259.

[143] Park, J.E., Vakili-Farahani, F., Consolini, L., Thome, J.R., 2011. Experimental study on condensation heat transfer in vertical minichannels for new 
refrigerant R1234ze(E) versus R134a and R236fa. Exp. Therm. Fluid Sci. 35, $442-454$.

[144] Agarwal, R., Hrnjak, P., 2014. Effect of sensible heat, condensation in superheated and subcooled region incorporated in unified model for heat rejection in condensers in horizontal round smooth tubes. Appl. Therm. Eng. 71, 378-388.

[145] Agarwal, R., Hrnjak, P., 2015. Condensation in two phase and desuperheating zone for R1234ze(E), R134a and R32 in horizontal smooth tubes. Int. J. Refrig. $50,172-183$.

[146] Spatz, M., Minor, B., 2008. HFO-1234yf: A low GWP refrigerant for MAC. VDA Alternative refrigerant. Winter Meeting, Saalfelden, Australia.

[147] European Comission, June 21, 2013. Implementation of Directive 2006/40/EC - State of play. Brussels, Belgium.

[148] European Comission, January 23, 2014. Refrigerants used in mobile air condition systems (MAC) - State of play. Brussels, Belgium.

[149] Lee, Y., Jung, D., 2012. A brief performance comparison of R1234yf and R134a in a bench tester for automobile applications. Appl. Therm. Eng. 35, 240-242.

[150] Zilio, C., Brown, J.S., Schiochet, G., Cavallini, A., 2011. The refrigerant R1234yf in air conditioning systems. Energy 36, 6110-6120.

[151] Qi, Z., 2015. Performance Improvement Potentials of R1234yf Mobile Air Conditioning System. Int. J. Refrig. 58, 35-40.

[152] Jarall, S., 2012. Study of refrigeration system with HFO-1234yf as a working fluid. Int. J. Refrig. 35, 1668-1677.

[153] Navarro-Esbrí, J., Mendoza-Miranda, J.M., Mota-Babiloni, A., BarragánCervera, A., Belman-Flores, J.M., 2013. Experimental analysis of R1234yf as a drop-in replacement for R134a in a vapor compression system. Int. J. Refrig. $36,870-880$. 
Analysis of fluoride fluids with low global warming impact in vapour compression systems. Experimental evaluation of different alternatives for commercial refrigeration.

[154] Wang, C.C., 2014. System performance of R-1234yf refrigerant in airconditioning and heat pump system - An overview of current status. Appl. Therm. Eng. 73(2), 1412-1420.

[155] Pottker, G., Hrnjak, P., 2015. Effect of the condenser subcooling on the performance of vapor compression systems. Int. J. Refrig. 50, 156-164.

[156] Navarro-Esbrí, J., Molés, F., Barragán-Cervera, Á., 2013. Experimental analysis of the internal heat exchanger influence on a vapour compression system performance working with R1234yf as a drop-in replacement for R134a. Appl. Therm. Eng. 59(1-2), 153-161.

[157] Cho, H., Lee, H., Park, C., 2013. Performance characteristics of an automobile air conditioning system with internal heat exchanger using refrigerant R1234yf. Appl. Therm. Eng. 61(2), 563-569.

[158] Mota-Babiloni, A., Navarro-Esbrí, J., Barragán, Á., Molés, F., Peris, B., 2014. Drop-in energy performance evaluation of R1234yf and R1234ze(E) in a vapor compression system as R134a replacements. Appl. Therm. Eng. 71(1) 259-265.

[159] Spatz, M.W., Sethi, A., Yana Motta, S.F., 2012. Latest Developments of Low Global Warming Refrigerants for Chillers. 14th International Refrigeration and Air Conditioning Conference at Purdue West Lafayette, USA, Paper 1352.

[160] Spatz, M. W., 2012. Latest Developments of Low Global Warming Refrigerants for Chillers. Chillventa, Nuremburg, Germany.

[161] Brasz, J.J., September 9-10, 2013. Oil-free centrifugal refrigeration compressors: from HFC134a to HFO1234ze(E). 8th International Conference on Compressors and their Systems, London, UK.

[162] Janković, Z., Sieres Atienza, J., Martínez Suárez, J.A., 2015. Thermodynamic and heat transfer analyses for R1234yf and R1234ze(E) as drop-in replacements for R134a in a small power refrigerating system. Appl. Therm. Eng. 80, 42-54. 
[163] Karber, K.M., Abdelaziz, O., Vineyard, E.A., 2012. Experimental Performance of R-1234yf as a Drop-in Replacement for R-134a in Domestic Refrigerators. 14th International Refrigeration and Air Conditioning Conference at Purdue West Lafayette, USA, Paper 1228.

[164] Leighton, D., Hwang, Y., Radermacher, R., 2012. Modeling of Household Refrigerator Performance with Low Global Warming Potential Alternative Refrigerants. ASHRAE Trans. 118, 658-665.

[165] Yana Motta, S.F., Vera Becerra, E.D., Spatz, M.W., 2010. Analysis of LGWP Alternatives for Small Refrigeration (Plugin) Applications. 13th International Refrigeration and Air Conditioning Conference at Purdue West Lafayette, USA, Paper 1149.

[166] Majurin, J., Staats, S.J., Sorenson, E., Gilles, W., 2015. Material Compatibility of HVAC\&R System Materials with Low GWP Refrigerants. Sci. Technol. Built Env. 21, 491-501.

[167] Wasim Akram, M., Polychronopoulou, K., Polycarpou, A.A., 2013. Lubricity of environmentally friendly HFO-1234yf refrigerant. Tribol. Int. 57, 92-100.

[168] Wasim Akram, M., Polychronopoulou, K., Polycarpou, A.A., 2014. Tribological performance comparing different refrigerant-lubricant systems: The case of environmentally friendly HFO-1234yf refrigerant. Tribol. Int. 78, $176-186$.

[169] Bobbo, S., Zilio, C., Scattolini, M., Fedele, L., 2014. R1234yf as a substitute of R134a in automotive air conditioning. Solubility measurements in two commercial PAG oils. Int. J. Refrig. 40, 302-308.

[170] Sun, Y., Wang, X., Gong, N., Liu, Z., 2015. Solubility of trans-1,3,3,3tetrafluoropropene (R1234ze(E)) in pentaerythritol ester heptanoic acid (PEC7) and in pentaerythritol tetranonanoate (PEC9) between $283.15 \mathrm{~K}$ and $353.15 \mathrm{~K}$. Fluid Phase Equilib. 387, 154-159. 
Analysis of fluoride fluids with low global warming impact in vapour compression systems. Experimental evaluation of different alternatives for commercial refrigeration.

[171] Sarbu, I., 2014. A review on substitution strategy of non-ecological refrigerants from vapour compression-based refrigeration, air-conditioning and heat pump systems. Int. J. Refrig., 46, 123-141,

[172] Mota-Babiloni, A., Navarro-Esbrí, J., Barragán-Cervera, A., Moles, F., Peris, B., 2015. Analysis based on EU regulation no 517/2014 of new HFC/HFO mixtures as alternatives of high GWP refrigerants in refrigeration and HVAC systems. Int. J. Refrig. 52, 21-31.

[173] Dang, Y., Kim, H.S., Dang, C., Hihara, E., 2015. Measurement of vapor viscosity of R1234yf and its binary mixtures with R32, R125. Int. J. Refrig. 58, 131-136.

[174] Dang, Y., Kamiaka, T., Dang, C., Hihara, E., 2015. Liquid viscosity of lowGWP refrigerant mixtures (R32 + R1234yf) and (R125 + R1234yf). J. Chem. Thermodyn. 89, 183-188.

[175] Chen, Q., Qi, H., Zhang, S., Hong, R., Chen, G., 2015. An experimental study of PVTx properties in the gas phase for binary mixtures of HFO-1234yf and HFC-134a. Fluid Phase Equilib. 385, 25-28.

[176] Chen, L.X., Hu, P., Zhu, W.B., Jia, L., Chen, Z.S., 2015. Vapor-liquid equilibria of fluoroethane (HFC-161) + 2,3,3,3-tetrafluoroprop-1-ene (HFO1234yf). Fluid Phase Equilib. 392, 19-23.

[177] Hu, P., Chen, L.X., Zhu, W.B., Jia, L., Chen, Z.S., 2014. Vapor-liquid equilibria for the binary system of 2,3,3,3-tetrafluoroprop-1-ene (HFO-1234yf) + 1,1,1,2,3,3,3-heptafluoropropane (HFC-227ea). Fluid Phase Equilib. 379, $59-61$.

[178] Hu, P., Chen, L.X., Zhu, W.B., Jia, L., Chen, Z.S., 2014. Isothermal VLE measurements for the binary mixture of 2,3,3,3-tetrafluoroprop-1-ene (HFO1234yf) + 1,1-difluoroethane (HFC-152a). Fluid Phase Equilib. 373, 80-83. 
[179] Hu, P., Chen, L.X., Chen, Z.S., 2014. Vapor-liquid equilibria for binary system of 2,3,3,3-tetrafluoroprop-1-ene (HFO-1234yf) + isobutane (HC-600a). Fluid Phase Equilib. 365, 1-4,

[180] Hu, P., Chen, L.X., Chen, Z.S., 2013. Vapor-liquid equilibria for the 1,1,1,2tetrafluoroethane (HFC-134a) + 1,1,1,2,3,3,3-heptafluoropropane (HFC-227ea) and 1,1,1-trifluoroethane (HFC-143a) + 2,3,3,3-tetrafluoroprop-1-ene (HFO1234yf) systems. Fluid Phase Equilib. 360, 293-297.

[181] Dong, X., Guo, H., Gong, M., Yang, Z., Wu, J., 2013. Measurements of isothermal (vapour + liquid) equilibria data for $\{1,1,2,2$-Tetrafluoroethane $(\mathrm{R} 134)+$ trans-1,3,3,3-tetrafluoropropene $(\mathrm{R} 1234 \mathrm{ze}(\mathrm{E}))\}$ at $\mathrm{T}(258.150$ to 288.150)K. J. Chem. Thermodyn. 60, 25-28.

[182] Yang, Z., Gong, M., Guo, H., Dong, X., Wu, J., 2013. Phase equilibrium for the binary mixture of \{1,1-difluoroethane $(\mathrm{R} 152 \mathrm{a}+$ trans-1,3,3,3tetrafluoropropene (R1234ze (E)) \} at various temperatures from 258.150 to 288.150 K. Fluid Phase Equilib. 355, 99-103.

[183] He, M., Qi, X., Liu, X., Su, C., Lv, N., 2015. Estimating the Viscosity of Pure Refrigerants and Their Mixtures by Free-Volume Theory. Int. J. Refrig. 54, $55-56$.

[184] Akasaka, R., 2013. Thermodynamic property models for the difluoromethane $(\mathrm{R}-32)+$ trans-1,3,3,3-tetrafluoropropene (R-1234ze(E)) and difluoromethane + 2,3,3,3-tetrafluoropropene (R-1234yf) mixtures. Fluid Phase Equilib. 358, 98-104.

[185] Di Nicola, G., Passerini, G., Polonara, F., Stryjek, R., 2013. PVTx measurements of the carbon dioxide + trans-1,3,3,3-tetrafluoroprop-1-ene binary system. Fluid Phase Equilib. 360, 124-128.

[186] Di Nicola, G., Arteconi, A., Nardini, G., Stryjek, R., 2013. Solid-liquid equilibria measurements of the carbon dioxide $+2,3,3,3$-tetrafluoroprop-1-ene 
Analysis of fluoride fluids with low global warming impact in vapour compression systems. Experimental evaluation of different alternatives for commercial refrigeration.

and carbon dioxide + trans-1,3,3,3-tetrafluoropropene mixtures. Fluid Phase Equilib. 354, 54-58.

[187] Kiani, M., Papari, M.M., Nowruzian, Z., Moghadasi, J., 2015. Application of modified Tao-Mason equation of state to refrigerant mixtures. Korean J. Chem. Eng. 32, 1361-1368.

[188] Dong, X., Gong, M., Shen, J., Wu, J., 2011. Experimental measurement of vapor-liquid equilibrium for (trans-1,3,3,3-tetrafluoropropene $(\mathrm{R} 1234 \mathrm{ze}(\mathrm{E}))+$ propane (R290)). Int. J. Refrig. 34, 1238-1243.

[189] Kondo, S., Takizawa, K., Tokuhashi, K., 2013. Flammability limits of binary mixtures of ammonia with HFO-1234yf, HFO-1234ze, HFC-134a, and HFC125. J. Fluorine Chem. 149, 18-23.

[190] Yang, Z., Wu, X., Wang, X., Tian, T., 2015. Research on the Flammable Characteristics of Fluoroethane (R161) and Its Binary Blends. Int. J. Refrig. 56, 235-245.

[191] Li, M., Dang, C., Hihara, E., 2012. Flow boiling heat transfer of HFO1234yf and R32 refrigerant mixtures in a smooth horizontal tube: Part I. Experimental investigation. Int. J. Heat Mass Tran. 55(13-14), 3437-3446.

[192] Koyama, S., Takata, N., Fukuda, S., 2010. Drop-in Experiments on Heat Pump Cycle Using HFO-1234ze(E) and Its Mixtures with HFC-32. 13th International Refrigeration and Air Conditioning Conference at Purdue West Lafayette, USA, Paper 1155.

[193] Hossain, A., Onaka, Y., Afroz, H.M.M., Miyara, A., 2013. Heat transfer during evaporation of R1234ze(E), R32, R410A and a mixture of R1234ze(E) and R32 inside a horizontal smooth tube. Int. J. Refrig. 36, 465-477.

[194] Kondou, C., BaBa, D., Mishima, F., Koyama, S., 2013. Flow boiling of nonazeotropic mixture R32/R1234ze(E) in horizontal microfin tubes. Int. J. Refrig. $36,2366-2378$. 
[195] Wang, X., Amrane, K., 2014. AHRI Low Global Warming Potential Alternative Refrigerants Evaluation Program (Low-GWP AREP) - Summary of Phase I Testing Results. 15th International Refrigeration and Air Conditioning Conference at Purdue, West Lafayette, USA, Paper 1416.

[196] Hickman, K., 2013. Reference list for low GWP refrigerants testing AirConditioning, Heating, and Refrigeration Institute (AHRI) Low-GWP Alternative Refrigerants Evaluation Program (Low-GWP AREP). Lit. Rev.

[197] Shapiro, D., 2013. System Drop-In Tests of R-134a, R-1234yf, Opteon ${ }^{\mathrm{TM}}$ XP10, R-1234ze(E), and N13a in a Commercial Bottle Cooler/Freezer. AirConditioning, Heating, and Refrigeration Institute (AHRI) Low-GWP Alternative Refrigerants Evaluation Program (Low-GWP AREP). TEST REPORT \#8.

[198] Kopecka, M., Hegar, M., Sulc, V., Berge, J., 2013. System Drop-In Tests of Refrigerant Blends L-40, DR-7 and ARM-30a in a Trailer Refrigeration Unit Designed for R-404A. Air-Conditioning, Heating, and Refrigeration Institute (AHRI) Low-GWP Alternative Refrigerants Evaluation Program (Low-GWP AREP). TEST REPORT \#9.

[199] Schlosser, C., 2012. System Drop-in Test of L-40, L-41a and N-40b in Ice Machines. Air-Conditioning, Heating, and Refrigeration Institute (AHRI) Low-GWP Alternative Refrigerants Evaluation Program (Low-GWP AREP). TEST REPORT \#2.

[200] Minor, B., Leck, T., August 14, 2013. Update on DuPont low GWP HFObased technologies. OzonAction Webinar.

[201] Yana Motta, S.F. Low-GWP Refrigerants for Air Conditioning and Refrigeration Applications. Retrieved online at: http://www.unep.org/ozonaction/Portals/105/documents/virtualexpo/IIIHoneywell_Samuel\%20Yana-Motta.pdf_(23.10.15.). 
Analysis of fluoride fluids with low global warming impact in vapour compression systems. Experimental evaluation of different alternatives for commercial refrigeration.

[202] Mota-Babiloni, A., Navarro-Esbrí, J., Barragán-Cervera, Á., Molés, F., Peris, B., 2015. Experimental study of an R1234ze(E)/R134a mixture (R450A) as R134a replacement, Int. J. Refrig. 51, 52-58.

[203] Schultz, K., Kujak, S., 2013. System Drop-In Tests of R134a Alternative Refrigerants (ARM-42a, N-13a, N-13b, R-1234ze(E), and Opteon ${ }^{\mathrm{TM}}$ XP10) in a 230-RT Water-Cooled Water Chiller. Air-Conditioning, Heating, and Refrigeration Institute (AHRI) Low-GWP Alternative Refrigerants Evaluation Program (Low-GWP AREP). TEST REPORT \#7.

[204] Tewis Smart Solutions, 2014, El rigor y metodología demuestran los beneficios del R450A* (Solstice ${ }^{\circledR}$ N13) en su carrera hacia un futuro, Retrieved online at: http://www.tewis.com/newtewis/blog/descargas/Tewis_Mayo_14.pdf (23.10.15.).

[205] Honeywell International Inc, 2014. Solstice ${ }^{\circledR}$ N13 (R-450A). Innovative Refrigeration System, Combining the 'Best of Both Worlds'. Retrieved online at: $\quad$ http://www.honeywell-refrigerants.com/europe/wpcontent/uploads/2014/10/Case_Study_Groupe_Auchan_Solstice_N13_4pp_L R-140923.pdf (23.10.15.).

[206] Linde Gases Division. R449A - Opteon ${ }^{\circledR}$ XP40. Lower global warming potential replacement for R404A and R507. Retrieved online at: https://www.boconline.co.uk/internet.lg.lg.gbr/en/images/BAMPG_Refrigeran ts_R449A410_140677.pdf (23.10.15.).

[207] Mota-Babiloni, A., Navarro-Esbrí, J., Barragán, Á., Molés, F., Peris, B., 2014. Theoretical comparison of low GWP alternatives for different refrigeration configurations taking R404A as baseline. Int. J. Refrig. 44, 81-90.

[208] Yana Motta, S.F., Spatz, M.W., Vera Becerra, E., July 16-19, 2012. Low global warming refrigerants for commercial refrigeration systems. 14th 
International Refrigeration and Air Conditioning Conference at Purdue, West Lafayette, USA, Paper 1351.

[209] Rajendran, R., 2014. Promising Lower GWP Refrigerants In Air-Conditioning And Refrigeration Systems. Retrieved online at: http://www.unep.fr/bangkoktechconference/docs/IIIB2\%20Rajan\%20Rajendran_Bangkok\%20Technical\%20Conference\%202013\% 20Final.pdf (23.10.15.).

[210] Prapainop, R., Suen, K.O., 2012. Effects of refrigerant properties on refrigerant performance comparison: A review. Int. J. Eng. Res. App. (IJERA) 2(4), 486-493.

[211] Honeywell, 2012. Technology issues regarding Blends of Refrigerants. Retrieved online at: http://www.honeywellrefrigerants.com/europe/?document=honeywell-blends-technology-issues2012-presentation \& download=1 (23.10.15.).

[212] Lemmon, E.W., Huber, M.L., McLinden, M.O., REFPROP, 2014. NIST Standard Reference Database 23. v.9.1. National Institute of Standards, Gaithersburg, MD, USA.

[213] Tillner-Roth, R., Baehr, H.D., 1994. An international standard formulation of the thermodynamic properties of 1,1,1,2-tetrafluoroethane (HFC-134a) for temperatures from $170 \mathrm{~K}$ to $455 \mathrm{~K}$ at pressures up to $70 \mathrm{MPa}$. J. Phys. Chem. Ref. Data 23, 657-729.

[214] Richter, M., McLinden, M.O., Lemmon, E.W., 2011. Thermodynamic Properties of 2,3,3,3-Tetrafluoroprop-1-ene (R1234yf): Vapor Pressure and prho-T Measurements and an Equation of State. J. Chem. Eng. Data 56(7), 3254-3264.

[215] Thol, M., Lemmon, E.W., 2013. To be published in Int. J. Thermophys. 
Analysis of fluoride fluids with low global warming impact in vapour compression systems. Experimental evaluation of different alternatives for commercial refrigeration.

[216] Suess, J., Rasmussen, B. D., and Jakobsen, A., 2000. Impact of Refrigerant Fluid Properties on the Compressor Selection. International Compressor Engineering Conference at Purdue, West Lafayette, USA, Paper 1388.

[217] Taylor, J.R., 1997. An Introduction to Error Analysis, second ed. University Science Books, Sausalito.

[218] Mota-Babiloni, A., Navarro-Esbrí, J., Barragán, A., Molés, F., Peris, B., 2015 Drop-in analysis of an internal heat exchanger in a vapour compression system using R1234ze(E) and R450A as alternatives for R134a. Energy 90, 16361644.

[219] Mota-Babiloni, A., Navarro-Esbrí, J., Barragán, A., Molés, F., Peris, B., Verdú, G., 2015. Evaluación de Alternativas al R404A en Tuberías de Sistemas de Refrigeración. Revista Iberoamericana de Ingeniería Mecánica 19(1), 17-27. 
Analysis of fluoride fluids with low global warming impact in vapour compression systems. Experimental evaluation of different alternatives for commercial refrigeration.

\section{PhD Activities}

Articles in JCR indexed journals

1. Molés, F., Navarro-Esbrí, J., Peris, B., Mota-Babiloni, A., 2016. Experimental evaluation of HCFO-1233zd-e as HFC-245fa replacement in an organic rankine cycle system for low temperature heat sources. Appl. Therm. Eng. http://dx.doi.org/10.1016/j.applthermaleng.2016.01.011.

2. Mendoza-Miranda, J.M., Mota-Babiloni, A., Navarro-Esbrí, J., 2016. Evaluation of R448A and R450A as Low-GWP alternatives for R404A and R134a using a micro-fin tubes evaporator model. Appl. Therm. Eng. 98, 330339.

3. Mota-Babiloni, A., Navarro-Esbrí, J., Molés, F., Peris, B. Verdú. G., 2016. A review of refrigerant R1234ze(E) recent investigations. Appl. Therm. Eng. 95, 211-222.

4. Mota-Babiloni, A., Navarro-Esbrí, J., Barragán, A., Molés, F., Peris, B., 2015 Drop-in analysis of an internal heat exchanger in a vapour compression system using R1234ze(E) and R450A as alternatives for R134a. Energy 90, 16361644. 
5. Mota-Babiloni, A., Navarro-Esbrí, J., Peris, B., Molés, F., Verdú. G., 2015 Experimental evaluation of R448A as R404A lower-GWP alternative in refrigeration systems. Energy Conv. Manag. 105, 756-762.

6. Molés, F., Navarro-Esbrí, J., Peris, B., Mota-Babiloni, A., Kontomaris, K., 2015. Thermodynamic analysis of a combined organic Rankine cycle and vapor compression cycle system activated with low temperature heat sources using low GWP fluids. Appl. Therm. Eng. 87, 444-453.

7. Navarro-Esbrí, J., Milián, V., Mota-Babiloni, A., Molés, F., Verdú, G., 2015. Effect of mean void fraction correlations on a shell-and- tube evaporator dynamic model performance. Science and Technology for the Built Environment, 21(7), 1057-1072.

8. Mota-Babiloni, A., Navarro-Esbrí, J., Barragán, A., Molés, F., Peris, B., Verdú, G., 2015. Commercial refrigeration - An overview of current status. Int. J. Refrigeration 57, 186-196.

9. Peris, B., Navarro-Esbrí, J., Molés, F., Martí, J.P., Mota-Babiloni, A., 2015. Experimental study of an ORC (organic Rankine cycle) for low grade waste heat recovery in a ceramic industry. Energy 85, 534-542.

10. Mota-Babiloni, A., Navarro-Esbrí, J., Barragán, A., Molés, F., Peris, B., 2015. Analysis based on EU Regulation No 517/2014 of new HFC/HFO mixtures as alternatives of high GWP refrigerants in refrigeration and HVAC systems. Int. J. Refrigeration 52, 21-31.

11. Peris, B., Navarro-Esbrí, J., Molés, F., Martí, J.P., Mota-Babiloni, A., 2015. Experimental characterization of an Organic Rankine Cycle (ORC) for microscale CHP applications. Appl. Therm. Eng. 79, 1-8.

12. Peris, B., Navarro-Esbrí, J., Molés, F., González, M., Mota-Babiloni, A., 2015. Performance evaluation of an Organic Rankine Cycle (ORC) for power and CHP (combined heat and power) applications from low grade heat sources. Energy 82, 269-276. 
Analysis of fluoride fluids with low global warming impact in vapour compression systems. Experimental evaluation of different alternatives for commercial refrigeration.

13. Peris, B., Navarro-Esbrí, J., Molés, F., Collado, R., Mota-Babiloni, A., 2015. Performance evaluation of an Organic Rankine Cycle (ORC) for power applications from low grade heat sources. Appl. Therm. Eng. 75, 763-769.

14. Mota-Babiloni, A., Navarro-Esbrí, J., Barragán, A., Molés, F., Peris, B., 2015. Experimental study of an R1234ze/R134a mixture (R450A) as R134a replacement. Int. J. Refrigeration 51, 52-58.

15. Mendoza-Miranda, J.M., Belman-Flores, J.M., Gallegos-Muñoz, A., MotaBabiloni, A., Navarro-Esbrí, J., 2014. Computational tool for experimental refrigeration system analysis using spreadsheets. DYNA 89 (6), 0-10.

16. Mota-Babiloni, A., Navarro-Esbrí, J., Barragán, A., Molés, F., Peris, B., 2014. Drop-in energy performance evaluation of R1234yf and R1234ze(E) in a vapour compression system as R134a replacements. Appl. Therm. Eng. 71(1), 259-265.

17. Molés, F., Navarro-Esbrí, J., Peris, B., Mota-Babiloni, A., Barragán-Cervera, A., 2014. Low GWP alternatives to HFC-245fa in Organic Rankine Cycles for low temperature heat recovery: HCFO-1233zd-E and HFO-1336mzz-Z. Appl. Therm. Eng. 71(1), 204-212.

18. Molés, F., Navarro-Esbrí, J., Peris, B., Mota-Babiloni, A., Barragán-Cervera, A., 2014. Theoretical energy performance evaluation of different single stage vapour compression refrigeration configurations using R1234yf and R1234ze(E) as working fluids. Int. J. Refrigeration 44, 141-150.

19. Mota-Babiloni, A., Navarro-Esbrí, J., Barragán, A., Molés, F., Peris, B., 2014. Theoretical comparison of low GWP alternatives for different refrigeration configurations taking R404A as baseline. Int. J. Refrigeration 44, 81-90.

20. Navarro-Esbrí, J., Molés, F., Peris, B., Barragán-Cervera, A., MendozaMiranda, J.M., Mota-Babiloni, A., Belman, J.M., 2014. Shell-and-tube evaporator model performance with different two-phase flow heat transfer 
correlations. Experimental analysis using R134a and R1234yf. Appl. Therm. Eng. 62(1), 80-89.

21. Navarro-Esbrí, J., Mendoza-Miranda, J.M., Mota-Babiloni, A., BarragánCervera, A., Belman-Flores, J.M., 2013. Experimental analysis of R1234yf as a drop-in replacement for R134a in a vapor compression system. Int. J. Refrigeration 36(3) 870-880.

Articles in non-JCR indexed journals.

1. Mota-Babiloni, A., Navarro-Esbrí, J., Barragán, A., Molés, F., Peris, B., Verdú, G., 2015. Análisis basado en el Reglamento (UE) No 517/2014 del R448A como fluido de bajo PCA alternativo al R404A. Frio Calor Aire Acondicionado 43(479), 14-20.

2. Mota-Babiloni, A., Navarro-Esbrí, J., Barragán, A., Molés, F., Peris, B., Verdú, G., 2015. Evaluación de Alternativas al R404A en Tuberías de Sistemas de Refrigeración. Revista Iberoamericana de Ingeniería Mecánica 19(1), 17-27.

3. Mendoza-Miranda, J.M., Mota-Babiloni, A., Navarro-Esbrí, J., Belman-Flores J.M., Rubio-Arana. J.C., Peris-Pérez, B., Molés-Ribera, F., 2013. Evaluación del R134a, R1234yf y R152a para sistemas de refrigeración. Revista Iberoamericana de Ingeniería Mecánica 17(2), 03-11.

\section{International conferences}

1. Peris, B., Navarro-Esbrí, J., Molés, F., Mota-Babiloni, A. ORC Applications from Low Grade Heat Sources. 3rd International Seminar on ORC Power Systems (ASME ORC 2015), Paper 134, Brussels, Belgium; 12-14 October 2015. 
Analysis of fluoride fluids with low global warming impact in vapour compression systems. Experimental evaluation of different alternatives for commercial refrigeration.

2. Navarro-Esbrí, J., Molés, F., Peris, B., Mota-Babiloni, A. Small Scale ORC Design for a Cogeneration Solar Biomass Suported Application. 3rd International Seminar on ORC Power Systems (ASME ORC 2015), Paper 93, Brussels, Belgium; 12-14 October 2015.

3. Mota-Babiloni, A., Navarro-Esbrí, J., Barragán, A., Molés, F., Peris, B., Verdú, G. Efectos del Reglamento (UE) No 517/2014 sobre el R134a. HFO puros y mezclas como alternativas. XIII Congreso Ibero-Americano de Climatización y Refrigeración (CIAR), Madrid, Spain, 28-30 April 2015.

4. Mota-Babiloni, A., Navarro-Esbrí, J., Barragán, A., Molés, F., Peris, B., Verdú, G. Efectos del Reglamento (UE) No 517/2014 sobre el R404A. R448A como alternativa. XIII Congreso Ibero-Americano de Climatización y Refrigeración (CIAR), Madrid, Spain, 28-30 April 2015.

5. Peris, B., Navarro-Esbrí, J., Molés, F., Mota-Babiloni, A., Barragán-Cervera, Á. Mejora de un Sistema de Cogeneración mediante el Ciclo Rankine Orgánico (ORC). XIII Congreso Ibero-Americano de Climatización y Refrigeración (CIAR), Madrid, Spain, 28-30 April 2015.

6. Mota-Babiloni, A., Navarro-Esbrí, J., Barragán, A., Molés, F., Peris, B., Belman-Flores, J.M. Dimensionado de tuberías para mezclas HFC/HFO en sistemas al R404A. 1er Reunión Latinoamericana de Estudiantes de Posgrado, Salamanca, Guanajuato, Mexico, 8-10 October 2014.

7. Mota-Babiloni, A., Navarro-Esbrí, J., Barragán, A., Molés, F., Peris, B., Belman-Flores, J.M. Capacidad Frigorífica de Alternativas al R134a en una Instalación Experimental. XX Congreso Internacional Anual de la SOMIM, Juriquilla, Querétaro, Mexico, 24-26 September 2014. 
8. Mota-Babiloni, A., Navarro-Esbrí, J., Barragán, A., Molés, F., Peris, B. Evaluación de la sustitución del R404A por R407F en aplicaciones de refrigeración comercial. CYTEF 2014, VII Congreso Ibérico y V Iberoamericano de Ciencias y Técnicas del Frío, Tarragona, Spain, 18-20 June 2014.

9. Molés, F., Navarro-Esbrí, J., Mota-Babiloni, A., Barragán, A., Peris, B. Mejora de la eficiencia energética en un drop-in con R1234yf mediante el uso de un intercambiador subenfriamiento-recalentamiento. CYTEF 2014, VII Congreso Ibérico y V Iberoamericano de Ciencias y Técnicas del Frío, Tarragona, Spain, 18-20 June 2014.

10. Barragán, A., Navarro-Esbrí, J., Mota-Babiloni, A., Molés, F., Peris, B. Dimensionado de tuberías para refrigerantes de bajo PCA como alternativas al R134a. CYTEF 2014, VII Congreso Ibérico y V Iberoamericano de Ciencias y Técnicas del Frío, Tarragona, Spain, 18-20 June 2014.

11. Barragán, A., Mota-Babiloni, A., Navarro-Esbrí, J., Molés, F., Peris, B. Revisión de nuevas alternativas fluoradas de bajo potencial de calentamiento atmosférico en climatización y refrigeración. CYTEF 2014, VII Congreso Ibérico y V Iberoamericano de Ciencias y Técnicas del Frío, Tarragona, Spain, 18-20 June 2014.

12. Mota-Babiloni, A., Mendoza-Miranda, J.M., Navarro-Esbrí, J., Milián-Sánchez, V., Barragán-Cervera, A. Comparación Experimental de Correlaciones utilizadas en Ebullición Forzada con R134a. XVIII Congreso Internacional Anual de la SOMIM, Salamanca, Guanajuato, Mexico, 19-21 September 2012.

13. Mendoza-Miranda, J.M., Mota-Babiloni, A., Navarro-Esbrí, J., Belman, J.M., Barragán-Cervera, A. Aplicación en Microsoft Excel para Análisis de Datos Experimentales en una Instalación de Compresión de Vapor. IV Congreso Iberoamericano de Ciencias y Técnicas del Frío, Madrid, Spain, 22-24 February 2012. 
Analysis of fluoride fluids with low global warming impact in vapour compression systems. Experimental evaluation of different alternatives for commercial refrigeration.

\section{National conferences}

1. Peris, B., Navarro-Esbrí, J., Molés, F., Mota-Babiloni, A. Optimización teórica del ciclo Rankine orgánico (ORC) para el aprovechamiento de fuentes térmicas de baja temperatura. IX Congreso Nacional de Ingeniería Termodinámica, Cartagena, Spain, 3-5 June 2015.

2. Peris, B., Navarro-Esbrí, J., Molés, F., Mota-Babiloni, A. Modelado del Ciclo Rankine Orgánico (ORC) a partir de datos experimentales. IX Congreso Nacional de Ingeniería Termodinámica, Cartagena, Spain, 3-5 June 2015.

3. Molés, F., Navarro-Esbrí, J., Peris, B., Mota-Babiloni, A. Evaluación teórica de fluidos de trabajo con bajo potencial de efecto invernadero como alternativas al HFC-245fa en ciclos orgánicos Rankine. IX Congreso Nacional de Ingeniería Termodinámica, Cartagena, Spain, 3-5 June 2015.

4. Mota-Babiloni, A., Navarro-Esbrí, J., Mendoza-Miranda, J.M., Molés, F., Belman-Flores, J.M. Evaluación de correlaciones de ebullición forzada en interior de tubos con el fluido R1234yf. $8^{\circ}$ Congreso Nacional de Ingeniería Termodinámica, Burgos, Spain, 19-21 June 2013.

5. Molés Ribera, F., Navarro Esbrí, J., Barragán Cervera, Á., Mota Babiloni, A. Análisis teórico de la influencia del intercambiador intermedio en ciclos de compresión de vapor usando fluidos de bajo GWP alternativos al R134a. $8^{\circ}$ Congreso Nacional de Ingeniería Termodinámica, Burgos, Spain, 19-21 June 2013.

6. Mota-Babiloni, A., Mendoza-Miranda, J.M., Navarro-Esbrí, J. Revisión del Refrigerante R1234yf como Alternativa de Bajo GWP en Refrigeración y Climatización. XXVII Congreso Nacional de Termodinámica, El Cerrillo, Toluca, Mexico, 10-14 September 2012. 


\section{Book chapters}

1. Barragán-Cervera, Á., Navarro-Esbrí, J., Molés, F., Mota-Babiloni, A., Peris, B., 2015. Evaporadores y sistemas de desescarche. Capítulo 5. Fundamentos de refrigeración. ATECYR, Madrid, Spain, ISBN: 978-84-95010-54-4.

2. Barragán-Cervera, Á., Navarro-Esbrí, J., Mota-Babiloni, A., Molés, F., Peris, B., 2015. Diseño, cálculo y selección de componentes en una instalación tipo. Capítulo 19. Fundamentos de refrigeración. ATECYR, Madrid, Spain, ISBN: 978-84-95010-54-4.

Research stays

1. Analysis of low-GWP refrigerants for a residential heat pump. University of Liège (3 months). Liège, Wallonie, Belgium, 2015.

2. Estudio de la eficiencia energética de una instalación de compresión de vapor con $\mathrm{CO} 2$ en modo transcrítico. Universidad of Guanajuato (3 months). Salamanca, Guanajuato, Mexico, 2014.

Articles reviewed

1. Energy and Exergy Analyses of Advanced Power Generation and Absorption Refrigeration Cycles using Excel-Thermax. Comput. Appl. Eng. Educ., 2015.

2. General review of solar-powered closed sorption refrigeration systems. Energy Conv. Manag., 2015.

3. Investigating the Suitability of Carbon Dioxide Gas as Refrigerant in a Low Pressure Air-Conditioning System - Using CFD. ASHRAE J., 2014. 
Analysis of fluoride fluids with low global warming impact in vapour compression systems. Experimental evaluation of different alternatives for commercial refrigeration.

\section{University lectures}

1. Energy Technology (9 hours). Bachelor's Degree in Industrial Organisation Engineering, School of Industrial Engineering, Universitat Politècnica de València, 2015.

2. Energy Technology (30 hours). Bachelor's Degree in Energy Engineering, School of Industrial Engineering, Universitat Politècnica de València, 2015.

3. Energy Intensive Industries (21 hours). Bachelor's Degree in Energy Engineering, School of Industrial Engineering, Universitat Politècnica de València, 2015.

Seminars imparted

1. Mobile Air Conditioning: Fluids and systems. Instituto Politécnico Nacional Campus Guanajuato. Silao, Guanajuato, México, 14 November 2014.

2. Commercial refrigeration: Fluids and systems. $21^{\mathrm{a}}$ Semana Nacional de Ciencia y Tecnología, UTSOE, Valle de Santiago, Guanajuato, México, 15 October 2014. 